\title{
Interaction epilepsy, sleep, antiepileptics : a clinical neurophysiological study
}

Citation for published version (APA):

Declerck, A. (1983). Interaction epilepsy, sleep, antiepileptics : a clinical neurophysiological study.

[Doctoral Thesis, Maastricht University]. Swets \& Zeitlinger. https://doi.org/10.26481/dis.19830602ad

Document status and date:

Published: 01/01/1983

DOI:

10.26481/dis.19830602ad

Document Version:

Publisher's PDF, also known as Version of record

\section{Please check the document version of this publication:}

- A submitted manuscript is the version of the article upon submission and before peer-review. There can be important differences between the submitted version and the official published version of record.

People interested in the research are advised to contact the author for the final version of the publication, or visit the DOI to the publisher's website.

- The final author version and the galley proof are versions of the publication after peer review.

- The final published version features the final layout of the paper including the volume, issue and page numbers.

Link to publication

\footnotetext{
General rights rights.

- You may freely distribute the URL identifying the publication in the public portal. please follow below link for the End User Agreement:

www.umlib.nl/taverne-license

Take down policy

If you believe that this document breaches copyright please contact us at:

repository@maastrichtuniversity.nl

providing details and we will investigate your claim.
}

Copyright and moral rights for the publications made accessible in the public portal are retained by the authors and/or other copyright owners and it is a condition of accessing publications that users recognise and abide by the legal requirements associated with these

- Users may download and print one copy of any publication from the public portal for the purpose of private study or research.

- You may not further distribute the material or use it for any profit-making activity or commercial gain

If the publication is distributed under the terms of Article $25 \mathrm{fa}$ of the Dutch Copyright Act, indicated by the "Taverne" license above, 


\section{INTERACTION \\ EPILEPSY - SLEEP - ANTIEPILEPTICS}

A Clinical Neurophysiological Study 


\section{CIP-GEGENENS}

Deolerck, August

Interection epilepsy, sleep "antiepileptics : clinical

neurophysiological study $/$ August Deolerck; [ill. Chris

Verejken]. - Lisse: Swets keitinger. - III."tab. "fig"

Proefschrift Mastricht. - Met lit. opg. - Met

5 amenvetuing in het Nederlands

ISBN $90-265-0471-3$

5150606.1 UDC 616.85

Trefw. : epilepsie.

Cover design: Chris Vereijken

Printed in the Netherlands by Offsetdrukkerij Kanters B.V., Alblasserdam Copyright 1983 A. C. Declerck and Swets \& Zeitlinger B.V.

Alle rechten voorbehouden. Niets uit deze uitgave mag worden verveelvoudigd, opgeslagen in een geatiomatiseerd gegevensbestand, of openbaar gemaakt, in enige vorm of op enige wijze, hetzij elektronisch, mechanisch door fotokopieèn, opnamen, of op enige andere manier, zonder voorafgaande schriftelijke toestemming van de wigever.

All rights resented. No parts of this publication may be reproduced, stored in a retrieval system. or transmitted, in any form or by any means, electronic, mechanical, photocopying, recording or otherwise, whithout the prior written permission of the publisher. 


\section{Interaction}

\section{Epilepsy - Sleep - Antiepileptics}

\section{A Clinical Neurophysiological Study}

\section{PROEFSCHRIFT}

TER VER KRIJGING VAN DE GRAAD VAN DOCTOR IN DE GENEESKUNDE AAN DE RIJKSUNIVERSITEIT LIMBURG, OP GEZAG VAN DE RECTOR MAGNIFICUS PROF. DR. H. C. HEMKER, VOLGENS BESLUTT VAN HET COLLEGE VAN DEKANEN IN HET OPENBAAR TE VERDEDIGEN OP DONDERDAG 2 JUNI 1983 DES NAMIDDAGS OM 16.00 UUR PRECIES, IN DE AULA DER UNIVERSITEIT

DOOR

\section{AUGUST DECLERCK}

GEBOREN TE WESTKERKE (B) 
Promotor : Prof. Dr. J. M. F. Mol

Referenten: Prof. Dr. R. S. Reneman

Dr. A. Wauquier

Bij het tot stand komen van het onderzoek werd apparatuur ter beschikking gesteld door de Commissie Landelijke Epilepsie Onderzoek van de Gezondheidsorganisatie T.N.O. 
I would like to thank all the people who played some role in the realization of this thesis, especially if I have forgotten to mention them by name.

My interest in electroencephalography and the diagnostic possibilities it offers would never have been awakened without the stimulating and friendly encouragement of $D x$. A.J. Simons. My interest in research into a plethora of medical and non-medical problems has been frequentiy motivated and tempered by the enthusiasm or criticism of pr.

A. Wauquier.

At the start of my research investigations I have always been able to completely rely on the enthusiasm of my co-workers (Mrs. M. PansRaedts, Miss A.M. Schiltz, Mrs. R. Sijben-Kiggen, Mrs. J. PeetersSijben, Miss M. Sengers, Miss M. te Dorshorst, Mrs. E. Voets-Petiet, and Messis. J. Vervisch, Chx. Vereljken, F.V. Renswouw, T. Lustemhouwer and F. Kums.

Special mention must also be made of the following people who played important roles in the completion of my thesis:

Prof. Dr. J.M.E. MOL, my promotor, who repeatedly urged me to rework the results of my studies into a clinically useful thesis.

Mrs. T. de Leijer-Boexenkamp my secretary, who not only repeatediy typed my corrected versions of the text, but who also helped with the cataloguing of the literature data, she could always call upon the collaboration of Mrs. Haneveer-Dingenen, the librarian.

Ir. W. Martens, who was responsible for the automatic clasisification of the sleep analyses and the experimental results. Further, together with Dris. G. Clincke, he completed the statistical analysis of the data.

Mr. Chr. Verejjken, who in addition to his work as EEG-technologist, took on the task of ensuring that the figures were suitably placed in the manuscript.

Drs. D. Ashton, who improved the language of the English version, and Mrs. L. Geentjens, both from Janssen Pharmaceutica, who was responsible for typing and ordening the English version of the final text.

Finally, I would like to thank the Directors of the Kempenhaeghe for their interest, and the many colleagues who gave me moral aupport. during my research. 
Listye

E $2 \mathrm{~s}$

Mileke

Stefaan 


\begin{tabular}{|c|c|}
\hline A.E. & Antieplleptic arugs \\
\hline ARAS & Macending reticular activating system \\
\hline As & Atyplical apike wave \\
\hline Av. & Awake \\
\hline $\mathbb{B} \cdot \mathrm{D}$ & Benzodiazepine derivatives \\
\hline carb. & Carbama zeplne \\
\hline clon. & Clonazepam \\
\hline Chlor. & chlorazepate \\
\hline c/sec & Cycle of per second \\
\hline D.P.H. & Di pheny l hydantoin \\
\hline E. & Epileptic $\mathbb{E E G}$ phenomena \\
\hline $\mathrm{ECG}$ & Electroca ralography \\
\hline $\mathrm{EEG}$ & Electroencepha lography \\
\hline EMG & Blectromyography \\
\hline EOS & Electrooculogr aphy \\
\hline EST & Effective sleep time \\
\hline FSW & Splke wave of fast frequency $(\geqslant 4 \mathrm{c} / \mathrm{sec})$ \\
\hline Gen.E. & Generalized epillepsy \\
\hline LSW & Spike wave of low frequency $(\leqslant 2.5 \mathrm{c} / \mathrm{sec})$ \\
\hline MSW & Multiple spike wave \\
\hline N.A.E. & No antiepileptics \\
\hline $\mathrm{N}, \mathrm{E}$. & No epileptic EEG phenomena \\
\hline N. REM sleep & Non-REM sleep \\
\hline Part.E. & Partial epilepsy \\
\hline PSD & Partial sleep deprivation \\
\hline PSW & Poly $(\geqslant 2$ spikes) spike wave \\
\hline $\mathrm{R}$ & Respiration \\
\hline REM & Rapid eye movements \\
\hline REM Sleep & REM sleep \\
\hline RLLI? & Ram latency time \\
\hline $\mathrm{RM}$ & Re spiratory movements \\
\hline $\mathbf{s}$ & Spike $(>11 \mathrm{c} / \mathrm{sec})$ \\
\hline SEM & slow eye movements \\
\hline SH & Shaxp wave $(<1 \mathrm{l} \mathrm{c} / \mathrm{sec}$ and $>5 \mathrm{c} / \mathrm{sec})$ \\
\hline SL IT $^{\prime}$ & sleep latency time \\
\hline Sod. V. & Sodium valproate \\
\hline $\mathrm{SSD}$ & Sielective sleep deprivation \\
\hline TRT & Total registration time \\
\hline TSD & Total sleep deprivation \\
\hline TST & Total sleep time \\
\hline
\end{tabular}


II.1. Polygraphic sleep investigation and sleep classification

II.2. Epileptic EEG phenomena and electroclinical classification

2.1. Epileptic EEG phenomena

2.2. Electroclinical classification of the epilepsies

2.2 .1 . The primarily generalized epilepsies have following characteristics

2.2 .2 . The secondarily generalized epliepsies have following characteristics

2.2 .3 . The partial epilepsies have following characteristics

II.3. Sleep polygraphy for the diagnosis of epilepsy

3.1. The spontaneous nocturnal sleep

3.2. Spontaneous sleep during the day or siesta sleep

3.3. Drug-induced sleep

3.4. Sleep after sleep deprivation

II.4. Sleep affected by epilepsy and antiepileptics

4.1. Sleep affected by the appearance of epileptic phenomena.

4.2. Sleep affected by the intake of antiepileptics

II. 5. Summary

IV.1. Subjects

IV.2. Methods

2.1. Recording method

2.2. Analysies 
v.1. Diagnostic gain

V.2. Electroencephalographic confirmation of the clinical diagnosis

v.3. Diagnostic gain as a function of the sleep procedure

v.4. Diagnostic gain as a function of the sleep stage and depth of sleep

v.5. Diagnostlo gain as a function of the sleep cycle

v.6. Diagnostic gain in function of the recording time

v.7. Diagnostic gain during the sleep latency period

v.8. Diagnostic gain during N.REM $1-2$ and N. REM 3-4 period

v.9. Sleep deprivation and hyperventilation

v.10. Sleep deprivation and intermittent light flash stimuli (LFS)

V.11. Summary

CHAPTER VI COMPOSITION OF THE ALI-NIGHT SLEEP IN EPILEPTICS

VI.1. Materials and methods

VI.2. Results

2.1. Sleep composition of the first and secona cycle in the control group

2.2. Sleep composition of the first and second cycle of the clinical group

2.3. Sleep composition of the first and secona cycle in epileptic patients which do not have epileptic EEG phenomena (N.E.) in their recordings, aepending on whether (+A.E.) or not (-A.E.) they take antiepileptic drugs 
2.4. Sleep composition in patients having epileptic EEG phenomena (W. S.) and which therefore take antlepileptios (+A.E.) or antieplleptics in conjunction with benzodiazepine derivatives (A.E.+B.D.)

2.5. Sleep composition of the first and second cycle in the presence of eplleptic EEG manifestations and the intake of antiepileptics, divided per type of epilepsy

2.6. Sleep composition of the first and second cycle of the control group versus the clinical group

2.7. Sleep composition of the first and second sleep cycle in function of age 54

VI.3. Discussion and summary

CHAPTER VII COMPOSITION OF THE SLEEP FOLLOWING SLEEP DEPRIVATION IN EPILEPTICS

VII.1. Materials and methods

VII.2. Results

2.I. Sleep composition of the first and the second sleep cycle in the control group

2.2. Composition of the first and second sleep cycle in patients (CL group)

2.3. Composition of the first and second sleep cycle in patients without epileptic EEG phenomena, dependent on whether they take or do not take antiepileptics

2.4. Sleep composition following sleep deprivation in patients having epdleptic EEG phenomena and which take artieplieptics in combination with or without benzodiazepine derivatives

2.5. Composition of the flist and second sleep cycle following sleep deprivation, in the presence of epileptic EEG phenoment and the intake of antieplieptics, depending on the type of epilepsy

2.6. Composition of the first and second sleep cycle in the clinical categories for the age group 20-40 years

2.7. Diffexences in sleep composition of the first and second sleep cycle between patients belonging to the age groups $5-20$ years vexsus $20-40$ years 
2.8. Composition of the first sleep deprivation cycle in subjects below the age of 25 years in periods of 5 years

VII..3. Discussion and summary

CHRPAER VIIT THE INELUENCE OF RMTIEPILEPTIC MEDICATIONS ON SLEEP-WMKEFULNESS PAITERNS

VIII.1. Materials and methods

VIII. 2. Results

2.1. Sleep composition in patients treated with sodium valproate

2.2. The sleep composition in patients treated with carbamazepine

2.3. The sleep composition in patients treated with diphenyl hydantoin

2.4. sleep composition in patients treated with carbamazepine and sodium valproate

2.5. Sleep composition in patients treated with carbamazepine and dipheny 1 hydantain

2.6. Composition of the first sleep deprivation cycle and its dependence of antiepileptic medication

2.7. Composition of the sleep in patients treated with antiepileptics in combination with chlorazepate or clona.zepam

VIII.3. Di.scussion and summary

CHANGES OF THE EEG AND POLYGRAPHIC EEG PATTERNS

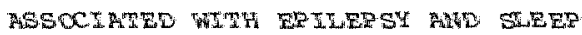

1X.1. Morphological changes of the epileptic EEG phenomena occurring during sleep following sleep deprivation

IX.2. The influence of REM sleep following sleep deprivation on epileptic EEG phenomena

IX.3. Postictal sleep pictures

IX.4. Fragmentation of the sleep

IX.5. Moxphological changes of the $\mathrm{K}$-complexes in epileptic subjects 
IX.6. The value of non-EBG sleep parameters in patients which had or were suspected to have epilepsy

6.1. The electro-oculogram 108

6.2. The electronyogram 110

6.3. Respiration 110

6.4. The electrocandiogram 112

IX.7. General summary 112

CHAPTER $X$ PROCEDURES FOR THE APPLICATION OF THE TOTAL SLEEP DEPRI VATION METHOD (TSD) 116

X.1. The simple routine and TSD procedure 116

X.2. The complex long-term TSD procedure 117

X.3. The directed TSD procedure 118

CHAPTER XI DISCUSSION

XI.1. Neurophysiological background of the interaction sleep and epilepsy

XI.2. Discussion of our own investigation procedure and results 122

2.1. The TSD procedure (Chapter IV) 122

2.2. The value of TSD for the electroencepha lographic diagnosis of epilepsy (Chapter $v$ )

2.3. Sleep structure of the all-night sleep in epileptics (chapter VI) 124

2.4. The sleep structure of TSD sleep in epileptios (Chapter VII)

2.5 . Sleep structure following TSD depending on the antiepileptic medication (Chapter VII)

2.6. Age and the Influence on leep (Chapter VI-VII)

2.7. Changes of the morphological aspects of the EEG fitting with epilepsy and sleep (Chapter IX)

2.8. The value of the total aleep deprivation method (chapter $x$ )

XI.3. Conclustons and perspectives 
Add.I. Experiences with automated seep analysis (w.L.J. Martens)

1.1. Sleep classification

1.2. Quantification of the parameters

Add.2. Statistical method (W.L.J. Waxtens)

Introduction

Criteria for a sleep cycle

Construction and use of confidence intervals for the mean

Add.3. Tables (bis) with complenentary data. corresponding to the simplified tables mentioned in the chapters VI, VII and VII

Add.4. Inst of tables and figures 
Almost a century ago cowers (1885) and Fere (1890) pointed out that in some epileptics the attacks mainly accurred or increased during nocturmal sleep. Iater Langdon-Down and Brain (1929) and patry (1931) showed that there was a correlation betwen the occurrence of epileptic attacks and the sleep-wakefulness rhythm. This association has been studied extensively by Janz (1962) who divided the epiLepsies into "Aufwach, Schlaf und Diffuse Epilepsien". Of the 211.0 studied patients there were 34 which mainly had attacks during daytime during wakefulness, 45 with attacks during noctumal sleep and 21 with attacks both during the day and during the night.

After the introduction of electroencephalography (Berger, 1929) it became possible to study the association between epilepsy and sleep in a more precise way (Passouant, 1951, 1962). Gibbs and Gibbs (1942) were the first to use sleep as a method in the field of epilepsy diagnosis. Apart from the spontaneous nocturnal sleep, spontaneous sleep during daytime (siesta), arug-induced sleep, and sleep deprivation have been studied. Especially the last method has been used successfully in many laboratories (Degen, 1979) as an addition to routine EFG recording. Due to the fact that there is no uniform method of producing sleep deprivation (Gereby, 1978, Tartara al., 1980) it is difficult to compare the results of the sleep deprivation method with those obtained with spontaneous nocturnal sleep. Therefore, it appeared desirable to investigate the conditions reguixed for sleep deprivation recording which would result in an optimal diagnostic result.

In general it is accepted that a good night sleep is required in ardex to be in a good condition and to perform adequately during daytime. Many epileptics complain about a lack of fitness and subnormal performance. It is reasonable therefore, to question whether they had sufficient and adequate sleep.

sleep can be judged by flling in a questionnalre or by carrying out a polygraphic sleep investlgation. By using EEG sleep recordings. carried out in epileptic patients, in the framework of supplementary diagnosis, it is possible to study thedir sleep. From such studies it can be derived in what way and to which degree the sleep in epileptics differs from the deep in normal persons and whethex theso differences depend on the kind of epilepsy and the kind of drug therapy. Here also the question is how to achleve an optlmal seep deprivation and recording, such that the sleep in itself can be juaged.

on the basis of a literature survey and an analyeis of our own investigations we will attempt to answer these two questions in the following chapters. For this purpose, data from the literature are sampled which relate to the following:

1. the epileptic EEG deviations and the polygraphic judgement of sleep

2. the different kinds of sleep methods used to improve the diagnosis of epilepsy;

3. the changes in the eplleptic EEG phenomena which may occur during sleep:

4. the sleep changes which may occur as a consequence of the epilepsy or the intake of antiepileptics. 
on the batis of our ow investigations we kould like to know whether the polygraphlo sleep recording arter one night sleep deprivation:

1. $1 \mathrm{e}$ ar effective and wiseful metrod for the detection of epilepsy and for the judgement of the sleep;

2. which conditions need to be fulfilled in order to approach the eftect of a total night sleep recording:

3. how the sleep composition changes, because depriwation interferes with the effects caused by epilepsy or the intake of antiepileptics;

4. Whether comparable moxphological EEG changes are seen.

By combining the results of our own investigations with those obtained in the literature we attempted to arrive at a critical juagement of the value of polygraphic EEG investigations for diagnosing eplieptic EEG phenomena and changes in the sleep in eplleptics.

In addition, special attention will be given to the way in which sleep deprivation should be carried out and how the results should be interpreted. It is hoped that insight will be gained into the way certain antieplieptics exert their therapeutic effects, and a number of suggestions will be made to improve epilepsy diagnosis in the future. 
The present chapter surveys findings in the literature with respect to sleep and epilepsy and is sumarized in four partis:

1. polygraphic sleep investigation and the partition of sleep:

2. the electroencephalographic epilepsy phenomena and the electroclinical classification:

3. the different sleep methodologies which have been applied to diagnose epilepsy"

4. sleep changes which may occur as a conseguence of having epllepsy or due to the intake of antiepileptics.

\section{II.1. POL YGRAPHIC SLEEP INVEST IGATION AND SLEEP CLASSIFICATION}

Decades ago (Moruzi and Magoun, 1949) sleep was considered as an expression of rest of the organism and the central nervous system. It was thought that sleep was caused by a decrease in the activity of the ascending reticular formation (ARAS), a brainstem structure thought to be responsible for the maintalnance of wakefulness. During such a passive rest condition the brain would function in a very simple and undifferentiated way.

Less than ten years after the introduction of the clinical use of the EEG (Berger, 1929) Loomis et al. (1935, 1937) could differentiate between 5 stages of sleep, each stage being characterized by a specific EEG picture. During nocturnal sleep these stages appeared to occur repetitively in a cyclic fashion.

Aserinsky and kleitman (1953) discovered for the first time that rapid eye movements occurred during certain sleep periods. These eye movements could be recorded graphically by means of placing periorbital skin electrodes (electro-oculography or EOG). These eye movements appeared to be conjugated. The sleep periods during which rapid eye movements (REM) were seen, were termed by Dement (1955) as FEM sleep and the other periods as non-REM sleep (M.RIM). Dement and Kleitman (1957) found that REM sleep occurred in a cyclic fashion interrupted by longer periods of $\mathrm{N}$. REM sleep. "The total duration of the two states of sleep lasted about 90 to 100 minutes.

It appeared very soon that $\mathbb{R E M}$ and $\mathrm{N}$. REM differed from each other in many aspects. Apart from a difference in the EEG Jouvet and Michel (1959) and Berger (1961) found that the muscle activity (EMG) was strikingly low during PEM sleep. Othex physlological parameter such as heart rhythm, respiration, blood pressure and body temperature behave differentially auring the two states of sleep. In general, the measured values are lower and more regular during N. REM sleep as compared to FEM sleep. On the basis of these differences it has been stated (Oswald, 1962 ) that sleep is not a simple passive proces but rather an expression of a complex and active brain function. Wakefulness, REM and N.REM sleep are therefore considered as three different degrees of consciousness (Jouvet, 1962).

Because the two states of sleep: FFM and $N$. REM sleep differ from each other in many aspects a new sleep cllassiftcation was introduced taking non-EEG parameters into account. A frequently used sleep classification on the basis of polygraphlc criteria was established 
AWIAKE: random, faist

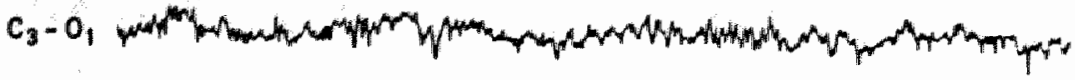

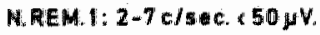

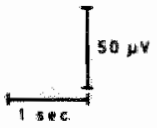

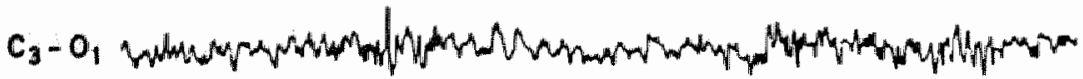

N.REM.2:sillepspindle (s) and $K$-complexes (K)

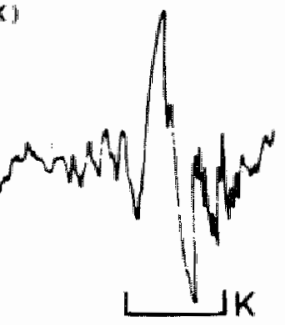

WH. REM. $4: 0.5-2 \mathrm{c} / \mathrm{s} \in \mathrm{C}, 75 \mathrm{jW}$

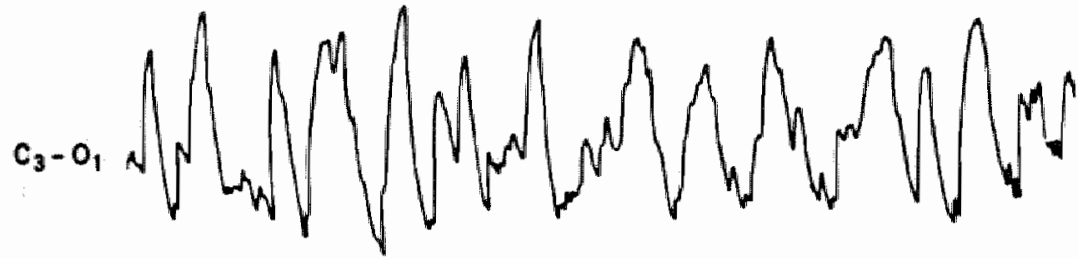

REMirandom, last and sawtooth wavel (st.)

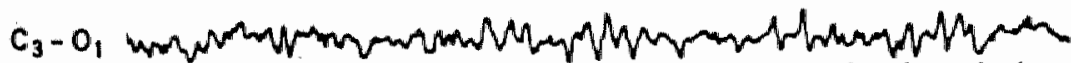
Is.t.

FIG. II.I.

EEG patterns according to the different human sleep stages and states (from Haur1, 1977).

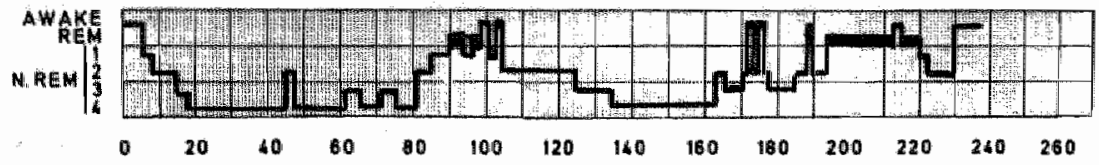

WIG. II.2.

Exampl of a hypnogram. 
and published by Redutschaffen and Kales (1968). On the basis of the changes in the $\mathbb{E E G}, E O G$ and $\mathrm{WMG}$ a difference was nade between REM and N.REM sleep. The latter was further diferentlated into a stages, stage 1 - 4 denoting a progressively increasing depth of sleep. An example of the different states and stages is represented in Fig. II. I.

Hereafter follows a desciption of each sleep stage as based on EEG and nor-EEG characteristics (1).

stage $\mathbb{N}$. REM I: The EEG is characterized by the disappearance of the wakefulness rhythms and the appearance of low voltage rhythms not exceeding $50-70$ microvalts of varying frequencies between 2 and $7 \mathrm{c} / \mathrm{sec}$. In the vextex region triphasic sharp waves of 100 to $200 \mathrm{~m}$ crovolt amplitude and lasting 50 to 200 msec are seen* The EOG shows intermittent slow eye movements (SWM). The EMG shows muscle activity which is lower than during wakefulnes 5 .

Stage N. FAM 2: The EEG consists of low voltage unstable rinythms, sleep spindles and $K$-complexes. sleep spindles are "a group of rhythmic waves characterized by progressively increasing then gradually decreasing amplitude. The waves are monomorphic, diphasic and symmetical with respect to the baseline with a stable frequency of 12 to $14 \mathrm{c} / \mathrm{sec}$ and variable duration of $1-6 \mathrm{sec}^{\mathrm{t}}$. A K-complex is "a sharp negative hygh voltage EEG wave, which is followed by a slower positive component and can be elicited by external stimuli".

No eye movements are seen in the FOG and the EMG shows a further decrease of the muscle activity.

Stage N.REM 3: The EEG is characterized by polymorphic wares of 0.5 to $2 \mathrm{c} / \mathrm{sec}$ ith an overall amplitude of more than 75 microwolts. These delta rhythms are present for more than $20 \%$, but less than 50 of the recording time.

There are no eye movements and the muscle activity is further decreased.

Stage N. FEM 4: During moxe than 50 of the time 0.5 to $2.5 \mathrm{c} / \mathrm{sec}$ delta rhythms are seen, which have a high amplitude and which are more regular than during leep stage N.REM 3. Sporadic sleep spindles occur. there are no eye movements anymore and the muscle activity rematm Low.

State REM : The EEG is desynchronized consisting of low voltage rhythms of varyling frequencies reserbiling stage

(1) - "The sleeping Braln", Glossary, pp. 508-522 (Edjtor: Chase, 1971).

- "Glossary of rerms used in the sleep Disoraexs clastification". Sleep, pp. 123-129, 1979 .

- "Glossary of standardized Terminology for sleep and Biologlcal Phythim Research" sleep, pp. 287-288, 1980 .

- "Handbook of EEG and Clinical Neurophysiology", vol. 11, parte A. , pp. $58-73,1977$. 
W. FWM 1. Howerer, there are no sharp vertex waves, but rather saw-tooth like waves derived from the occipital corter (Dement, 1972). During this sleep state, mariy rapla conjugated eye mowements are seen, often predominantly in the horizontal direction.

The EMG activity is very low, especially in the neck and chin muscles, and the postural muscles of trunk, ams and legs "In the face and fingers this low muscle activity is interrupted by short-lasting tonic contractions.

The increased depth of $\mathbb{N}$. REW sleep is also expressed by a progresstive decrease of heart and respiration trequency, blood pressure, body temperature and urine and gastric acid secretion (snijdex et a1., 1964). Wherefore, this sleep is ofter considered as quiet sleep. This term, however, is incorrect since during the N. FEM sleep an enhanced cerebral blood flow with preservation of axygen uptake $\mathbb{1} s$ observed. In addition electrical skin resistance is also increased (Dement, 1972).

In contrast to the $\mathbb{N}$. PFM sleep during REM sileep the heart frequency and respiration become irregular and the respiratory centex in the bxainstem becomes les: senstive towards $\mathrm{CO}_{2}$ changes (Phillipson et a 1. 1975). Further there is a disturbance of temperature regulation (shaplro et al., 1974). Due to these changes REM sleep is often termed active sleep (Lena and parmeggiani, 1964) or paradoxical sleep (Jouvet and Michel, 1965) because the desynchronized EEG picture and the presence of rapid eye movements with the eyes closed resembles wakefuliness with eyes open.

Because of the characteristic EEG phenomena N.REM stage 2 is often termed splndle sleep and $\mathrm{N}$.RFM sleep 3 and 4 as delta sleep. Presently, the most used texms are FEM and N.REM sleep, N. REM 1 and 2 and N. REM 3 and 4 respectively denoting 1 ight and deep slow wave sleep. It is common to represent the cyclic appearance of the different sleep stages in a hypnogram (Fig. II.2.).

The duration of the different stages of the sleep is changing during the course of the nitght: at the beginning of the night there is more deep silow wave sleep and less light slow wave sleep than at the end of the night. In normal adults the following percentage sleep partition 1 s seen (Kales and Kales, 1970): REA: $20-25$ : N.REM 1: 5 N.REM 2: $50-55$ N.REM 3: 10 and N.REM 4: 10 15 . During aging N.REM 3 and 4 alow wave sleep decreases and N. RPM Leep il increases.

\section{II.2. EPILEPTIC EEG PHENOMENA AND ELECTROCLINICAL CLASSIFICATION}

Intexpretation of findings in the older literature on epileptic HEG phenomena is diffloult since a different terminology was used. A considerable step forward has been made since the introduction of the standardized $20-20$ system for electrode placement (Jasper, 1958), the establighment of criteria for an EEG investigation for clinical purposes (Kugler, 1963, Mac Gillivray, 1974), the introduction of a standardized terminology of EEG rhythm (Storm van Leeuwen et al." 1966) and a uniform interpretation of EEG rhythms in relation to the 
clinic (Manus, 1961). Since oux investigations studied the relationship between polygraphic sleep patterms and epileptio frg phenonena and their relation towards the clinic, it is necessary to define these phenomena sufficiently.

\subsection{Epileptic EEG phenomena}

the definitions of eplieptic EEG phenoment were based on the terminology described in the "Handbook of EEG and clinical Neurophysiology". Hereafter fillows a description of the definitions which will be used extensively in the text.

- Epileptic discharge: A neuronal discharge characterized by the simultameous excessive activation of a large number of cells which may be recorded by electroencephalographic techniques as a paroxysmal wave form, usually in the form of a spike (S), sharp wave (SH), spike and wave (SW) or other such complex.

- Paroxysm: A group of waves which appears and disappears abruptlyr and which is clearly distinguished from background activity by a different frequency, morphology and amplitude.

- spike: (s): A wave, distinguished from background activity and having a duration of $1 / 12$ sec or less, prevalently negative polarity and an amplitude from $50-150$ microvolt. poly-spikes are constituted by several closely grouped spikes (usually from 2 to 6 ).

- Sharp waves (SH): A usually negative wave, distinguished from background activity with a duration of more than $1 / 12$ and less than $1 / 5$ sec, an amplitude of 100 - 200 microvolts, with a vertical ascending segment and a more prolonged descending segment.

- Complex: A group of two or more waves, clearly distinguidhed from background activity, and occurring with a well recognized forin or recurring with consistent form.

- Spike and wave (SW): A complex of two waves, one with a duration of $1 / 12 \mathrm{sec}$ or less (S) and the other with a duration of $1 / 5-1 / 2$ sec (W).

- Polyspike wave (PSW): A SW complex with more than one spike.

- Sharp and wave (SHW): A complex of two waves, one having a duration between $1 / 2$ and $1 / 5 \sec (\mathrm{SH})$, the other between $1 / 5-1 / 2 \sec (W)$.

- Sharp and slow wave (SH.SW): A complex of two waves, one having a duration between $1 / 12$ and $1 / 5$ sec (SH), the othex between $1 / 2$ and 1 sec $($ Slow $w)$.

paxoxysmal epileptic discharges can invade both hemispheres, one hemisphere, or part of one hemlsphere. In EEG termis these paroxysmal epileptic âscharges can be generalized, lateraldzed, partial or focal. Generalized (gen.) means that the epileptic EEG phenomena are recorded aimultaneously from all electrodes in both hemispheres; latieralized (lat.) means that they occur predominantly or exclusively in one hemisphere; partial (part.) means that these occur regionaliy but are registered from more than one electrode or focal (foc.) when these are regiftered only from one eleictrode.

Further, one defines duration af the eplieptic discharges, the degree and in which way the grapho elements lave a regular (reg.) or irregular (irreg.) form, frequency and amplitude and whether these occur symetrically (symm.) or asymmetrically (asymm.) and synchronous (synchr.) or asynchronous (asynchx.) above homologous brain regions. 
Finally, one can define whether these eplieptic ExG phenomena posses a typleal (typ.) or atyplcal (atyp.) aspect and whether these change during the sleep.

\subsection{Electrocilinical clasafication of the epliepsies \\ Fifteen year ago the epliepsies were mainly classified on} the bas of a cinical symptomatology and a posible etiology . Later more criterla tere considered of importance for a proper classification, theix ictal and intexictal eplleptic and nori-epileptic EEG phenomena played an important role. The combination of clinical ard neurophysiological data were the basis of a classification system purposed by "International League against Epliepsy" (Clinical and lectroencephalographic classification of epileptic seizures, Epilepsa, 1970A, 1.1, 102-113; Proposal for an international classification of the epliepsies, Epliepsia, 1970B, 11, 117-119).

In this clasification the epllepsies have been categorized according five clinical and three neurophysiological criteria into three main forms: the primary generalized epilepsies (pr.gen.) "the secondary generalized (sec.gen.) and the partial (part.) epilepsies.

The five clinical criteria are: (1) the clinical form of the epilepsy, (2) the interictal. presence or absence of organic brain damage, with the presence of neurological, neuroradlological, mental or pisychological deviation, (3) the age of onset, (4) the presence or absence of definable causes, (5) the degree of possible treatment with antiepileptics.

The neurophysiological criteria are: (1) the lictal EEG picture, (2) the interlictal EEG picture, (3) the neurophysological mechanisms at the origin of the epileptic discharges.

2.2.1. The primarily generalized epilepsies have following characteristics:

clinical: - The sudden appearance of clinical epileptic manifestations, eithex of the absence type (petit mal: P.M.), the tomic clonic type (grand mal: G.M.) or myoclonic type (mycl.), by which the muscle contractions are present from the start;

- Onset at childhood or adulthood;

- Absence of cerebral. damage interictallyi

- absence of defimable etlology, but often a heriditary predisposition;

- Benelicial response to antiepileptics.

EEG : During the ictal signs diffuse eplieptic EEG phenomena are present, consisting of 10 c/sec rhythms, described as "epileptic reoruting rhythm" $(\mathbb{E} \cdot \mathbb{R} \cdot \mathbb{R}$.$) , typical and atypi-$ cal sw and PSW complexes.

- Interictal appearance of eplleptic EEG discharges with similar characteristics as during the attacks, the EEG background pattern shows a tendency to slow synchronization,

- The different forms of primarily generalized epilepsy cannot be divided on the basis of the etiological mechanisms of origin since these are 4 nsufficiently known. 


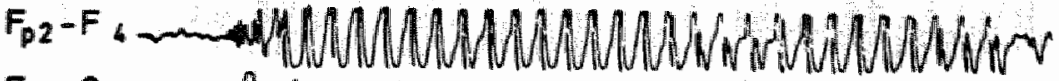

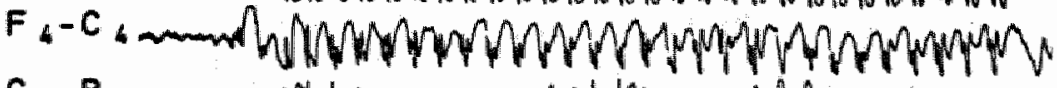

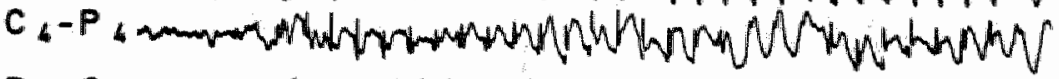

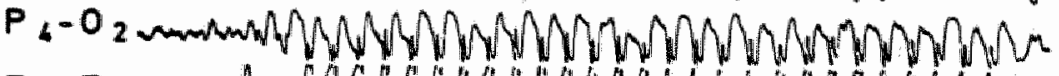

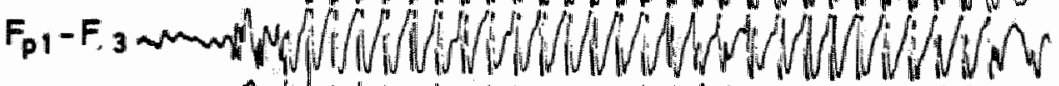

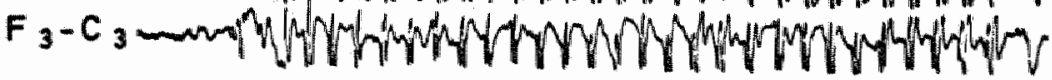

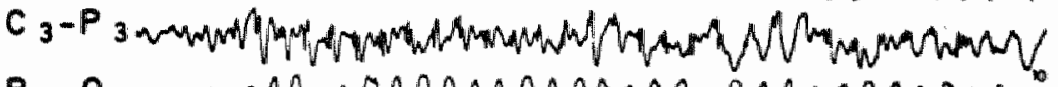

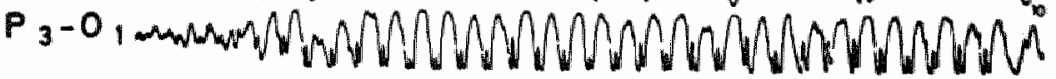

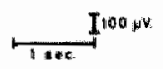

FIG. TI.

Example of primarily generalized epilepsy ( 3 c/sec)*

2.2.2. The secondarily generalized epilepsies have folClinical: - They consist of tonicmclonic (T.C.), tonic (T), atondc (Ht) attacks, massive bllateral myocloris, collapses and atypical absences. These clinical signs can be generalj.zed fiom the beginning of the attack or they can be spread diffusely after a local onset.

- Interictally there are neurological, neuroradiological, psychological or mental signs of cerebral damage:

- Selam there is an evident etjology, but often there are signs of a diffuse or mutifocall cerebral damage;

- The antiepileptics of irst choice have only a Ilmited effect, benzodiazepines sometimes have better effects.

EEG :- During the lotal signs epileptic recruting rhythm,

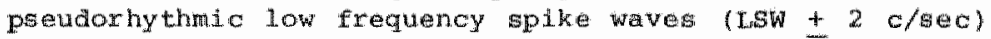
and isolated low waves occur;

- Interictally, there is a affusely disturbed eds ploture whth epileptic EEG phenomena of whol the former 1 is rem lated to the clinical plcture which can be of a secirlo or unspecific nature:

- To the specific forms belong those which appear in combination with myoclonia such as the progresive myocionic epilepsy of unverrich-Iuraborg and the intention myoclonic form of epilepsy such as in the oyndrame of pamsayHunt: apecific is the syndrome of west or myoclonic oncephalopathy with hypsarrhythma, or by ictaliy as well ab interictally diffuse usw with varying lacalizaton, and the syndrome of Lennox-Gastaut or the petst mal variant. where ISW vaxy with fast spike waves (Fsw, more than 4 cisec). 


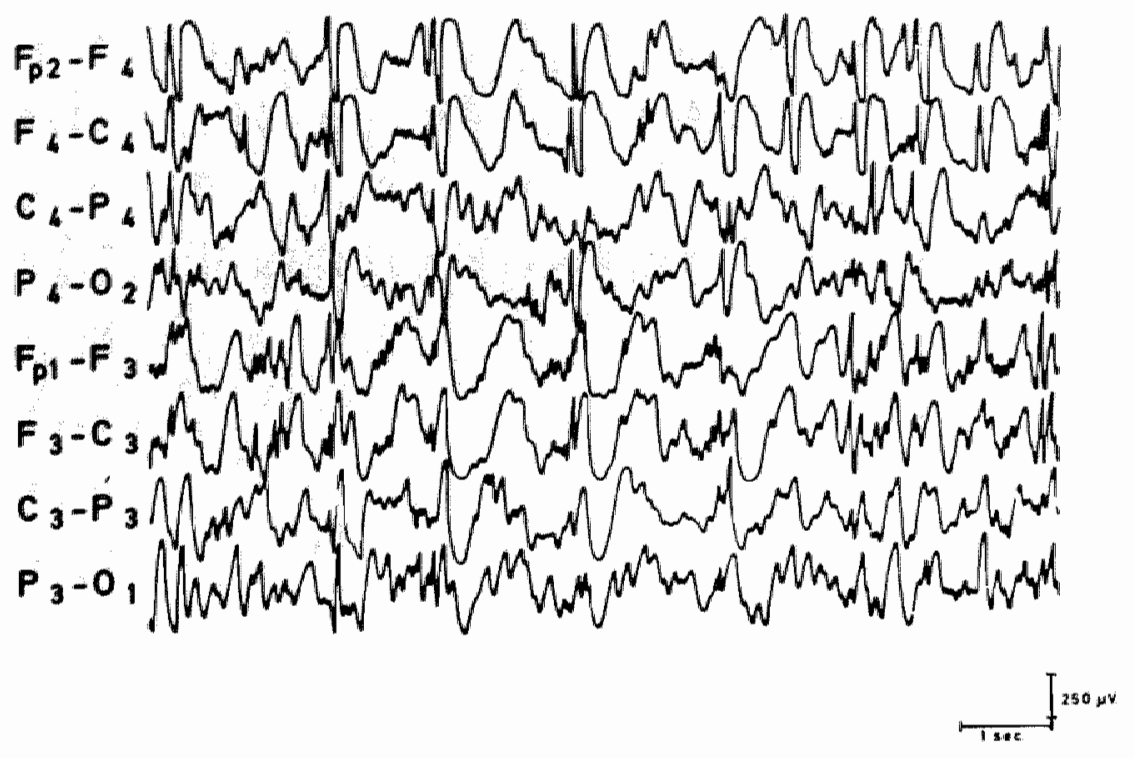

EIG. II.4.

Example of secondarily generalized epliepsy (hypsarythmie).

2.2.3. The partial epilepsies have following characteris-

clinical: - The first clinical symptom as well as the most pronounced clinical symptoms are very different and depend on the anatomical locilization of epileptic discharges. Depending on the complexity of the appearance, one differentlates between simple (s) and complex (c) forms.

- Interictally there axe signs of the cincumscribed cortical damage;

- It can appear at each age but seldom in early childhood;

- An organic injury is often at the origin:

- A reasonable to sufficient treatment with antiepileptics 1 s possible.

FIG : - The discharges consist of local spikes, sharp waves, typical or atypical splke waves, especially slow and sharp wave complexes. They occur isolated or in series of warying duration.

- Interictally similar paroxysmal discharges occux. The background plcture is often normal in the simple epileptic form, but is associated with the slowing in the more complex form.

\section{I.3. SLEEP POLYGRAPHY FOR THE DI AGNOSIS OF EPILEPSY}

Gibbs and Gibbs (1942) were the first to carry out the EEG sleep investigations in epileptic patients, because they observed 


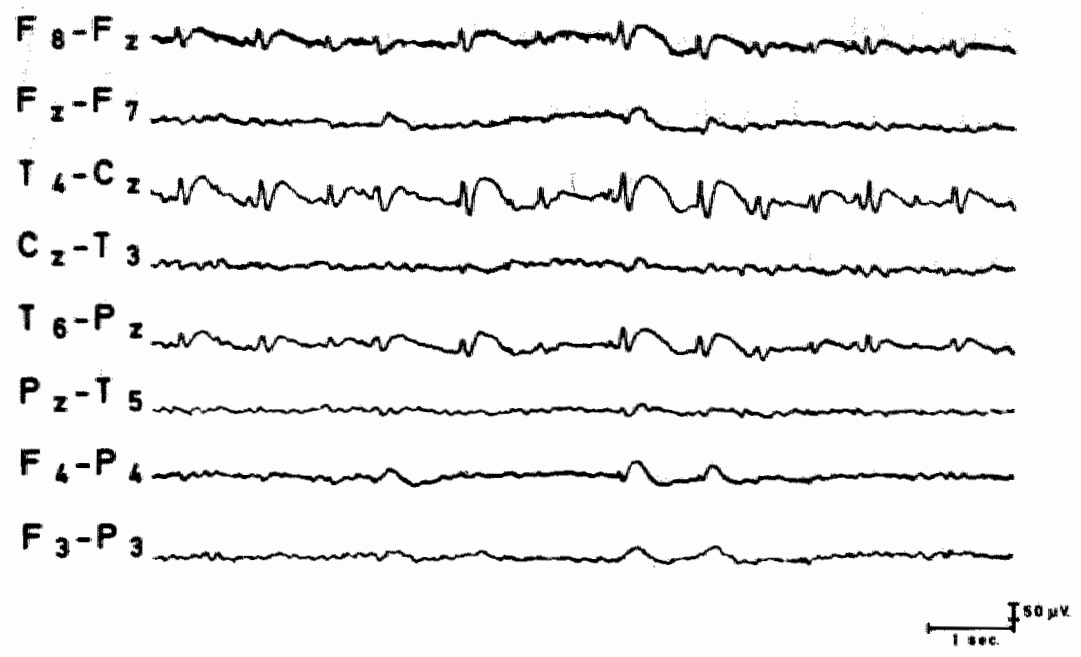

FIG. II.5.

Example of complex partial epllepsy (psychomotor type).

that epileptic EEG phenomena increased during the sleep. "Thereafter sleep has been used as a diagnostic aid in the field of epilepsy by many authors (Bancaud et al., 1965; Cadilhac and passouant, 1965; Gastaut et al., 1965a, Angeleri, 1969). Different procedures have been used: spontaneous sleep during night (all-night and interrupted sleep) or day (siesta sleep), drug-induced sleep or sleep following preceding sleep deprivation.

3.1. The spontaneous nocturnal sleep leptics the attacks mainly occurred during sleep at night (sleep ox s-type), in other patients during the day (awake or A-typel, or in others during night and day (random or R-type).

The patients of the s-type suffer malnly from a primarily generalized attack of the tonic-clonic type and a partial complex attenk for instance of the psychomotor type. Many patients of the A-type suffer from a primarily generalized epilepsy of the absence type tand those of the R-type of a focal epliepsy with secondarily generalization.

Many investigators established that the accurrence of epileptic EEG deviations depended on the depth and the kind of sleep. According Broughton (1972) the EEG abnormalities fitting with primarily generalized epilepsy of the gxand mal type increased during $\mathbf{N}$. REM and decreased during REM sleep. According sato et al. (1973) and Schwartz et a1. (1964), diffuse $3 \mathrm{c} / \mathrm{sec}$ spike waves fitting with primarly generalized epilepsy of the absence type, remain present duxing REM sleep. The features of the grand mal as well as of the petat-mal 
type are duly seen durling falling agleep (belangh et al., 2962 ; ka zamatsuri, 1964).

The increase of eplaeptic abnomalities during sleep of the secondarily generalized epllepsies is dependent on the syndrome. With the apedific syndrome of unverricht-Lundborg and kamsay-Hunt there is an Increase during $W . P E M ~ 1-2$ leep and a decrease during $N$. PEM $3-4$ sleep. RaM seep is often lacking in these patients (Rassouant and cadilhac, 1970). The apeclfte synaromes such as the syndrome of west (hypsarrhythmia) and the syndrome of Lennow-Gastaut (petit-mal variant) are differentlally affected by the sleep. In the symarome of West the long series of aspectfic spike waves paroxysm are interrupted during the N. FEM slieep and suppressed during the RFM sleep. In the syndrome of Lennox-Gataut they increase during the light $\mathrm{N} \cdot \mathrm{REM}$ I-2 sleep and decrease during N.REM $3-4$ sleep (Gastaut et a1., 1975; Inoure al i., 1977).

The partial epilepsies may be increased during $N$. REM $1-2$ sleep, and the abnormalities often tend to spread. In contrast, RFM repetitively leads to a better limitation of the spread (Findji et al., 1978). Accoraing Broughton (1972) partial epilepsies with superficial cortical temporal aischarges would jncrease during $N$. FEM $1-2$ sleep, whereas the deeper stuated temporal and frontal foci would be expressed espectaliy during REM sleep.

Measuring the spike activity in the focus as a function of time, 1 it appears that there is an increase during N.PFM $1-2$ sleep and even more during N. REM 3-4 sleep (Gozukimizi et al., 1982; Montplaisir, 1980). This has been confirmed by lieb et al. (1980) who found that in deeper laying cortical foci, there was a three-fold increase during $\mathbb{N}$. REM $1-2$ and a six-fold increase during $\mathrm{N}$. REM 3-4 sleep, and none or a very ilmited increase auring REM sleep.

The findings by schwartz et al. (1964) axe of importance: they found that the increase of focal epileptic EEG abnormalities do not only depend on the depth of sleep but also on their localization. They found an increased spike activity during $N$. REM 1 sleep when the injury was localized in the left occipital cortex and an increase during $\mathbb{N}$. RFM $2-3$ and 4 sleep when the injury was localized in the xight temporal region.

Many investigators polnted at the importance of REM sleep for the localization of the primarily epileptic focus, since this becomes more clrcumscribed during REM sleep (Montplaisix et a1. " 1979; Perria et all, 1966, Fossis et a $1 ., 2974$ ).

Apart from the quantity of the epileptic EEG abnormalities also their form dan change during sleep. Broughton (1972) pointed at the tendency to the formation of polyspike wave complexes during N.FEM aleep, with a greater preponderance during N.REM $1-2$ than during 3-4 - leep. Sato et al. (1973) categorized the morphological changes of the pike waves according depth of $N$. REM slew.

During the $\mathrm{N}$. REM 1 sleep the $3 \mathrm{c} / \mathrm{sec}$ splkes retain their regularity but the duration of the paroxysms becomes shorter. During N.REM 2 sleep the spike waves become irregular with changing frequencies between 2 and 4 o/sec and a more pronounced polyspike wawe formation. simultaneously these paroxysms shorten and their number increases. The decreased duration and increased number of spike-waves is even more pronounced during $N$. REM sleep 3-4, during which they remain irregular but their frequency changes to $2.5-1.5 \mathrm{c} / \mathrm{sec}$. 
Passouant (1975) has demonstrated that the changes ir spike-wives are Inked to the associated clinical form of epilepsy. Thus, the generalized $3 \mathrm{c} / \mathrm{sec}$ spike waves seen in the primarily generallzea epilepsy of the absence type, increased during $\mathrm{N}$. REM $1-2$ sleep and developed towaras polyspike wave formation. These changes would not occur during deep $N$. REM $3-4$ sleep, and also posslbly not during kFN sieep.

In contrast, the spike wave paroxysms which occur in the primarily generalized epilepsy of the tonic-clonic type increased during all stages of W. REM sleep. In absence of the myoclonic type, the polyspike wave paroxysms axe seen during wakefulness, and retain ox increase their appearance during all stages of the $\mathbb{N}$. REM sleep. According Erba and Moschen (1980) also the aspecific spike wave conplexes are influenced by sleep. This is manifested by the formation of polyspike wave complexes during $N+R E M ~ 1-2$, the aspecific aspect increases during $N$. REM $2-3$ sleep and 1 s suppressed during $N$.REM 4 and RFM sleep. The most important findings in the literature concerning the influence of the different sleep stages on epileptic EEG phenomena are sumarized in the following table (Table IX.6.).

Table TI.6.

Sumary of some literature findings concerning the influence of the aifferent sleep states and stages on epileptic EG phenomena.

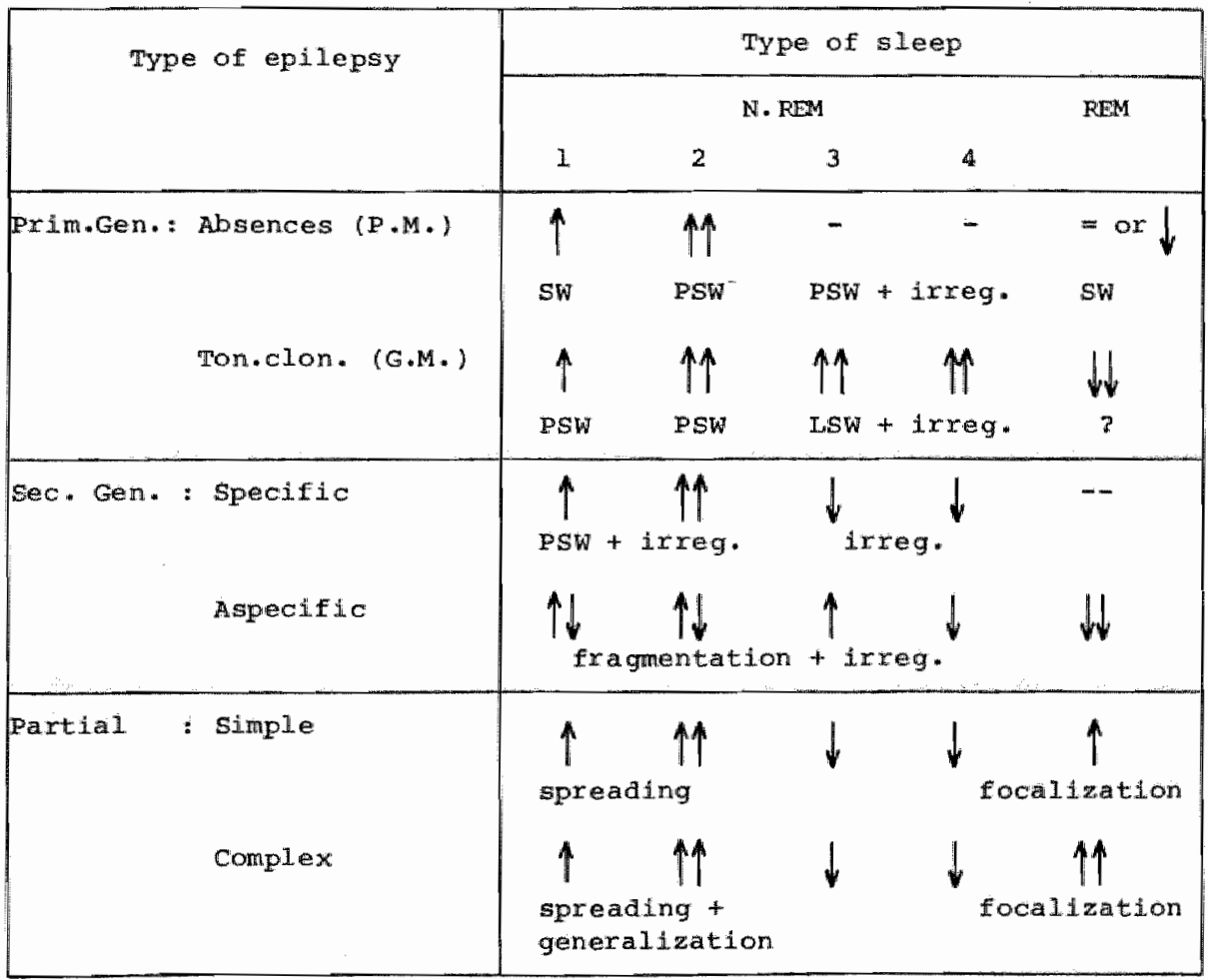


Frow this incompliete sumbiary lange differences between W. Fru and Fay sleep are apperent for both general and for partial epilepsy. It is therefore not surpiring that one has assigned convulsive features to the W. In sleep and anticonvulsant features to the RE sleep (Melert-Evert, 1978). An explanation has been sought in the difference in the level of activity of the reticulax activation system during HEM and FEM sleep. This system would be less active during N. RE seep, through which the inhibition of cortical neurons decreases and thalamocortical hypersynchronous mechanisms increase. The activity of this system increases again during REM sleep, though the cortical inhibition would be comparable with that found auring wakefulness (Feemey et al., 1977; Gloor, 1980 and Montplaisir et al., $1980)$.

From the 1iterature summarized above, it is clear that the recordling of total night sleep during which all sleep stages are present to a sufficient degree, can be a considerable contribution to the affirmation of, and a better description of the different forms of epilepsy. With the aid of this procedure Jovanovic (1966) found that there was a diagnostic gain of 34 in subjects suspected of having epliepsy. Unfortunately, this method is very labour intensive and too expenisive to be used routinely. Therefore, many investigators have applied it fairly selectively. Broughton (1972) advised to use this method for the detection of an epileptic focus not seen during wakefulness or which rapidly gives rise to secondarily generalization. Sometimes the sleep recording is restricted to the first part of the night (interrupted sleep). This procedure is based on the experience that in many patients the epileptic EEG phenomena are mainly seen during the first part of the night (Marosfi, 1980).

\subsection{Spontaneous sleep during the day or siesta sleep}

the possibility to record sleep during daytime is large in small children and promoted in countries where siesta sleep belongs to the normal life pattern. Different investigators made use of this need ar habit to detect epileptic EEG abnormalities by recording during sliesta sleep (Cadilhac and. Passouant, 1965; Gastaut et al., 1965a, Wnight et a 1., 1977).

This procedure has the disadvantage that this kind of sleep is

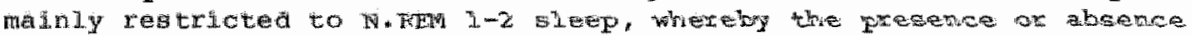
of HEN sleep depends on the precise point of time of the recording. Berger et a 1 . (1971) have demonstrated that the opportunity to record REM sleep fis largest in the morning and decreases during the course of the day, with an Increaged opportunity to record deep N. REM sleep. The constitution of sleep is further dependent on all sorts of factors ijke envixonmental noice (zimerman, 1970), temperature (SchmidtKessen and Kendel, 1973), the kind and time of the proceeding meal (Jacobs and MoGinty, 1971; Karacan et a1., 1975) and the use of alicohol (Rundell et al., 1972). Further taking the large individual difm rerences into account $u_{t}$ is clear that the slesta sleep is not well sulted for comparative investigations. 


\subsection{Drug-juaviced sleep}

Preceding or during a routine investigathon a short-acting barbiturate is taken oraly (kuyex and Buit-Gutter, 1974). Whis results rainly in N.PEM $1-2$ sleep and sometimes a N. REM $3-4$ sleep, stages during which epileptic EEG phenomena, flttirg wh different forms of epilepsy are often increased. Because the dose used is low (e.g. $50 \mathrm{mg}$ secobarbital), adults wll have no or limited inconvenience, except for a light sleepiness (Potwin et a1., 1975). The disadvantage of these substances is that they are antiepileptios (Longo, 1977ע, which might suppress the epileptic EEG phenomena and in adaition they may imfluence the interictal EEG pattern as well as the polygraphic sleep pattern in an unnatural way (Gabriel and Albani, 1977; Montagu, 1971). Fox similax reasons benzodiazepines, mainly suppressing generalized epileptic EEG abnormalities (Boyer, 1966) are not advised (Greenblatt and shader, 1973).

Some investigators (e.g. Degen, 1982) used phenothiazine-derivatives to promote light slow wave sleep. This superficial sleep cam be favorable for the detection of partial epilepsy and the many transitions from wakefulness to sleep can favour the occurrence of generalized epllepsy. These products, however, have the disadvantage that they mainly promote brainstem lability, by which artificial abnormalities are Induced which are not normally seen in these persons.

\subsection{Sleep after sleep deprivation}

Every person restricted from fulfilling his need to sleep will compensate as soon as the possibility is given to do so. This method known as the sleep deprivation method is applied for instance, to know how a subject reacts to lack of sleep and how subsequent sleep is modified. Depending on the procedure applied one differentiates between total, partial and selective sleep deprivation. Total sleep deprivation means that one stays awake for 24 consecutive hours and minimaliy lacks one night sleep. Partial sleep deprivation means that one shortens abruptly or gradually the nocturnal sleep by some hours. Selective sleep deprivation means that one prevents the occurrence of a particular sleep stage. This is malniy restricted to REM sleep or to N. REM 4 sleep.

Selective REM sleep deprivation was applied for the first time by Dement (1960). According Hartman (1973) REM sleep is important for the storing and assimilation of information and for the maintalnance of emotional stability and good social adaptation. According Albert (1975) and Vogel (1975) REM deprivation has no Immediate implications for psychological functioning and learning capacity, but adustment to new situations is hampered (GIaubman et al., 1978). When RFM sleep is deprived, N. REM sleep retains lits usual composition and sieep oyclicity (Dement, 1960).

The effects following partial sleep deprivation depend on whethex the sleep reduction is applied abruptly or gradually. Abruptly mearis that the sleep is suddenly shortened by 3 to $4 \mathrm{~h}$, and gradually means that the sleep is shortened by half an hour to $1 \mathrm{~h}$ weekly. By a gradual reduction it is feasible to shorten the sleep by 4 to $5 \mathrm{~h}$ whout influencing dally performance (Friedman et al." 1974; Johnson and Mcleod, 1973). According Naitoh (1976) this is based on the fact that each person has his own minimal sleep requirements * Reaching 
thil minimil level one still feels that one has had a good sleep and the perfomance on the subsequent day is normal. In contrast to graduel leep reduction an abrupt sleep deprivation leads to an immedlate decrease of alertness and attention (Hartley and shirley. 1977). This negatiwe effect is however short lasting, disappearing after few days (Webb and Agnew, 1974). After partial sleep deprivathon the compensatory leep is chaxacterized by a decreased $\mathrm{N} . \mathrm{RBM} I-2$

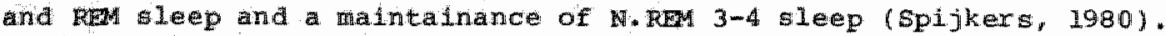

The effects of total sleep deprlvation have been studied extensively (Jovanovic et all. 1971; waitoh et al., 1971). Following total sleep depirivation the performance of tasks lasting more than 20 min decreased (Wilkinson, 1965). Often, there is a slight prolongation of the reaction time towards sensory stimuli (Lisper and Kjellberg, 1972; Nillams et a 1., 1964); or learning is disturbed as evident from retention difficulties (Glenvilie et al., 1978).

physical or biochemical changes are minimal or absent (webb and carturigt, 1978). This is evident for instance from the fact that autonomic functions wuch as heart rhythm, blood pressure, respiration and body temperature remain stable. An abnormal degee of fatigue most often occurs only after total sleep deprivation of $48 \mathrm{~h}$, often belng associated with a figt decrease of cortisol and of 17 hydroxy sterold concentration in plasma (Akerstedt et a.1."1980).

After a total sleep deprivation of 24 h the ensuling sleep is characterlzed by a shortening of the sleep latency, an increase of deep N. FEM 3-4 sleep, with or without a decreased REM sleep (Berger et al. 1971). The increase in $N$. REM 3-4 sleep is age-dependent and. largest in young persons (Webb, 1972). The moment at which the compensatory sleep during the day takes place is important: moxe REM leep would occur in the morning and more $N$. RFM $3-4$ slleep in the evening (Fukuda et al., 1981). The cyclicity of this compensatory Heep is maintained, but certain sleep phenomena such as K-complexes and sharp vertex waves might occur in a somewhat modified form (Fothova et al., 1980).

In view of the small number of side-effects following a total sleep deprivation of $24 \mathrm{~h}$ and the fact that the effects on the compensatory sleep are well studied, it is not a surprise that sleep deprivation has been applied as a procedure for the diagnosis of epilepsy. For it allows to perform a sleep recording of limited durathon, because of a fast onset of sleep, rapidly attaiming N.RFM 3-4 a leep while retaining 1 ight $N$. TEM $1-2$ sleep and $\mathbb{R E M}$ sleep (Berger et a.. 1971$)$.

It one accepts that $2 / 5$ (Janz, 1962) of the epileptics mainly have their selzures at night and that epleptio discharges mainly occur auring W.PEM 1-2 seep (Patry et a1., 1971) then one has to answer the following two questions:

1. Are the nocturnal seizures determined by a circadian rhythm or do they occur in relation to sleep?

2. Does the compensatory sleep of epileptics contain a sufficient amount of N.REM $1-2$ and REM sleep to diagnose and localize ep $1-$ leptic abnormalities?

Therefore, the Ilterature with respect to the methodology and the diagnostic resultis obtained with total sleep deprivation was investigated. (The findings here are restricted to total sleep deprivation, TsD, whilch means that the subjects were continuously awake for at least $24 \mathrm{~h}$ ). 
By means of TSD Scollo-Lavizarri et all (1973) could confirm the diagnosis of epllepsy in 57.1 versus 16.7 , as compared to a routine EEG registered during daytime. Comparative results were obtained by clemens and Merey (1980) and by Degen and Degen (1980). studying group of 115 patients suspected of having partial complex epllepsy of the psychomotor type, Degen and negen (1980) alagnozed epilepsy in 47.8 using a nomal night sleep recording and 55.3 s following $T S D$ carried out $24 \mathrm{~h}$ after the normal sleep in the same patients. With the two procedures combined, the authors confirmed the diagnosis in 62.2 of the cases.

Schwarz and zangemeister (1978) compared the total recordings in which epileptic seizures, fitting with generalized and partial epilepsy of the psychomotor type, were present during a routine $\mathbb{E}$ in recording, with those found during routine EEG recording combined with provocation tests and those obtalned during sleep following wsi. The percentage increased from 11.5 to 48 and 88 for the generalized epilepsy and from 16 to 39 and 83 for the psychomotor type of epilepsy.

The extent of the registered diagnostic gain depends on a number of factors such as type and severity of epilepsy, intake of antiepileptics, the presence of epileptic and non-epileptic EEG abnormal1ties found in the routine EEG, the age, and whether or not this leep procedure is combined with other provocation tests.

As mentioned above Degen and Degen (1980) found epileptic EEG phenomena in 54 of their patients during sieep following TSD. Hexeof, 78 of them had generalized epilepsy and only 22 of their patients had partial epilepsy. Clemens and Mezey (1980) which also arrived at a positive diagnosis in 53 of their patients found, a slightly different proportion. of the epileptics suspected of having a generalized epliepsy 52 \%ad EEG abnormalities fitting with this form, 64 had EEG abnormalities fitting with partial epilepsy with a temporal localization and 29 had EEG abnormalities fitting with the partial epilepsy with a non-temporal localization.

The diagnostic gain of the generalized seizures of the grand mal type was largest when the selzures were short-lasting $(<5 \mathrm{~min})$ and occurred several times a month (Degen, 1980). Depending on whether or not clinical seizures were present (pothova et a.. 1980) epileptic EEG abnormalities were found respectively in 10 and 6 during a routine EEG recording, increasing to 52 and 41 o during sleep folLowing TSD.

When antiepileptics are taken regularly, tewer sileep recordings in which epileptic EEG phenomena are present, axe found than when antiepileptios are not taken (Deisenhammer and Klingler, 1978). These authors could confirm epilepsy as detected by the EEG in only 15 of the patients which were treated and in 52 in a non-treated group.

When EEG abnormalities of non-epileptic nature were present, then epileptic EEG phenomena increased from 34 to 56 during seep after $\mathbb{S S D}$ (Mattsion et a1. 1965). When epileptic abnormalities wexe found during a routine EEG, then they mostly wexe found in all sleep stages. Howewer, when these abnormalities were absent during a routine EEG, then they were recorded mostly during W. REM 2 sleep (Degen, $1980)$.

The degree of activation present during a routine EEG recording appeared of importance. In persons in which the EEG indicated the 
high activity (fast low voltage activity as an expression of desynchrontzation) Clemens and Mezey (1980) found an increase to 23 of the recordinge with eplleptic ERG phenomena aftex mSD. In relaxed personit, of which the EEG was characterlzed by a well-formed and high Woltage lpha rhyth, an increase to 35 was found and a further increase when the routine EEG showed signs of lability.

The age of the patients is also of importance: the diagnostic gain Is larger in persons below 18 years than in adults and it decreases gradualdy abowe 40 years (Tartara et al., 1980).

In some laboratories (Ritter et aI., 1977) the TSD procedure is combined with provacition tests such as hyperventilation and intermittent light flashes. Ritter et al. (1977) obtained an additional gatn of 13 when they used TSD in combination with hyperventilation.

very important lis the observation made by many investigators (Helneman, 1966, Johnison, 1969; Jovanovic et al., 1971; Scaxpalezos et al., 1980; Tartara et al., 1980) that TSD of $24 \mathrm{~h}$ in non-epileptics never provoked clinical or electroencephalographic epileptic mandestations.

It appears thus that sleep after TSD is a very useful and efficient method for the diagnosis of epileptic EEG manifestations. oller-Daurella (1966) mentloned the following advantages: 1 . It is a simple method, 2. epileptic EEG phenomena not detected in a routine EEC are found, 3. activation of EEG phenomena fitting with generalized as well as partial epilepsy are found, 4 . it induces sleep in a physlological. way, 5. It is a burdensome test compaxable to the supplementary severe effort of dally life. Also Passouant (1975) described this method as a very useful procedure in the field of epilepsy diagnosis because: 1 , one night sleep deprivation is sufficient, 2. antlepileptic drug medication does not have to be stopped, 3. the method can be used in combination with other provocation methods such as hyperventilation and intermittent light flashes, 4. false positive results are obtained only seldomy, 5 . the effect is based on deprivation itself.

up to the present, it is not known which biochemical and physiological changes occurring during sleep following sleep deprivation are the cause of a decreased threshold for epileptic EEG phenomena. The longer duration of sleep recordings as compared to a EEG routine recording cannot explain the diagnostic gain (Pratt et al.. 1968). The forced wakefulness leading to an increased sleepiness can also not explain the diagmostio gain (Gellex et al., 1969).

Finally, a short survey of differences in duration and the method ol leep recording following $24 \mathrm{~h}$ TSD is given hereafter. Gereby (1978) records for 20 miln, Wittenbecher and kubieki (1977) record for $30 \mathrm{~min}$, Degen (1980) records for a variable duration between 17 and $47 \mathrm{~min}$ depending on the results, schwarz and zangemelister (1978) for $40 \mathrm{~min}$, scollo-Lavizarri et al. (1977) $60 \mathrm{~min}$, whereas Tartara et al. (1980) start with period of wakefulness for $20 \mathrm{~min}$, including intermittent light flashes, followed by a sleep recording of about 60 min, whereafter the patients are wakened and asked to hyperventilate. Due to these differences, the results obtained in the different laboratories are alfflcult to compare.

It has to be mentioned that in young children one dewiates from the absolute rule that a total sleep deprivation has to consist of wakefulness for at least $24 \mathrm{~h}$. Instead a partial sleep deprivation 
is applied. Bechinger and Kornhuber (1976) keep children below the age of 3 years awake for half a night. Wittenbecher and kublick 1 (1977) allow children, younger than 4 years to sleep from 22 to $6 \mathrm{~h}$ and those between 4 and 1.4 years between 24 and $6 \mathrm{~h}$, whereas rothova et al. (1980) prescribed a sleep deprivation of $4 \mathrm{~h}$ in chilaren below the age of a years, six hours in children between the age of and 12 years and a total night for children above the age of 12 years.

\section{II.4. SLEEP AFFECTED BY EPILEPSY AND ANTIEPILEPTICS}

Epileptic phenomena result from sudden massive discharges of large groups of cortical cells, occurring when the inhibiting influences are becoming weak. The degree of this inhibition depends to a large extent on the activity of the ascending reticular activating system (ARAS). Likewise, this structure is responsible for the maintainance of wakefulness during daytime. Its level of activity is much lower during N.REM sleep, which may be the reason why clinical and subclinical (electroencephalographic) eplleptic events may easily occur during sleep (Gloor, 1980, Montplaisir et al., 1980). Since the ARAS system is as important for sleep wakefulness regulation as for the occurrence of epileptic manifestations, it is admissible that a disturbance in its function can give rise to epileptic as well as sleep disturbances.

\section{I. Sleep affected by the appearance of epileptic phenomena There exists a variety of opinions in the literature con-} cerning the sleep changes which may occur as a result of "having epilepsy". For instance Passouant (1975) stated "the nocturnal sleep of epileptics is often normal: the number of cycles, the stages of slow we sleep, the duration of REM sleep, compared with the total sleep are not modified. Howevex, in some cases the organization of sleep is abnormal" .

Among the changes in N.REM sleep passouant (1975) mentions a decreased number of $K$-complexes and sleep spindles and a decrease of N. FEM 3-4 sleep. These findings have been confirmed by others (Findji et a1., 1978), but other researchers found an increase in x-complexes (Halasz, 1979) and of sharp vertex waves (Clemens and Mezey, 1980) in patients having generalized epilepsy.

Abnormalities in REM sleep have also been mentloned. Accoraing Passonant (1975) REM sleep in epileptics is often associated with a decreased density of rapid eye movements and of Ev rhythms wh saw tooth form. In adaition REM sleep is less table, being interxupted repetitively by short pexiods of REM $1-2$ sleep or wakefulness. Also non-EEG parameters might change being characterized by the presience of more muscle and movement artifacts (Jovanovic, 1966).

According certain investigators the sleep composition would be afferent depending on the time of preference of the occurence of epileptic attacks and the severity of epilepsy. According Jovanovic (1966) the sleep in patients which have their fits during the night. is characterized by a fast onset of sleep, the fast occurrence of much deep $\mathbb{N}$. REM 3-4 sleep and very few moments of wakefulness. The opposite would accur in patients mainly having wakefulness epilepsy. 
According Declerek et l. (1980) patients which have two forms of epllepsy have the tendency to sleep more superficialiy and awake more frequently. Analogous findings were described by Horita et al. (1981) who also found a rellationship between the degree of the disorganization of sleep and the severity of the abnormalities found in the routine EEG. Further Arguner (1977) found that an aggravation of epllepty was proceeded by a disorganization of the sleep.

The fiects on sleep in patients having cilinical attacks is dependent on the type and the number of these attacks. Thus coher and Dement (1965) found that generalized epllepsies of the tonic-cionic type do not influence N. REM sleep but give rise to suppression or delay of par leep. partial eplilepsies which have their origin in the amygdali or hippocampus appear not to affect sleep according Montplaisir (1979). Such abnomalities are present in epilepsies which have frontal or occipital cortical focus, but the sleep abnomalities are not speciflc for one of these localizations. However. Kublok1 (1969) found sleep abnormalities, specially of REM sleep, in partial epilepsies with a temporal localization.

whe value of the findings in the literature are difficult to judge, becanse many of the mentioned deviations in sleep also accur in other non-epileptic diseases and some of these even have a physiological origin. For example, Niedermeyer (1970) and Wittenbecher and Kublcki (1977) have pointed out that many sharp k-complexes and shaxp vertex wave can be found in young subjects below the age of 16 years Whout implicating that these indicate an epileptic predisposition. The strong suppression or the absence of sleep spindles is a regular experience in severe mentally retarded children (shibagaki et al.. $1980)$.

\subsection{Sleep affected by the intake of antlepileptics}

Antieplieptics are described as medicines which increase the firing threshold of nerve cells, shorten the duration of afterdischarges and prolonge the refractory period (Longo, 1977). By this they may more or less break the excessiue neuronal discharges. On the basis of their speciflcity they are divided into antiepileptics of first and second choice. To antiepileptics of first choice belong: barbiturates, hydantoins, succimides, valproate and carbamazepine. The majority of antiepileptics of second choice belong to the benzodiazepine derivatives. Sleep changes caused by the lattex group have been tudied extensively, in contrast to the first choice antiepileptice of which only the effect of barbiturates and to a lesser degree hydantoins are relatively well-known.

Following the intake of barblturates the first visjble effect is a decreased REM sleep (Rödex and Wolf, 1980). With prolonged intake (longer than 6 months) an increase of N. REM $1-2$ sleep appears whereas N. kew 3-4 sleep remains the same or decreases (Potvin et al., 1975). In certain persons barbltuxates lead to a pronounced increase in aleep spindies, often correlating with a positive treatment result (sengoku and wolf, 1981).

Following the intake of hydantoin derivatives sleep becomes steadier i.e. the subjects awake less, and sleep less easily switches from one stage to another (Fukuyama et al., 1979). Long term intake leads to a sleep pattern slmilar to that seen following barbiturate intake, because N. REM 1-2 sleep increases and FEM sleep decreases. 
succimide derivatives are antieplieptics mainly administered for the treatment of primarily generalized epilepsy of the absence petit mal) type. Röder and wolf (1981) demonstrated that these compounds increased the degree of activation by which patients tend to waken up during the sleep, 2 ncreased the amount of N.RM 1 sleep and decreased the amount of $\mathrm{N}$. REM $3-4$ sleep.

valproates are antiepileptics which are mainly applied for the treatment of generalized epilepsies. Apart from an increase in N. FEM 1 sleep and a decreased REM sleep, no other changes are known.

In healthy persons, carbamazepine can give rise to a decrease in REM sleep (wachner, 1980). In subjects with sleep disturbances, as a consequence of withdrawal of phenytoin (Murtay, 1977) or alcohol (Hasan et a1. 1980), or aue to psychic disturbances (Ballenger and Post, 1980) carbamazepine can improve sleep by decreasing the number of awakenings and by increasing the total amount of sleep.

Depending on their potency and duration of action, all benzom diazepines to a more or less degree, affect sleep. often they give rise to a fast onset of sleep, less awakening and a prolongation of the duration of the first sleep cycle. An increase in N.RBM $1-2$ sleep and a decrease in N. REM 3-4 sleep is also seen (Gaillard et al., 1973). Further it is known that long-acting benzodiazepinederivatives such as nitrazepam, may postpone or suppress RaM sleep. In how fax these changes can also be demonstrated by polygraphic recordings in epileptic patients treated with antiepileptics could not be determined from the literature.

II. 5. SUMMARY

On the basis of the literature we aimed at answering the following questions:

1. How can sleep and eplieptic abmormalities be judged electroencephalographically?

In order to judge sleep adequately, polygraphic recording including EEG rhythms, eye movements and muscle activity, is a necessity. According criteria set up by Rechtschaffen and Kales (1968), which make use of these three measures, sleep can be divided into N. PFM $1,2,3$ and 4 and RFM sleep. By setting out the duration and time of occurrence of the different sleep stages in sequence in a t.ime diagram. sleep composition can be judged adequately * In this respect it is desixable to describe the sleep composition using the internationaliy accepted teminology. Also the description and interpretation of epllepsy requires uniformity of the applied terminolagy. For the description of epileptic abnormalities, we made use of the definitions which are mentioned in the "Handbook of EEG and Clinical Neurophysiology" (11A, 58-73; 13A, 7-20). For the degcription of the different formis of epilepsy, we made use of the electroclinical classification proposed by the International League againgt Epilepsy.

2. Which sleep procedures have been used to diagnose epllepsy?

polygraphic sleep recordings as an expedient to confirm epliepsy was introduced by Gibbs and Gibbs in 1942. At the outset aifferent sleep procedures have been used: siesta sleep, all-night sileep, drug- 
Lnduced sleep and leep following preceaing sleep deprivation. At presient the most applied method 1 s total sleep deprivation for a perlod of $24 \mathrm{~h}$, followed by a polygraphic sleep recording of which the duration differs in the different laboratories.

3. How large is the diagnostic gain by sleep imwestigations?

The data from the literature malnily concern the all-night sleep and leep deprivation methods. The results obtalned by these two methods are comparabla: they provide a diagnostic gain of about 30 . to 40 as compared to the routine EEG investigation carried out during daytime. The size of the gain is dependent on the kind of seep as well as on the type of epilepsy. The size of the gain is largest during light $\mathrm{N}$. REM $1-2$ sleep, for all forms of epilepsy. often somewhat larger for the gereralized epilepsies than for the partial epllepsies. The galn is also dependent on the quantity and severity of the clinical and subclinical epileptic manifestations. the presence of absence of non-epileptic EEG abnormalities, the regular or irregular intake of antiepileptics and eventualiy corbination with other provocation methods.

4. How do the epileptic EEG phenomena change during the sleep?

There is a tendency towards the formation of polysplike waves during the N.REM 1-2 sleep, the splike wave paroxysms become shorter but their frequency of occurrence increases. The same tendencies, but to a lesser degree, exist during the N. ERM 3-4 sleep, but there is a propensity towards formation of low Erequency and irregular spike waves, long-Iasting paroxysms undergoling fragmentation.

5. Which sleep changes may occur by 'having epilepsy'?

It Is generally accepted that subclinical epileptic discharges hardly affect the sleep pattern. Following clinical attacks of the generalized type, the sleep pattern can be disturbed for some minutes and REM sleep can be temporarily suppressed. This, however, is almost never associated with a loss of cyclicity.

The effects on sleep caused by partial epilepsy would be dependent on the localization of the primary focus, whether temporall, mon-temporal, or superficial or deep cortically.

subjects in which the epilleptic attacks occur preferentially during the gleep or curing the day, would have a different sleep composition.

6. Is sleep affectra by the intake of antiepileptics?

of the first cholce antiepileptios, only the effects of the baxbiturates and hydantolns on the sleep are vell studied. rhese subbances Increase $1 \mathrm{ight} \mathrm{N}$. FFM $1-2$ sleep, all or not associated with a decreased FEM sleep. of the antlepileptics of second choice, the afects of benzodiazeplnes on the sleep are well-known. Apart from an increase in effective sleep, they affect the ratio between the N. RMM $1-2 / \mathrm{N}$. REM 3-4 sleep in favour of the light N. REM $1-2$ sleep. The barbiturates as well as the benzodiazepines give rise to an increase in the number of sleep spindles. 
Own investigations were started in ordex to clarify a number of questions of which the findings in the literature were unclear. These questions were necessary to evaluate precisely the advantages and disadvantages of the total sleep deprivation method, and then to use this information to set up criteria which need to be fulfilled in order to ascertain an optimal diagnosis. To this belongs not only the recording and interpretation of epileptic EEG abnormallties, but also sleep disturbances, caused by epllepsy or the intake of antiepileptics. In this view the following questions were considered of essential importance for our investigations.

1. Which are the conditions which need to be fulfilled for sleep following sleep deprivation resulting 1 in the highest possible yield for the diagnosis of epilepsy (Chapter $v)$ ?

2. How and to which degree does the sileep in epileptics differ from healthy persons and which factors determine these differences (Chapter VI)?

3. How and to which degree sleep deprivation affects the subsequent sleep in epileptics and on which factors does this depend (chapter VII)?

4. Do antiepileptics differentially affect sleep (Chapter VIII)?

5. Which morphological changes in the epileptic EEG phenomena occur during the sleep and which are the changes of the polygraphic sleep pattern as consequence of epilepsy (chapter IX)?

6. What 1 s the best method of sleep deprivation (Chapter $X$ )? 


\section{1. SUTUECMS}

Durling the pexlod 1976-1981, more than 6000 subjects were investigated electronencelographically in our Department of EEG and Clinical Heurophyslology of the Epllepsy Centre "Kempenhache" Heeze, wh the alm of confirming the existence or absence of epliepsy or to better define its form. All the subjects were referred by a general practitionex, neurologist or paediatrician. only at the request of the speciallst were addtional EEG investigations carried out, the oxder of these is represented in Table IV. 1 .

\section{TALLE IV.1.}

"Di grostic procedures".

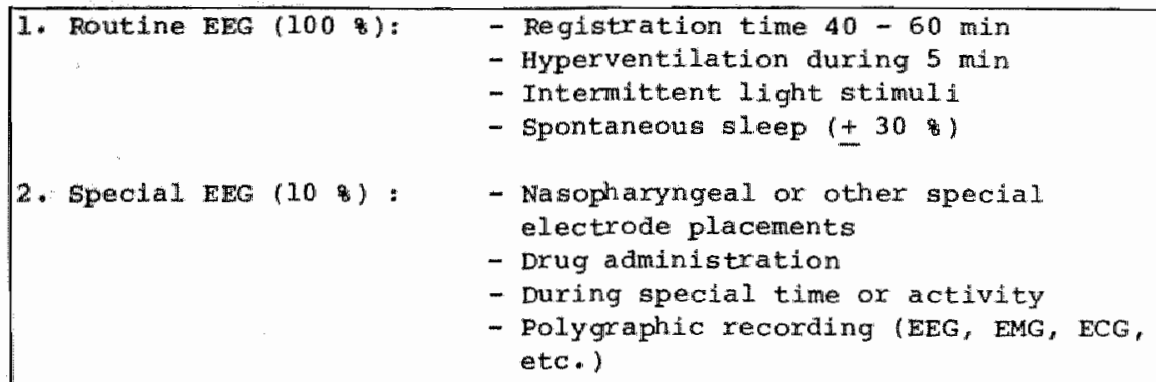

3. Sleep recordings $(258)$ : - Sleep after 1 night sleep deprivation $(3-5 \mathrm{~h} ; 2$ cycles)

- Interrupted sleep $(3-4 \mathrm{~h} ; 1$ cycle)

- All-night sleep $(7-11 \mathrm{~h})$

4. Long term EEG

registration (15 8) : - Ambulatory 4 channel cassette EEG monltoring $(24-48 \mathrm{~h})$

- EEG telemetry and videomonitoring $(2-24$ h)

In all aubjects a routine EEG recording lasting 40-60 min was carried out. In about 30 of these, short-lasting $\mathbb{N}$. REM $1-2$ and sporadically N.IRM 3-4 sleep were recorded. In those cases where this routine investigation did not provide enough information to answer the query, additional EEG investigations were done.

In about 10 of the subjects this additional investigation consisted of a second $E E G$ recording differing from the routine $E E G$ recording in certain aspects: 1) a different electrode localization. o.g. applying nasopharyngeal electrodes; 2) the recording at times or in conditions during which the complaints mainly occur, e.g. during 
eating: 3) applying arugs to check their efficacy on eplieptic Eec abnomalities; 4) polygraphic recording of physiological changes together with the EEG in order to better study their association.

In about 25 (1500) of the subjects aleep recording was carred out as a supplementary investigation. Depenaing on the presumed clinical form of epilepsy, a choice was made between spontaneous sleep recording, elther an all-night sleep $(7-11 \mathrm{~h})$ or an interrupted sleep $(3-4 \mathrm{~h})$, or sleep $(3-4 \mathrm{~h})$ after sleep deprivation (an interrupted period of 24 h wakefulness).

The sleep deprivation method was applied in $65 \%$, al1-night sleep recordings in $18 \%$, and interrupted sleep in 17 of the subjects. The predominance of the sleep depxivation method is due to the fact that this was our method of first choice. The interrupted sleep was applied in chilaren below the age of 7 years, and in persons with a psychomotor retardation ox with behaviouxal disturbances, in which no effective sleep deprivation could be applied. Total night sleep recordings were carried out in subjects in which seluures mainly occurred during the night, or in those in which the attacks were clearly assoclated with sleep and of which this association was not sufficiently confirmed during a sleep deprivation recording.

since 1978, the number of patients in which a long-lasting EeG recording was carried out increased from 3 to 15 .

More than 80 of the patients, in which a sleep recording was carried out in the period 1976-1981 were between 7-50 years of age, and were of either sex. At the moment of the sleep investigation $2 / 3$ of them stayed in our clinic mostly for a short period, and $1 / 3$ were investigated as outpatients. In no case was antiepileptic medication interrupted and a sleep recording was only carried out when drug treatment had not changed for minimally one week.

\section{IV.2. METHODS}

\subsection{Fecording method}

For the all-might sleep recordings, the sleep habits of the patients concerning time and way of sleeping were taken into account. For the sleep deprivation recordings, great emphasis was given to the demand that the subjects should be awake for an uninterrupted period of 2 : $\mathrm{h}$. In the clinic, wakefulness was continuously controlied by paramedical personnel, whereas for the outpatients, 1 t was checked whether this condition was suffielently fulfilied. If not, these persons were asked to come to the clinic on the night preceding the investigation, where the same paramedical staff actively controlled wakefuiness.

The polygraphic recordings were carxied out by expertienced techilcians in three specially adapted recording rooms. Each was equipped with a 16 or 21 channel mingograph (Elema-schönarder, Sllemeng). These were connected to minicomputer (PDP 11/34) for on-1ine analysis or to al 7 -channel instrumentation recorder (Racal store 70 ) for off 1 ine analysis.

Twelve to sixteen channels were used for recording the $\mathbb{E} E$ G rhythms, the remaining channels were used for recording eye movements (EOG), electrocardiogram (ECG), muscle activity of the chin (ENG) and respiratory movements (FM). In order to enhance the compaxability between sleep recordings a standard electrode placement according the 
finternationally proposed $10 / 20$ configuration was chosen, as shown in Figures $\mathbb{H}_{\mathrm{W}} \cdot 2$, and $\mathbb{I V} \cdot 3$.

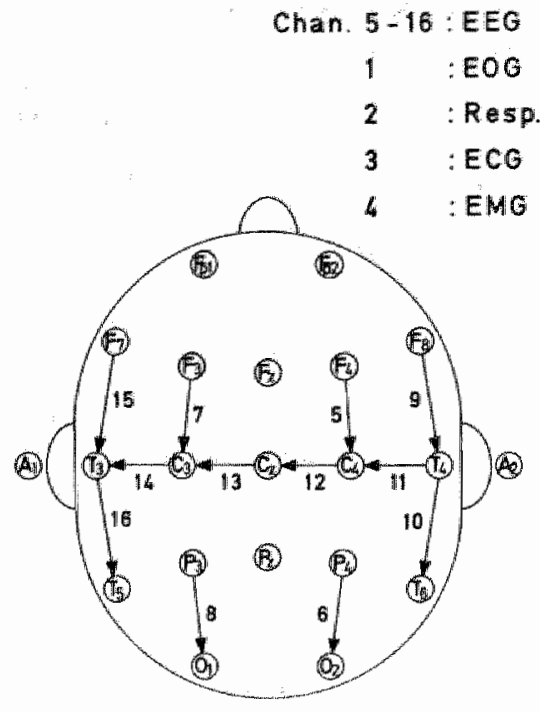

FIG. IV.2.

Position of electrodes by using a 16 -channed reconder
Chan. 5-21: EEG

$1-2: E O G$

$3 \quad$ Resp.

4 : EMG

$13:$ : CG

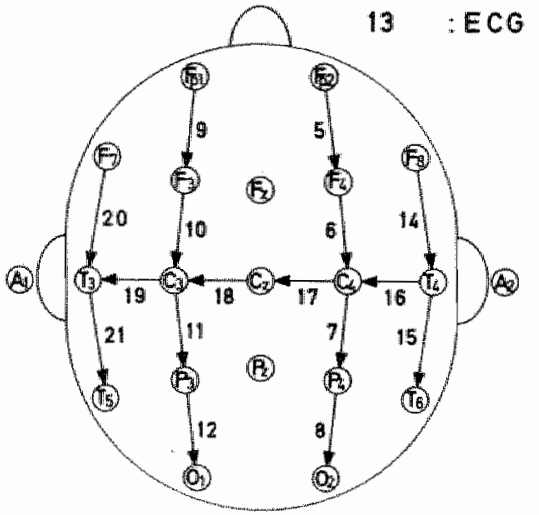

FIG. IV.3.

Position of electrodes by using

a 21-channel recorder.

With the selection of above derivations it was alimed to optimalize the EEG phenomena of importance for an adequate juagement of epilepsy and of sleep.

For defining epilepsy, it is important to differentiate diffuse from partial forms. This means that for the generalized forms, one should be able to record the fitting EEG phenomena simultaneously from the anterior (F4-C4 and $\mathrm{F} 3-\mathrm{C} 3$ ) and the posterior (P4-O2 and P3m0I) brain regitons of right and left hemisphere. For the partial form or the epilepsies caused by discharges orlginating from a resttricted brain area it is known that they are predominantly lacalized In the temporal region, which is the reason for which these regions are represented by 6 derivations in the used configuration 6 F8-T4 and F7-T3, T4-T6 and $\mathrm{T} 3-\mathrm{T} 5, \mathrm{~T} 4-\mathrm{C} 4$ and $\mathrm{T} 3-\mathrm{C} 3 \mathrm{l}$.

In order to partition the seep In REM and the different stages of N. KEM Geep, it is important to xecord the EEG phenomena optimally. During sleep the regionaliy specific wakefulness rhythm disappear, for ingtance the occipltal and central alpha rhythms and locally or difusely. other EEG phenomena or rhythis occur. Thus light slow wave sleep is characterized by the presence of sharp vertex waves and sleep splndles, locallzed maximally in the prexolandic region. Deep slow wave sleep is charactexized by the occurrence of alffuse delta activity through which local differences are less expressed. This requires a recording with a suffictently large number of channels. 
2.2.1. Visual analysis

The polyomaphic recoraings of EEG, EOG and EMG were analyzed according to the criteria of kechtschaften and kales (1968). The partition into wakefulness, N. REM 1 to 4 sleep and REM sleep was done for each 60-sec period and based on the kind and depth of sleep predominantly present during this period. The results were represented in hypnogram drawn on the form, on which different parameter were indicatied in a standardized way: the sleep procedure, data concerning the subject studied, clinical and diagnostic data and medication. In adition, the time of occurrence of epileptic activity during sleep was indicated, as shown in Figure IV.4.

The duration of each stage of wakefulness and leep in minutes and in percentage of the total recoraing time were indicated below the hypogram. Further the following parameters were recorded: total recoraing time (TRT), sleep latency (SLT) 1.e. the time lapsing between the beginning of the recording and the occurrence of at least 5 min uninterrupted sleep, the total sleep time (MS) 1 .e. the total recording time minus the sleep latency, the number of awakenings during the sleep and their total duration (N $+T)$, the effective sleep time (EST) $1 . e$. the total sleep time minus the time of awakenings during the sleep and, the REM latency (RLT) 1 .e. the time elapsing between the beginning of the recording and the beginning of the first REM period.

For each of the non-FEG parameters it was indicated how they were related to a specific stage of the sleep in so fax they were of importance for judging the sleep and epilepsy. This allowed to indicate whether the muscle tone, density of rapid eye movements, heart function and respiration during $N$. RFM and REM sleep conformed to the exprectations.

Apart from the polygraphic phenomena of importance for the classification of sleep the epileptic activity was also described in a detailed way. The type of epilepsy was indicated with the aid of aymbols mentioned in chapter II.2. Also, the duration of the epileptic discharges was noted and the percentage of the recording time during which these accurred as compared to the total amount of wakefulness, N. REM 1-2, M. REM 3-4, or REM sleep was calculated.

The interpretation focused on the diagnostic meaning of the epileptic EEG phenomena and on the quantitative and qualitative partition of the polygraphic sleep picture.

\subsubsection{Automatic sleep analysis}

The automatic sieep añalyis of long term EEG racordings, by means of a digital computer, was staxted covitinely in 1979. Therefore we used a modified software program, developed by Wa uquier et al. (1979), to analyse on-1ine the sleep of one subfect. based on two EEG-channels, dexived from $T 4-C 4$ and $P 4-02$, one EOG and one EMG channel. These four signals were analysed in epoch of 30 seconds and from each epoch eight parameters were extracted, whlich could be displayed afterwards.

The computer plot of such an analyais is shown in Fig. IV.5. "The time course, in minutes, is indicated in the abcissa, and in the ordinate from the bottom (1) to the top (8) the elght parameters and 


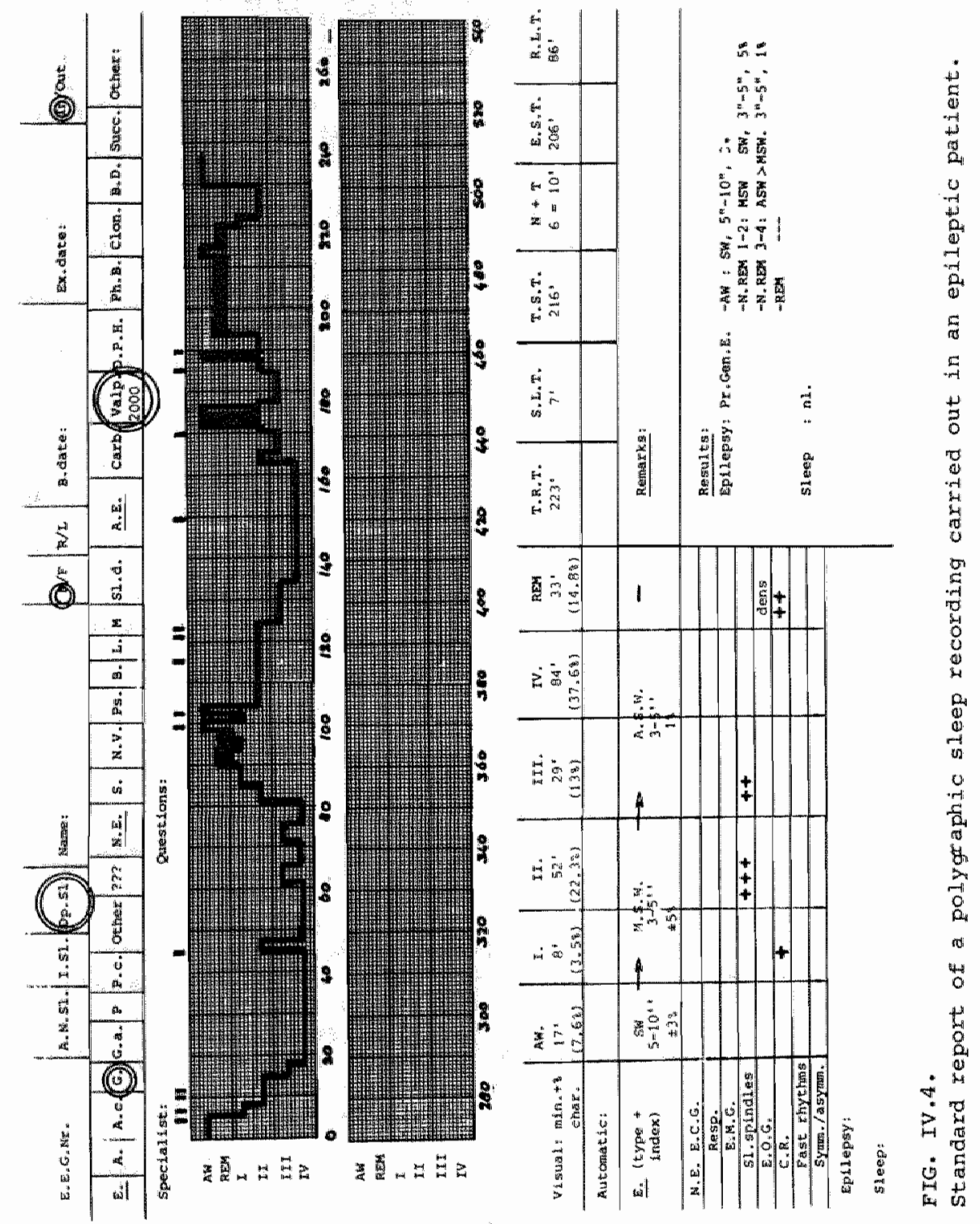




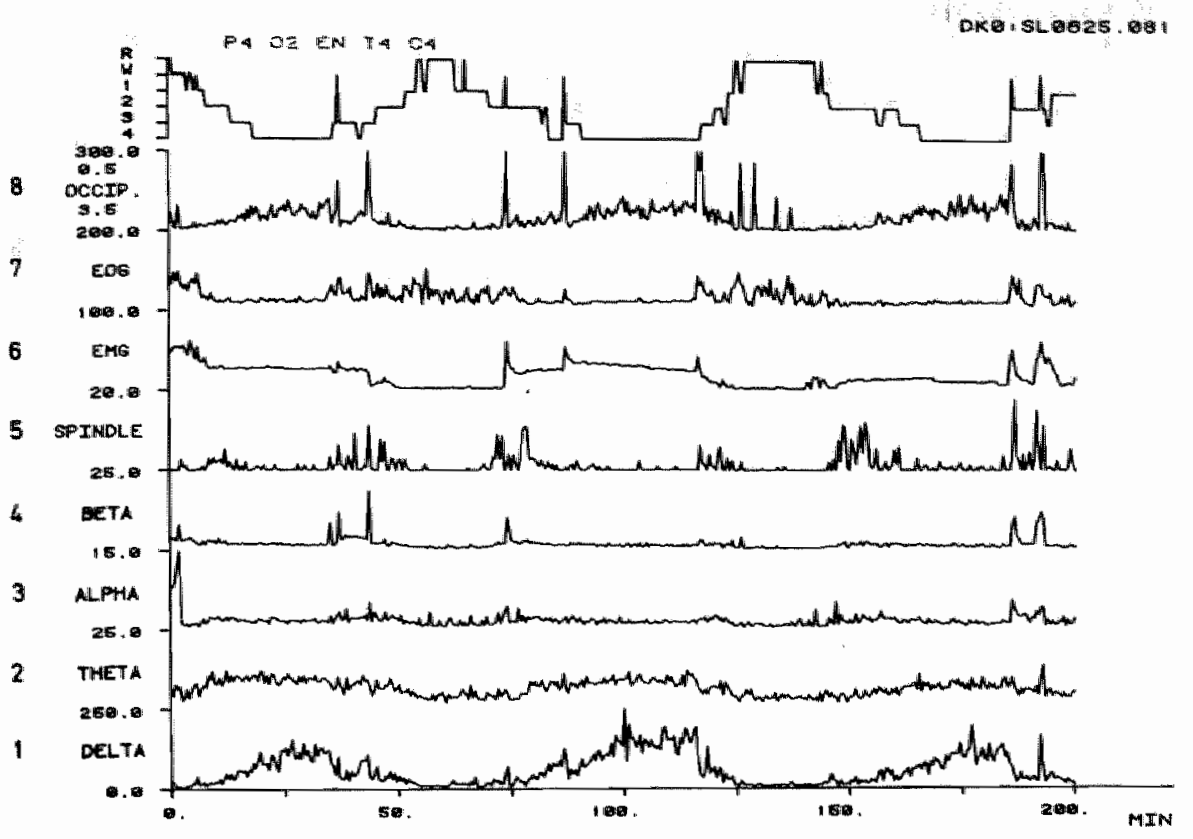

FTG. IV.5.

Example of automatic sleep analysis with sleep clessification (Mauquier et al.., 1978).

at the top (9) the autonatic sleep classification. Below the significance of each parameter is briefly commented on but a more detailed explanation can be found in addendum 1 .

1. The Iirst parameter represents the power of the delta rhythms $(0.5 \mathrm{~Hz}-3.5 \mathrm{~Hz})$ derived from T4-C4, calculated for every 30 seconds in succession. This delta time course is closely related to the depth of the N. REM sieep.

2. The second parameter represents the time conrse of the theta waves as determined by suming the power density from $3.5 \mathrm{~Hz}$ to $7.5 \mathrm{~Hz}$. This time course was mostly very similar to the delta actilty ad was not 50 important for the sleep classification.

3. The third parameter represents the time course of the dph waver (7.5 Hz-1. $\mathrm{Hz} \mathrm{Hz}$, which was very useful for the detection of awake pertods.

4. Finally, the fourth parameter indicates the time course of the beta waves (1.1.5 $\mathrm{Hz}-25 \mathrm{~Hz})$.

5. The fifth parameter shows the occurrence of sleep apinales. They are detected by a further segmentation of each 30-second epoch into 0.8-second periods, followed by spectral anaysis and an evaluation of the power density of the EFG activity between $11.25 \mathrm{~Hz}$ and $15 \mathrm{~Hz}$. It was the most important parametex for the identification of the N. REM 2 sleep. 
6. The sixth parameter represents the time course of the chin or submental musle activity based on the mean amplitude of the EMG signal. This parameter was used cor detection of movement artefacts.

7. Whe seventh parameter is calculated on the same way as the EMG and indicated the occurrence of eye movements. This parameter is necessary for the recognition of REM sleep.

B. Pinaly, the elghth parameter shows the time course of the delta waves derived from $4-02$ and was important to confirm the diffuse presence of delta activity during the W. RF 3-4 sleep.

9. To classify the sleep recording in stages, 6 epochs were chosen vidully a being representative examples for the dufferent sleep stages: Using these individual examples, the classification is carried out automatically, based on minimal distance criteria (Wauqulex et al." 1979).

In general there was a good agreement between the automatic and the visual classification of the $\mathbb{N}$. RFM 2 and the $\mathbb{N}$. REM 4 but only $a$ moderate agreement of the N.REM 1 and N.REM 3 (Martens et al., 1980). one of the reasions could be the suboptimal quantification of the parameters tevilting into a hig sensitivity for artefacts isee also addendum 1). Therefore, we attempted to develop a method which could also be applled to at least three subjects simultaneously. In August 1981 the new method (Martens et al., 1981) reached the operational tage and flgure IV.6. shows an example of such an analysis.

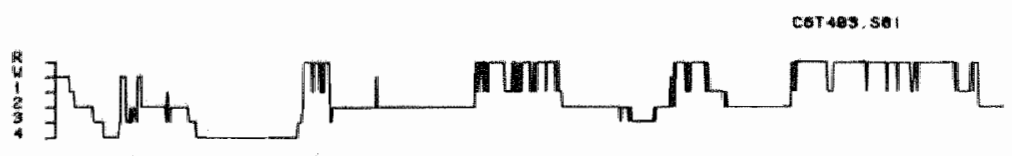

12 R E H

11 政, M.

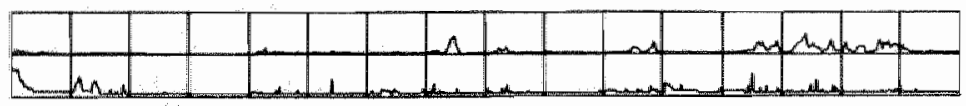

10

Punger,

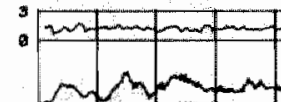

hum

SIGHA
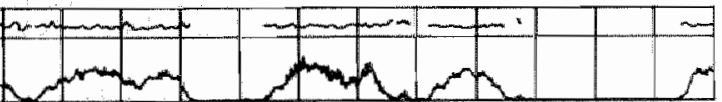

6

7

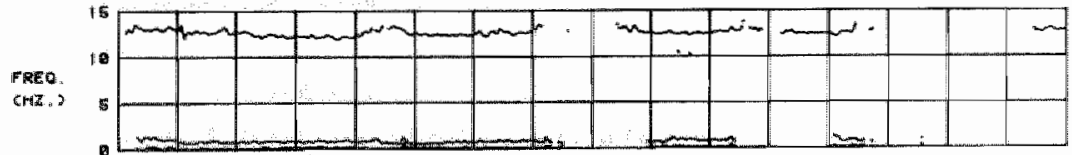

5

4 Gita

3 NLPFA

$2 \quad$ TEETA

1

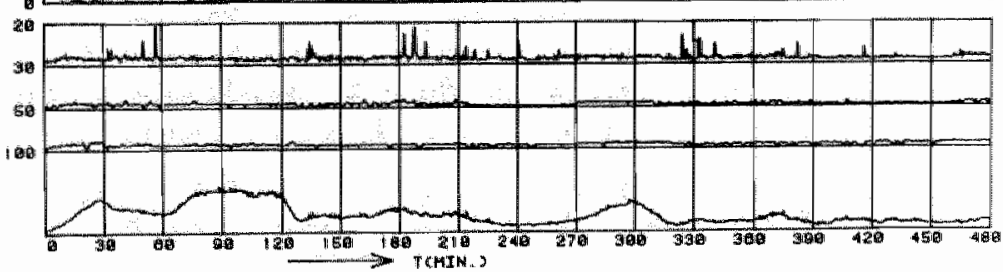

FIG. IV.

Example of atomatic sleep analysis with sleep classification (Maxtens et a1., 1981). 
Again the time couxse is indicated in the abscissa and the alfferent parameters subdivided into four groups in the ordinate from the bottom (1) to the top (12).

In the lowest rectangle, parameter 1 to 4 represient the time course of the delta, theta, alpha and beta rhythi, calculated on amplitudo base (for a detailed explanation is refered to addendum 1 ).

In the second rectangle, the frequency characteristics $(5,6,7)$ of the delta, theta and alpha rhythms, are indicated only if they exceed certain determined levels. If this is the case the peak frequency and band width of the rhythms are represented by two lines. A naxrow trace reflects a very stable rhythm (like a pure sine-wave) and a broad trace corresponds to a high variability. In the upper part the peak frequency of the sleep spindles is indicated by one simple line ( 8 ).

In the third rectangle, the time course (9) of the sleep spinale activity is established together with their time duration (10).

In the fourth rectangle, the mean amplitude of the muscle activity (EMG) is depicted in the lower part (11) and the time course of the rapid eye movements, as detected from the $\mathbb{E O G}$, In the upper part (12).

on the top of figure IV.6. the hypnogram is platted, calculated on the same way as described in the first method. The computer plots have been used by the physician as an aid to the visual analysis which can be done more easily and more quickly $(50$ to 80 less).

In the future the matexial stored on a magnetic disk, will be used for more detailed quantitative and qualitative studies to analyse some special sleep features.

\section{3. MATERIAL}

In order to answer the questions posed by the aims of the study (Chapter III, p. 34) the visual analysis and reporting of the sleep recordings carried out in the period 1976-1980 were used. The reasons for diagnosing epilepsy electroencephalographlically during sleep recoralings were due to an insufficient confirmation, description or the lack of evidence for the all or none existence of epileptic EEG abnormalities gained during a routine EEG investigation.

In order to determine the diagnostic gain, the number of sleep recordings containing eplieptic EFG phenomena of a selected group of patients were counted " Further, it was studied in what percentage of the patients which had a known clinical form of epilepsy, epilepsy could be confirmed on the basis of a sleep recording, versus those of which the diagnosis was doubtful, and how many sleep recordings without eplleptic phenomena were found, In subjects for which no clinical grounds existed to diagnose epilepsy.

Further, the gain of epilepsy diagnosis with respect to the applied sleep procedure and the clinical form of epilepsy was determined. In addition, it was investigated to what extent the epileptic EEG phenomena depended on the sleep stages and recording time. In order to find out whether the presence of epileptic EEG phenoment or axug therapy influence the sleep, a group of patients were studied in which spontaneous night sieep recording was taken and a sleep recording following $24 \mathrm{~h}$ sleep deprivation. The sleep deprivation effect was measured by comparing the duration and composition of the firgt and second cycle of both types of sleep. 
From our patient material, groups of patients were selected which were treated with either one or maxima11y two antiepileptics, in oxder to tudy whether serp changes were drug-dependent. Finally, apart from the guartitative aspects attention was also given to the moxphologlcal changes which epileptic EEG phenomena might undergo (Chaptex $I X)$.

\section{IV.4. GUMMREY}

During the pertod 1976-1981, sleep recordings were carried out In about 1500 patients with the alm of investigating whether the clindeal complatnts were due to epileptic alscharges. In 65 of the cases leep after. $24 \mathrm{~h}$ sleep deprivation and in 35 spontaneous nocturnal sleep was studied. Sleep was polygraphically recorded by means of 16 or 21 -chamel mingographs, of which 12 to 16 charniels were used for recording EEG rhythms and 4 or 5 channels for recording non-EEG parameters. The large number of EEG channels was necessary on the one hand to dilferentiate partial from generalized forms of epilepsy and on the other hand to adequately partition the sleep into the different sleep stages on the basis of visual analysis. The result of this analysis was registered on a standardized way on a form on which the hypnogram and a number of quantitative and cualitative spects of the sleep were noted. Also, the type of epileptic EEG phenomena, their time of occurrence and their duration were noted on the same form.

Therefore, it was possible to judge epileptic EEG phenomena in function of the leep and vice versa for each sleep investigation. This report also allowed to solve the problems of our investligations as mentioned in chapter III.

With the aid of computer (PDF 11/34) 25 of the sleep recordings made since 1979 were analyzed and automatically classified. This resulted in an improved method by which it became feasible to analyse sleep on-line in 3 patients simultaneously since 1981 . With the ald of automatic reporting, the time required to visually analyse the sleep could be reduced to $1 / 3$. 
In this chapter an answer is sought for the following guestlon What is the value of lomg term polygraphe sleep investigations for determining epileptic ERG phenomena fitting with epilepsy and what are the conditioms which need to be fulfilied for this polygaphic siep investigation?

The material used to answer this question consisted of b tatal of 1503 sleep recordings carried out during the period $1976-1981$ as supplenent to the routine $\mathbb{E}$ ro recording, to confirm the wastence or absence of epilepsy ox to better describe its form. me general question has been divided into a numer of smaller questions which are dealt with in sequence hereater.

\section{V.1. DIAGNOSTIC GAIN}

The number of sleep recordings made since 1976 are shown in Table V.1. The number of epileptic EkG phenomena found in routine and sleep recordings, in rumber and percentage of the total number of subjects investigated, are indicated for each year. The aifrexence between both indicates the absolute diagnostic gain.

studied over the total period the alagnostic gain ranged from 24.7 (1979) to 32.1 \& (1977). The equal gain of 26.2 in 1976 and 1981 can be ascribed to a comparable increase in postive EEG findings in routine and leep recordings. of the 1503 patsents, 566 (37.6\%) had epileptic EEG phenomena in their routine EEG recordings. Nevertheless a supplementary sleep EEG recording was done in thege patientes becalse the number and specificity of epileptjc EEG phenomena Found during the routine EEG recording was too small to define the form ar epilepsy precisely. By means of the complementary sleep investigation an additional diagnosis was possible in 311 (54.9 of the 566 patients, denoted as a relative gain.

TABLE V.1.

Number (n) and percentage (s) of routine and sleep EFG recomdings during the period 1976-1981 with epileptic Ee phenomena.

\begin{tabular}{|c|c|c|c|c|c|c|}
\hline $\begin{array}{l}\text { Wumber of } \\
\text { patients } \\
1976-1981\end{array}$ & \multicolumn{2}{|c|}{$\begin{array}{l}\text { Fpileptic phenomena } \\
\text { in routine EEG } \\
\text { n }\end{array}$} & \multicolumn{2}{|c|}{$\begin{array}{c}\text { Epileptic phenomena } \\
\text { in sieep EEG } \\
n\end{array}$} & \multicolumn{2}{|c|}{ Gatin } \\
\hline $1976=99$ & 30 & $30 \cdot 3$ & 56 & 56.5 & 26 & 26.2 \\
\hline $1977=237$ & 75 & 31.6 & 151 & 63.7 & 76 & 32.1 \\
\hline $1978=234$ & 82 & 35.0 & 250 & 64.1 & 68 & 29.9 \\
\hline $1979=267$ & 109 & 40.8 & 175 & $65 \cdot 5$ & 66 & 24.7 \\
\hline $1980=326$ & 118 & 36.2 & 218 & 66.9 & 100 & 30.7 \\
\hline $1981=340$ & 152 & 44.7 & 241 & 70.8 & 89 & 26.2 \\
\hline$=1503$ & 566 & 37.6 & 991 & 65.9 & 425 & $28 \cdot 3$ \\
\hline
\end{tabular}


In 9 patients $(1.6 \%)$, no epliteptic EEG phenomena were pound during the gleep recordings although, they were present in routine EEG. of these, sever had generalized low erequency spike waves and two tocallzed spike in the routine EEG.

\section{2. ELACTEOENCEP HALOG RAPHIC CONF IEMATION OF MUE CLINICAL DIAGNOSIS}

The patient population was divided into 3 subgroups on the basis of anamestic and Cl1nical findings mentioned on the request form by the demanding speclailst. The first group consisted of patients of which the existence of epilepsy was considered very possible $(4)$, the second group consisted of patients of which the diagnosis epilepsy could nelther be confirmed nor denied (2), the thitd group consisted of patients of which the existence of epilepsy was rejected (-). In an andlogue way the polygraphic sleep recordings were diwided into three categories. The positive category consisted of recordings in which EEG deviations occurred, which even without knowledge of anamnestic and clinical data, immediately suggested the diagnosis of epilepsy. In the doubtrul category EEG abnormalities are too small or unspecific to allow diagmosing a specific form of epilepsy. However" in relation to the clinical findings these abnormalities are valuable in order to suppoxt the diagnosis of epilepsy. The negative group consisted of patients in which neither specific nor aspecific eptleptc EEG deviations were found during the recordings. The combination of the clintcal and electroencephalographic partition, allows to find out whether the $\mathbb{E E G}$ diagnosis correlates with the clinical findlings as shown in Table V.2.

The large percentage of sleep recordings with EEG confirmation of the clinical diagmosis in which the presence $(+)$ or the absence (-) of epilepsy was stated with a high probability, lis striking. For the clinical subgroup of which the existence of epilepsy was considered very likely (t) or possible (?), it is apparent that a larger percentage of speciflc epileptic EEG abnomalities was found auring the sleep than during the routime EEG recording, this is 84.2 versus 35.1 for the positive group and 56.4 versus 20.5 for the doubtEul group.

TARE V.2.

Electroncephalougaphic confirmation of epilepsy accoraing to the olindeal digriosis.

\begin{tabular}{|c|c|c|c|c|c|c|}
\hline \multirow{3}{*}{$\frac{\text { Ginical diagnosis }}{\text { beriod } 1976-1981}$} & \multicolumn{6}{|c|}{$\begin{array}{l}\text { of EEG registrations with positive (4), doubtful } \\
\text { (?) and without }(-) \text { epileptic EEG phenonena during }\end{array}$} \\
\hline & \multicolumn{3}{|c|}{ Routine $\mathbb{E E G}$} & \multicolumn{3}{|c|}{ Sleep EEG } \\
\hline & + & 3 & - & + & $?$ & - \\
\hline$+n: 654$ & 35.1 & 19.3 & 45.6 & 94.2 & 7.0 & 8.8 \\
\hline$? \mathrm{~m}: 454$ & 20.5 & 25.6 & 53.9 & 56.4 & $28 \cdot 2$ & 15.4 \\
\hline$-n: 395$ & - & 0.5 & 99.5 & 0.75 & 2.0 & 97.25 \\
\hline
\end{tabular}


For the calculation of the diagnostic gain in function of the sleep pracedure, restriction was made to 666 sleep recordings carried out in the period 1980-1981, of which 108 were all-night, 101 interrupted and 404 sleep recordings following sleep deprivation. 53 (8) sleep recordings were not considered further because the patient lept for less than 1 whole sleep cycle. Concerning the clintical probabilthy of having or not having epilepsy " this group was randomly selected and was comparable with the total patient population $(\mathrm{V} .2$.$) . For each$ of the sleep procedures, the number of recordings during which EEG phenomena were found fitting with generalized or partial epilepsy, were calculated as sumarized in Table V.3.

TABLE V*3.

Gain of electroencephalographic epilepsy diagnosis depending on the sleep recording method versus the clinical form of epllepsy.

\begin{tabular}{|c|c|c|c|c|c|c|c|}
\hline \multirow{2}{*}{\multicolumn{2}{|c|}{$\begin{array}{r}\text { sleep methods } \\
n\end{array}$}} & \multicolumn{2}{|c|}{ Generalized epilepsy } & \multicolumn{2}{|c|}{ Partial epilepsy } & \multicolumn{2}{|c|}{ Total } \\
\hline & & $\mathrm{m}$ & 8 & $\mathrm{n}$ & 8 & $\mathrm{n}$ & 8 \\
\hline AI 1-n当ght: & 108 & 42 & 38.8 & 26 & 24.0 & 6.8 & 62.9 \\
\hline Interrupted & 102 & 33 & $32 * 6$ & 27 & 26.7 & 60 & 59.4 \\
\hline Deprivation & 404 & 131 & 32.4 & 102 & 25.2 & $2: 3: 3$ & 57.6 \\
\hline Total: & 613 & 206 & 33.6 & 155 & 25.3 & 361 & 58.7 \\
\hline
\end{tabular}

Independent of the sleep procedure used more patients have an electraencephalographic diagnosis of epilepsy in the generalized epilepsy group than in the partial epilepsy. The alagnostic gain for the generalized epilepsy is about 6 o higher using the ald-night sleep procedure than the other two methods. such difference is not found for the partial epilepsy.

\section{V.4. DIAGNOSTIC GAIN AS A FUNCTION OF THE SLEEP SPAGE AND DEPTH OF SIEEP}

of the 404 subjects of which sleep following sleep deprivation was recorded during the period $1980-1981,233$ had epileptic EEG abnormalities, of which 131 fitted with genexalized epilepsy and 102 fitted with partial epilepsy. 233 times N.REM 1 and 2 sleep was recorded of which $211(90.5$ ) was combined with $\mathrm{N}$. REM $3-4$ sleep and 143 times $(61.3$ ) with REM sleep.

For both types of epilepsy it was studied how much epileptic EEG phenomena were found during Iight N. REM $1-2$, deep N. RBM 3-4 sleep and FEM sleep, as shown in Table V.4. 
TAELE V.4.

Diagrogit of eplepsy according to the sleep states and stages auring seep aeprivation registration.

\begin{tabular}{|c|c|c|c|c|c|}
\hline \multirow[t]{2}{*}{ Bleep stage } & \multicolumn{2}{|c|}{$\begin{array}{c}\text { EEG jons of generalized } \\
\text { epllepsy (Gen.E.) }\end{array}$} & \multicolumn{3}{|c|}{$\begin{array}{c}\text { EEG signs of partial epilepsy } \\
\text { (Part.E.) }\end{array}$} \\
\hline & ก: 131 & 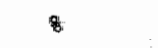 & & 102 & 8 \\
\hline N. $\mathbb{R H} \quad 1-2$ & 118 & 90.0 & & 100 & 98.0 \\
\hline N. REA $3-4$ & 70 & 54.4 & & 41 & 40.2 \\
\hline PEM & 7 & 5.3 & & 35 & $34 \cdot 3$ \\
\hline
\end{tabular}

For both types of epilepsy eplieptic EEG phenomena predominantly occurred during N. REM $1-2$ sleep, but were also found extensively durIng deep silow wave seep. There is a striking difference as far as FEM sleep is concermed: here predominantly EEG phenomena fitting with partial epllepsy were found. In this respect it should be mentioned that the percentages described in the table were calculated for the total group. In the group with generalized epilepsy 81 out of 131 had ReM sleep and in the group of partial epilepsy 62 out of 102 . Recalculating the percentage occurrence of eplleptic EEG phemomena in those having $\mathbb{R}$ M sleep, eplleptic EEG phenomena were present in respectively 8.6 and 56.4 for the generalized and paxtial epliepsy.

\section{V.5. DIAGNOSTIC GAIN AS A FUNCTION OF THE SLEEP CYCLE:}

If during the first cycle of a sleep recording no epileptic EEG abnormalities are seen, one can doubt whether further recording makes sense. Of the 233 TSD recordings (Table V.4.), 127 consisted of two well formed sleep cycles during which well recognizable interictal FEG phenomena fitting with generalized or partial epilepsy occurred either in both or in one sleep cycle. The results of this comparative investigation are sumarized in Table V.5., in which epileptic

TARUE V.5.

Electromeephalogxephic confirmation of epliepsy during the first or aecond sleep cycle.

\begin{tabular}{|c|c|c|c|c|c|}
\hline \multicolumn{2}{|c|}{ Cycle } & Gen. E. & Part.$E$. & Gen. + Part $\mathbf{E}$. & Total \\
\hline lst & $2 \mathrm{nd}$ & $m=58$ & n: 42 & $n: 27$ & ก: 127 \\
\hline+ & + & 43 & 34 & 26 & 103 \\
\hline+ & - & 6 & 1 & - & 7 \\
\hline- & + & 9 & 7 & 1 & 17 \\
\hline
\end{tabular}

t* sleep cycle with epileptic EEG phenomena.

-: sleep cycle whout pileptic EEG phenomena. 
EEG abnoxmalities are indicated by a + respectively during the first and second cycle for both types of epilepsy.

From this Table it appears that EEG abnormalities were prescnt in both sleep cycles in $B 1$ o $(103 / 127)$ of the subjects investigated, thougi generally more abundant during the first cycle. If the sleep recordings had been interrupted systemtically after the first oycle, the diagnosis of epilepsy would have been insufficient in $17(13.4$ ( ) of the investigated subjects.

\section{V.6. DIAGMOSTIC GAIN IN FUTCT ION OF THE RECORDING TIME}

on the basis of the literature it was impossible to obtain a clear answer to the question af how long sleep reeordings following TSD had to be carried out, in order to obtain a sufficiently high electroencephalographic confimation of epilepsy. In many laboratories the recordings were restricted to a maximum of one houx independently of the kind and depth of sleep. Therefore it was considered of interest to know the size of the diagnostic gain following a 30 min recording time and to which extent this gain increased following a successive prolongation of the recording time with $30-m i n$ periods. To answer the posed question the group of 666 patients (v.3.) was extended to 933 by adding those patients recorded auring 1979 .

In $626(67$ \%) sleep was investigated following ISD. of these 626 . 38 ( 6 ) had insufficient sleep because of continuous interruptions: by wakefulness and the lack of an uninterrupted period of 30 min of sleep. The remaining 588 sleep recordings lasted for a mean of $3-4$ hours and all consisted of at least 1 , but mainly 2 sleep cycles. Their hypnogram was divided into successive $30-\mathrm{min}$ periods, the first one starting at the onset of the polygraphic sleep recording.

In 270 of the 588 investigated persons, epileptic EFG abmormalities were found during the first 30 -min period of which 124 fitting with generalized epilepsy, 97 fitting with partial epilepsy and 49 , which had EEG abnormalities fitting with generalized epilepsy with in addition abmormalities fitting with partial epilepsy. For each of the following 30-min pexiods the number of recordings during whilch for the first time epileptic abnormalities were seen were counted, and summarized in Table V.6.

From the mable it appears that in 270 or $45.9 \%$ of the lnvestigated subjects, epilepsy could be confirmed during the flrst $30-m i n$ pertod" This is the period during which many changes occur since in most patients transitions from wakefulness to $N$. RFM $1-2$ and $N$. RIM $3-4$ sleep appear. The gain achleved during the second period $(31-60$ min) il $1 / 5(24 / 124)$ for the generalized epllepsy and $1 / 6$ (16/97) for the partial epilepsy as compared to the gain of the first period, which still is half of the combined group (27/49). The additional galin of 9.9 (58/588) achleved during the third perlod 1 s still considerable and might be associated with changes occurring at the end of the first sleep cycle, i.e. a transition from N. REM 3-4 to N.REM $1-2$ or REM sleep. Calculating the positive diagnostic findings in function of time, the following is obtained: after $1 \mathrm{~h} 57.3 \%$, after $2 \mathrm{~h}$ $69.4(+12.1 \%$, after $3 \mathrm{~h} 73.15 \%(+3.75 \%$ and after $4 \mathrm{~h} 74.5 \%$ $(+1.35$ ). The figure between bxackets is indicating the gain as compared to the preceding hour. These results are surmarized in Fig. V.7. 


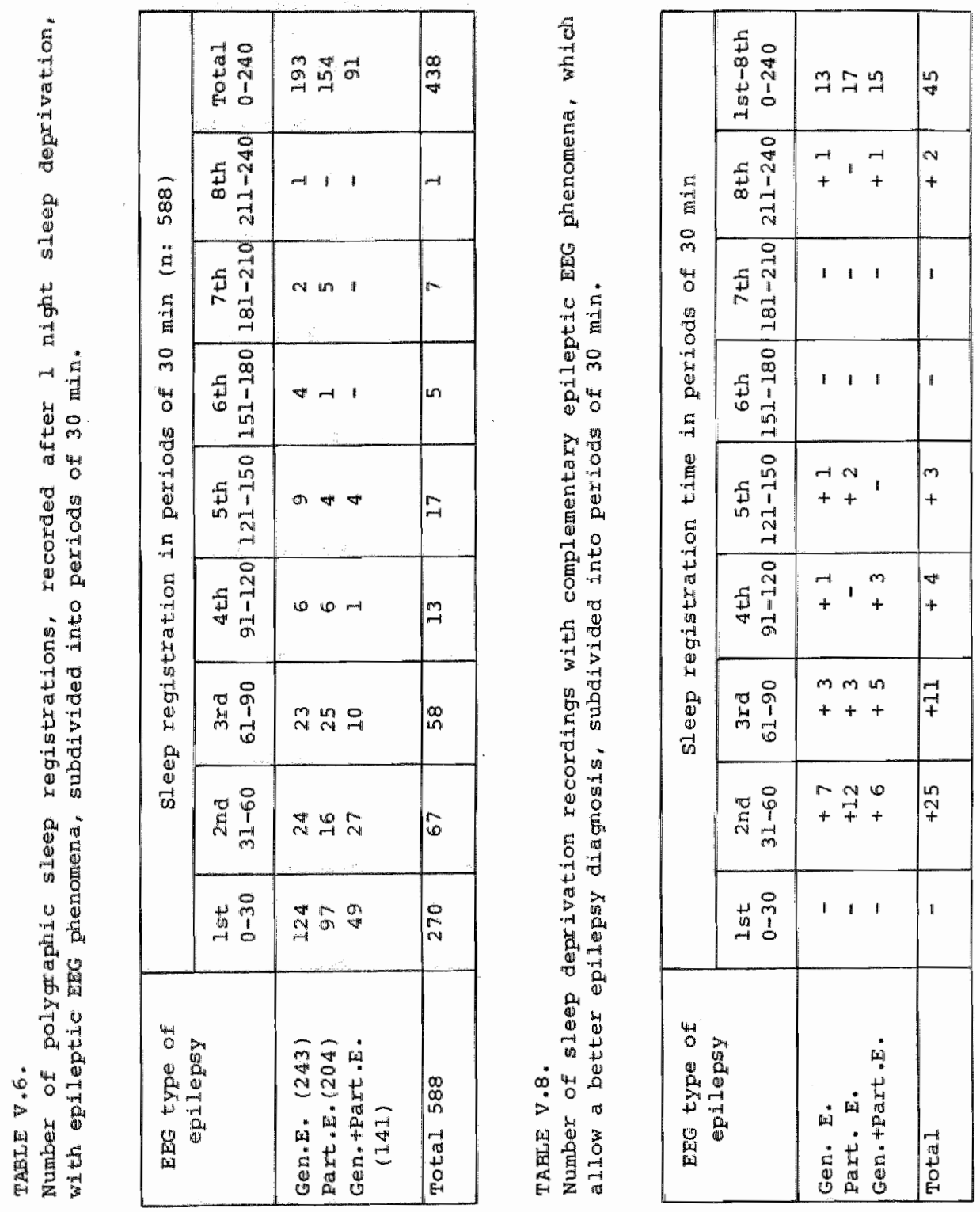




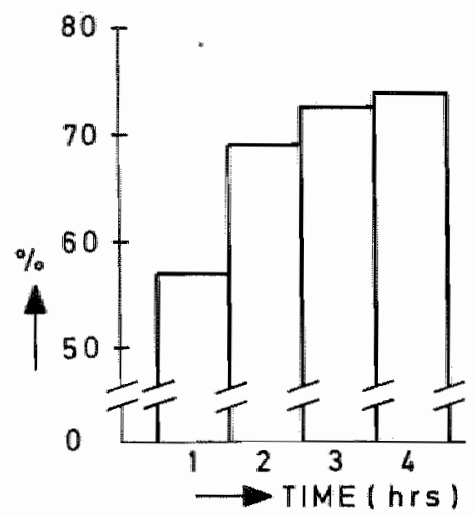

EIG. V.7.

Percentage of sleep recordings with epileptic EEG phenomena in relation to the registration time.

With the present material it was further investigated how the epilepsy diagnosis could be improved by recording other epileptic EEG phenomena. These additions could consist of changes in localization. fitting more with a partial complex than with a simple form of epilepsy, the occurrence of secondary generalizition or the appearance of a second type of epilepsy. In analogy with Table V.6. we calculated the number of supplementary epilepsy diagnostic findings for each $30-$ min period as summarized in Table V.8.

These figures demonstrate that the diagnosis could be improved in 36 (6.1 8) patients during the first additionad houx (3lst-90th min). The further improvement in 7 patients (1.2 was found by recording the second hour (9lst-150th min).

\section{V.7. DIAGNOSTIC GAIN DURING THE SLEEP IJATENCY PERIOD}

In order to investigate the supposition that an increase of epileptic EEG abnomalities following sleep deprivation is a consequence of a shortage of sieep unrelated to the subsequent sleep, the results of all-night sleep were compared with those obtained following the ISD. The percentage recordings with epileptic EEG findings during the sleep latency period using both methods was calculated. The aleep latency is the time period of wakefulness lapsing between the start of the recording and the occurrence of uninterrupted leep for at least $5 \mathrm{~min}$. As shown in Table $V .9$. this pexcentage was respectively 26.5 and 11.6 for the all-right sleep and the sleep following TSD. For the interpretation of these percentual values one has to consider that the mean sleep latency during the all-night sleep is longer than durling the sleep following sleep deprivation. Using the sleep recordings taken during $1980-1981$, the mean sleep latency is 41.3 min following all-night sleep and $6.3 \mathrm{~min}$ following sleep after sleep deprivation 
THELE V.9.

Mean duration and percentage of positite $(+)$ eplleptic Enc findings during the sleep latency period (S.I.Tw) for the all-night sleep and the sleep deprivation method.

\begin{tabular}{|c|c|c|}
\hline & Mlinight & sleep deprivation \\
\hline S.L.T. in min. & 41.3 & 6.3 \\
+.E. & 26.5 & 11.6 \\
\hline
\end{tabular}

From Table V.9. It appears that the sleep latency of the deprivation method is 6.5 times smaller than the latency during al1-night ileep recordings. The percentage epileptic EEG phenomena, however, 16 only 2.3 times smaller during the sleep deprivation method than during the all-night sleep recordings. This might indicate that the deprivation of sleep to a certain degree faclilitates the occurrence of eplieptic manifestations.

\section{V.8. DIAGNOSTIC GAIN DURING N. RFM 1-2 AND N-RTM 3-4 PERIOD}

From the literature it is known that following TSD sleep latency 1 short and $\mathrm{N} . \mathbb{R} \mathrm{RM} 3-4$ is reached rapidly. In addition, there is a markeid change in the composition of the first sleep cycle, i.e. an increase in N.REM 3-4, a decrease in N.REM $1-2$ and eventually a postponement of $\mathrm{RE}$ gleep. The question therefore was whether the changed Gleep pattern was associated with an increase in epileptic EEG abnormallties.

To answer this question, it was studied in how many subjects epjleptic EEG phenomena were found during the first $N$.REM $1-2$ and $N$. REM 3-4 period, using 100 all-night sleep recordings and 500 sleep deprivation recordings carried out before the end of 1981 . The results are given in Table v.l.o.

TABLE $\$ .10$.

positive alagnostie findings of epilepsy during the first N. REN $1-2$ and N. REM 3-4 periods: all-night versus sleep deprivation method.

\begin{tabular}{|l|cc|cc|}
\hline \multirow{2}{*}{ sleep stages } & \multicolumn{3}{|c|}{ Number and percentage positive findings } \\
\cline { 2 - 5 } & A11-night $(\mathrm{n}: 100)$ & Sleep deprivation $(\mathrm{n}: 500)$ \\
\hline N. $1-2$ & 47 & 47 & 211 & 42.2 \\
N. & 30 & 30 & 137 & 27.4 \\
\hline
\end{tabular}


From rable w10. It can be seen that the number of sleep recoraings containing epileptic abnormalities during both light and deep slow wave sleep are almost equal using both sleep recording procedures. This argues against the hypothesis that the increase in EEG findings are due to the changed sleep pattern following sleep deprivation.

\section{V.9. SLEEP DFPRIVATTON AND HYPERVENTIIATTON}

The hyperventilation test is considered as a good provocation test which promotes the occurrence of diffuse spike wave paroxysms, especially the typical $3 \mathrm{c} / \mathrm{sec}$ spike waves and polyspike wave complexes. This test can be combined with a sleep investigation.

In order to evaluate its effects, 60 patients in which a sleep deprivation investigation had been carried out were asked to hyperventilate for $5 \mathrm{~min}$ preceding and following a sleep recording. In 26 patients generalized spikes or spike wave paroxysms were seen during the sleep. Only in 3 of them were splke wave paroxysms allo seen during the hyperventilation test, in two patients preceding and following the sleep investigation and in one patient only during the period following the sleep. In 13 patients EEG abnormalities fitting with partial epilepsy were observed during sieep. This was only seen 3 times during the hyperventilation test. In none of 60 patients, were epileptic EEG phenomena abserved during the hyperventilation test whlch were not also seen during the sleep recording.

Although the number of patients studied is smali, it is suggested that hyperventilation possibly does not provide an important diagnostic gain when combined with $3-4$ h sleep recordings following one night total sleep deprivation. In addition, it appeared that at least $1 / 3$ of the 60 patients investigated, experienced considerable difficulties in carrying out hyperventilation in a suitable way.

\section{V.20. SLEEP DEPRIVATION AND INTERMITTENT LIGHT FIASH STTMULI (LFS)}

The occurrence of spike wave paxoxysms can be promoted by LFS. The typical $3 \mathrm{c} / \mathrm{sec}$ spike waves and polyspike wave paroxysms are particularly sensitive, whereas low erequency spike wave paroxysms increase more during sleep (Telby, 1969). On the basis of these observations it was considered meaningful to combine both test

In a series of 50 patients which had or wexe suspectied of having generalized epilepsy and for which an additional sleep deprivation investigation was required, $\mathbb{F}^{\mathrm{S}}$ was applied preceding and following sleep recording. The group consisted of 23 males and 27 females. between the age of 8 and 56 years of which 32 were younger than 30 years. Of these 36 had a clinical form of generalized epillepsy, of which 21 of the primarily type and 15 of the secondarily type and 14 subjects were sumpected of hawing a generalized form of epllepsy.

Light stimuli of 2 msec duration of $50-130$ lux, measured at the comea, were given in alternation with 5-sec periods without LFs. The frequency of the stimuli was increased by one per second from 1 to 12 during the successive stimulation periods, followed by stimulation frequencies of $13,16,20,25$ and 30 per second. The test was 
carxied out as well with eyes open as with eyes closed. of the 50 patientingestigated 37 had splke wave paroxysms during the sleep. In 6 of then splke wave paroxyms occurred during the iight flashes in these were seen during both test periods and in 2 patients only during 1 test period, one preceding and one following the sleep recording. In 4 patients the spikes or spike tave paroxysms appeared generalized and were sufficiently mecific to denote these as epileptogenic. These were 4 patients on which the diagnosis of primarily generallized epilepsy was posed of which 3 were of the absence type. only in one of them were generalized spike wave paroxysms found fol1 owling light flashes during a routine EEG recoraing. Nevertheless, all 4 had specific epileptic EEG phenomend during the sleep. In 2 patients the reaction was aspecific and consisted of unstable and often short-lasting periods of varying spikes, localized maximally parieto-occipita11y.

As wh the hyperventilation test, it can be concluded that light flasher combined with long term sleep xecordings (minimally $3 \mathrm{~h}$ ) do not further contribute to the diagnosis of epilepsy. However, the seritivity of some patients to intermittent light flashes $(5 / 50)$ is increased due to the shortage of sleep.

\section{V.1.1. SUMMARY}

In order to confirm or to deny the diegnosis of epilepsy electroencephalographically a long term EEG recording $(3-10 \mathrm{~h})$ as a supplement to the routine EEG investigation was performed in 1503 subjects during the period 1976-1981. The number of patients in which epileptic EEG abnormalities were found during the routine EEG recording was $566(37.6 \%)$ and $991(65.9$ ) during the sleep recording, which is a diagnostic gain of 28.3 . The epileptic abnormalities seen in 566 patients during the routine $\mathbb{E E G}$ could be better described following sleep in 311 patients. In 9 patients no epileptic abnormalities were found during the sleep.

The percentage sleep recordings containing specific epileptic abnormallties depended to a large degree on the probability by which epilepsy could be confirmed or denied on the basis of anamestic and clinical findings. When the epilepsy was considered very probable, spectelic epileptic abnormalities were observed in 84.2 of the sleep recordings, this in contrast to the recordings of patients of which the diagnosis of epilepsy was unlikely, where spectelc abnormalities were only found in 0.75 of the cases. When the diagnosis was doubtful, then specifl.c eplleptic EEG abnormalities occurred in 56.6 and aspectifo ERG abnomalities in 28.6 of the sleep recordings.

whe EEG confirmation of partial epilepsy was independent of the applied sleep procedure. For the generalized epliepsy the confimation was 6 higher during all-night sleep recordings than during Interrupted sleep and sleep following sleep deprivation. For each of the 3 methods, the diagnostic gain was larger for the generalized epilepsy than for the partial epilepsy. Ir all sleep recordings following sleep deprivation in which epileptio EEG abnormalities were present N.REM $1-2$ sleep was found. N.REM 3-4 and REM sleep was present in respectively 90 and 61 . For both generalized and partial 
epilepsy, epileptic EEG abnormalities nalniY occurred during N. REM 1-2 sleep. Thus ligt sleep would have been sufficlent to conflrm the existence of generalized epilepsy in 90 and partial epilepsy in 98 of the cases. For the detection of the remaining 10 of the generalized epliepsy the recording of deep N.RM $3-4$ sleep was necessary and for the remaining 2 of the partial epllepsy recording of REM sleep was necessary.

The pexcentage sleep recordings during which EEG abnormalities were discovered depended on the duration of the recording. During the sleep following sleep deprivation epileptic EEG phenomena were found 86.4 during the first sleep cycle and in 13.6 only during the second cycle. This result was supported by an investigation from. which it appeared that epileptic abnormalities were present in 77 during the first hour and in 93.1 following a 2 -h recording. whis means that epilepsy would have been insufficiently demonstrated in respectively 23 and 7 of the patients, if the recordings had been interrupted after 1 or 2 hours. Further, it appeared that it was not indicated to stop the recording following the appearance of the first eplleptic manifestations, since in these patients other epileptic EEG abnormalities were found during a later phase, by which the diagnosis could be further improved.

The mean latency in subjects kept awake for 24 h was only 6.3 min, which is much shorter than the mean sleep latency of 41.3 min following a spontaneous night sleep. During this short perilod of wakefulness preceding the onset of sleep epileptic EEG phenomena were only observed in 11.6 of the recordings. This finding argues against the assertion that the short wakefulness period following one night sleep deprivation is sufficient to diagnose epileptic EEG abnormalities.

The EEG confirmation of epilepsy was not improved by combining the sleep recording following one night sleep deprivation with hyperventilation or with ligt flashes. All patients in which eplieptic EEG abnormalities were found during these tests also had them during the sleep recordings. In addition, in $1 / 3$ of the patients the hyperventilation test could not be performed following one night sleep deprivation because of an excessive sleepiness.

on the basis of our results, it can be stated that the sleep recording following $24 \mathrm{~h}$ uninterrupted wakefulness is a valuable method to diagnose epilepsy electroencephalographically. In order to be optimaliy effective the following conditions should be fulf 1 led:

1. The recording has to be made following a total night wleep deprivation. Otherwise, the duration and depth of sleep will often be insufficient.

2. The duration of the recording has to be sufficiently long in oxder to register minimally one complete sleep cycle (1.5-2 h), but preferentially 2 sleep cycles $(3-4$ h) .

3. It is desirable that sleep is composed of light N. deep N. REM 3-4 sleep and REM sleep.

4. With the aid of a large number of EEG derivations it must be possible to detail the localization and spread of epileptic abnormalities and to classify the sleep, in conjunction with non-EEG parameters, into N. REM $1,2,3$ and 4 and REM sleep. 
It is ofter thought that the listlessness of some epileptics may be ssociated with leep disturbances, caused by the appearance of epileptic dicharges or by the long term intuke of antiepileptics. decording a number of data from the literature this line of thought is Incorrect. In this chapter it is almed to answer the following questions: (1) whether the composition of sleep in eplieptics differs from that of healthy persons and whether these differences aepend on (2) the presence $\left(E_{*}\right)$ or absence (N.E.) of epileptic EEG discharges, (3) the type of epliepsy with which they concur (Gen. E.: Part. E. and Gen* + Part. El, (4) the presence or absence of antiepileptic medication ( + or - A.E.) (5) especially with regard to benzodiazepine dertivatives (+ B.D.) and (6) whether the differences are ge-deperdent.

\section{WI. 1. MATERI ALS AND METHODS}

Two groups of subjects were investigated: one group of patients (clinical group or CL) and a group of non patients (control group or co). The patients $(\mathrm{n}=113)$ were subjects suspected of having epilepsy of which an ali-night sleep recording was taken as a supplement

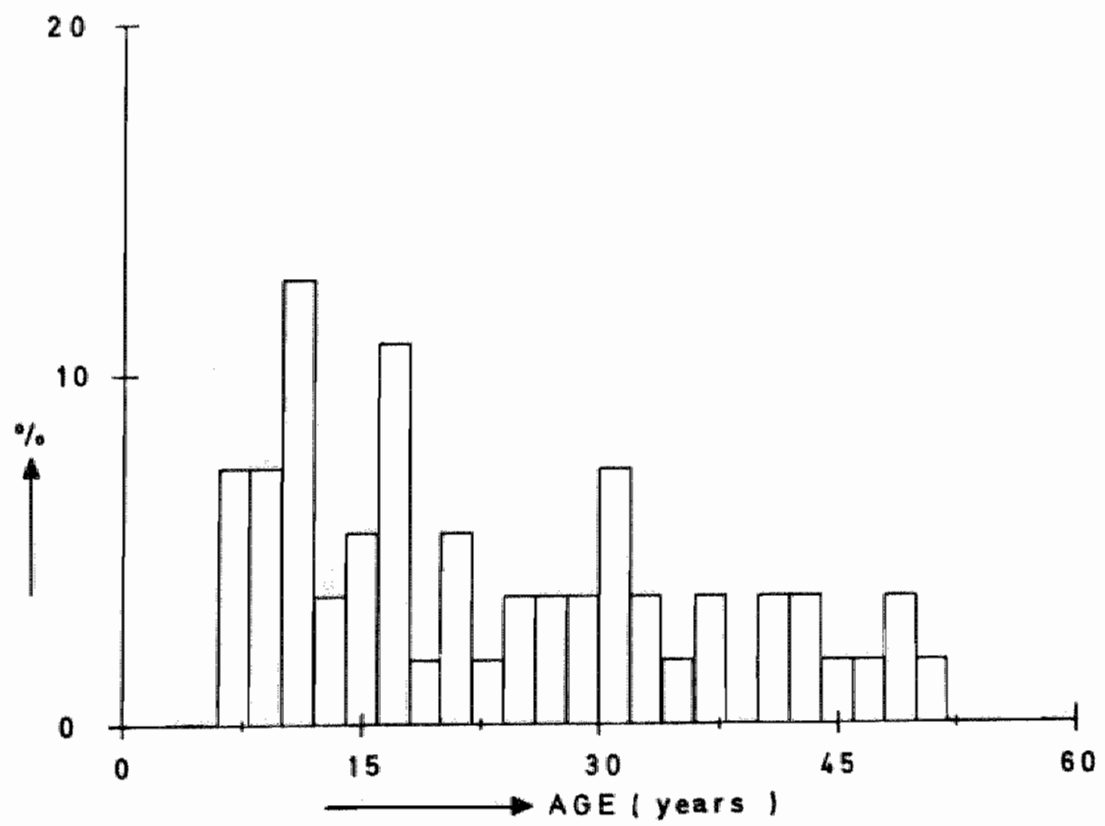

FIG. VI.1.

Age distribution in years of the 55 male patients. 
to the routine EEG investigation. With the aid of hypnogyams the sleep composition was studied. The sleep recording of patientes during which a period of 15 min following an electroclinical fit cowld not be classified were aisregarded. In adition cycles consisting of more than $60 \mathrm{~min}$ wakefulness and more than $120 \mathrm{~min}$ N.REN $1-2$ or N. REM 3-4 sleep were not evaluated. Following this selection the CI group consisted of 55 males and 38 females of whilh 80 were between the age of 7 and 40 and 23 subjects were older. The age distribution for the males and fentes is represented in figures VI. 1 . and VI.2.

The co group consisted of 9 females between the age of 21 and 30 years. At the time of the investigation all were healthy and none took medicines knowr to affect sleep.

The analysis has been restricted to the fixst and second cycle because these two cycles (1) generaliy consist of light as well as deep N.REM and RFM sleep, (2) are comparable to the two sleep eycles recorded after applying total sleep deprivation method, (3) are often sufficient to register epileptic EEG abnormalities.

For each indiwidual subject the sleep pattern of both cycles was described by the total duration of the cycles, the time of wakefulness, the effective sleep time and the duration of N.REM $1-2$. N. REM $3-4$ and REM sleep.

of these parameters the mean, standard deviations and confidence intervals of the control and clinical group further divided into subgroups, were calculated. On the basis of the confidence intervals of the means the statistical significance of differences between both groups for the different parameters was evaluated.

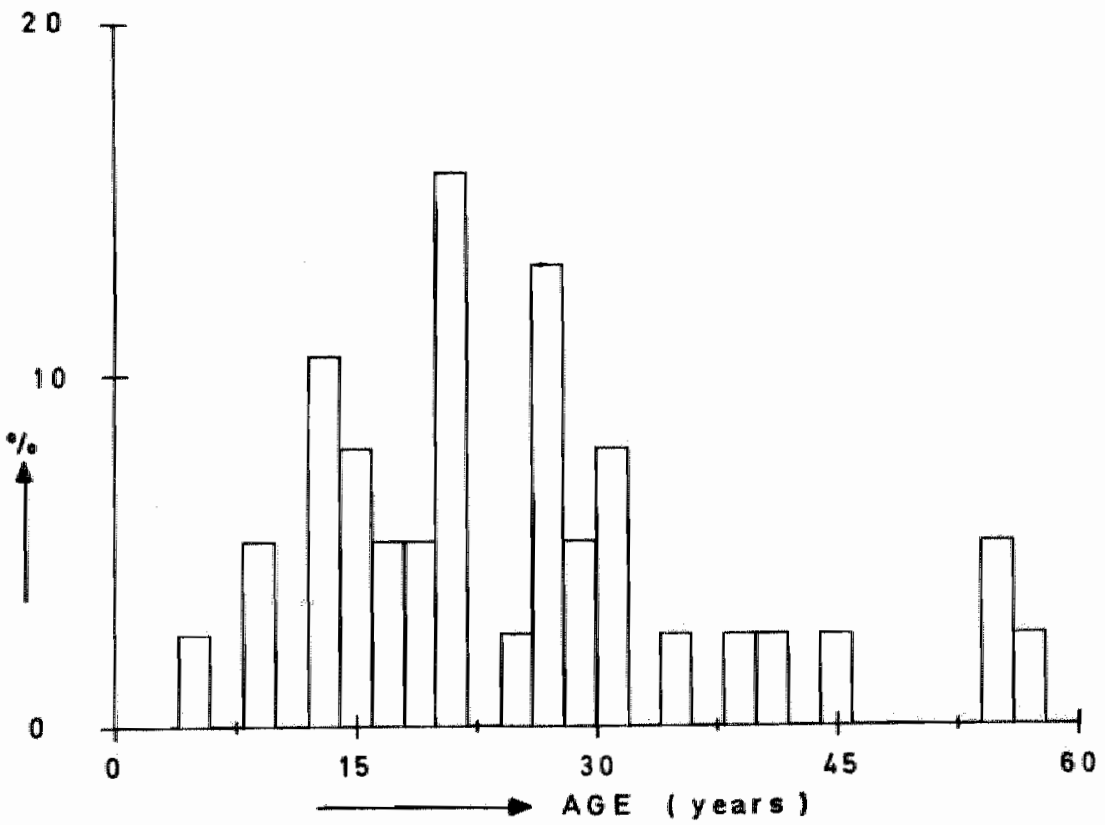

FIG. WI.2*

Age distribution in years of the 38 female patiente 
In order to enhance the legibility of the following tables only the furean values and the significance of the diffexences are indicated. More elaborate tables including standard deviations and confidence intervals of the values axe given in the addenda (chapter XIII), which in addition enter into the reasons for the cholce of the tatistical methods.

\section{V.2. IEESUTTS}

2.1. Sleep compostion of the first and second cycle in the control group

The mean duration (minutes) of the different sleep parameters of the co group for the first cycle (upper row and second cycle (lower row) is summarized in Table VI.3.

TAELE VI. 3 .

Quantitative composition of the first and second cycle during allnight sleep recordings of the control population.

\begin{tabular}{|c|c|c|c|c|c|c|c|}
\hline $\mathrm{co}$ & $\mathrm{n}$ & $\begin{array}{l}\text { Total } \\
\text { cycle }\end{array}$ & $\begin{array}{l}\text { Time } \\
\text { awake }\end{array}$ & $\begin{array}{l}\text { Ef fective } \\
\text { sleep time }\end{array}$ & N. FEM $1-2$ & N. REM 3-4 & REM \\
\hline$C Y: 1$ & 9 & 85.5 & 7.7 & 77.8 & 39.2 & $31 \cdot 2$ & 7.4 \\
\hline $\mathrm{Cy} * 2$ & 9 & 90.1 & 3.9 & 86.2 & 40.6 & 29.8 & 15.8 \\
\hline
\end{tabular}

In both cycles there is a preponderance of light slow wave sleep, which is evident from the ratio N.REM 1-2/M. RFM 3-4, being 1.26 for the first cycle and 1.36 for the second cycle. The somewhat longer duration of the second cycle is due to a higher amount of REM sileep. The sleep composition of both cycles of the $c 0$ group is in complete agreement with the values of similar age groups mentioned in other studies (Coenen, 1979; Foret and Webb, 1981; Philipson et all., 1980).

\subsection{Sleep composition of the first and the second cycle of the clindeci group}

Depending on the presence or absence of epileptic EEG mandfestations during the first and the second cycle, the CL group has been subdivided, respectively denoted as $\mathbb{N} * E$. and $E$. For both categorles the sleep composition per cycle as compared to the co group is represented in Table VI.4. and VI.5.

The group without epileptic phenomena has a significantly longer duration of the total sleep cycle $(p<0.05)$ and more effective sleep, due to a tendency to have more N.REM $1-2$ sleep. more REM sleep and more wakefulness. The group with epileptic phenomena has also a significantly longer duration of the total sleep cycle ( $p<0.05$ ) and more effective sleep ( $p<0.025)$ caused by an increase of all sleep stages which individually, however, do not reach a statistically significant level. The CL group differs from each other because the 
TABTE VI.4.

composition of the first cycle of all-night sleep recordings of patients, respectively without $(\mathrm{H} . \mathrm{E}$.$) and with (E.) eplleptic EEG phe-$ nomena, in comparision with the co group.

\begin{tabular}{|c|c|c|c|c|c|c|c|}
\hline $\mathrm{Cy} \cdot 1$ & $\mathrm{n}$ & $\begin{array}{l}\text { Total } \\
\text { cycle }\end{array}$ & $\begin{array}{l}\text { Time } \\
\text { awake }\end{array}$ & $\begin{array}{l}\text { Effective } \\
\text { sleep time }\end{array}$ & $\mathrm{N} \cdot \mathrm{BEM} \quad 1-2$ & N. REM $3-4$ & $\mathbb{R}$ \\
\hline$\infty$ & 9 & 85.5 & 7.7 & 77.8 & 39.2 & 31.2 & 7.4 \\
\hline $\begin{array}{l}\text { N.E. } \\
\text { E. }\end{array}$ & $\begin{array}{l}39 \\
54\end{array}$ & $\begin{array}{l}103.9 * \\
104.8 *\end{array}$ & $\begin{array}{r}12.0 \\
6.2\end{array}$ & $\begin{array}{l}91.9 \\
98.6 * *\end{array}$ & $\begin{array}{l}50.7 \\
48.6\end{array}$ & $\begin{array}{l}29.3 \\
39.4\end{array}$ & $\begin{array}{l}11.9 \\
10.6\end{array}$ \\
\hline
\end{tabular}

* $\mathrm{p}<0.05 ; * \mathrm{p}<0.025$

group with eplieptic EEG phenomena is less awake and has more deep N. REM 3-4 sleep.

As evident from Table VI.5. the differences as compared with the control group during the second cycle are less pronounced.

TABLE VI. 5.

Composition of the second cycle in all-night sleep recordings of the patients without $\left(\mathrm{N} \cdot \mathrm{E}_{*}\right)$ and with (E.) epileptic EEG phenomena.

\begin{tabular}{|lcc|c|c|c|c|c|}
\hline Cy. 2 & $\mathrm{n}$ & $\begin{array}{c}\text { Total } \\
\text { cycle }\end{array}$ & $\begin{array}{c}\text { Time } \\
\text { awake }\end{array}$ & $\begin{array}{c}\text { Ef fective } \\
\text { sleep time }\end{array}$ & N. REM 1-2 & N. REM 3-4 & REM \\
\hline CO & 9 & 90.1 & 3.9 & 86.2 & 40.6 & 29.8 & 15.8 \\
\hline N.E. & 35 & 103.1 & 7.3 & 95.8 & 48.9 & 27.8 & 19.1 \\
E. & 51 & 102.1 & 5.2 & 96.9 & 52.2 & 28.7 & 16.0 \\
\hline
\end{tabular}

The patients have a longer duration of the second cycle. This prolongation is mainly due to a higher amount of N.REM $1-2$ sleep.

There are no important differences between both CI groups.

2.3. Sleep composition of the flrst and second cycle In epileptic patients which do not have epilieptic EEG phenomena (N.E.) in their recordings, depending on whether (+ A.E.) or not ( - A.E.) they take antiepileptic drugs

In order to trace whether the intake of antiepileptics is also responsible for the changes in the sleep composition, the CL group without eplieptic EEG phenomena was subdivided into a category which ald not (N.E.-A.E.,) and into a category which did (N.E.+A.E..) take antiepileptics. Because of the small number ( $n=4$ ), patients treated with A.E. In combination with benzodiazepine derivatives were not considered further. The results of this comparison for the first cycle is represented in Table VI.6. and for the second cycle in Table VI. 7 . 
TABLE VI.6.

Composition of the first cycle of all-night sleep recordings without eplleptic EEG phenomena and whout or with antiepileptic arug treatment.

\begin{tabular}{|c|c|c|c|c|c|c|}
\hline$C y \cdot 1$ & $\begin{array}{l}\text { Total } \\
\text { cycle }\end{array}$ & $\begin{array}{l}\text { Time } \\
\text { awake }\end{array}$ & $\begin{array}{l}\text { Effective } \\
\text { sleep time }\end{array}$ & N. FIDI $1-2$ & H. PEM 3-4 & PEN \\
\hline $\mathrm{CO}$ & 85.5 & 7.7 & 77.8 & $39 \cdot 2$ & 31.2 & 7.4 \\
\hline$M, E,-A$, E , 18 & 125.9 & 16.8 & 99.1 & 56.4 & 30.7 & $12.0 *$ \\
\hline
\end{tabular}

* $\mathrm{P}<0.025$

Patients not taking antiepileptics have a significantly longex sleep cycle $(p<0.025)$. This is attributed to an increase in W. FaM 1-2 sleep, in awake and in RFM sleep. These changes with the exceptlon of the REM sleep, are seen to a much lesser degree in patients which take antieplieptics.

The clinical groups differ from each other because subjects which take antiepileptios have a shorter total cycle caused by a tendency to awake less and to have less light N.PEM $1-2$ sleep.

TABLE WI. 7 .

Composition of the second cycle of all-night sleep recordings without epileptic EEG phemomena and without or with antiepileptic drug treatment.

\begin{tabular}{|c|c|c|c|c|c|c|}
\hline $\mathrm{Cy} \cdot 2$ & $\begin{array}{l}\text { Total } \\
\text { cycle }\end{array}$ & $\begin{array}{l}\text { Time } \\
\text { awake }\end{array}$ & $\begin{array}{l}\text { Ef fective } \\
\text { sleep time }\end{array}$ & N. PEM $1-2$ & $\mathbb{N}$. FEM 3-4 & $R E M$ \\
\hline $\mathrm{co}$ & $90 . \mathbb{1}$ & 3.9 & 86.2 & 40.6 & 29.8 & 15.8 \\
\hline $\begin{array}{ll}\text { N.E. }-\mathrm{A} \cdot \mathbb{E} \cdot 16 \\
\text { N.E.+A.E. }\end{array}$ & $\begin{array}{r}106.6 \\
98.6\end{array}$ & $\begin{array}{c}10.6 * \\
3.1\end{array}$ & $\begin{array}{l}96.0 \\
95.5\end{array}$ & $\begin{array}{l}47.7 \\
45.3\end{array}$ & $\begin{array}{l}28 \cdot 4 \\
31.6\end{array}$ & $\begin{array}{l}19.9 \\
18.6\end{array}$ \\
\hline
\end{tabular}

$p<0.05$

The group not taking antiepileptics has a longer second sleep cycle, becomes more awake $(P<0.05)$ and tends to have more $\mathrm{P}$. REM $1-2$ leep.

The group which takes antiepileptics has a sleep composition hardiy different from non-patients.

The two clinical groups aiffer considerably from each other, because patients taking antiepileptics become less awake. 
2.4. Sleep compasition in patients having epileptid wrG phenomenc (E..) and which therefore take antieplieptics (+A.F.) or antiepileptios in conjunction with benzodiagepine derivatives (A.T. $+B . D$.

Bemzodiazepine derivatives may give rise to an inoremse ir N. REM 1-2 sleep sometimes combined with a decrease in $N$. RFH $3-4$ sleep and REM sleep and with less awakenings. In a comparative investigation it was sought whether these compounds in combination with antiepileptics affect the sleep in a comparable way. Beciuse 10 patients also take other medicines the $\mathrm{CL}$ group is reduced to 44 persons of which only 5 take antiepileptics in conjunction with benzodiazepdne derivatives. The results are sumarized in Table VI.8. and VI.9.

TTABLE VI.8.

Sleep composition of the first all-night cycle in recordings with epileptic EEG phenomena, treated with antiepileptic arugs, with (E.+A.E.+B.D.) or without combination with benzodiazepine derivatives $(\mathrm{E} \cdot+\mathrm{A} \cdot \mathrm{E} \cdot \mathrm{-B} \cdot \mathrm{D} \cdot)$.

\begin{tabular}{|l|r|c|c|c|c|c|c|}
\hline Cy. I & n & $\begin{array}{c}\text { Total } \\
\text { Cycle }\end{array}$ & $\begin{array}{c}\text { Time } \\
\text { awake }\end{array}$ & $\begin{array}{c}\text { Effective } \\
\text { sleep time }\end{array}$ & N.FEM $1-2$ & N. FEM 3-4 & REM \\
\hline CO & 9 & 85.5 & 7.7 & 77.8 & 39.2 & 31.2 & 7.4 \\
\hline $\begin{array}{r}\text { E.+A.E* } \\
\text { E.+A.E* } \\
\text { +B.D. }\end{array}$ & 39 & $107.8 *$ & 7.3 & $100.5 * *$ & 45.8 & 44.0 & 10.7 \\
\hline
\end{tabular}

The group of patients which only take antiepileptics had a significantly longer sleep cycle $(\mathrm{p}<0.05)$, more effective sleep $(\mathrm{p}<0.025)$ and more deep N. RFM 3-4 sleep.

Althougt the sleep composition in patlents taking antieplleptics in conjunction with benzodiazepine deriwatives is clearly changed, mainly because of an important increase in N. RFM $1-2$ sleep this group does not differ significantly from the non-pationt group. rhis is aue to the large interindividual aifferences within this smal group.

Both clinical groups show important differences in the composition of the $N$. FEM sleep. patients which take antieplleptics have more light $N$. REM $1-2$ sleep as well as more N.REM 3-4 sleep, whexeas patients who also take benzodiazepine derlvatives oniy have more iligt 1 . REM $1-2$ sleep.

patients only taking antiepileptios tend to have more $N$. Kow $1-2$ sleep. The same tendency exists for those taking also benzodiazepine derivatives, but this is associated with a decreased N.RPM 3-4 sleep and FEM sleep* 
TABLE VI.9.

Compostion of the second all-night sleep cycle in recordings wth eplieptic EEG phenonena, treated with antiepileptic drugis, with $(\mathbb{E} \cdot+$ A.E.+B.D. $)$ or without combination with benzodiazepine deriwatives $\left(E * E_{*} \cdot E_{*}-B \cdot D \cdot\right)$.

\begin{tabular}{|cc|c|c|c|c|c|c|}
\hline Cy.2 & $n$ & $\begin{array}{c}\text { Total } \\
\text { cycle }\end{array}$ & $\begin{array}{c}\text { Time } \\
\text { awake }\end{array}$ & $\begin{array}{c}\text { Ef fective } \\
\text { sleep time }\end{array}$ & REM 1-2 & N.REM 3-4 & REM \\
\hline CO & 90.1 & 3.9 & 86.2 & 40.6 & 29.8 & 15.8 \\
\hline $\begin{array}{rr}\text { E.+A.E. } \\
\text { E.A.E. } \\
+ \text { B.D. }\end{array}$ & 57 & 101.9 & 5.5 & 96.4 & 50.7 & 29.2 & 16.5 \\
\hline
\end{tabular}

2.5. Sleep composition of the first and second cycle in the presence of epileptic EEG manisfestations and the intake of antieplleptics, divided per type of epllepsy

This investigation aims at finding out whether the sleep composition $1 \mathrm{~s}$ dependent on the kind of epileptic EEG phenomena fitting with respectively generalized (Gen.), partial (Part.) or a combination of both (Gen.+Part.) forms of epilepsy. The mean values of the different sleep parameters for the three categories of epilepsy are given in Tables VI.10. and VI.11. for the first and second cycle respectively.

TABLE VI.10.

sleep composition of the first all-night cycle in recordings with interlctal epileptic EEG paroxysms belonging to Generalized, Partial or Generalized with Partial epilepsy.

\begin{tabular}{|cc|c|c|c|c|c|c|}
\hline Cy. I & $\mathrm{n}$ & $\begin{array}{l}\text { Total } \\
\text { cycle }\end{array}$ & $\begin{array}{l}\text { Time } \\
\text { awake }\end{array}$ & $\begin{array}{c}\text { Ef fective } \\
\text { sleep time }\end{array}$ & N. REM 1-2 & N. REM 3-4 & REM \\
\hline CO & 85.5 & 7.7 & 77.8 & 39.2 & 31.2 & 7.4 \\
\hline Gen.E. & 14 & 104.9 & 7.9 & 97.0 & 49.1 & 40.0 & 7.9 \\
Part.E. & 13 & 106.4 & 8.5 & 97.9 & 39.5 & 46.4 & 12.0 \\
Gen. \\
Part.E.
\end{tabular}

* $\mathrm{p}<0.05$

As compared to the $c 0$ group for all categorles a longer duration of the cycle and more effective sleep is found, significant $(p<0.05)$ for the group of patients which have a combination of two forms of epliepsy. In all categories there is a tendency to have more deep N. REM 3-4 sleep, and both categories with generalized epilepsy also have more light N.REM $1-2$ sleep. 
TABLE VI.II.

sleep composition of the second all-night cycle in recordings with epileptic EEG paroxysms belonging to generalized, partial or generalized with partial epilepsy.

\begin{tabular}{|c|c|c|c|c|c|c|c|}
\hline $\mathrm{Cy} \cdot 2$ & $n$ & $\begin{array}{l}\text { Total } \\
\text { cycle }\end{array}$ & $\begin{array}{l}\text { Time } \\
\text { awake }\end{array}$ & $\begin{array}{l}\text { Ef fective } \\
\text { sleep time }\end{array}$ & N. REM $1-2$ & NA. FDE $3-4$ & REM \\
\hline $\mathrm{CO}$ & 9 & 90.1 & 3.9 & 86.2 & 40.6 & 29.8 & $15 . \theta$ \\
\hline Gen.E. & 12 & $110: 1$ & 5.8 & $104: 3$ & 55.6 & 33.1 & 15.6 \\
\hline $\begin{array}{l}\text { Part "E. } \\
\text { Gen.t }\end{array}$ & & 96.2 & 6.3 & 89.9 & 46.0 & 26.0 & 17.9 \\
\hline Part.E. & 12 & 99.9 & 4.3 & 95.6 & 51.0 & 28.8 & 15.8 \\
\hline
\end{tabular}

For all categories there is a tendency to have a longer second cycle, consisting of more effective sleep and more $N \cdot R B M I-2$ sleep. This increase is more pronounced for patients having $\mathbb{E E G}$ phenomena fitting with generalized epilepsy.

2.6. Sleep composition of the first and second cycle of the control group versus the cinical group

The previous tables mention differences in the sleep composition of the first and second cycle between patients and non-patients. Tables VI.12, and VI.13. sumumize the various subgroups.

The different categories of patients have been divided into 3 main groups. The first group consists of patients without epileptic EEG abnormalities (categories 2 and 3 )" the second group consists of patients with epileptic EEG abnormalities, treated with antieplleptics (categories 4, 5 and 6), the third group consists of patients with epileptic EEG abnormalities and which are treated with antiepileptics in conjunction with benzodiazepine derivatives. The significance of differences as compared to the control group are indicated for each of the sleep parameters.

The total cycle duration is shortest for the $c 0$ group. Group I, patients without $\mathbb{E E G}$ abnormalities, tend to have a longer first cycle. Group 2 has a longer cycle and a same tendency exists for gxoup 3 .

Al though the duration of wakefulness for the various categories differs largely, these differences are not significant for the 3 main groups.

For the fective sleep time the differences are comparable to those of the total cycle duration.

For adl 3 patient groups there is a tendency to obtaln more N. REM 1-2 sleep, except for the categories whlich have EEG abnormalities fitting with partiai epilepsy (2.5.). Deep N.REM 3-4 sleep is only increased for the group 2, patients having epileptic EEG abnormalities and which take antiepileptics. All patients have more pas sleep except for those having EEG abnormalities fitting with genexalized epllepsy. 


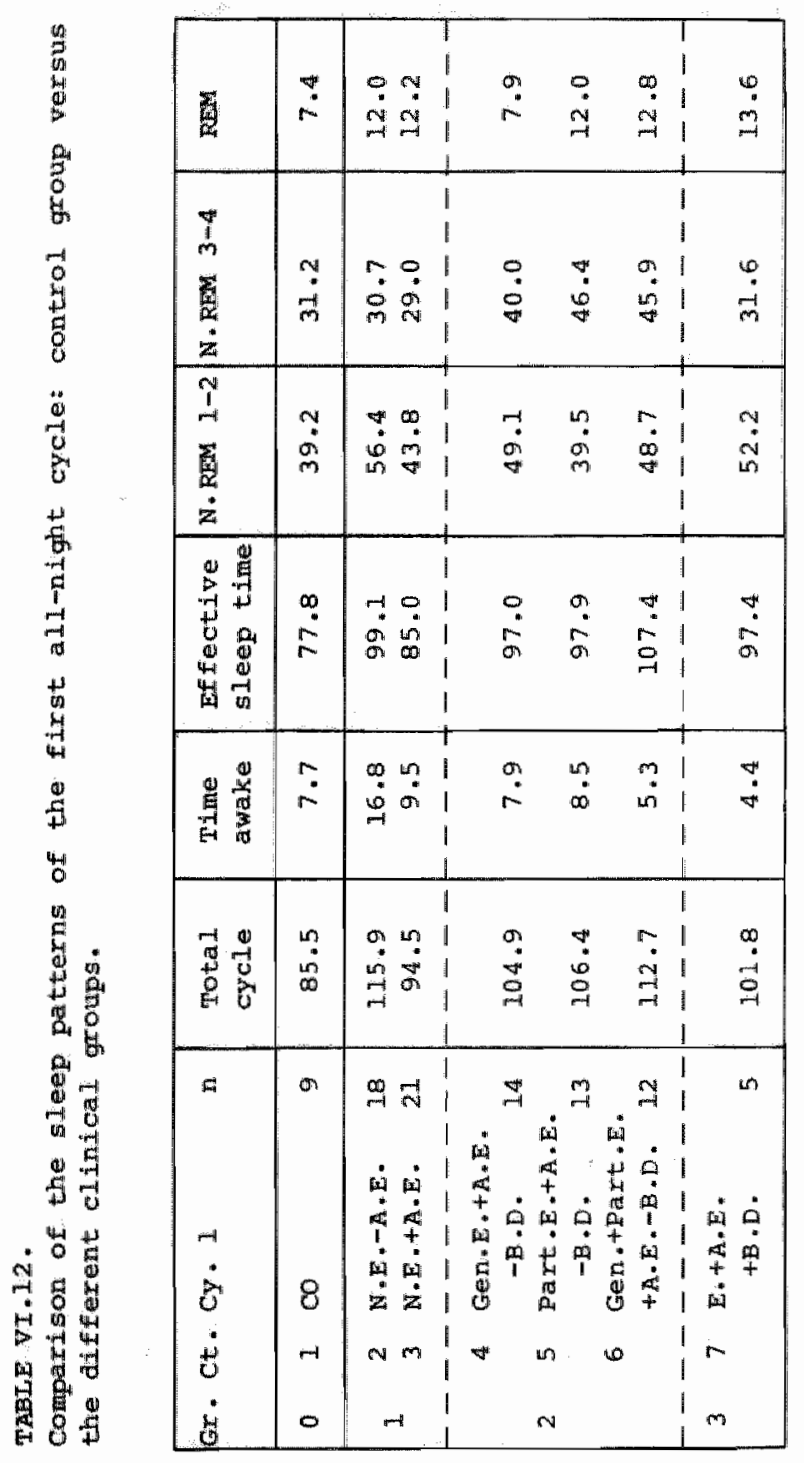




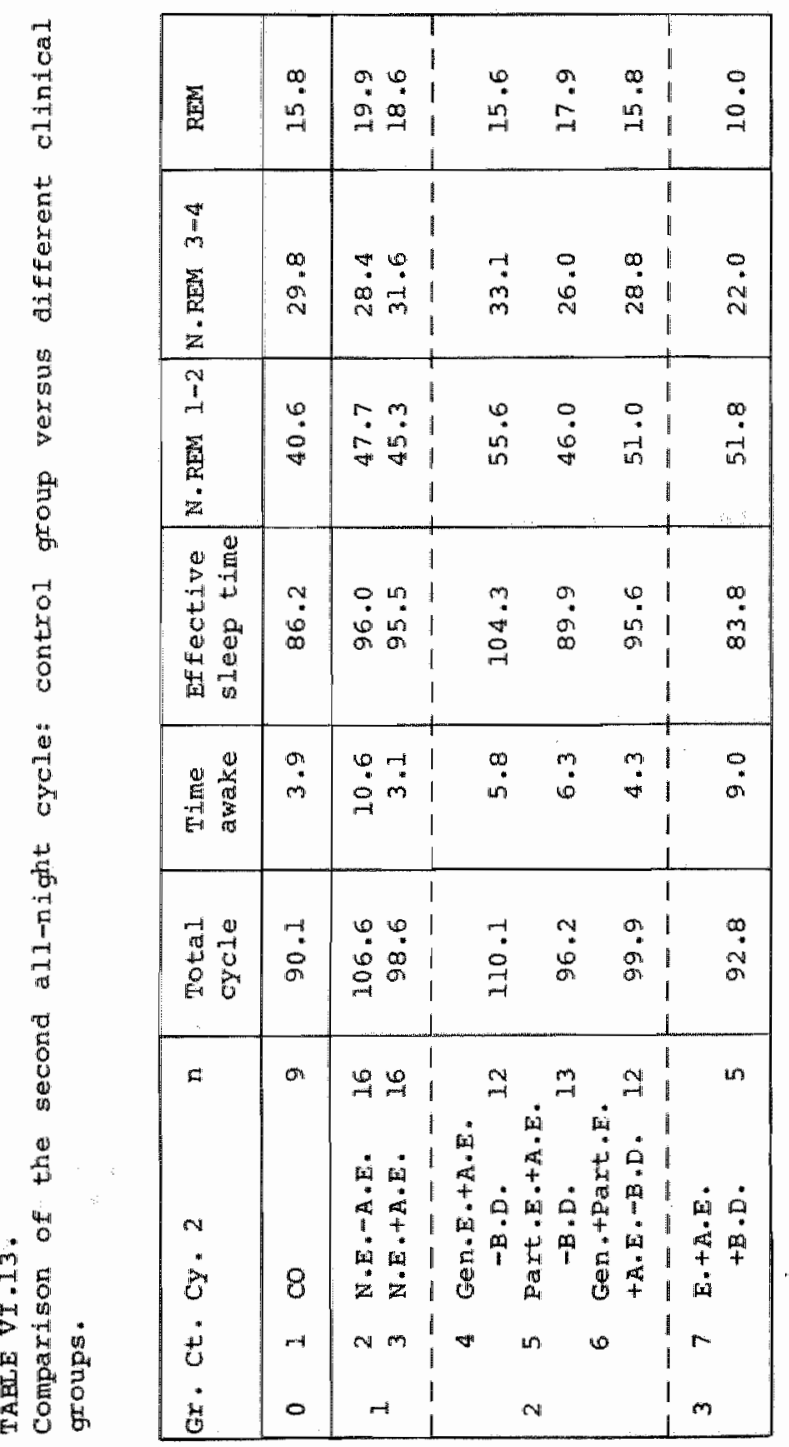


There are no significat differences in the sleep composition of the second cycle between the three patient groups, though there is a cendency to observe 1 ess Fem sleep in group 3 , which apart from antiepileptic also take benzodiazepine derivatives.

\subsection{Sleep compostition of the first and second sleep cycle in function of age \\ Since the control group consisted of subjects between the} age of 21 and 30 years, it appeared meaningful to compare these with a group of patlents of the same age. The number of patients of each clinical group is too small to be further divided into subgroups, thexefore, patients having different forms of epilepsy were considered as one group, also there was no significant differences in the sleep pattern of these different subgroups (Tables VI.10. and VI.11.).

From this group, 3 gubgroups were constituted respectively to the age of 10 years $(n=12)$, from 11 to 20 years $(n=12)$ and from 21 to 30 years $(n=8)$. The mean values for each sleep parameter for the first and second cycle and for each age group are compared with the control group in Tables VI..14, and VI.15.

\section{TABLE VI. 14}

Comparison of the sleep pattern of the first all-njght cycle in patients with eplleptic EEG paroxysms and treated with antiepileptic arugis: control group versus 3 clinical groups, respectively between $3-10,11-20$ and $21-30$ years old.

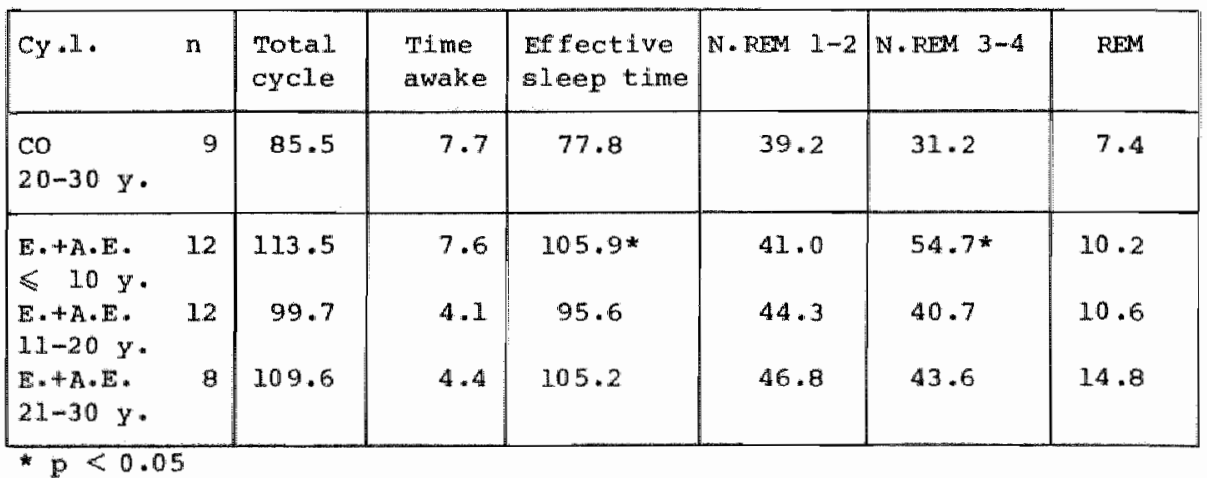

The group of patients to the age of 10 years differs most fxom the control group. There is a longer sleep duration and more effective s leep $(p<0.05)$ mainly caused by more deep $\mathbb{N}$. REM $3-4$ sleep $(p<0.05)$. In the other age groups there is an increase of all sileep stages whout reaching statistical significance.

In contragt to the first cycle, the age group from 11 to 20 years has a different sleep composition as compared to the control group during the second cycle of the sleep. There is a larger cycle duration, more effective sleep $(p<0.05$ ) and more 1 ight $\mathbb{N}$. REM $1-2$ sleep. 
TAELE VI.15.

Comparison of the sleep pattern of the second al1-nugh cycle in patients with epileptic EEG paroxysms and treated with antleplleptlo drugs: control group versus 3 clinical groups, respectively between the age of $3-10,11,-20$ and $21-30$ years.

\begin{tabular}{|c|c|c|c|c|c|c|c|}
\hline $\mathrm{Cr} \cdot 2$ & $\mathrm{n}$ & $\begin{array}{l}\text { Total } \\
\text { cycle }\end{array}$ & $\begin{array}{l}\text { Time } \\
\text { awake }\end{array}$ & $\begin{array}{l}\text { Ef fective } \\
\text { sleep time }\end{array}$ & M. REN $1-2$ & $N \cdot$ REW $3-4$ & RFH \\
\hline $\begin{array}{l}c 0 \\
20-30 y\end{array}$ & 9 & 90.1 & 3.9 & 86.2 & 40.6 & 29.8 & 15.8 \\
\hline $\begin{array}{l}\text { E. +A.E. } \\
\leqslant 10 \mathrm{y}\end{array}$ & 12 & $95 \cdot 3$ & 5.8 & 89.5 & 47.2 & 26.0 & 16.3 \\
\hline $\begin{array}{l}E \cdot+A_{n} E \\
11-20 \quad y\end{array}$ & 12 & 119.8 & 2.8 & $117.0 *$ & 64.8 & 35.4 & 16.8 \\
\hline $\begin{array}{l}\mathrm{E}+\mathrm{A} \cdot \mathrm{E} \\
21-30 \mathrm{Y}\end{array}$ & 8 & 105.0 & 3.2 & 101.8 & 44.8 & 37.0 & 20.0 \\
\hline
\end{tabular}

$* \mathbb{p}<0.05$

For both the first and second cycle there is no sugnificant difference between the control and the clinical group in the age group 21 to 30 years. Patients tend to have a longer sleep cycle duration becalise of an increase of all sleep stages.

\section{VI.3. DISICUSSION AND SUMMARY}

Our investigations aimed to find out whether al1-night sleep in eplieptics is different from that in healthy persons. For this purpose an all-night sleep recording was carried out in 113 epileptics and in 9 carefully selected non-epileptics and thereafter analyzed and registered in a hypnogram. In 93 patients and in ald 9 non-patients sleep cycles could be subdivided into light and/or deep N. REM and REM sleep.

The group of 93 patients were subdivided into categories depending on the presence or absence of epileptic EEG phenomena, the type of epilepsy, the intake of antiepileptics or antlepileptics in comblnation with benzodiazepine derivatives. Differences in the sleep composition of the first and second cycle could therefore be related to the criteria differentiating the different categories.

the healthy persons all had a well-formed sleep pattern. The duration of the cycles as well as the relative proportion of the different sleep stages corresponded with that in nomal persong as described in the literature by varlous authors (Coenen, 1979, Foret and Webb, 1981, philipson et al., 1980).

Because the group mainiy consisted of subjects between the age of 10 and 50 years, an age period during which the leep pattern is relatively stable (Fischgold et al., 1959 a), it was possible to compare the afferent categories in patients with the sleep pattern in nomals. Patients with epileptic EEG abnormalities and which took 
antieplieptice did not have a significantly different sieep composition, and were therefore, considered as one group. Fugure VI.26. showis the mean value (min) and confidence intervals $(1 / 2 a=p<0.05)$ of the total cycle duration, the time of wakefulness and the effective leep tine, for the first and second sleep cycle in patients as compared to the control group.

\section{FIRST CYCLE}

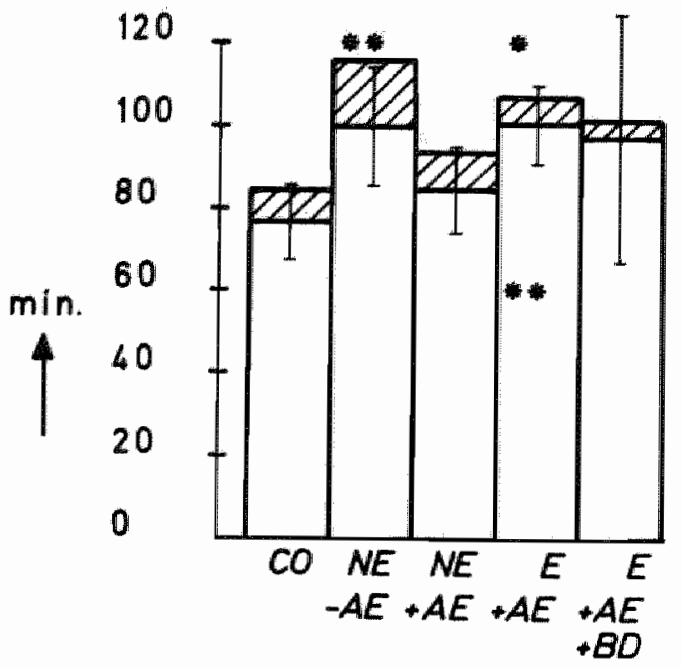

SECOND CYCLE

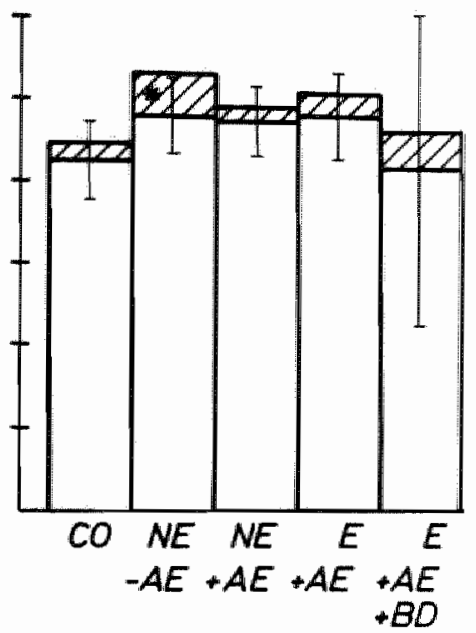

Fig. VI.16.

Mean values, in minutes, of the total sleep cycle, the time awake $(D)$, and the effective sleep time ( $\square$ ) during the first and the second sleep cycle of the control and the different clinical categories.

* $\mathrm{p}<0.05 * \mathrm{p}<0.025$.

1. All patients had a longer lasting sleep cycle. The increase is largest for patients without epileptic EEG abnormalities and which do not take antieplleptice, during both the first $(p<0.025)$ and second cycle. Though somewhat less pronounced, patients with epileptic EEG abnomalities, which take antlepileptics, also have a igniliantly $(\mathrm{p}<0.05)$ longer lasting first cycle.

2. Although the time of wakefulness differs considerably for the different categories of patients, these differences are statisticaliy not significant, except during the second cycle for the patients without epileptic EEG phenomena, which do not take antiepileptics $(\mathrm{p}<0.0 .5)$.

3. The mean effective sleep in patients is increased as compared to the control group, which is significant for the category with epileptic EEG phenomena and which take only antiepileptics $(\mathrm{p}<0.025)$.

4. In ordex to get a better insight into the sleep stability, the percentage effective sleep as compared to the total cycle duration has been calculated. This is represented in Figure VI.17. 

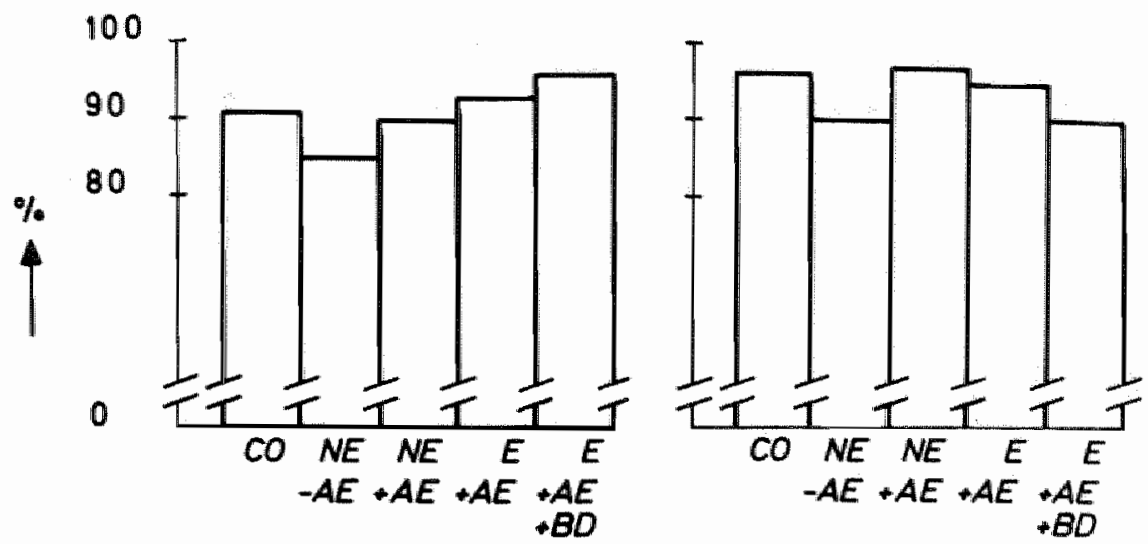

Fig. VI. 17 .

Pexcentagie of effective sleep time in the control and aifferent clinical categories during the fixst and second all-night cycle.

As comparea to the control group, for both cycles, patients with epileptic EEG abnomalities and which do not take antiepileptios hawe less effective sleep. Those treated with antiepileptlis only have approximately as much effective sleep auring both cycles. whereas those treated with antiepileptics and benzodiazeplne a rivatives have more effective sleep during the fixst cycle and less effective sleep during the second cycle.

The effectiwe sleep is composed of N. REM and REM sleep. The mean values of these two sleep states for the different categorjes of patients as compared to the control group are summarized in Figure VI. 18.

5. Patients have aigher amount of RE sleep during the first eycle. but the differences are statisticaly not significant. During the

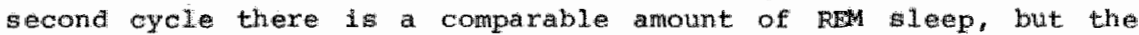
category treated with antiepileptios and benzodicapdnes tend to have somewhit l.es REA sleep.

6. During both cycles patients have nore N. FhM gleep. Ihis Inorease is only gignificant during the first cycle for the category with epileptic abnormalities and which take antiep 1 eptics (p< 0 in 05 .

It appeared of interest to find out whether the increased N.REM

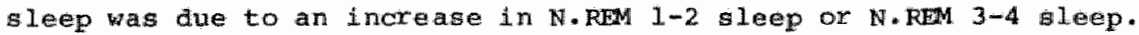
The comparison 15 giwen in Figure VI.19.

7. For both cycles, all patients have more $N$. RAM $1-2$ sidep ard tilese differences are largest for the category without epileptic me abnormalities and which do not take antiepileptice, and for patients with epileptio EFG phenomena treated with antiopileptics in combination with benzodiazepine derivates. 
FIRST CYCLE

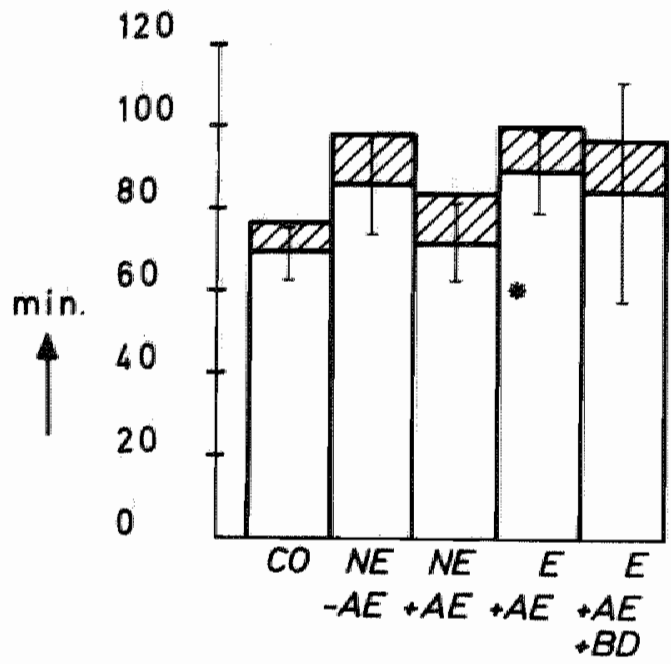

SECOND CYCLE

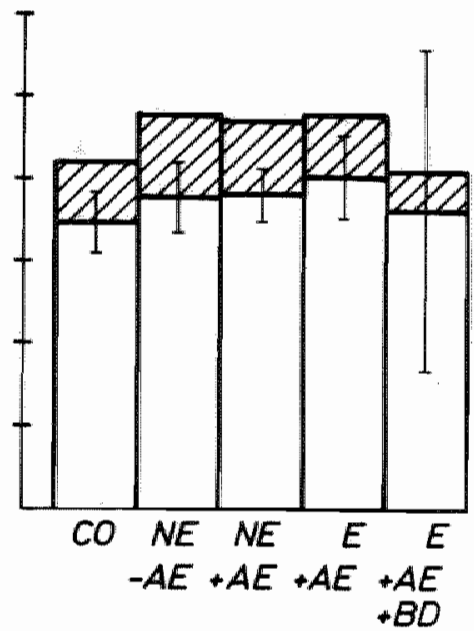

FIG. VI.18.

Mean values, in minutes, of N.KWM ( $\square$ ) and REM (Q) sleep during the first and second all-night cycle of the control and the different clinical categrories.

$\mathrm{p}<0.05$

FIRST CYCLE

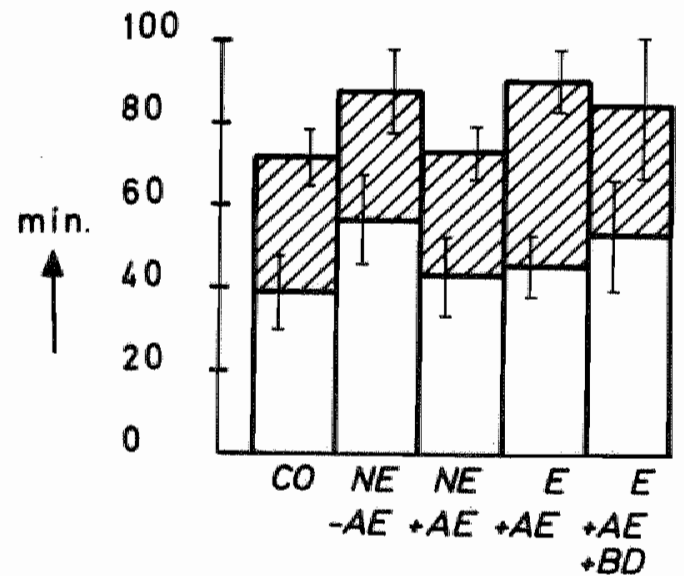

SECOND CYCLE

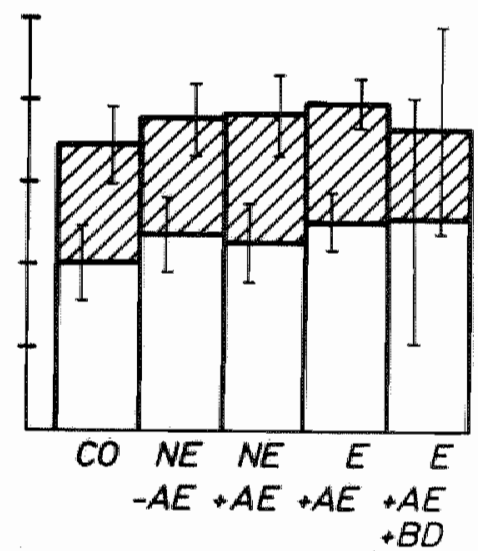

PIG*VI. VI.

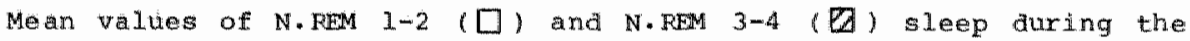
Eixst and second al-night cycle of the control and the different clinical categories. 
8. During the first cycle, patients with eplieptic EEG abnormalities, which take antiepileptics, have more deep N.REM 3-4 sleep puring the second cycle the group treated with antiepileptics in combination with benzodiazepine derivatives tend to have less deep N. PEM 3-4 sleep.

9. The changes in the quantity of light and deep N.REN sleep are begt expressed by the proportion of the N.REM $1-2 / \mathrm{N}$. REM $3-4$ sleep as represented in Figure VI. 20 .

FIRST CYCLE

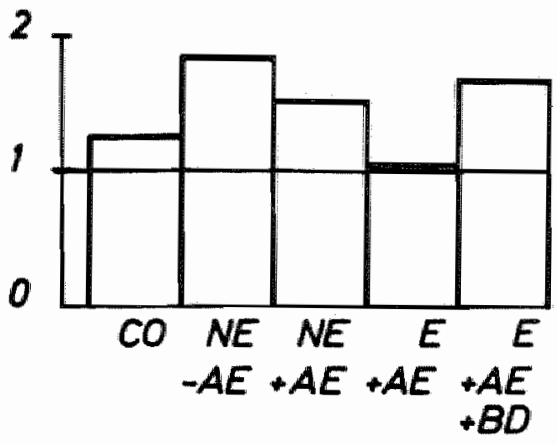

SECOND CYCLE

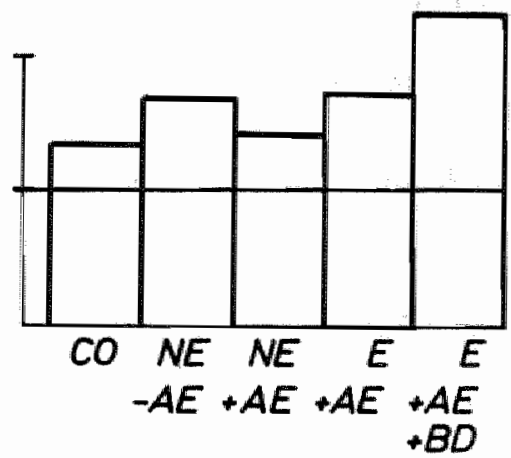

FIG. VI.20.

Ratio of the N.RM $1-2 / \mathrm{N}$. REM $3-4$ sleep during the first and second all-night sleep cycle of the contral and the diffexent clinical categori.es.

Only the category with epileptic EEG phenomena, which takes antiepileptics, has a ratio smalier than in the control group during the first cycle. All other categories have a largex ratio than the control group (1.26) respectively $1.84,1.51,1.65$ for the group without epileptic EEG phenomena, with or without the intake of antiepileptics and for the group which take antiepileptics and benzodiazepine derivatives.

These differences are less promounced during the second cycle where all patients groups have a somewhat larger ratio, most pronounced for the group treated with antiepileptics and benzodiazeplines $(2.35)$ as compared to the control group (1.36).

With the results summarized above the different questions can be answered as follows:

1. Is the sleep composition of the first and second sleep cycle in epileptics different from that in healthy persons?

There is a difference because patients have a longer auration of the cycle aue to an increased $\mathrm{W}$. RE sleep, of which the ratio N. REM $1-2 / 3-4$ is changed.

2. Are tire differences dependent on the presence or absence of epileptic EEG abnormalities during the sleep recording? 
Taking only the aubclinlcal eplieptic $5 E G$ abrotmalities or the eplleptic discharges which severely disturbed the sleep for less than 15 m, then it appears that the changed sleep composition cannot be associated with the presence or absence of epileptic EEG abnormalities.

3. Are these differences in the sleep composition dependent on the type of epilepsy to which the EEG abnormalities fit?

The composition of the effective sleep is partly dependent on the kind of epileptic abnormalities seen during the sleep recording. The category which have abnormalitles fitting with generalized epllepsy have more Ifght $N$. FEM $1-2$ as well as more $N$. RDM 3-4 sleep but no increased PEM leep. The category with partial epilepsy has more N.REM 3-4 sleep and REM sleep and an equal amount of N. FEM 1-2 sleep. The category which have EEG abnormalities fitting Wth both types of epilepsy have an increase in N.REM 1-2, N. FEM 3-4 and REM sleep.

4. Is the sleep composition dependent on intake of antiepileptics?

patients taking antiepileptics had a short cycle during which they awake less and thus have more effective sleep. During the first cycle there is relatively more deep $M \cdot R$ RM $3-4$ sleep for patients having epileptic EEG abnormalities.

5. Is the sleep composition further changed when benzodiazepine derivatives are added to antieplleptics?

Adaling benzodiazepines results in an increased duration of both sleep cycles, with a relatively larger increase of $\mathrm{N}$. REM $1-2$ sleep and a decrease of wakefulness.

6. Are the differences age-dependent?

Epileptlcs only treated with antiepileptics have an age-dependent leep composition. subjects up to and including 10 years have a relatively higher amount of $N$. REM 3-4 sleep during the first cycle; aubjects from 11 up to and including 20 years have a relatively high amount of 1 ight $\mathrm{N} . \mathbb{R E M} 1-2$ sleep during the second cycle; the composition of the effective sleep for the age category between 20 and 30 years resembles the control. 
In chapter $V$ it was shown that, provided specific conations are fulfilled, the sleep deprivation method is very suitable for recording epileptic EEG phenomena. Two of these conaitions were that a recording had to follow a total night sleep deprivation and that the recording had to be sufficiently long to obtain two sleep cycles.

on the basis of the literature given in chapter II, the changes in sleep composition following total sleep deprivation were described, for instance more deep N.PEM $3-4$ sleep especially in the first sleep cycle."

In chapter VI it was established that all-nlglt sleep in epileptics differs in certain aspects from that in healthy persons. The difference might be associated with the presence of epileptic EEG abnormalities during the sleep and the intake of antiepileptics.

Chapter VII aims at investigating: (1) how the first and second sleep cycle are composed following sleep deprivation in epileptios; (2) whether the composition is dependent on the presence or absence of epileptic EEG plienomena during the sleep; or (3) the type of epilepsy (Gen.E.; Part.E., and Gen. Part.E.): or (4) intake of antiepileptics (+ or - A.E.), (5) in combination with benzodiazepine derivatives (4.D.) and (6) whether the changes are age-dependent.

\section{VII.1. MATERIALS AND METHODS}

As in chapter VI two groups were investigated: a group of patients (clinical group: CI) and a group of healthy persons (control group: CO). For the composition of the CL group, 61.7 sleep deprivation recordings carried out during the periad 1979-1981 in subjects suspected of having epilepsy, were used. For the investigation the first and second sleep cycle were used on the condition that duxing one sleep cycle no more than $60 \mathrm{~min}$ wakefulness and no more than 120 min M.REM $1-2$ sleep or $120 \mathrm{~min} N$.REM 3-4 sleep were present.

After applying these criteria 548 (B8.8 8) recordings of which 295 from males and 253 from females were retained. Hereof 251 (45.8 \&) werce between the age of 5 and 20 years, $232(42.3$ b) between the age of 20 and 40 years and 55 (11.9 between the age of 40 and 60 years. "the age distribution is represented in Figures VII.1. and VII.2.

The control group consisted of 15 nurses between the age of 20 and 40 years. All were healthy and none took mediclnes known to influence sleep. They were familiar with the procedure of EEG and polygraphic sleep investigations. As in the patients, a $3-4-$ h polygraphic registration was carried out between $7-12$ h in the morning following a total night sleep deprivation.

In analogy with the all-night sleep recordings patients were diwided Into a number of categories depending on the presence or absence of epileptic EEG phenomena during the recording and whether they took only antiepileptics or in combination with benzodiazepine derivatives. For each category mean values of the vaxious sleep parameters were calculated, together with the atandard deviations of the 


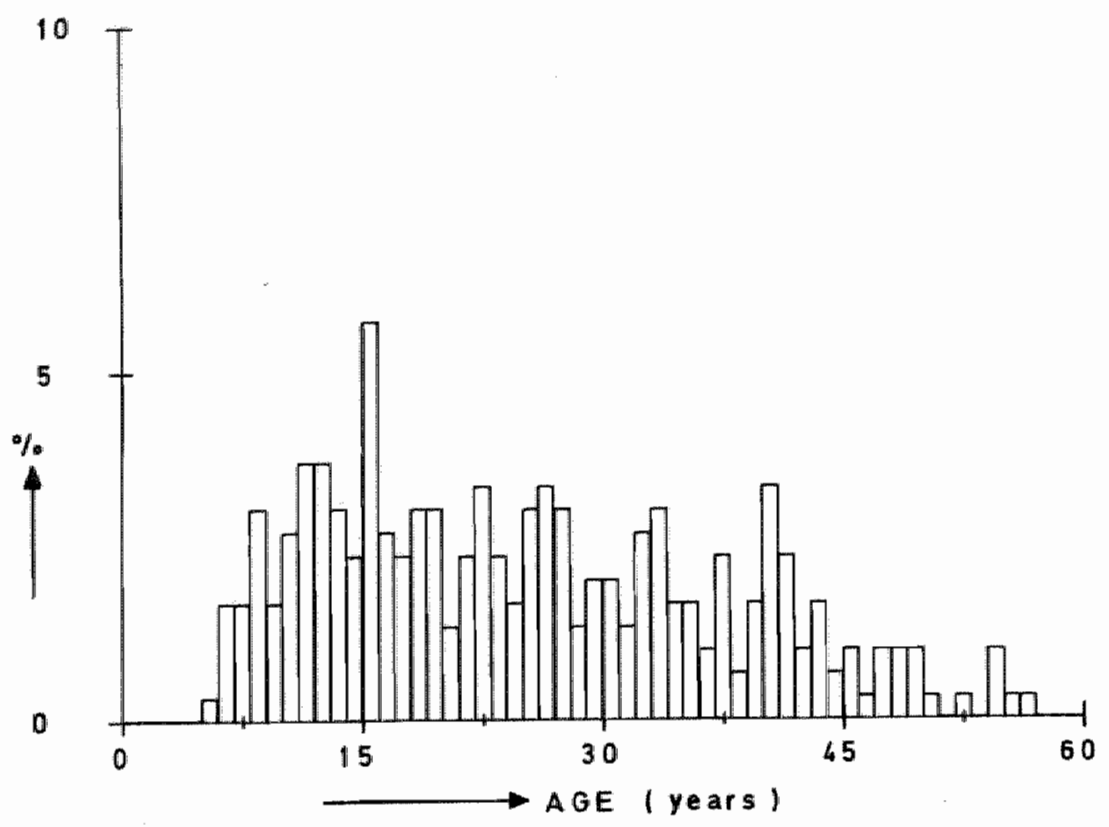

EIG. VII.

Age diftibution in years of the 295 male patients.

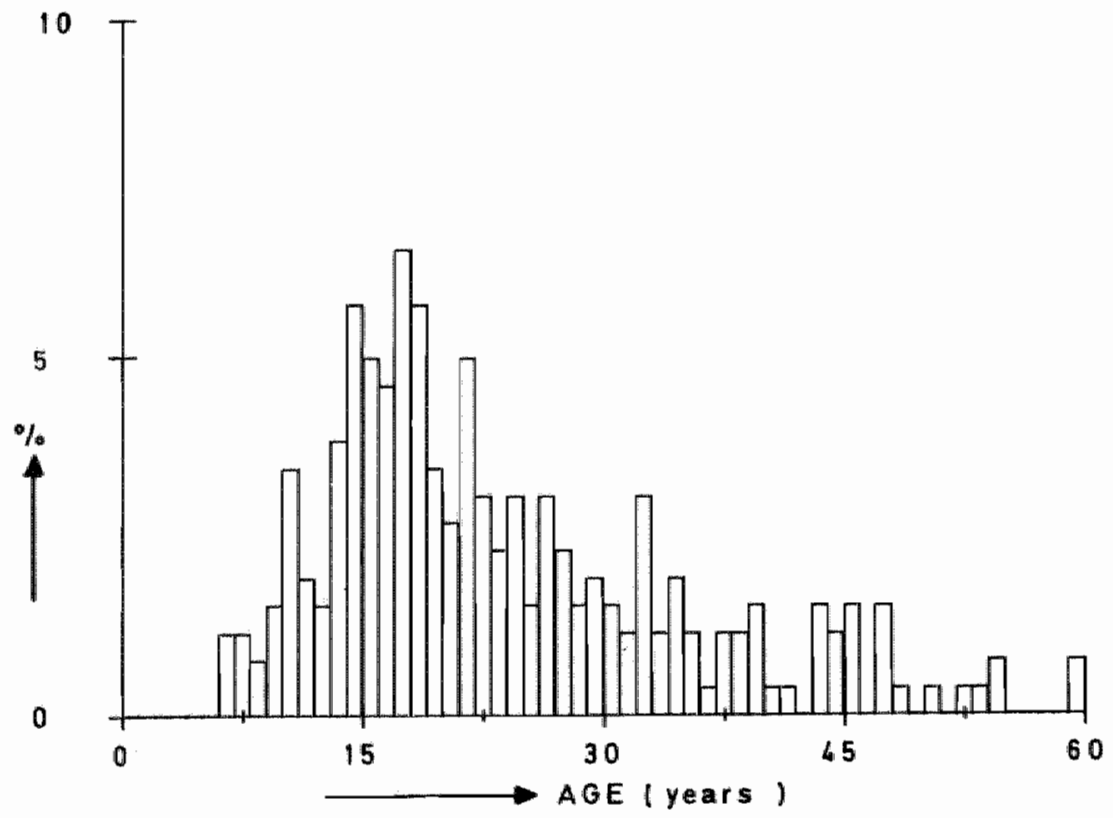

FIG. VIT.2.

Age distribution in years of the 253 female patients. 
mean and the confidence intervals. In the following tables only the means and significance of differences as based on the confidence intervals are given. More detalled surveys are sumarized in tables of the addenda (Ada. 3). The sleep composition of the total clindol group (total group: IP) and for the age group 20-40 years (sellected group: S) has been compared with the control group. For each comparison the most pronounced differences with respect to the first and second sleep cycle of the total night sleep are given.

\section{2. RESULTS}

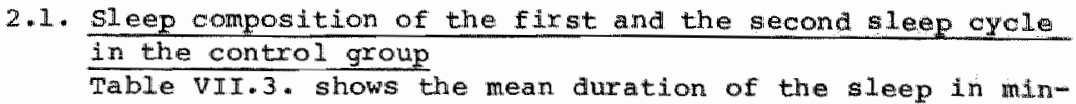
utes during the first cycle (upper rowl and of the second cycle (lower row).

TABLE VII.3.

Quantitative composition of the first and second cycle during the sleep deprivation recordings of the control group.

\begin{tabular}{|lc|c|c|c|c|c|c|}
\hline Co & $\mathrm{n}$ & $\begin{array}{l}\text { Total } \\
\text { Cycle }\end{array}$ & $\begin{array}{c}\text { Time } \\
\text { awake }\end{array}$ & $\begin{array}{l}\text { Ef fective } \\
\text { sleep time }\end{array}$ & N.REM 1-2 & N. REM 3-4 & REM \\
\hline $\mathrm{CY} .1$ & 15 & 77.1 & 5.1 & 72.0 & 28.5 & 34.8 & 8.7 \\
$\mathrm{CY} .2$ & 14 & 84.4 & 2.8 & 81.6 & 38.8 & 30.4 & 1.4 \\
\hline
\end{tabular}

The second sleep cycle lasts longer and contains more light N. REM 1-2 and REM sleep. The changed composition of the N.REM sleep is evident from the ratio N. RFM 1-2/N. REM 3-4, which 1 s 0.82 for the first cycle and 1.28 for the second cycle. Both sleep cycles are shorter than during the all-night sleep and in addition there is a different composition of the N.REM sleep. The ratio N.REM $1-2 / N$. REM $3-4$ is 0.82 for the deprivation sleep and 1.26 for the all-night sleep. This is due to a decrease in the light N.REM $1-2$ sleep by $10.7 \mathrm{~min}$ and an increase of the N. REM $3-4$ sileep by 3.6 min.

\subsection{Composition of the first and second sleep cycle in pa-} tients (CI group)

Patients have been divided into two categories, one with and one without epileptic EEG phenomena during the sleep recording. The sleep composition of the first and second cycle for the total group and for the selective age group of each category is wumarized in Tables VII.4, and VII.5.

Both clinical groups have a significantly longer sleep cycle (P $<0.01)$, due to moxe N.REM sleep. In the category without epileptic EEG phenomena the significant increase in N.REM 3-4 leep $(\mathbf{p}<0.05)$ is observed and in the category with epileptic EEG phenomena an increase in $N$. REM $1-2$ sleep $(p<0.05)$ and $N$. PBM $3-4$ sleep. 
THERE

composition of the firet cycle during slep deprivation recordings of patents without (N.E.) ara with (E.) epileptic Eec phenomena. for the total group (T) and for the selective group (S).

\begin{tabular}{|c|c|c|c|c|c|c|c|}
\hline$c y \cdot 1$ & $n$ & $\begin{array}{l}\text { Total } \\
\text { cycle }\end{array}$ & $\begin{array}{l}\text { Tirne } \\
\text { awake }\end{array}$ & $\begin{array}{l}\text { Effective } \\
\text { sleep time }\end{array}$ & N. FEM $1-2$ & N. FES $3-4$ & REM \\
\hline co & 15 & 77.1 & 5.1 & 72.0 & 28.5 & 34.8 & 8.7 \\
\hline $\begin{array}{l}N \cdot E \cdot(T) \\
N \cdot E \cdot(B)\end{array}$ & $\begin{array}{l}226 \\
104\end{array}$ & $\begin{array}{l}93.6 * \\
95.5\end{array}$ & $\begin{array}{l}4.9 \\
4.7\end{array}$ & $\begin{array}{l}88.7 * * * \\
90.8\end{array}$ & $\begin{array}{l}33.2 \\
37.6\end{array}$ & $\begin{array}{l}46.2^{*} \\
41.9\end{array}$ & $\begin{array}{r}9.3 \\
21.3\end{array}$ \\
\hline $\begin{array}{l}\text { E. }(\mathrm{T}) \\
\text { E. (S) }\end{array}$ & $\begin{array}{l}322 \\
128\end{array}$ & $\begin{array}{l}93.6 * * \\
94.4\end{array}$ & $\begin{array}{l}4.5 \\
5.4\end{array}$ & $\begin{array}{l}89.11^{*} \\
89.0\end{array}$ & $\begin{array}{l}36.5 * \\
38.0\end{array}$ & $\begin{array}{l}43.8 \\
40.7\end{array}$ & $\begin{array}{r}8.8 \\
10.3\end{array}$ \\
\hline
\end{tabular}

* $\mathrm{P}<0.05 ; * * \mathrm{p}<0.01$

Whe duration of the first cycle of both clinical groups is about 10 min shorter than that found in all-night recordings. Likewise there re differences in the ratio N.FFM 1-2/N. REM 3-4 sieep. In the goup without epileptic EEG phenomena this ratio is 0.72 versus 1.73 fallowing an all-night sleep recoraing and in the group with epileptic EEG phenomena 0.82 versus 1.23 .

TABLE VII. 5 .

Composition of the second cycle during sleep deprivation recordings of patients without (N.E.) and with (E.) epileptic EEG phenomena (T $=$ total group; $s=$ selective group).

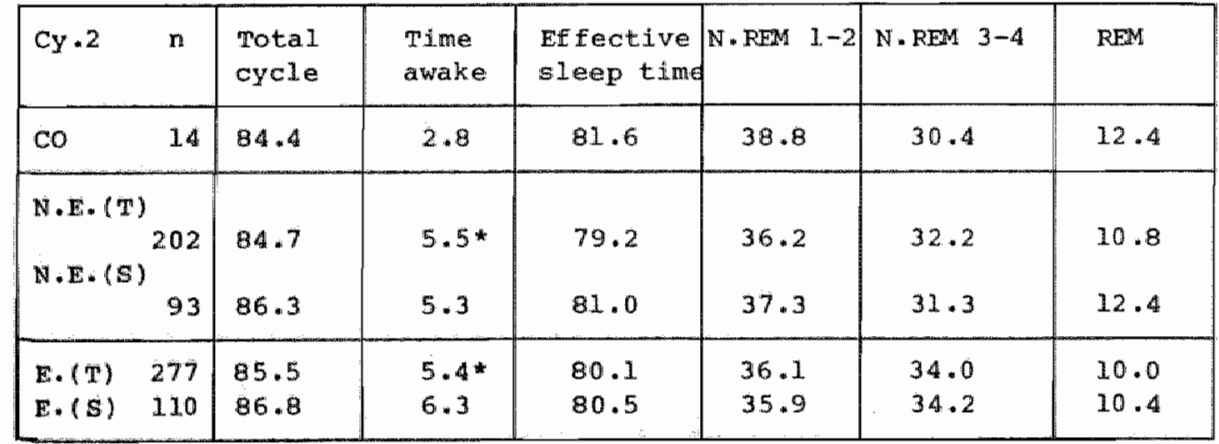

$* \mathrm{p}<0.05$

The composition of the second sleep cycle in both clinical groups (Table VII.5.) is hardly different from that of the control group, except for somewhat longer periods of wakefulness. As compared to 
the second cycle of the all-night recording, the total sleep cycle duration is shorter ( 18 and $17 \mathrm{~min}$ ), aue to less $N$. Fkil $1-2$ sleep $(13$ and $16 \mathrm{~min}$ ) and REM sleep ( 8 and $6 \mathrm{~min}$ ). This difference $1 \mathrm{~s}$ also expressed in the ratio N. REM $1-2$, N. REM $3-4$ sleep which for the group without epileptic phenomema is 1.12 following the sleep deprivation versus 1.76 following an all-night sleep recording and for the group with epileptic phenomena 1.06 versus 1.82 .

2.3. Composition of the first and second sleep cycle in patients without epileptic EEG phenomena dependent on whether they take or do not take antiepileptics

The question posed here is whether the sleep deprivation effect depends on the intake of antiepileptics. Of the 226 patients without eplleptic EEG phenomena in their recordings, 99 did not take medicines, 112 took only antiepileptics, 13 took antieplieptios and different medicines for psychic or somatic diseases and only 2 in combination with benzodiazepine derivatives. The sleep composition of the category which do not take medicines and the group which take only antiepileptics is represented in Table VII.6. and VII.7.

TABLE VII.6.

Composition of the first cycle during sleep deprdvation recondings of patients, without epileptic EEG phenomena $\left(N_{0} \mathbb{E}_{*}\right)$ and without (-A.E.) or with (+A.E.) antiepileptic arug treatment $(\mathrm{T}=$ total group; $\mathrm{S}=$ selective group).

\begin{tabular}{|c|c|c|c|c|c|c|}
\hline $\mathrm{CY} \cdot 1$ & $\begin{array}{l}\text { Total } \\
\text { cycle }\end{array}$ & $\begin{array}{l}\text { Time } \\
\text { awake }\end{array}$ & $\begin{array}{l}\text { Ef fective } \\
\text { sleep time }\end{array}$ & N. REMI -2 & $N \cdot \mathbb{R F M} 3-4$ & REM \\
\hline 15 & 77.1 & 5.1 & 72.0 & 28.5 & 34,8 & 8.7 \\
\hline $\begin{array}{l}\text { M.E.-A.E. (T) } \\
\text { M.E.-A.E. (S) } \\
48\end{array}$ & $\begin{array}{l}90.7 * * \\
94.7\end{array}$ & $\begin{array}{l}5.2 \\
5.2\end{array}$ & $\begin{array}{l}85.5 * \\
89.5\end{array}$ & $\begin{array}{l}31.3 \\
34.5\end{array}$ & $\begin{array}{l}45.2 \\
42.7\end{array}$ & $\begin{array}{r}9.0 \\
12.3\end{array}$ \\
\hline $\begin{array}{c}\text { W.E.A.E.(T) } \\
1.12 \\
\text { W.E.A.E.(S) }\end{array}$ & $\begin{array}{l}94.8 * * \\
97.2\end{array}$ & $\begin{array}{l}3.8 \\
4.0\end{array}$ & $\begin{array}{l}91.0 * * \\
93 \cdot 2\end{array}$ & $\begin{array}{l}33.3 \\
39.6\end{array}$ & $\begin{array}{l}48.1^{*} \\
42.9\end{array}$ & $\begin{array}{r}9.6 \\
10.7\end{array}$ \\
\hline
\end{tabular}

The same differences as observed for the total group (Table VII.4.) are found here for both categories, mainly an increase in deep N.REM $3-4$ sleep $(\mathbb{P}<0.05)$. This effect 1 also expressed in the ratio N.REM $1-2 /$ N. REM 3-4 sleep which for both groups is 0.69 versus 0.82 for the control group. Eatients between the age of 20 and 40 years have a smaller increase in N.REM 3-4 ileep but this is compensated by a slight increase in N.FEM $1-2$ sleep. 
Both patient categories become less awake as compared to the allnight seep recordings. In addition the group which do not take medicines have an important shortening of the cycle duration $(-25.2$ min).

TAELE VII. 7.

Composition of the second cycle during sleep deprivation recordings af patient without epileptic EEG phenomena (N.E.) and without (-A.E.) or wth ( + A.E.) artieplleptic drug treatment $(T=$ total group; $S=$ (arelective group).

\begin{tabular}{|c|c|c|c|c|c|c|}
\hline $\mathrm{Cy} \cdot 2$ & $\begin{array}{l}\text { Total } \\
\text { cycle }\end{array}$ & $\begin{array}{l}\text { Time } \\
\text { atwake }\end{array}$ & $\begin{array}{l}\text { Effective } \\
\text { sleep time }\end{array}$ & $N \cdot \operatorname{REMI}-2$ & N. REM 3-4 & $R E M$ \\
\hline 14 & 84.4 & 2.8 & 81.6 & 38.8 & 30.4 & $12 \cdot 4$ \\
\hline $\begin{array}{l}\mathrm{N} \cdot \mathbb{E}_{m}-\mathrm{A} \cdot \mathrm{E} \cdot(\mathrm{T}) \\
\mathrm{N} \cdot \mathrm{E},-\mathrm{A} \cdot \mathrm{E} \cdot(\mathrm{S})^{99}\end{array}$ & $\begin{array}{l}82.1 \\
80.9\end{array}$ & $\begin{array}{l}5.1 \\
5.4\end{array}$ & $\begin{array}{l}77.10 \\
75.5\end{array}$ & $\begin{array}{l}35.9 \\
35.5\end{array}$ & $\begin{array}{l}30.3 \\
26.3\end{array}$ & $\begin{array}{l}10.8 \\
13.7\end{array}$ \\
\hline $\begin{array}{c}\mathrm{N} \cdot \mathrm{E} \cdot+\mathrm{A} \cdot \mathrm{E} \cdot(\mathrm{T}) \\
\mathrm{H}(01 \\
\mathrm{N} \cdot \mathrm{E} \cdot+\mathrm{A} \cdot \mathrm{E} \cdot(\mathrm{S})\end{array}$ & $\begin{array}{l}86.4 \\
91.0\end{array}$ & $\begin{array}{l}5.8 * \\
5.4\end{array}$ & $\begin{array}{l}80.6 \\
85.6\end{array}$ & $\begin{array}{l}36.6 \\
39.3\end{array}$ & $\begin{array}{l}33.0 \\
35.3\end{array}$ & $\begin{array}{l}11.0 \\
11.0\end{array}$ \\
\hline
\end{tabular}

* $\mathrm{p}<0.05$

Except for more wakefulness $(\mathrm{p}<0.05)$ the sleep composition of the second sleep cycle in both patient groups is comparable to that of the control group. The category without epileptic EEG phenomena and which do not take antiepileptics differs from the all-night sleep recondings as follows: they have a shorter sleep cycle $(-24.5 \mathrm{~min})$, there is less REM sleep $(-9.1 \mathrm{~min})$, there are less awakening $(-5.5$ min), the ratio $N$. REM $1-2 / N$. REM 3-4 sleep is 1.18 following a sleep deprivation versus 1.68 following an all-night sleep recording. Though the differences remain they are smallex for the group which take antleptleptics: they have a shorter sleep cycle $(-12.2 \mathrm{~min})$, less PEM sleep $(-7.6 \mathrm{~m} / \mathrm{n})$ and the ratio $N$. REM $1-2 / \mathrm{N}$. REM $3-4$ sleep following a sleep deprivation recording is 1.11 versus 2.43 following an all-night sleep recording.

2.4. Sleep composition following sleep deprivation in patients having epileptic EEG phenomena and which take antiepileptics in combination with or wilhout benzodiazepine derivatives:

Benzodiazepine derivatives often give rise to an increase in N.REM 1-2 sleep. It was therefore of interest to trace whether swch an effect is still present in patients treated with antiepileptics and benzodiazepine derivatives following sleep deprivation.

of the 322 patients in which epileptic EEG phenomena were found durling the sleep, 221 took only antieplieptics, 37 took antiepileptics in comblnation with benzodiazepine derivatives, 16 took anti- 
epileptics and other medicines and 48 only took other medicines. The sleep composition of patients taking only amtiepileptics or antiepileptics in combination with benzodiatepine derivatives are represented in VII. B. and VII.9..

TABLE VII.8.

Composition of the first sleep depriwation cycle in patients with epileptic EEG phenomena ( $\mathrm{E}$.$) treated with antiepileptic drugs, in$ combination with (+A.E.-B.D.) or without ( $+A_{*} E_{*}+B_{.}$.) benzodiazepine derivatives ( $T=$ total group; $S=$ selective group).

\begin{tabular}{|c|c|c|c|c|c|c|}
\hline $\mathrm{Cy} \cdot \mathrm{z}$ & $\begin{array}{l}\text { Total } \\
\text { cycle }\end{array}$ & $\begin{array}{l}\text { Time } \\
\text { awake }\end{array}$ & $\begin{array}{l}\text { Ef fective } \\
\text { sleep tine }\end{array}$ & N. REM I -2 & $N \cdot R E M 3-4$ & REM \\
\hline 15 & 77.1 & 5.1 & 72.0 & 28.5 & 34.8 & 8.7 \\
\hline 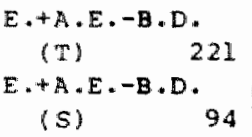 & $\begin{array}{l}92.2 * * 1 \\
92.7\end{array}$ & $\begin{array}{l}5.0 \\
5.4\end{array}$ & $\begin{array}{l}87.2 * \\
87.3\end{array}$ & $\begin{array}{l}33.7 \% \\
33.4\end{array}$ & $\begin{array}{l}44.3 \\
43.1\end{array}$ & $\begin{array}{r}9.2 \\
10.8\end{array}$ \\
\hline $\begin{array}{l}\text { E. }+ \text { A.E.+B.D. } \\
\begin{array}{l}(T) \\
\text { E.+A.E.+B.D. } \\
\text { (S) }\end{array}\end{array}$ & $\begin{array}{l}104.9 * \\
108.6\end{array}$ & $\begin{array}{l}2.1 * \\
3.5\end{array}$ & $\begin{array}{l}102.8 * \\
105.1\end{array}$ & $\begin{array}{l}46.0 * \\
65.1\end{array}$ & $\begin{array}{l}50.1 \\
3.8 .8\end{array}$ & $\begin{array}{l}6.7 \\
5.2\end{array}$ \\
\hline
\end{tabular}

Both clinical categories have a significantly longer sleep cycle (p $<0.01$ ) and more effective sleep ( $p<0.025$ ), which is based on an increase in N.PEM $1-2$ sleep $(p<0.025)$ and $N$. REM $3-4$ sleep. In the group treated with benzodiazepine derivatives this increase is somewhat larger, but there is however a decreased REM sleep.

As compared to the all-night sleep recording patients which only take antieplieptics have a shorter sleep cycle $(-15.6 \mathrm{~min})$ and less N. AEM $2-2$ sleep $(-12.1$ min). This difference does not exist in patients of the age group 20-40 years, treated with antlepileptictin combination with benzodiazepine deriwatives.

Except for a higher amount of wakefulness $(p<0.05)$, the differences in the sleep composition of patients only treated with antepileptics as compared to the control croup as well as to the patients treated with benzodiazepine derivatives, are negligible (Table VI. I.9). both clinlcal categories have a shorter second sleep cycle $(-15 \mathrm{~min})$ as compared to the ali-night sleep recordings, due to less N. REM $1-2$ sleep. As chown in Table vir.9.

2.5. Composition of the first and second sleep cycle following sleep deptration, in the presence f epileptic EEG phenomena and the Intake of antiepileptics, depending on the type of epilepsy

The question here is whether the sleep deprivation fitects depend on the type of the epileptic EEG abnormalities recorded during 
TABLE VIT.9.

Composition of the second sleep deprivation cycle in recordings with epileptic EEG phenomena (E*) with antiepileptic arug treatment, in

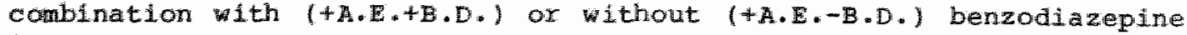
derivatives $(T=$ total group; $s=$ selective group).

\begin{tabular}{|c|c|c|c|c|c|c|}
\hline Cy. 2 & $\begin{array}{l}\text { Total } \\
\text { cycle }\end{array}$ & $\begin{array}{l}\text { Tume } \\
\text { awake }\end{array}$ & $\begin{array}{l}\text { Ef fective } \\
\text { sleep tims }\end{array}$ & N. PENA $1-2$ & N. FEN 3-4 & REM \\
\hline 14 & 84.4 & 2.8 & 81.6 & 38.8 & 30.4 & 12.4 \\
\hline 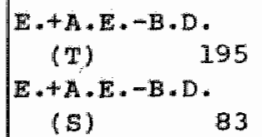 & $\begin{array}{l}86.2 \\
87.6\end{array}$ & $\begin{array}{l}5.6 \% \\
7.0\end{array}$ & $\begin{array}{l}80.6 \\
80.6\end{array}$ & $\begin{array}{l}36.5 \\
35.9\end{array}$ & $\begin{array}{l}34.3 \\
34.2\end{array}$ & $\begin{array}{c}9.8 \\
10.5\end{array}$ \\
\hline $\begin{array}{l}\mathrm{E} \cdot+\mathrm{A} \cdot \mathrm{E} \cdot+\mathrm{B} \cdot \mathrm{D} \cdot 2 \\
(\mathbb{T}) \\
\begin{array}{l}\mathrm{E} \cdot+\mathrm{A} \cdot \mathrm{E} \cdot+\mathrm{B} \cdot \mathrm{D} \cdot \\
(\mathrm{S})\end{array}\end{array}$ & $\begin{array}{l}77.8 \\
79.0\end{array}$ & $\begin{array}{l}2.6 \\
5.2\end{array}$ & $\begin{array}{l}75.2 \\
73.8\end{array}$ & $\begin{array}{l}30.0 \\
34.1\end{array}$ & $\begin{array}{l}34.8 \\
30.9\end{array}$ & $\begin{array}{r}10.4 \\
8.8\end{array}$ \\
\hline
\end{tabular}

* $p<0.05$

the sleep. A difference was made between recordings containing EEG abnomalities fitting with generalized, paxtial or both forms of epilepsy. The sleep composition for the first and second sleep cycle for the different categories is represented in Tables VII.10. and VII.11.

TABLE VII.10.

Composition of the first sleep deprivation cycle in recordings with epileptic EEG paroxysms belonging to genexalized, partial or general1 zed with partial epilepsy ( $T=$ total group; $S=$ selective group).

\begin{tabular}{|c|c|c|c|c|c|c|c|}
\hline$C y \cdot 1$ & $\mathrm{n}$ & $\begin{array}{l}\text { Total } \\
\text { cycle }\end{array}$ & $\begin{array}{l}\text { Time } \\
\text { awake }\end{array}$ & $\begin{array}{l}\text { Effective } \\
\text { sleep time }\end{array}$ & N. REML-2 & N. $\operatorname{REM} 3-4$ & REM \\
\hline $\mathrm{CO}$ & 15 & 77.1 & 5.1 & 72.0 & 28.5 & 34.8 & 8.7 \\
\hline $\begin{array}{c}\text { Gen. +A.E. } \\
\text {-B.D. (T) } \\
\text { Gen.A.A.E. } \\
- \text { B.D. (S) }\end{array}$ & $\begin{array}{l}98 \\
33\end{array}$ & $\begin{array}{l}94.4 * * \\
96.9\end{array}$ & $\begin{array}{l}5.5 \\
9.2\end{array}$ & $\begin{array}{l}88.9 * \\
87.7\end{array}$ & $\begin{array}{l}34.2 \\
39.8\end{array}$ & $\begin{array}{l}45.8 \\
37.7\end{array}$ & $\begin{array}{r}8.9 \\
10.2\end{array}$ \\
\hline $\begin{array}{r}\text { part.+A.E. } \\
\text {-B.D. (T) } \\
\text { Part.+A.E. } \\
- \text { B.D. (S) }\end{array}$ & $\begin{array}{l}74 \\
37\end{array}$ & $\begin{array}{l}92.1 * * \\
92.5\end{array}$ & $\begin{array}{l}4.6 \\
4.3\end{array}$ & $\begin{array}{l}87.5 * * \\
88.2\end{array}$ & $\begin{array}{l}31.6 \\
29.7\end{array}$ & $\begin{array}{l}45.5 \\
46.5\end{array}$ & $\begin{array}{l}10.4 \\
12.0\end{array}$ \\
\hline $\begin{array}{c}\text { Gen.+Part.+A } \\
+ \text { B.D. (IT) } \\
\text { Gen.+Part. }+ \\
- \text { B.D.(S) }\end{array}$ & $\begin{array}{l}. \mathbb{E} \\
49 \\
2 . \mathbb{E} \\
24\end{array}$ & $\begin{array}{l}87.8 \\
87.5\end{array}$ & $\begin{array}{l}4.3 \\
2.2\end{array}$ & $\begin{array}{l}831.5 \\
85.3\end{array}$ & 36.2 & 39.5 & $\begin{array}{r}7.8 \\
10.0\end{array}$ \\
\hline
\end{tabular}

$* p<0.025$ 
All 3 clinical categories have a longer sleep cycle and moxe exfective sleep. This is largest for patients having one form of epilepsy $(\mathrm{p}<0.025)$ and is based mainly on more $\mathrm{N}$. REM $3-4$ sleep. In patients which have both types of epilepsy, the prolongation of the sleep cycle is less pronounced. This is for the total group mainly based on an increase in light $N$. REM $1-2$ sleep and for the age group between 20-40 years due to an increase in deep N. REM $3-4$ sleep. IT. is difference is also evident from the ratio N.REM $1-2 / N$. REM $3-4$ sleep, which is 0.82 for the control group and for patients with generalized, partial or both types of epilepsy is respectively $0.74,0.69$ and 0.91 . For the 3 clinical categories the sleep following sleep deprivation differs from the all-night sleep in that the sleep cycle is shorter $(-10$ to $25 \mathrm{~min})$, which for patients having one type of epllepsy is mainly due to less $\mathrm{N}$. REM $1-2$ sleep and for patients having two types of epilepsy due to a decrease in N. REM $1-2$ as well as N.REM 3-4 sleep.

TABLE VII.12.

Composition of the second sleep deprivation cycle in recordings with epileptic EEG paroxysms belonging to generalized, partial or generalized with partial epilepsy ( $\mathrm{T}=$ total group; $\mathrm{S}=$ selective group).

\begin{tabular}{|c|c|c|c|c|c|c|c|}
\hline $\mathrm{Cy} \cdot 2$ & $\mathrm{n}$ & $\begin{array}{l}\text { Total } \\
\text { cycle }\end{array}$ & $\begin{array}{l}\text { Time } \\
\text { awake }\end{array}$ & $\begin{array}{l}\text { Effective } \\
\text { sleep ting }\end{array}$ & $N \cdot \operatorname{REMI}-2$ & N. IREM3-4 & REM \\
\hline $\mathrm{CO}$ & 14 & 84.4 & 2.8 & 81.6 & 38.8 & 30.4 & 12.4 \\
\hline $\begin{array}{c}\text { Gen. }+ \text { A.E. } \\
-B \cdot D \cdot(T) \\
\text { Gen.+A.E. } \\
-B \cdot D \cdot(S)\end{array}$ & $\begin{array}{l}86 \\
26\end{array}$ & $\begin{array}{l}86.3 \\
84.6\end{array}$ & $\begin{array}{l}5.0 \\
7.1\end{array}$ & $\begin{array}{l}81.3 \\
77.5\end{array}$ & $\begin{array}{l}36.7 \\
34.2\end{array}$ & $\begin{array}{l}34.1 \\
32.4\end{array}$ & $\begin{array}{l}10.5 \\
10.9\end{array}$ \\
\hline $\begin{array}{r}\text { Part.+A.E. } \\
-B . D .(T) \\
\text { Part.+A.E. } \\
\text {-B.D.(S) }\end{array}$ & $\begin{array}{l}64 \\
33\end{array}$ & $\begin{array}{l}82.9 \\
85.3\end{array}$ & $\begin{array}{l}5.3 \\
6.5\end{array}$ & $\begin{array}{l}77.6 \\
78.8\end{array}$ & $\begin{array}{l}34.4 \\
35.8\end{array}$ & $\begin{array}{l}33.9 \\
34.0\end{array}$ & $\begin{array}{l}9.3 \\
9.0\end{array}$ \\
\hline $\begin{array}{c}\text { Gen.+Part.+A } \\
- \text { B.D. (T) } \\
\text { Gen.+Part. HA } \\
\text {-B.D.(S) }\end{array}$ & $\begin{array}{l}\text {.E. } \\
45 \\
. E . \\
24\end{array}$ & $\begin{array}{l}90.5 \\
93.9\end{array}$ & $\begin{array}{l}7.1 \\
7.4\end{array}$ & $\begin{array}{l}83.4 \\
86.5\end{array}$ & $\begin{array}{l}39.0 \\
38.0\end{array}$ & $\begin{array}{l}35.0 \\
36.3\end{array}$ & $\begin{array}{r}9.4 \\
12.2\end{array}$ \\
\hline
\end{tabular}

All 3 clinical groups tend to be more awake (Table VII.11.). The duration of the sleep cycle is shorter as compared to an all-night sleep recording and this decline is largest for the group which has generalized epilepsy $(-24 \mathrm{~m} / \mathrm{n})$, caused by a decreased N.RFM $1-2$ and REM sleep. 
2.6. Composition of the first and second sleep cycle in the clinical categories for the age group $20-40$ years

The question studied here is whether the sleep composition of patients in the age group 20-40 years differ from the sleep composition in the total groups. The results are represented in Tables VII.12, and VII.13. Group 1 represents the control group. The different categories of patients re subdivided into 3 main groups: group 2: patients without epileptic EEG abnomalities during the sleep (categories 2 and 3 ): group 3 ; patients with epileptic EEG abnomalithes and which are treated with antiepileptics (categories 4 , 5 and 6$)$, group 4 : the same as the last group but treated with antiepileptics and benzodiazepine derivatives.

As compared to the control group the 3 elinical groups have a longer leep cycle, more effective sleep and more light $N *$ REM $1-2$ sleep. The category of patients treated with antieplieptics and berzodiazepine derivatives have more 1 ight $\mathrm{N} . \mathrm{RE} 4 \mathrm{~L}-2$ sileep as compared to the control group and to other clinlical groups. The groups cannot be differentiated statistlcally from each other otherwise, probably because of the relative small differences between the group and the large interindividual variability.

Though the clinical groups tend to spend more time awake, the differences in composition of the second sleep cycle are too small to aifferentiate these statistically from the control group (Table VII.13.). 


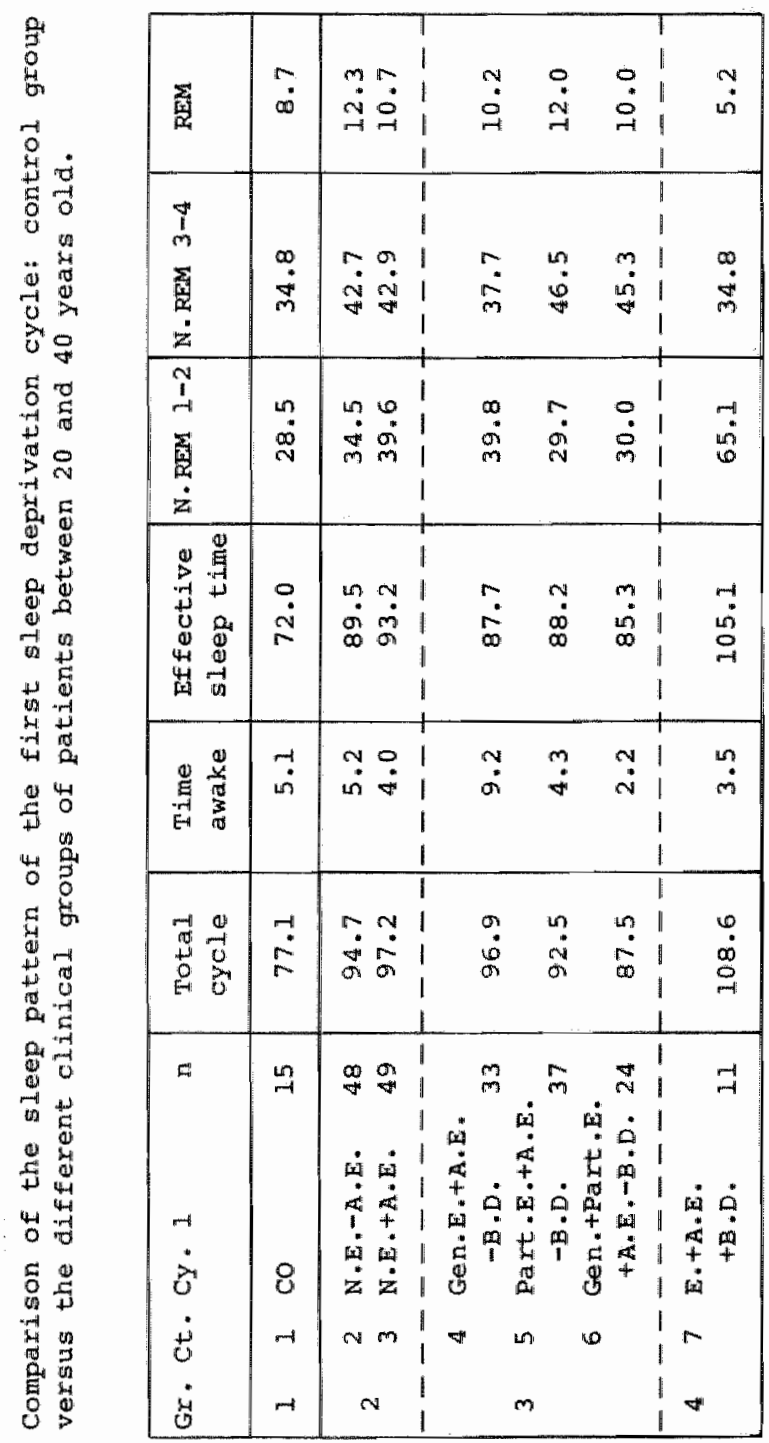




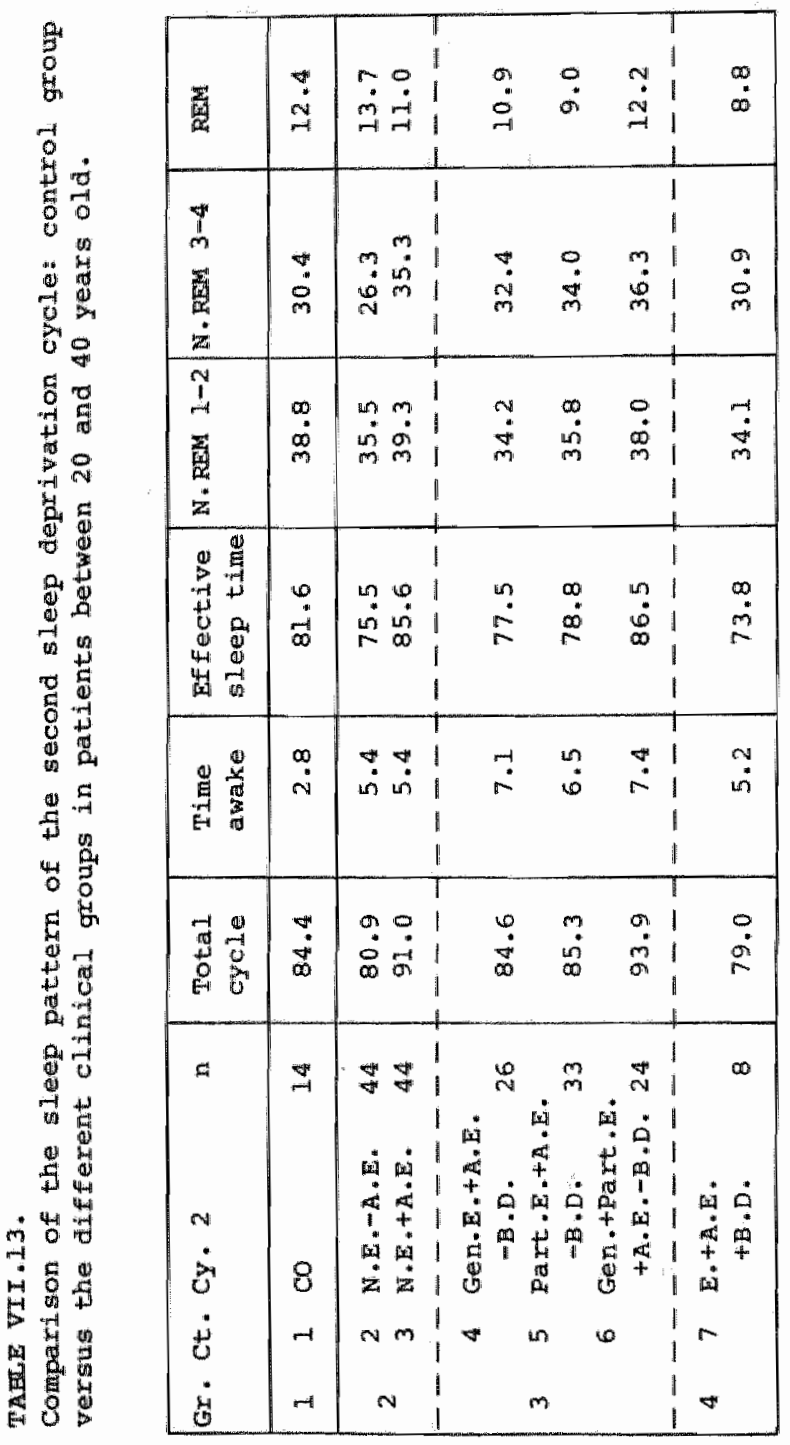


2.7. Differences in sleep composition of the first and second sleep cycle between patients belonging to the age groups $5-20$ years versus $20-40$ years.

Since in our patient material 251 subjects were younger than 20 years and 232 between the age of 20 and 40 years, these groups were large enough to compare the different clinical categories wh each other. The mean values for both age groups are represented next to each other in the Tables VII.14. and VII.15.

There axe no important differences in the total duration of the first sleep cycle between both age groups (Table VII.14.). Patients younger than 20 years tend to become less awake, but this difference is small. Most patients younger than 20 years have less light N. REM $1-2$ sleep and more deep N. REM 3-4 sleep. The difference in N. REM 1-2 sleep is significant for patients treated with antiepileptics and benzodiazepine derivatives $(p<.005$ ) and for patients which have no epileptic EEG abnomalities in their sleep recording and which take antiepileptios $(\mathrm{p}<0.01)$ and is less for patients having generalized epilepsy.

Below the age of 20 years there is significantily more N.REM $3-4$ sleep for patients which do not have epileptic EEG abnormalities and which take antiepileptics $(\mathrm{p}<0.01)$, and for those which have $\mathrm{EEG}$ abnomalities fitting with generalized epilepsy ( $\mathrm{p}<0.01)$. Except for those which take antiepileptics in combination with benzodiazepline derivatives, all patient categories of the age group below 20 years have a shorter REM sleep.

There are no substantial differences in the sleep composition of the second sleep cycle of both agle groups (Table VII.15.). Iust as for the first sleep cycle, patients below the age of 20 years tend to becone less awake, except for subjects which do not have epileptic EEG abnomalities and which take antiepileptics. 


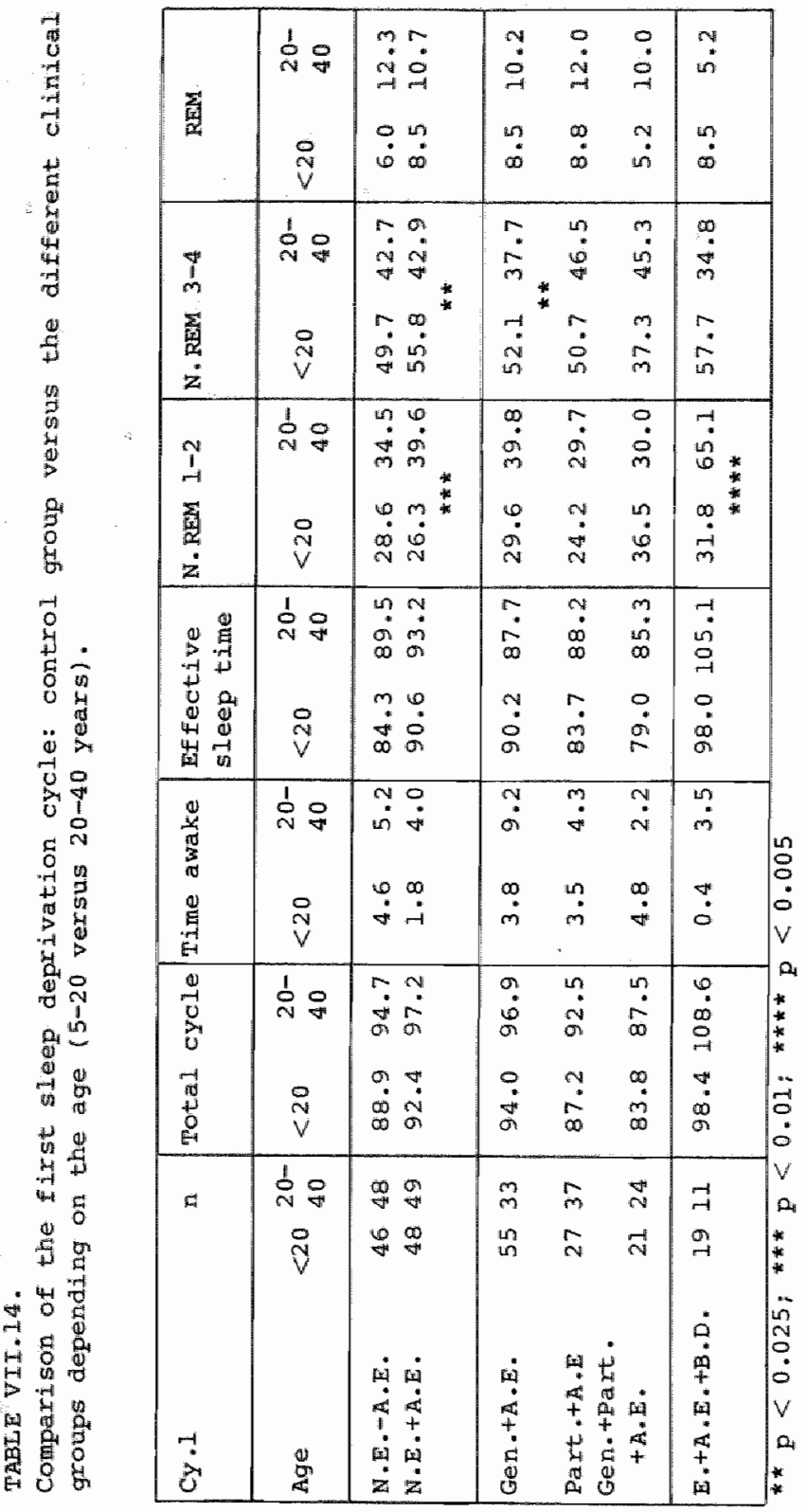




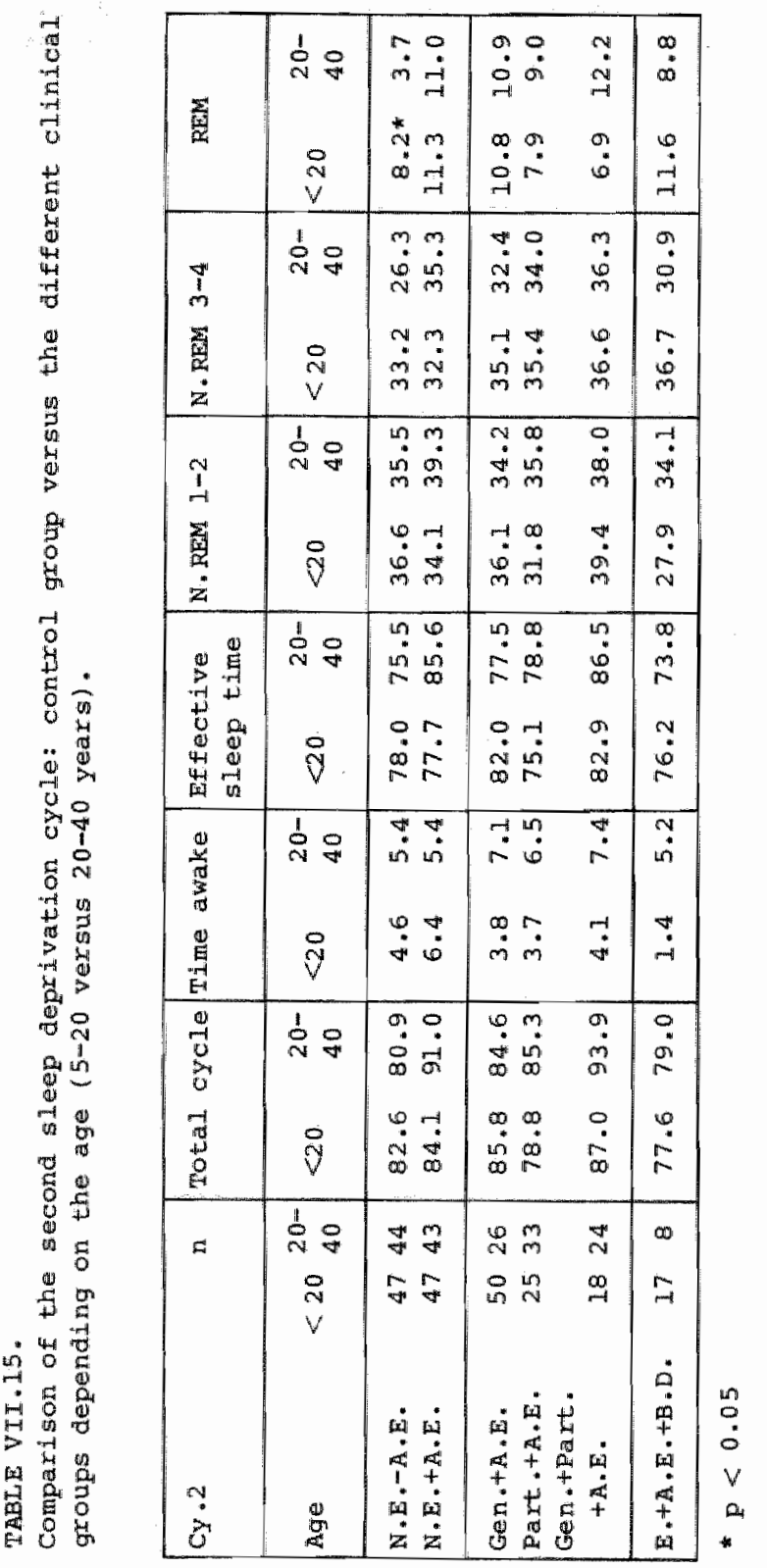


The amount of 1 ight . REM $1-2$ sleep and deep wEM 3-4 sleep is comparable for both age groups except for subjects between 20 and 40 year wich do not have eplleptic EEG phenomena and which do not take antieplieptics, which have less deep W. REM 3-4 sleep. The ratio N. 1-2 N. REM 3-4 is about 1 in the other clinical groups. REM slep of aubjects youger than 20 years which do not have epileptic EEG abnomalities and which do not take antiepileptics is significantly ( $p<0.05$ ) highex than fox the patients of the age group 20-40 years.

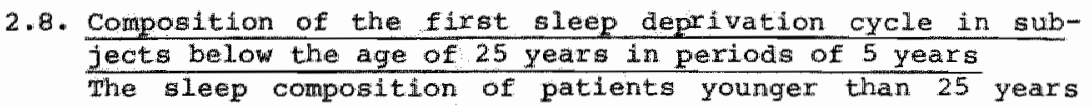
was studied, in orier to find out to which degree the sleep deprivation fect is age-dependent. The results are represented in Tables VII.16. (no antiepileptics), VII.I7. (only antiepileptics) and VII.1B. (antiepileptics and benzodiazepines)

There are no large differences in the conposition of the first sleep cycle for the different age groups (Table VII.26.). The deprivation effect consisting of a preponderant deep N. PREM 3-4 sleep is most pronounced for subjects youngex than 20 years. The ratio N. HEM 1-2, N. FEM 3-4 sleep of the age group 20-24 years is comparable to the ratio of the control group between the age of 20-40 years $(0.77$ versus 0.82$)$.

The youngest (5-9 years) and the oldest group $(20-24$ years) have respectively the shortest and the longest sleep cycle (Table VII.17.). The deprivation effect 1 s leat pronounced for the youngest groups which also shows less deep N. REM 3-4 sleep. For the other groups the deprivation effect is increased or comparable to the effect in patients which do not take antiepileptics.

For all age groups thexe is an increased total cycle length and a decrease in wakefulness, which is to be expected when benzodiazepine aerivatives are taken (Table VII.l8.). This also gives rise to an increase $10 \mathbb{N} \cdot \mathbb{R E M} i-2$ sleep, this is only seen here in patients older than 20 years.

For the age groups below 20 years, there is no increase in 1 ight N. REM 1-2 sleep but an increase in deep N. REM 3-4 sleep (deprivation effect), which for all groups is larger than in patients which do not take or only take antiepileptics. The deprivation effect is sustalined for the patient group between 20-24 years, but complemented by benzodiazepine effects since an increase in N.REM $1-2$ sleep is observed. 


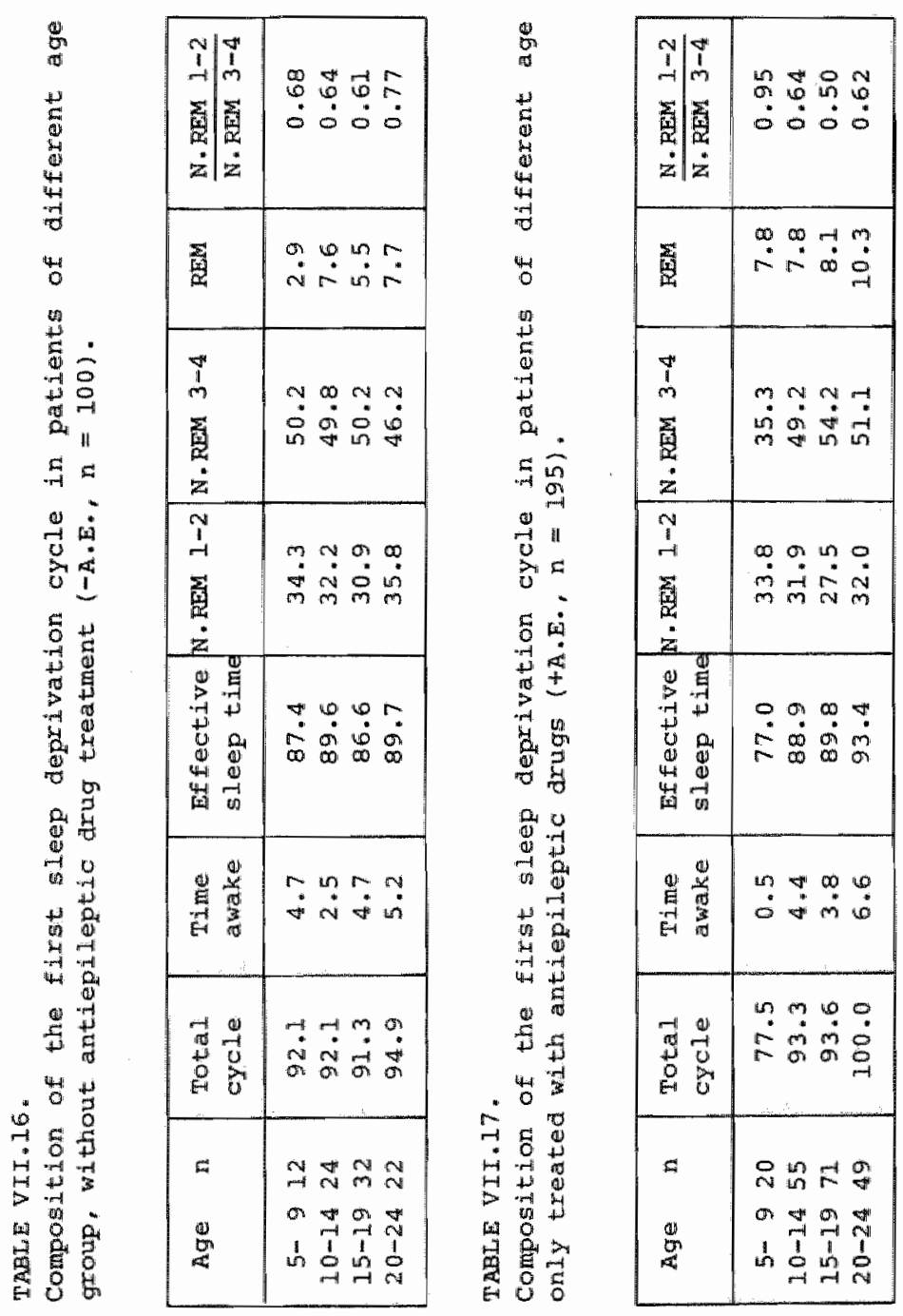




\begin{tabular}{|c|c|c|}
\hline 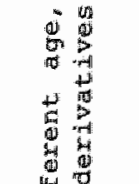 & 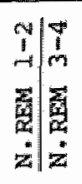 & $\begin{array}{llll}N & 0 & 0 & 0 \\
0 & 0 & 0 \\
0 & 0 & 0 & 0\end{array}$ \\
\hline 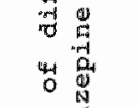 & 氙 & 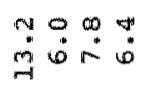 \\
\hline 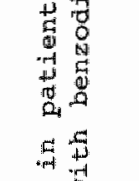 & $\begin{array}{l}\overrightarrow{1} \\
i \\
m \\
\text { 急 } \\
z \\
z\end{array}$ & 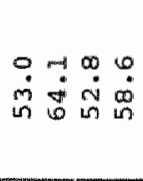 \\
\hline 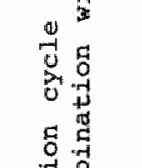 & $\begin{array}{c}1 \\
1 \\
-1 \\
1 \\
1 \\
2 \\
\dot{z} \\
\end{array}$ & 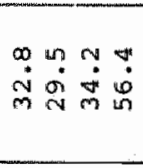 \\
\hline 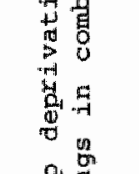 & 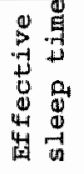 & $\begin{array}{l}0 \\
\dot{\sigma} \\
\sigma \\
\sigma\end{array}$ \\
\hline 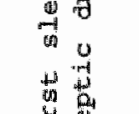 & 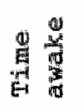 & $\begin{array}{lll}0 & m & 0 \\
0 & 0 & 0\end{array}$ \\
\hline 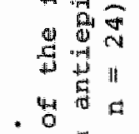 & $\begin{array}{l}7 \\
0 \\
0 \\
0 \\
0\end{array}$ & ơ \\
\hline 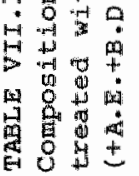 & 足 & 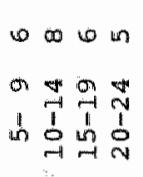 \\
\hline
\end{tabular}


Whis chapter deals with the composition of the fixst and second sleep cycle following sleep deprivation of subjects which are suspected to have epilepsy. In onder to find out whether the sleep structure is dependent on the presence or absence of epliteptic EEG abnomalities, the intake of antieplieptics, with or without the combination with benzodiazepine derivatives, the total population group was divided into a number of categories based on these criteria.

For the investigation hypnograms of the sleep following sleep deprivation of the total of 548 subjects were used. This group consisted of 295 males and 253 females. 251 belonged to the age group 5-20 years, 232 belonged to the age group 20-40 years and 65 were older than 40 years. The influence of medication was damined by using only the hypnograms of patients which took only antiepileptics or antiepileptics in combination with benzodiazepine derivatives, with the exclusion of all other medicines.

The influence of age was checked by studying the sleep composition of the total population and for patients between 20 and 40 yeaxs as compared to the control group, which consisted of 15 healthy persons between the age of 20-40 years.

The mean values and confidence intervals of the different sleep parameters are depicted in black diagrams in a similar way as for the al1-night sleep recordings. patients with epileptic EEG abnormalities are grouped together since there was no major difference between the different types of epilepsy. The restriction here is that only patients between 20 and 40 years axe considered.

\section{FIRST CYCLE}

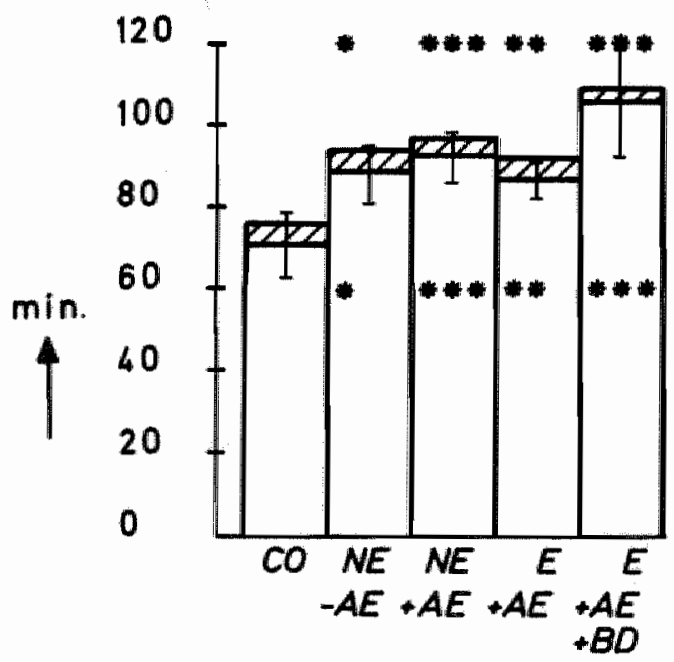

SECOND CYCLE

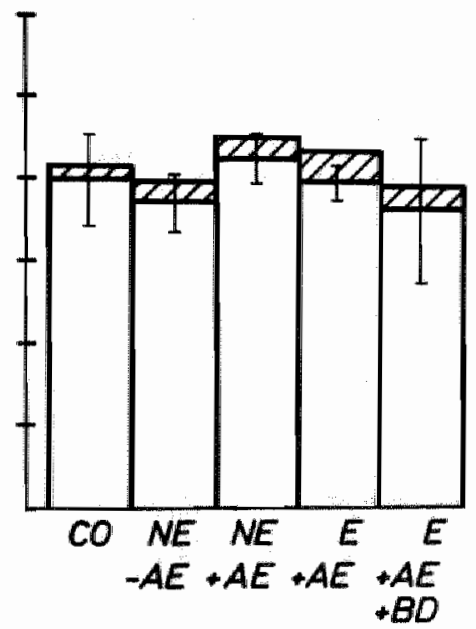

FTG. VII.19.

Mean values, in minutes, of the total sleep cycle, the time awake (D) and the effective sleep time ( $\square$ ) durling the first and second sleep deprivation cycle of the control and the different olinical categoriess $(20-40$ years $)$.

$* p<0.05 ; * * p<0.025 ; * * * 0<0.01$. 
buring the first sleep cycle following aifferences between the control group and the clinical categories exist:

1. The duration of the first sleep cycle is significantly longer for ail clidical categories $(\mathrm{p}<0.05$ to $\mathrm{p}<0.01)$, and 1 s most pronounced for patients treated with the combination of antiepileptics and benzodiazepine derivatives.

2. Following depritation thexe is less wakefulness as well in the control group as in the clinical group.

3. In analogy with the cycle duration, the mean effective sleep during the first sleep cycle is sigmificantly longer in all clinical categrories $(\mathrm{p}<0.05$ to $<<0.01)$.

4. Following leep deprivation the control group as well as the pathents have a higher percentage effective sieep, which amounts to more than 93 during both sleep cycles (Fig. WII.20.).

FIRST CYCLE

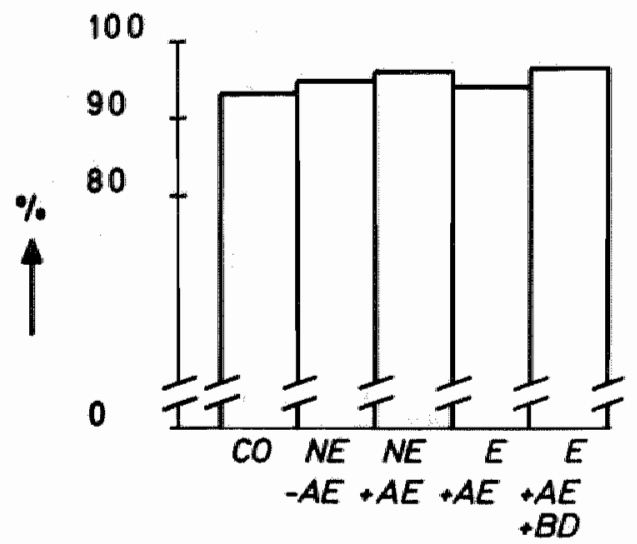

SECOND CYCLE

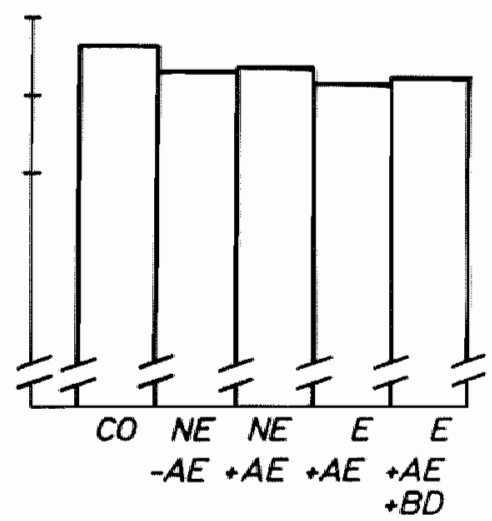

FIG. VII.20.

Percentage of effective sleep time in the control and the different elinical categories during the first and second sleep deprivation cycle.

Since effective sleep consists of $N$. REM and REM sleep, the ratio between both is depicted in EIg. VII.2I.

5. There are few differences in the amount of REM $s$ leep between the control and clinical groups and between the first and second sleep oycle, except for patients treated with the combination of antieplleptics and benzodiazepine derivatives, during the first cycle which tena to have less REM sleep*

6. The increase in cycle duration and effective sleep seen in patients during the first sleep cycle is based on a significant $(\mathrm{p}<0.05$ to $\mathrm{p}<0.005)$ increase in N.REM sleep; which is most pronounced for patients treated with the combination therapy. In ardler to know which part of the sleep increased most, the mean duration of $N$. REM $1-2$ sleep and $N \cdot$ REM 3-4 sleep is depicted in Fig. VII.22. 
FIRST CYCLE

SECOND CYCLE
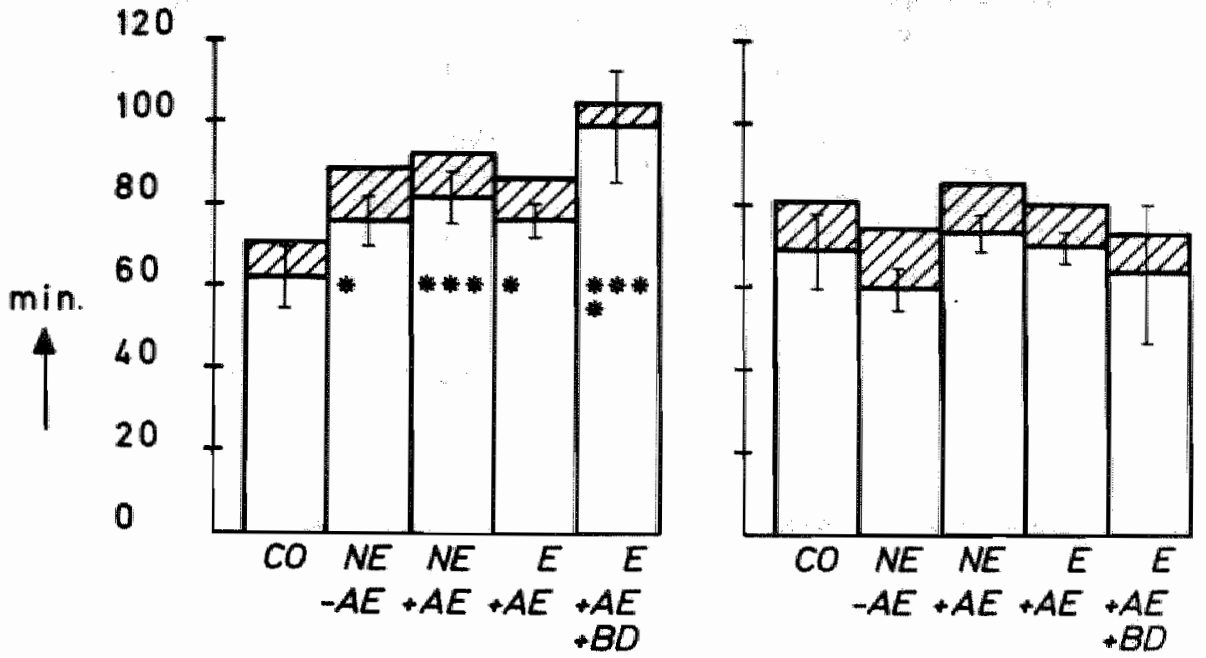

FIG. VII.21.

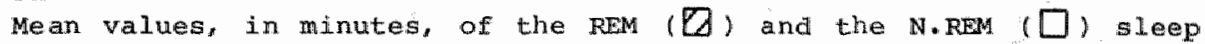
during the first and second sleep deprivation cycle of the control and the different cilmical categories.

$* \mathrm{p}<0.05 ; * * \mathrm{p}<0.01, * * * * \mathrm{p}<0.005$.

\section{FIRST CYCLE}

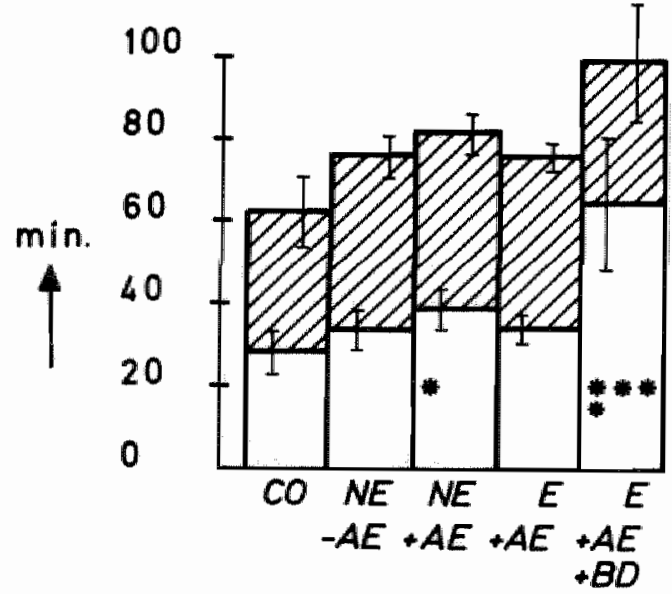

SECOND CYCLE

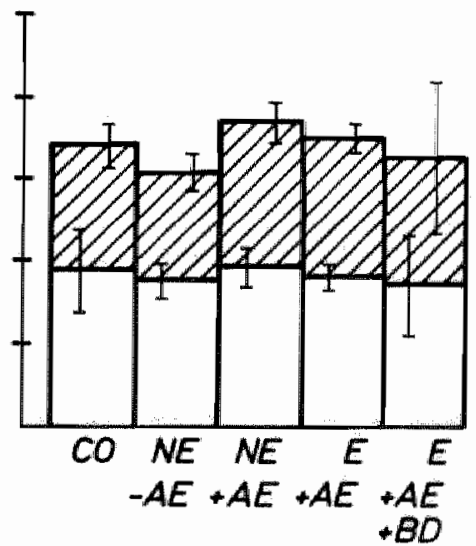

FIG. VII.22.

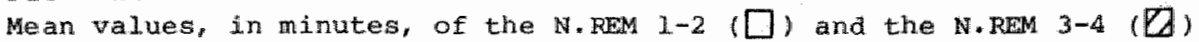
sleep during the first and second seep deprivation cycle of the control and the ajferent clinical categories (20-40 years).

* $\mathrm{P}<0.05 ; * * * 0.005$. 
7. Patiente have more 1. tep $1-2$ sleep during the first leep cycle. Thi diference is most pronounced for patients treated with the conbination of antieplieptics and benzodiazepine derivatives (p $<0.005$ ) and for patient without epileptic EEG abnormalities but which take antieplieptics $(\mathbb{P}<0.05)$. These differences are not found during the second leep cycle.

8. In all subjects there is more deep $N$. REM 3-4 sleep during the first cycle than during the second sleep cycle, but this increase is: not ignificant statistically. The duration of the N.REM 3-4 fleep is longex for both cyoles as compared to an all-night sleep recording (FIg. VI.19.).

9. Since the sleep cycles are shorter following sleep deprivation than during an all-night sleep recording, an increase in dieep N. REM 3-4 sleep has to result in a changed ratio N. REM 1-2/N. REM 3-4 sleep. The ratios for both sleep recording methods are depicted in Fig. VIr. 23.

\section{FIRST CYCLE}

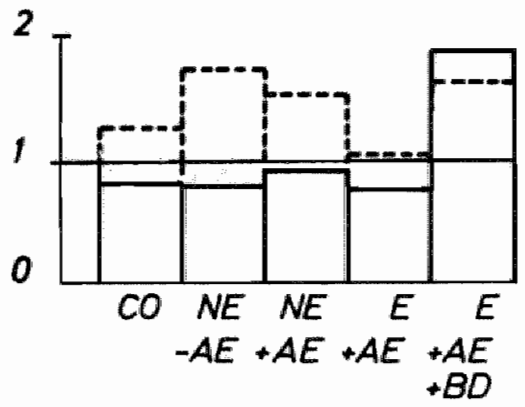

SECOND CYCLE

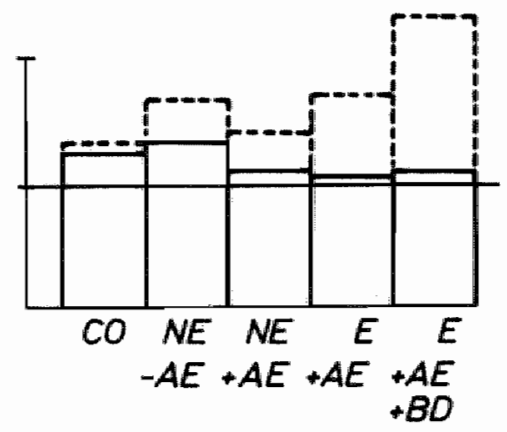

FIG. VII.23.

The N. REM $1-2 / \mathrm{N} \cdot$ REM $3-4$ ratio during the first and second sleep deprivation (__ ) and all-night (---) cycles of the control and the different clinical categories.

The ratio in all categories is smaller than 1 during the first sleep cycle and smaller than during the all-night sleep, except for the category treated with the combination of antiepileptics and benzodiazepine deriwtives. This is due to an increase in light as well as deep N. REM sleep, but mostly to an increase in N. REM 1-2 sleep. During the second sleep cycle the ratios are between 1.05 and 1.35 and are smaller for all categories than during the all-night sleep*

With the findings described above the questions posed at the beginning of this chapter can be answered as follows.

1. What is the composition of the first and second sleep cycle following sleep deptivation in epileptics?

There is a shortening of the cycle length. The sleep is less interrupted by awakening, whereby an effective sileep of more than 93 is reached during both sleep cycles. This increase is mainly 
based on an increase in the $\mathbb{N}$. RFM sleep. There $1 \mathrm{~s}$ a slight preponderance of deep N. REM 3-4 sleep auring the flrst cycle and a slight preponaerance of the light $N . \mathbb{R E M} 1-2$ sleep during the second cycle. These cycles thus differ from the all-night sleep recordings, where a preponderance of N.REM $1-2$ sleep is seen during both sleep cycles. During the first cycle this difference is very small for the categories which have epileptic beg abmormalities and which take only antiepileptics.

2 . Is the changed sleep composition dependent on the presence or absence of epileptic abnonmalities?

Both categories cannot be differentiated on the basis of this criterium, but they differ from their control groups by a significantly longer first sleep cycle, during which significantly more effective sleep occurs. These differences are not found during the second sleep cycle.

3. Is the sileep composition dependent on the type of epileptic EEG abnomalities?

Patients which do have EEG abnomalities fitting with elther generalized or partial epilepsy have relatively more deep N.REM 3-4 sleep than patlents which have combined form of epileptic EEG abnomalities. The latter group of patients have more light N. REM 1-2 sleep. This difference is also expressed in the ratio N.REM 1-2/N. REM 3-4 sleep, which is 0.69 for those having one type of epilepsy and 0.91 for those having a combined form of opllepsy. This ratio is 0.82 for the control group.

4. Is the sleep composition dependent on the intake of antiepileptics? subjects taking or not taking antiepileptics differ only silightly from each other during the first as well as during the second sleep cycle. This contrasts to the large differences found following an all-night sleep recording, where patients which do not take antiepileptics have a longer sleep cycle and have more a wa kenings.

5. Is the sleep composition changed when benzodiazepines are taken together with antiepileptics?

There is only a clear effect during the first sleep cycle, where a large increase in cycle length and a minimal time of wakefulness is observed. For the total age group there is a pronounced increase in light as well as deep N.REM sleep. In comparison with the control group patients belonging to the age group 20-40 years have two times as much N.REM $1-2$ sleep, though the amount of deep N. REM 3-4 sleep is comparable.

6. Are the changes age-dependent?

Patients younger than 20 years have more deep $\mathbb{N}$. REM $3-4$ sleep and less light $N$. REM $1-2$ and REM sleep. In all age groups there is more deep N. REM 3-4 sleep than N. RFM $1-2$ sleep and this is independent of the medication. The only exception are the children below 10 years treated with antieplieptics which have as much N. REM 1-2 sleep as N. REM 3-4 sleep.

Patients belonging to the age group 20-24 years and which do not take antiepileptics tend to have more 1 ight $N$. REM $1-2$ and lesa N. REM 3-4 sleep than the age group below 20 years. The benzodiazepine effect is also clear from this age on, where a large increase in M. REM 1-2 sleep is seen in combination with the sustained large anount of deep N.REM 3-4 sleep, as if the benzodiazepine effect is added to the sleep deprivation effect. 


\section{WAKEFULM SSS IATIERAS}

Th1s chaptex is aimed at fluding out whether the composition of the sleep following one night sleep deprivation depends on 1 . the type of antiepileptic medication taken, 2 . the type of the benzodiazepine derlvatives taken.

\section{VIII.1. MATERIALS AND METHODS}

From the patients of which an additional sleep deprivation investigation was carrled out during the pexiod 1979-1981 ( $\mathrm{n}=617$ ), Hollowing groups of patients were selected: those treated with either sodium valproate (Sod.V.) or carbamazepine (Carb.) or diphenylhydantoin (D.P.H.) or a combination of carbamazepine with sodium valproate or of carbamazepine with diphenylhydantoin or an antiepileptic in combination either with chlorazepate (A.E. + Chlor.), or clonazepam (A.E. + Clon.).

The investigation was limited to the sleep deprivation method, since it allowed to gather a sufficiently large number of patients to carry-out a rellable analysis. Further, patients with a multiple form of epilepsy were aiscarded since their sleep deprivation pattern diverged from the other clinical groups.

The final group consisted of 252 patients. Their partition per category of antleplleptic medication taken, further divided into sleep recordings with or without epileptic EEG abnormalities, and the mean age of these groups are given in Table VIII.I.

TABLE VIII. 1 .

Number and mean age of patients treated with different types of antiepileptic arugs or benzodiazepine derivatives.

\begin{tabular}{|r|l|l|l|l|l|l|c|}
\hline $\begin{array}{l}\text { Epileptic } \\
\text { patientg }\end{array}$ & Sod.V. & Carb. & D.P.H. & $\begin{array}{l}\text { Carb. } \\
\text { Sod.V. }\end{array}$ & $\begin{array}{l}\text { Carb. + } \\
\text { D.F.H. }\end{array}$ & $\begin{array}{l}\text { A.E. + } \\
\text { Chlo.. }\end{array}$ & $\begin{array}{l}\text { A.E. + } \\
\text { Clon. }\end{array}$ \\
\hline N.E. n & 19 & 32 & 11 & 11 & 13 & 4 & 6 \\
age & 21.2 & 27.9 & 31.5 & 18.8 & 24.5 & 18.4 & 25.2 \\
\hline n & 25 & 34 & 11 & 36 & 31 & 11 & 8 \\
& 17.7 & 23.2 & 23.2 & 20.9 & 31.0 & 20.9 & 23.3 \\
\hline
\end{tabular}

of the 252 patients, 123 (48.8 were between the age of 5 and 20 years, $113(44.8 \%$ ) were between the age of 21 to 40 years and 16 $(6.4$ ) were of the age between 41 to 60 years. A nearly equal number of sleep recordings with or without epileptic EEG phenomena were found in patients taking one antiepileptic. In patients treated with two antiepileptics, a substantial higher amount of sleep recordings with epileptic EEG phenomena were found. 
The dfferent parameters analyzed ane represented th Tables; 1 igniflcance of differences are indicated and in addition the ratio N. REN 1-2,N.REM 3-4 sleep is given, indicating the changes with the N.REM sleep.

VIII.2. RESULTS

2.1. Sleep composition in patients treated with sodium sleep cycle and in 39 also the second sleep cycle could be classitied properly. The sleep composition of both sleep cycles is represented in Table VIII.2.

TABLE VIII.2.

Composition of the first and second sleep cycle after one night sleep depxivation in patients only treated with sodium valproate.

\begin{tabular}{|c|c|c|c|c|c|c|c|}
\hline Sod.V. & $\begin{array}{c}\text { Total } \\
\text { cycle }\end{array}$ & $\begin{array}{c}\text { Time } \\
\text { awake }\end{array}$ & $\begin{array}{c}\text { Ef fective } \\
\text { sleep time }\end{array}$ & $\begin{array}{c}\text { N. REM } \\
1-2\end{array}$ & $\begin{array}{c}\text { N. REM } \\
3-4\end{array}$ & REM & $\begin{array}{c}\text { N. REM } \\
\frac{1-2}{3-4}\end{array}$ \\
\hline CY. 1 & & & & & & & \\
N.E. : 19 & 100.5 & 4.1 & 96.4 & 32.6 & 52.3 & 11.5 & 0.62 \\
E. :25 & 86.6 & 2.1 & 84.5 & 31.6 & $44.1 *$ & 8.8 & 0.72 \\
\hline Cy.2 & & & & & & & \\
N.E.:16 & 93.4 & 6.3 & 87.1 & 39.6 & 34.7 & 12.8 & 1.14 \\
E. :23 & 82.4 & 8.7 & 73.7 & 33.2 & 30.0 & 10.5 & 1.10 \\
\hline
\end{tabular}

* $\mathrm{p}<0.05$

Patients with epileptic EEG manifestations have a short sleep cycle, which is due to a decrease of all sleep stages. The difference is largest for the deep N. FEM $3-4$ sleep ( $p<0.05$ ) during the first sleep cycle, and during the second cycle less effective sleep accuxs.

For both groups the sleep deprlvation effect is visible in both sleep cycles, which is apparent from a small N. REM $1-2 / N \cdot$ REM $3-4$ ratio, this in comparison with an all-night sleep recording as well as compared to a sleep deprivation recording of the control group.

\subsection{The sleep composition In patients treated with carbamazepine \\ Except for a well-formed first sleep cycle, 55 of the 66} patients also have a complete second sleep cycle.

The composition of the first sleep cycle for both putient groups is nearly equal, polnting at a strong sleep deprivation affect, consisting of a preponderance of deep N. REM 3-4 sleep. Both groups have a longer lasting second sleep cycle due to more N.REM $1-2$ sleep. During the second sleep cycle, the sleep deprivation effect is still 
TREE VIII. 3 .

Composition of the first and second sleep cycle after one night sleep deprivation in patients only treated with carbamatepine.

\begin{tabular}{|c|c|c|c|c|c|c|c|}
\hline catb. n & $\begin{array}{l}\text { Total } \\
\text { cycle }\end{array}$ & $\begin{array}{l}\text { Time } \\
\text { awake }\end{array}$ & $\begin{array}{l}\text { Effective } \\
\text { slleep time }\end{array}$ & $\begin{array}{c}\text { W. REM } \\
1-2\end{array}$ & $\begin{array}{c}\mathrm{N}, \mathrm{EEM} \\
3-4\end{array}$ & REM & $\begin{array}{c}\text { N. REM } \\
\frac{1-2}{3-4}\end{array}$ \\
\hline $\mathrm{Cy} y * 1$ & & & & & & & \\
\hline W.E.: 32 & 31.9 & 2.0 & 79.9 & 24.8 & 44.5 & 20.6 & 0.56 \\
\hline E. $: 34$ & 78.8 & 2.9 & 75.9 & $21 \cdot 4$ & 43.2 & $1 x \cdot 3$ & 0.49 \\
\hline $\mathrm{Cy} \cdot 2$ & & & & & & & \\
\hline M.E.: $: 28$ & 93.9 & 5.7 & 88.2 & 39.4 & 33.1 & 15.7 & 1.19 \\
\hline E. $: 27$ & $84 \cdot 4$ & 2.8 & 81.6 & 33.1 & 39.1 & 9.4 & 0.85 \\
\hline
\end{tabular}

present in the group with epileptic EEG manifestations, as is apparent from the ratio N.REM 1-2/N.REM 3-4 sleep, which is 0.85 as compared to 1.28 in the control group.

\subsection{The sleep composition in patients treated with dipheny - hydantoln \\ This group consisted only of 22 patients, of which an} equal number with and without epileptic EEG abnomalities in their sleep recording were found.

TABU VIII. 4.

Composition of the first and second sleep cycle after one night sleep deprivation in patients only treated with diphenylhydantoin.

\begin{tabular}{|c|c|c|c|c|c|c|c|}
\hline D.P.H. n & $\begin{array}{l}\text { Total } \\
\text { cycle }\end{array}$ & $\begin{array}{l}\text { Time } \\
\text { awake }\end{array}$ & $\begin{array}{l}\text { Effective } \\
\text { sleep time }\end{array}$ & $\begin{array}{c}N \cdot \text { FEM } \\
1-2\end{array}$ & $\begin{array}{c}N \cdot \text { FEM } \\
3-4\end{array}$ & REM & $\begin{array}{c}\text { N. REM } \\
\frac{1-2}{3-4}\end{array}$ \\
\hline $\begin{array}{l}\text { OY: } 1 \\
N \cdot \mathbb{E}^{-}: 11 \\
\mathbb{E}: 11\end{array}$ & $\begin{array}{l}96.9 \\
86.9\end{array}$ & $\begin{array}{l}9.0 \\
5.0\end{array}$ & $\begin{array}{l}87.9 \\
81.9\end{array}$ & $\begin{array}{l}48.4 \\
31.9\end{array}$ & $\begin{array}{l}35.6 \\
40.1\end{array}$ & $\begin{array}{l}3.9 \\
9.9\end{array}$ & $\begin{array}{l}1.36 \\
0.79\end{array}$ \\
\hline $\begin{array}{r}C Y \cdot 2 \\
\text { N.E.: }: 7 \\
\text { E. }: 7\end{array}$ & $\begin{array}{l}86.6 \\
90.0\end{array}$ & $\begin{array}{l}4.3 \\
9.4\end{array}$ & $\begin{array}{l}82.3 \\
80.6\end{array}$ & $\begin{array}{l}35.0 \\
36.4\end{array}$ & $\begin{array}{l}34.9 \\
34.3\end{array}$ & $\begin{array}{r}12.4 \\
9.9\end{array}$ & $\begin{array}{l}1.19 \\
1.06\end{array}$ \\
\hline
\end{tabular}

The composition of the first sleep cycle is different in both groups, because this sleep deprivation effect is not evident in patients whlch have no epileptic EEG phenomena. However, also in patlents which have epileptic EEG phenomena, the sleep deprivation 
effect is less pronounced than in patients treated wh sodilum valproate or carbanazepine and is comparable to a sleep deprivation effect in non-patients.

The sleep composition during the second sleep cycle shows winor differences and is in accordance with the expectations following sleep deprivation.

\subsection{Sleep composition in patients treated with carbamazepine and sodium walproate \\ A total of 47 epileptics were treated with a combination} of carbamazepine and sodium valproate and in 36 of these epileptic EEG abnormalities were found in their sleep recordings, but none in 11 of them. Their sleep composition is shown in Table VIII. 5.

TABLE VIII. 5.

Composition of the first and second cycle of one night sleep deprivation in patients treated with carbamazepine and sodium valproate.

\begin{tabular}{|c|c|c|c|c|c|c|c|}
\hline $\begin{array}{l}\text { Carb.t } \mathrm{n} \\
\text { Sod.V. }\end{array}$ & $\begin{array}{c}\text { Total } \\
\text { cycle }\end{array}$ & $\begin{array}{c}\text { Time } \\
\text { awake }\end{array}$ & $\begin{array}{c}\text { Ef fective } \\
\text { sleep time }\end{array}$ & $\begin{array}{c}\text { N. REM } \\
1-2\end{array}$ & $\begin{array}{c}\text { N. REM } \\
3-4\end{array}$ & REM & $\begin{array}{c}\text { N. REM } \\
\frac{1-2}{3-4}\end{array}$ \\
\hline CY.1 & & & & & & & \\
N.E.:11 & 89.4 & 1.0 & 88.4 & 23.9 & 54.2 & 10.3 & 0.44 \\
E. $: 36$ & 86.0 & 1.8 & 84.2 & 22.6 & 49.1 & 12.5 & 0.46 \\
\hline CY.2 & & & & & & & \\
N.E.:11 & 83.6 & 1.0 & 82.6 & 26.7 & 41.3 & 14.6 & 0.65 \\
E. $: 35$ & 86.7 & 3.0 & 83.7 & 30.8 & 38.2 & 14.7 & 0.80 \\
\hline
\end{tabular}

For both sleep cycles there are no significant differences between the two clinical groups. There is a preponderance of deep M. REM sleep which is apparent from the ratio N.REM 1-2/N. REM 3-4 sleep: for both clinical groups this is respectively 0.44 and 0.46 during the first sleep cycle (in the control. group this ratio is 0.82 ) and during the second sleep cycle the ratio is respectively 0.65 and 0.80 (in the control group the ratio is 1.28 ). This polints at a frong sleep deprivation effect persisting during the second sleep cycle. In addition, the very few time spent awake is striking.

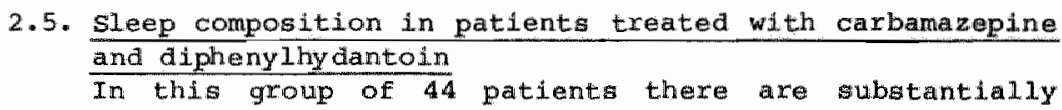
more sleep recordings with than without epileptic EEG phenomena. As is apparent from Table VIII.6. there are some differences in the mean sleep composition.

The group with epileptic EEG abnomalities has a shorter first sleep cycle due to less deep N.REM 3-4 sleep to a large extent neutralizing the expected sleep deprivation effect. The latter 
VII.G.

Composition of the first and second cycle after one night sleep deprivation in patients txeated with carbamazepine and diphenylhydantoin.

\begin{tabular}{|c|c|c|c|c|c|c|c|}
\hline $\begin{array}{l}\text { Canb.t n } \\
\text { D.P.H. }\end{array}$ & $\begin{array}{l}\text { Total } \\
\text { cycle }\end{array}$ & $\begin{array}{l}\text { Time } \\
\text { awake }\end{array}$ & $\begin{array}{l}\text { Effective } \\
\text { sleep time }\end{array}$ & $\begin{array}{c}\text { N. REM } \\
1-2\end{array}$ & $\begin{array}{c}\text { N. REM } \\
3-4\end{array}$ & REM & $\begin{array}{l}\text { N. FEM } \\
\frac{1-2}{3-4}\end{array}$ \\
\hline $\begin{array}{l}\mathrm{Cy} \cdot 1 \\
\mathrm{~W} \cdot \mathrm{E} \cdot: 1 \mathrm{3} \\
\mathrm{E} \cdot: 31\end{array}$ & $\begin{array}{r}102.3 \\
88.6\end{array}$ & $\begin{array}{l}3.9 \\
4.7\end{array}$ & $\begin{array}{l}98.5 \\
83.9\end{array}$ & $\begin{array}{l}38.2 \\
37.3\end{array}$ & $\begin{array}{l}49.5 \\
37.2\end{array}$ & $\begin{array}{r}10.7 \\
9.4\end{array}$ & $\begin{array}{l}0.77 \\
1.0\end{array}$ \\
\hline $\begin{aligned} \mathrm{CY} \cdot 2 & \\
\text { W.E. } & : 10 \\
\text { E. } & : 26\end{aligned}$ & $\begin{array}{l}92.7 \\
87.1\end{array}$ & $\begin{array}{l}3.4 \\
5.9\end{array}$ & $\begin{array}{l}89.3 \\
81.2\end{array}$ & $\begin{array}{l}41.6 \\
37.9\end{array}$ & $\begin{array}{l}35.4 \\
31.4\end{array}$ & $\begin{array}{l}12.3 \\
11.9\end{array}$ & $\begin{array}{l}1.17 \\
1.21\end{array}$ \\
\hline
\end{tabular}

effect still exists for the group without epileptic EEG phenomena and 1s comparable to the control group.

The composition of the second sleep cycle is comparable for both groups and inilar to the control group.

2.6. Composition of the first sleep deprivation cycle and its dependence of antiepileptic medication

From Tables VIIT.2. to 6 it appears that the differences in composition of the sleep of the vaxious clinical groups show the largest differences during the first sleep cycle independently af whether they have or do not have epileptic EEG abnoimalities in their recordings. In order to have a better survey, the values of the different sleep parameters for all clinical groups in comparison with the control group are summarized in Tables VIII.7. and VIII.8.

The longest sleep cycle, the most effective sleep and the highest amount of deep N. REM 3-4 sleep are found in patients treated with either sodium valproate $(\mathrm{p}<0.01$ to $\mathrm{p}<0.05)$ or carbamazepine in combination with diphenylhydantoin $(\mathrm{p}<0.05)$.

A strikingly different pattern is seen in patients treated only wth diphenylhydantoln since these have significantly more N. REM $1-2$ sloep $(p<0.05)$.

The differences in the composition of the sleep as compared to the control group in patients which have epileptic EEG abnomalities are relatively smal1. There 1.s, however, a tendency to awake less and to have more effective sleep, especilally in patients taking carbamazepine in conjunction with sodium valpraate. The latter drug combination also resulted in a significantely higher amount of $\mathbb{N}$. REM $3-4$ sleep $(\mathbf{p}<0.05)$. 
TABCE VIII.7.

Composition of the first cycle after one night sleep deprivation of sleep patterns thout epileptic EEG phenomena in patients treated with one or two antiepileptic drugs.

\begin{tabular}{|c|c|c|c|c|c|c|c|c|}
\hline $\begin{array}{l}\text { Crole } 1 \\
\mathrm{~N} . \mathrm{E}\end{array}$ & $n$ & $\begin{array}{l}\text { gotal } \\
\text { cycle }\end{array}$ & $\begin{array}{l}\text { Time } \\
\text { awake }\end{array}$ & $\begin{array}{l}\text { Effective } \\
\text { sleep time }\end{array}$ & $\begin{array}{c}\text { N. REM } \\
1-2\end{array}$ & $\begin{array}{c}\text { N. FEN } \\
3-4\end{array}$ & REDHA & $\begin{array}{c}N \cdot \text { REM } \\
\frac{1-2}{3-4}\end{array}$ \\
\hline $\mathrm{CO}$ & 15 & 77.1 & 5.1 & 72.0 & 28.5 & 34.8 & 8.7 & 0.82 \\
\hline sod.V. I & 19 & $100.5 * * *$ & 4.1 & 96.4 & 32.6 & $52 \cdot 3 *$ & 11.5 & 0.62 \\
\hline Carb. 3 & 32 & 81.9 & 2.0 & 79.9 & 24.8 & 44.5 & 10.6 & 0.56 \\
\hline D.P.H. I & 11 & 96.9 & 9.0 & 87.9 & $48.4 *$ & 35.6 & 3.9 & 1.36 \\
\hline $\begin{array}{l}\text { Carb.t } \\
\text { sad.v. } 1\end{array}$ & 11 & 89.4 & 1.0 & 88.4 & 23.9 & $54 \cdot 2 *$ & 10.3 & 0.4 .4 \\
\hline $\begin{array}{l}\text { Carb.t } \\
\text { D.P.H. } 1\end{array}$ & 13 & $102.3 *$ & 3.9 & $98.4^{*}$ & 38.2 & 49.5 & 30.7 & 0.77 \\
\hline
\end{tabular}

* $\mathrm{p}<0.05 ;$ *** $\mathrm{p}<0.01$

TABLE VIII.B.

Composition of the first cycle after one night sleep deprivation of sleep patterns with epileptic EEG phenomena in patients treated with one or two antiepileptic drugs.

\begin{tabular}{|c|c|c|c|c|c|c|c|}
\hline $\begin{array}{l}\text { Cycle } 1 \\
\text { E. n }\end{array}$ & $\begin{array}{l}\text { Total } \\
\text { cycle }\end{array}$ & $\begin{array}{l}\text { Time } \\
\text { awake }\end{array}$ & $\begin{array}{l}\text { Effective } \\
\text { sleep time }\end{array}$ & $\begin{array}{c}N \cdot \text { KEM } \\
1-2\end{array}$ & $\begin{array}{c}\text { N. REM } \\
3-4\end{array}$ & REM & $\begin{array}{c}N \cdot \mathrm{REN} \\
\frac{1-2}{3-4}\end{array}$ \\
\hline CO & 77.1 & 5.1 & 72.0 & 28.5 & 34.8 & 8.7 & 0.82 \\
\hline sod.W. $\quad 25$ & 86.6 & $2 \cdot 1$ & 84.5 & 31.6 & 4.4 .1 & 8.8 & 0.72 \\
\hline Cax $x$ b. $\quad 34$ & 78.8 & 2.9 & 75.9 & $21 * 4$ & 43.2 & $11 \cdot 3$ & 0.49 \\
\hline D.P.H. 11 & 86.9 & 5.0 & 81.9 & 31.9 & 40.1 & 9.9 & 0.79 \\
\hline $\begin{array}{l}\text { Carb.t } \\
\text { sod.v. } 36\end{array}$ & 86.0 & 1.8 & 84.2 & $22 \cdot 6$ & $49.1 \star$ & 12.5 & 0.46 \\
\hline $\begin{array}{l}\text { Carb.t } \\
\text { D.P.H. } 31\end{array}$ & 88.6 & 4.7 & 83.9 & 37.3 & 37.2 & 9.4 & 2.00 \\
\hline
\end{tabular}


2.7. Composition of the sleep in patients treated with anteplleptics in combination with chlorazepate or clonazepar In ordex to find out whether two different benzodiazepine dextutives affect sleep following sleep deprivation in a difrerential way, two groups of patient were studied: one group was treated with chlorazepate with a dally dose of 10-30 miglday, the other group was treated ith $1.5-4.5 \mathrm{mg} /$ day of clonazepam. The sleep composition. of the first and second sleep cycle of these groups is sumaxized in Table VTIT. 9 .

TABLE VIIT. 9 .

Coraposition of the fixst and second cycle after one night sleep deprivation in patients treated wh antiepileptic arugs in combination with chlorazepate (Chlor,) or clonazepam (Clon.).

\begin{tabular}{|l|c|c|c|c|c|c|c|}
\hline $\begin{array}{l}\text { Chlor. ox } \\
\text { Clon. }\end{array}$ & $\begin{array}{l}\text { Total } \\
\text { cycle }\end{array}$ & $\begin{array}{l}\text { Time } \\
\text { awake }\end{array}$ & $\begin{array}{l}\text { Effective } \\
\text { sleep time }\end{array}$ & $\begin{array}{c}\text { W. REM } \\
1-2\end{array}$ & $\begin{array}{c}\text { N. REM } \\
3-4\end{array}$ & REM & $\begin{array}{c}\text { N. REM } \\
1-2\end{array}$ \\
\hline CY.1. & & & & & & & \\
Chlor. 15 & 101.0 & 0.9 & 100.1 & 43.9 & 50.3 & 5.9 & 0.87 \\
Clon. 14 & 108.6 & 4.4 & 104.2 & 59.6 & 36.6 & 8.0 & 1.63 \\
\hline CY.2 & & & & & & & \\
Chlor. 13 & 87.7 & 0.7 & 87.0 & 31.3 & 43.9 & 11.8 & 0.71 \\
Clon. 8 & 79.8 & 3.3 & 76.5 & 32.0 & 36.4 & 8.1 & 0.88 \\
\hline
\end{tabular}

Both medication groups have a very lang first sleep cycle, which is due to an increase in the N.REM sleep. The increase in deep N. REM $3-4$ sleep 1 s larger than the increase in the $\mathbb{N}$. REM $1-2$ sleep in patients treated with chlorazepate, from which it can be derived that the deprivation effect is more pronounced than the benzodiazepine effect. In contrast, there is a strong increase in N. FEM 1-2 sleep in the patients treated with clonazepam, which points at an evident benzodiazepine effect. These effects are evident from the ratio N. REM $1-2 / N$. REM 3-4 sleep, which is 0.87 and 1.63 for patients treated respectively with chlorazepate and clonazepam as compared to 0.82 for the control group.

During the second cycle there is a predominant $N$. REM $3-4$ sleep in both medication groups, suggesting that the possible lack of sleep deprlvation effect during the first sleep cycle is compensated during the second sleep cycle. Finaliy, it is worth noting that both patient groups show few wakefulness auring both sleep cycles.

VIIT.3. DISCUSSION AND SUMMARY

In chapter VII it was shown that the sleep in eplieptics following one night sleep deprivation is changed, especialiy during the ixst slep cycle. In this chapter it was studied whether the effectis on the sleep are dependent on the type of antiepileptic medication taken. Therefore, the composition of the sleep fallowing one nigit sleep deprivation was studied in epileptics, which took only sodium 
valproate, carbamazepine or diphenylhydantoin or a combination of two of these antiepileptics, with the exclusion of other medicines.

Herein, different sleep parameters are depicted in block alagrams respectively for the patients with and without epileptic EEG abnormalities found in their sleep recordings as compared to the control group. Results obtained in patients taking eithex antieplleptics alone or in combination with chlorazepate or elonazepan are depicted.

Figure VIII.10. shows the mean values of the total sleep cycle, the amount of wakefulness and the amount of effective sleep obtained during the first sleep cycle for different medication groups.
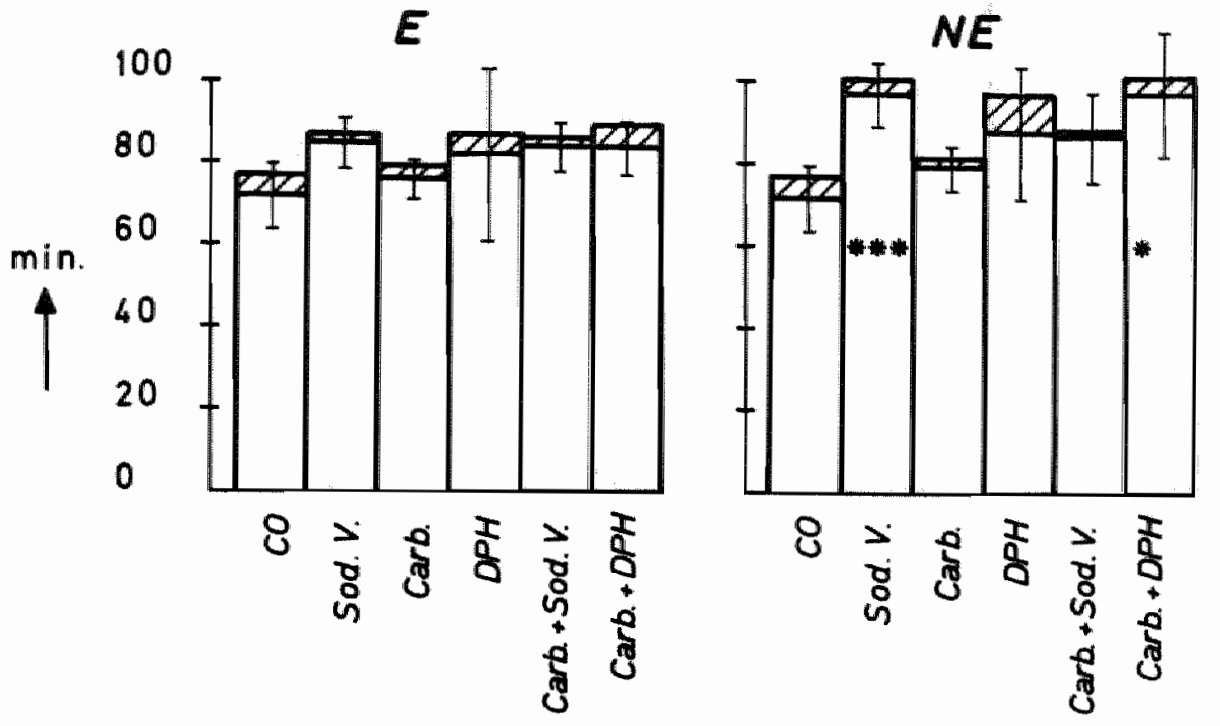

FIG. VIII.10*

Mean values, in minutes, of the total sleep time, the time awake (D), and the effective sleep time ( $\square)$ of the Eirst sleep deprivation cycle in patients with (E.) or without (N.E*) epileptic EEG phenomena treated with one or two different antiepileptic arugs.

* $\mathrm{p}<0.05 ; * * * \mathrm{p}<0.01$.

1. All patients have a longer first sleep cycle than the control group. This increase is smali for patients taking only caxbanazepine, but is important for thase taking sodium valproate or diphenylhydantoin or drug combinations, and more so for patients which do not have epileptic EEG abnormalities.

2. There is a higher amount of wakefulness only in patients which do not have epileptic EEG phenomena and which take diphenylhy antoin.

3. All patients have more effective sleep, but this is only algnificant $(p<0.01)$ fox patients which do not have eplleptic EEG abnormalities and which are treated with sodium valproate.

4. The percentage effective sleep is higher than the 93 of the control group, except for patients which do not have eplieptio EEG phenomena and which re treated with aiphenylhydartoin. This result is suminarized in Fig. VIII.11. 

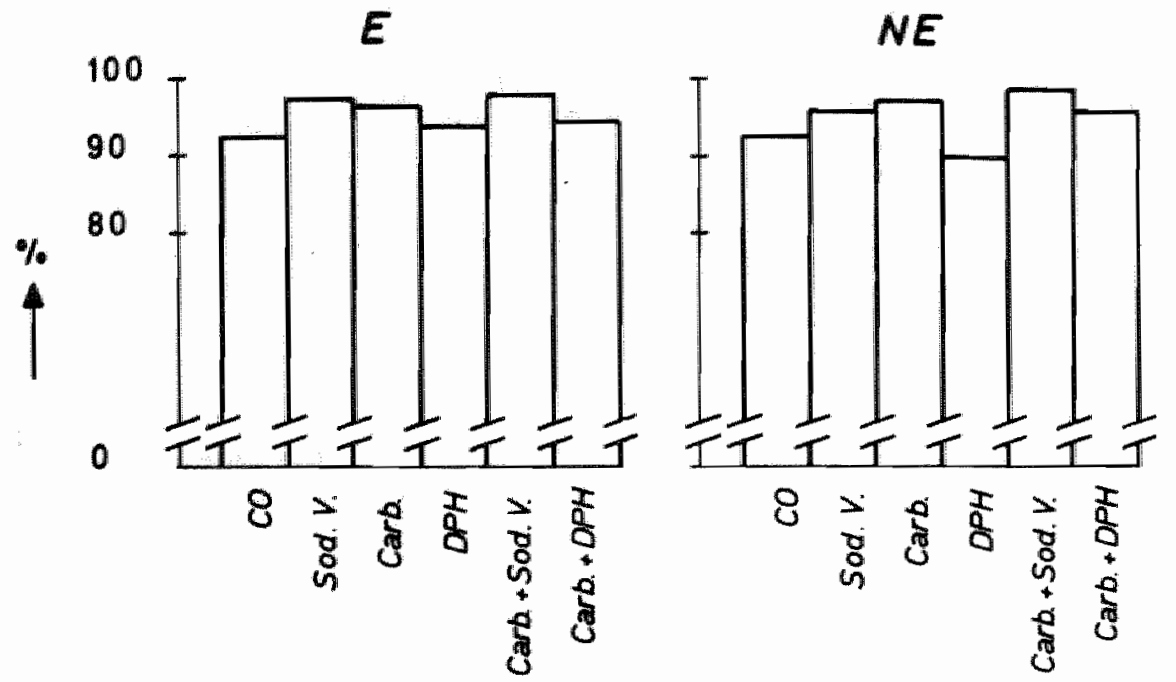

FIG. VIII.11.

Percentage of the effective slep time in the first sleep deprivation cycle of patients with (E.) or without (N.E.) eplleptic EEG paroxysms treated with different antiepuleptic drugs.

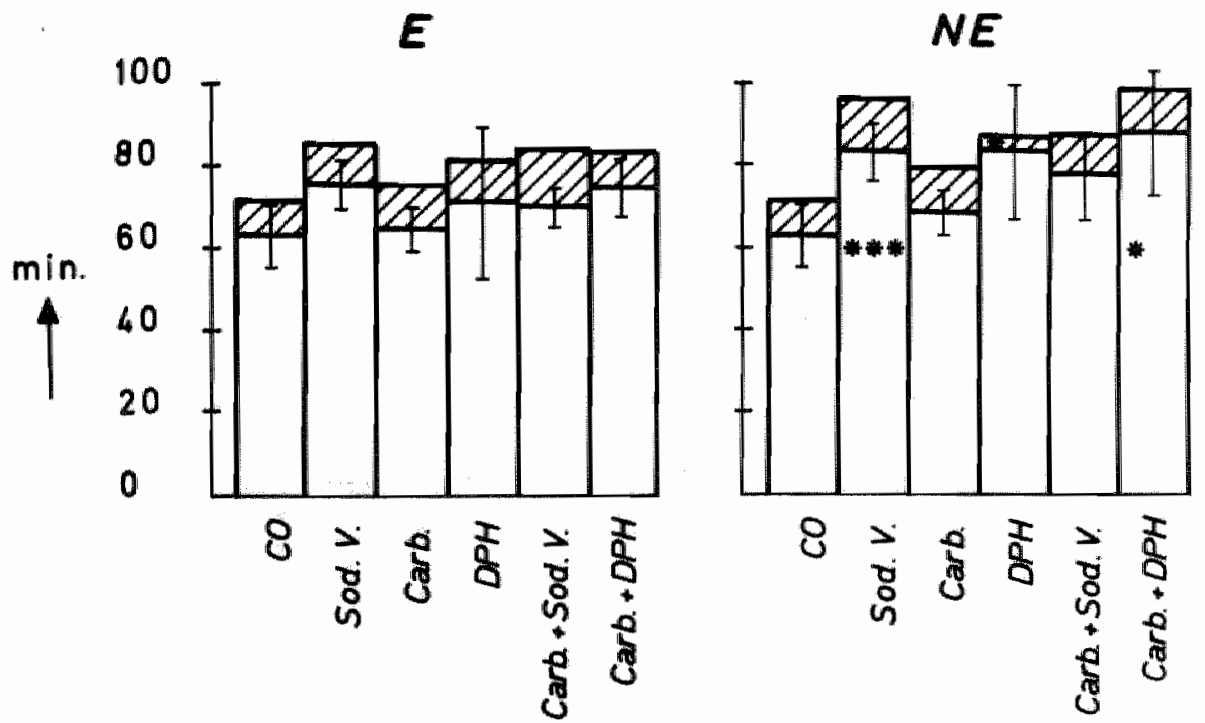

FIG. VIII.L2,

Mean values, in minutes, of the REM ( $Q$ ) and the N.REM ( $\square$ ) sleep during the first sleep deprivation cycle of patients treated with alfferent types of antiepileptic arugs.

$* \mathrm{p}<0.05, * * * \mathrm{p}<0.01$. 


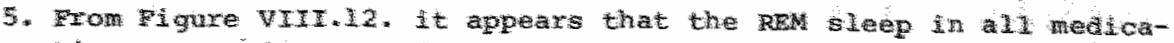

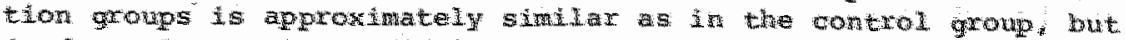

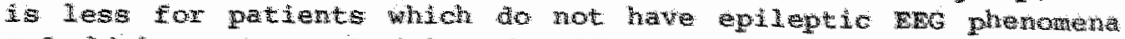

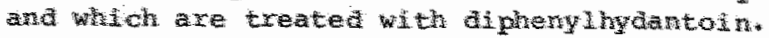

6. Whe W. The sleep tends to be higher in all patient categortes but

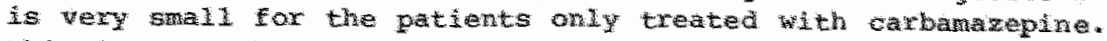
This increase is largest for patients inch do not have epileptic TEG phenonena.

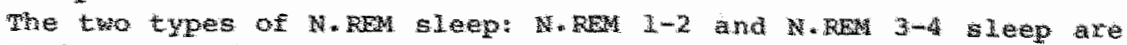

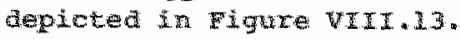

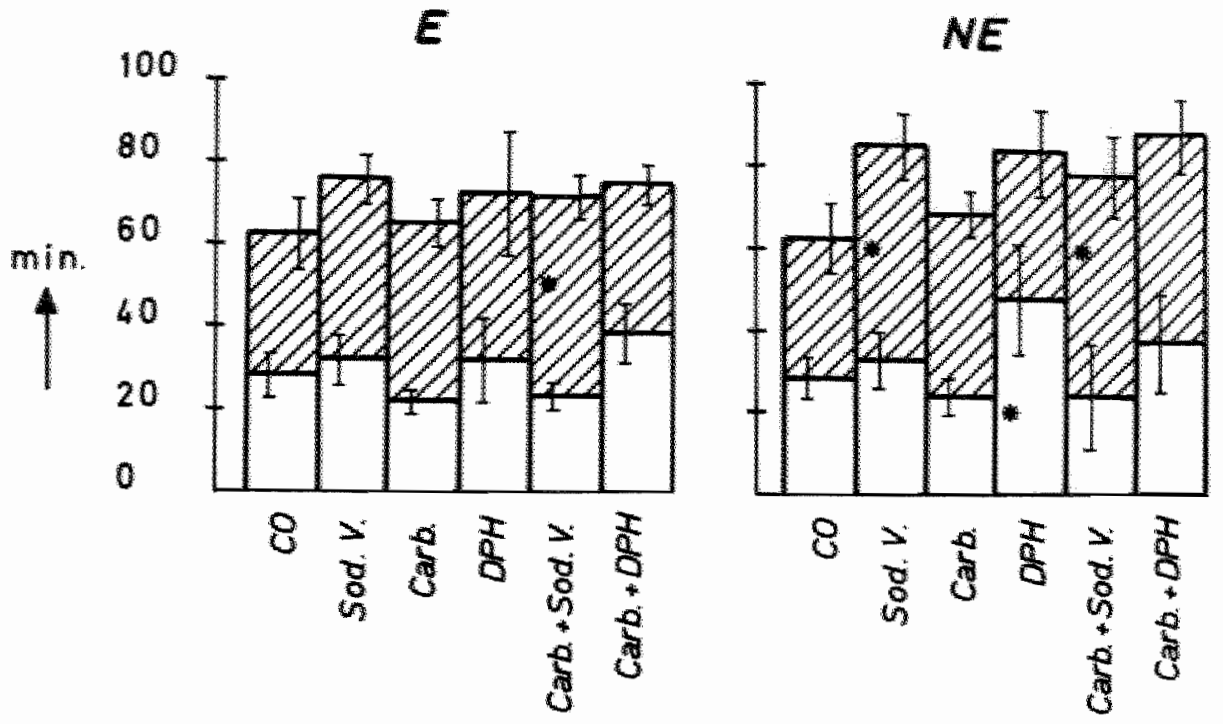

FTG. WIIIIS.

Mean values, in minutes of the $N$. RE $1-2$ (D) and the RaM $^{3-4}$ (D) sieep during the first sleep deprivation cyole of patients treated wh three different types of antieplieptic arugs.

* $p<0,05$.

7. Patients treated with carbamazepine either alone or in conjunetion with sodium valproate have less light $\mathbb{N}$. REM $1-2$ sleep. In contrast, those treated with diphenylhydantoln either alone or in conjunction with carbamazepine have more N. REM $1-2$ sleep.

8. Patients only taking sodium valproate or carbamazepline hive nore deep N.REM 3-4 sleep, an increase which becomes significant $(\mathrm{p}<0.05)$, when both medicines are taken. Such a tendency is also present in patients which do not have eplleptic EBG phenomena and which are treated with the combination of diphenylhydantoin with carbamazepine.

9. The effects caused by different medicines are best expressed by the ratio N.REM 1-2/N. RWM 3-4 sleep (Figure WII.14.). From this, a relatively strong increase in $\mathbb{N}$. REM $3-4$ sleep is more clear in 
patients only treated with carbamazepine $(0.49)$ or carbamazepine in combination with sodiun valproate $(0.46)$. Such an effect is also pregent in patients taking sodium walproate $(0.72)$, but is negligible for those patients which do have epileptic EEG pheromena in their EEG and are treated with diphenylhydantoin, but not for patlents which do not have eplleptic EEG phenomena.
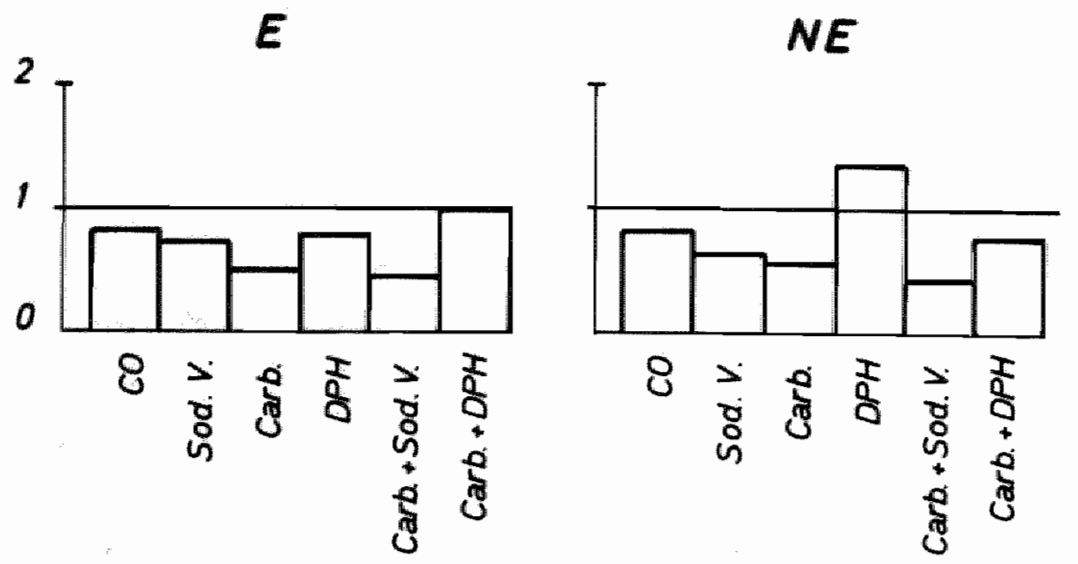

FIG. VIII.14.

N. RIEM 1-2/N. FEM 3-4 ratio of the first deprivation sleep cycle for 3 different types of antiepileptic arugs (sodium valproate, carbamazepine and diphenylhydantoin).

10. There is a significant increase in the length of the total first sleep cycle, containing more effective sleep $(\mathrm{p}<0.025)$ and more N. REM sleep $(p<0.01)$, in patients treated with the benzodiazepines chlorazepate or clonazepam in conjunction with antiepileptics. For chlorazepate, this is based on an increase in both N. REM $1-2$ and N.REM 3-4 sleep, whereas for clonazepam this is exclusively based on a significant increase of the $\mathbb{N}$. REH $1-2$ sleep $(p<0.025)$. These data are sumarized in Figure VIII.15. 


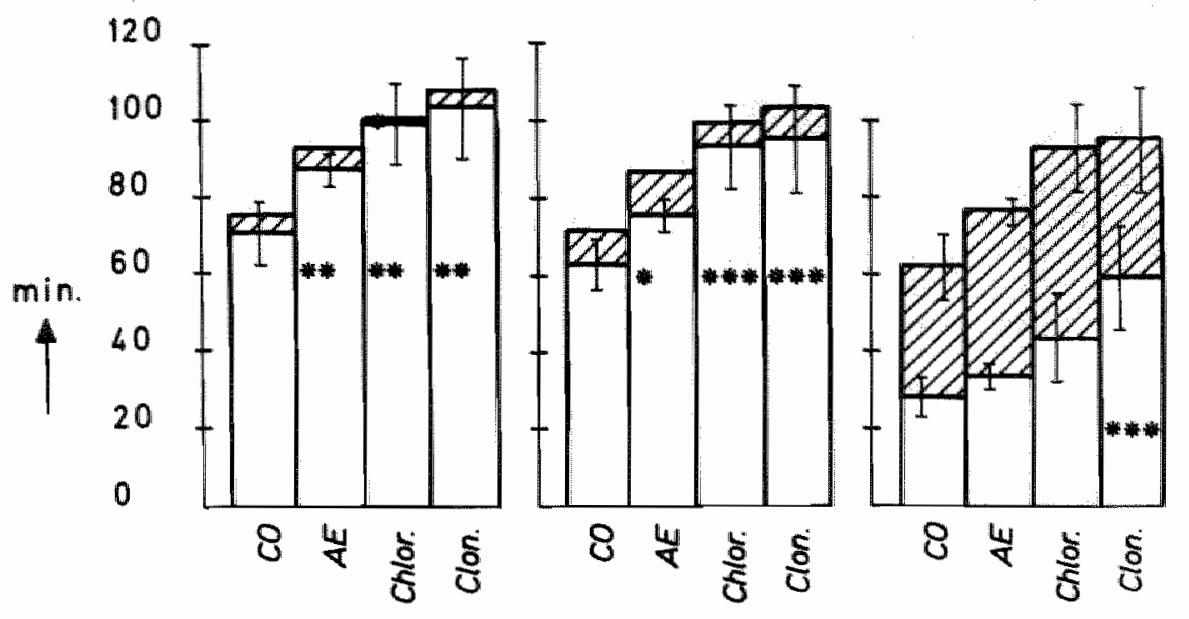

FIG. VIII.15. (a, b, c)

The mean values, in minutes, of the total cycle, divided in time awake ( $D$ ) and effective sleep time ( $\square$ ) (a), of the effective sieep time aivided $1 \mathrm{n}$ RFM (DJ) and N.REM sleep (D) (b) and the N. Fa sleep divided in N.REM 1-2 (口) and N.REM 3-4 (C) sleep in patients treated with antiepileptic drugs, or in combination with or without chlorazepate or clonazepam $(c)$.

* $\mathrm{p}<0.05 ; * \mathrm{p}<0.025 ; * * * 0.01$.

On the basis of these data it can be stated that the composition of the sleep following sleep deprivation differs depending on the kind of antiepileptic taken.

1. Carbamazepine gives rise to a strong change in the ratio $\mathrm{N}$. REM I-2/ M. REM 3-4 sleep by increasing deep sleep $(0.49)$.

2. Sodium valproate increases the length of the first seap cycle which is due to ar increase in effective and $N$. REM sieep with a relatively larger increase in the deep N.REM 3-4 sleep (0.72).

3. Previous effects are mare pronounced when both products are taken (0.46). This effect is fuxther evident also during the second Sleep cycile $(0.85)$.

4. As a result of the treatmentw wth dipherylhydantoin, the cycle length increases which is caused by more W. REM slep. The mount of light and deep W. KFM sleep in patiente which have epileptic EEG abnormalities is comparable, but in patlents which a not have epileptic EEG abnomalities, there is an increase of N. FEM $1-2$ sieep, such that the ratio N.REM $1-2 / \mathrm{N} . \mathrm{RFM} 3-4$ weep amounts up to 1.36 .

5. Even in combination with carbamazepine, the efiect obtalned with dipherylhydantain remins predominant.

6. The degree of the benzodizepine effects on sleep following wlep deprivation is even in combination with antiepileptics dependent on the type of medication taken. This aifference 1 s especially expressed in the way by which they influence the N. RMM sleep, whether only by increasing N.REM $1-2$ sleep (clonazepam), or by increasing light as weld as deep N.REM sleep (chlorazepate). 
In previous chapters it was shown to which degree the electroencephalographic diagnosis of epllepsy increased during sleep and how the composition of the sleep changed in function of the occurrence of EEG epileptic phenomena and the medication taken. Apart from the quantitative mutual interactions, qualitative interactions occur.

IX.1. MOREHOLOGTCAL CHANGES OF THE EPILEPTIC EEG PHENOMENA OCCURAING DURTNG SLEEP FOLLOWING SLEEP DEPRIVATION

It is known that the typical $3 /$ sec splike wave paroxysms (SW; Figure IX.1.) recorded during wakefulness tend to develop to polyspike wave complexes (PSW; EIgure IX.2.) during N.REM $1-2$ sleep and to Low Erequency spike waves (LSW; Figuxe IX.3.) during deep N. REM 3-4 sleep. During N.REM $1-2$ sleep the changes are often associated with an 1ncrease in number, and a decrease in the duration of the gereralized spike wave paroxysms. During the N.REM 3-4 sleep these changes are associated with an interxuption of long-lasting paroxysms, by which they obtain pseudorhythic aspect.
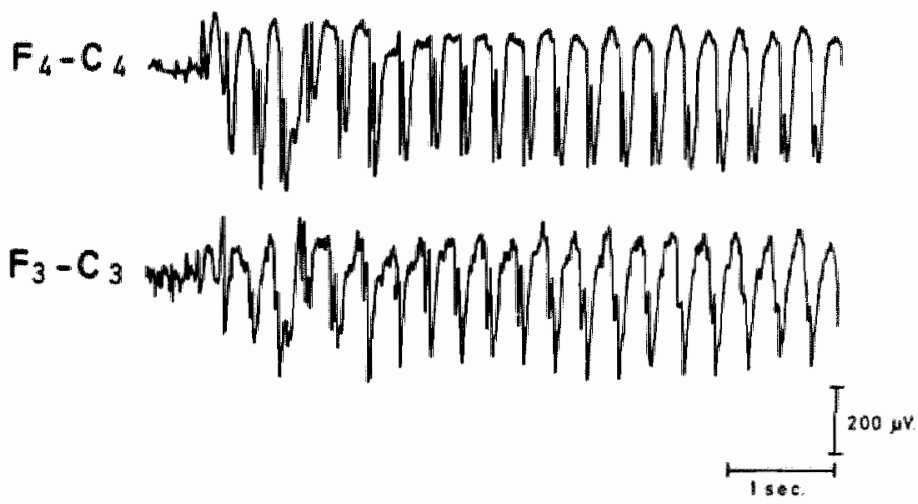

FIG . IX.1.

Example of typical spike wave complexes (sw).

In order to ascertain whethex these changles also occur duxing sleep following sleep deprivation, we studied three groups of 100 patients each, all of which had generalized spike wave paroxysms during their awake routine EEG recording. The three groups of patients alffered from each othex because the spike wave complexes consisted of either regular $3 / 5 e c$ spike waves, polyspike waves (at least 2 or more spikes per complex), or low frequency spike waves (equal to or lesis than $2.5 \mathrm{c} / \mathrm{sec}$ ). For each of the three groups the degree and 


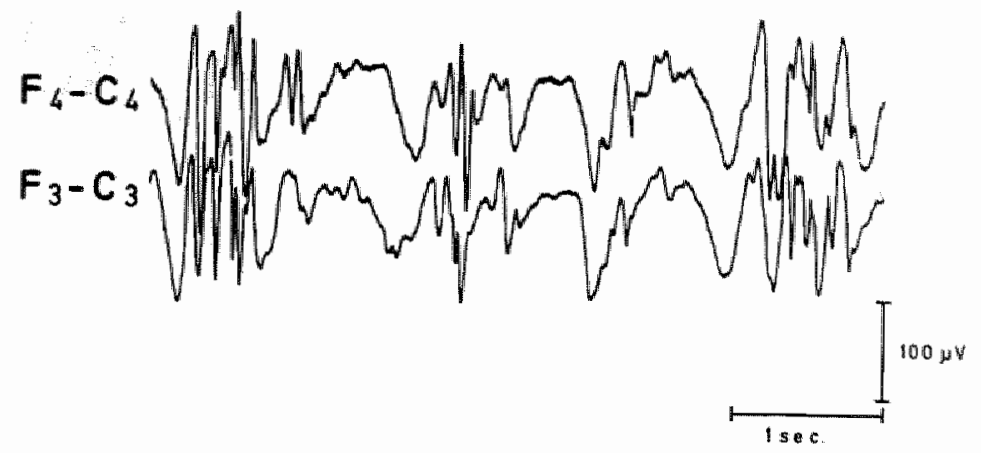

FIG. $I X+2$.

Example of polyspike wave complexes (PSW).

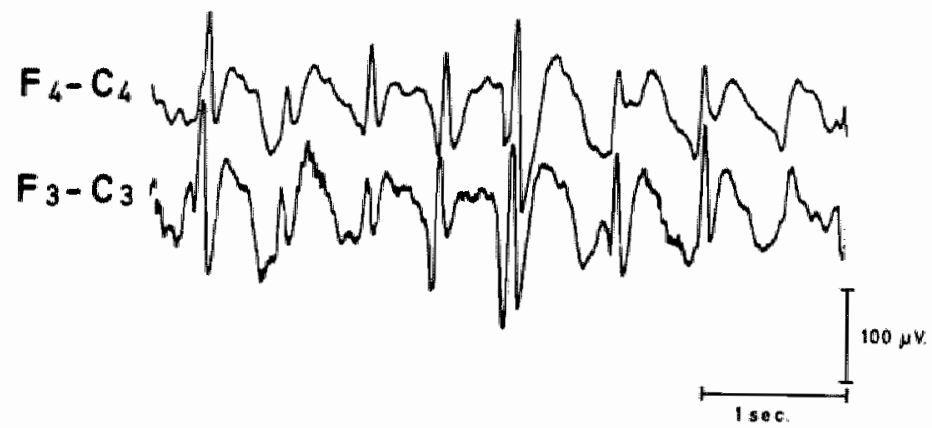

FIG. $I X \cdot 3$.

Example of low frequent spike wave complexes (LSW).

form of spike wave complexes were determined during N.REM $1-2$ and N. REM 3-4 silep following sleep deprivation. REM sleep was not considered in this investigation since the spike wave paroxysms dia not occur in the majority of the patients or because the romphology of: the spike wave paroxysmis was similar as that seen during wakefulneso. The results of this investigation for the three groups of patients are represented in Table IX.4.

In the group which had typlcal sw paroxysms, respectively 96 and 76 had also spike wave paroxysms during light N. REM $1-2$ sleep and deep N. REM 3-4 sleep. Most sW complexes retain their form (48 or tend to develop to a PSW farm (34) during W. REM 1.2 sleep. During N. REM 3-4 sleep $1 / 5$ (21 b) of sW paroxysms developed to asw form, $1 / 3(36$ ) developed to a $\mathrm{LSW}$ form, but $1 / 4(248)$ are not seen. In the PSW gxoup a large percentage 162 and 44 i retained their polyspike wave aspect during the $N$. REM sleep "It is striking that approximately $1 / 5$ (21 and 17 developed to a typlcal sw form. 
TPACE IX.4.

percentage of typical splke wave (SW), polygike wave (PSW) and Low frequent spike we (Lsw) paxoxysms during the sleep stages $N$. REM 1-2 and $H$. Rem $3-4$ sleep after one njght sleep deprivation, and the registrations without eplleptic EEG manifestations (N.E*), in comparison with the routine awke $\mathrm{EEG}$.

\begin{tabular}{|c|c|c|c|c|c|c|c|c|c|}
\hline \multicolumn{2}{|c|}{$\begin{array}{c}\text { Eplieptic } \\
\text { EG paroxysms }\end{array}$} & \multirow{2}{*}{\multicolumn{2}{|c|}{$\frac{\operatorname{sw}}{3 \mathrm{c} / \mathrm{sec}}$}} & \multirow{2}{*}{\multicolumn{2}{|c|}{$\frac{2 \mathrm{PSW}}{\mathrm{N} \cdot \mathrm{REM}}$}} & \multirow{2}{*}{\multicolumn{2}{|c|}{$\frac{\begin{array}{c}\mathrm{LSW} \\
\leqslant 2.5 \mathrm{c} / \mathrm{sec}\end{array}}{\mathrm{N} \text { REM }}$}} & \multirow{2}{*}{\multicolumn{2}{|c|}{$\frac{\text { N.E. }}{\text { N. REM }}$}} \\
\hline \multirow[t]{2}{*}{ Awake } & \multirow[t]{2}{*}{$\mathrm{n}$} & & & & & & & & \\
\hline & & $1-2$ & $3-4$ & $1-2$ & $3-4$ & $1-2$ & $3-4$ & $1-2$ & $3-4$ \\
\hline $8 W$ & 100 & 48 & 19 & 34 & 21 & 114 & 36 & 4 & 24 \\
\hline PSW & 100 & 21 & 17 & 62 & 44 & 12 & 22 & 5 & 17 \\
\hline LSW & 100 & 9 & 7 & 5 & 3 & 72 & 58 & 14 & 32 \\
\hline
\end{tabular}

The ISW group is the most stable group, since in respectively 72 and 58 the LSW paroxysms continued to exist during N.REM $1-2$ and M. REM 3-4 sleep.

The pexcentage of patients which during $\mathbb{N}$. REM $1-2$ sleep following sleep deprivation do not show epileptic phenomena is small, but for the LSW paroxysms group it can increase to 32 during N.REM 3-4 sleep.

Thus, 1 t can be stated that most spike wave paroxysmis retain their form or develop to a polyspike aspect during N. REM 1-2 sleep. Very striking is the fact that $1 / 5$ of the polyspike waves take a more typical splke wave form during the sleep. This is often associated whth a strong shortening of the duration of the paroxysms, eventually restricted to 1 or 2 conplexes. The low frequency spike waves constitute the most stable group, although spike waves were not seen aryy more during deep sleep in $1 / 3$ of the patients. This spike wave form is often seen in subjects which have signs of diffuse organic brain damage, a disorder which apart from epilepsy nay also cause psychomotor retardation and disturbances of the sleep.

\section{IX.2. THE INFLUENCE OF" REM SLEEP EOLLOWTHG SLEEP DEPAIVATION ON EPI- LEPTIC EEG PHENOME NA}

During REM sleep (Chapter II), EEG abnormalities fitting with primary generalized epllepsy are suppressed, except the typical. $3 \mathrm{~g} / \mathrm{sec}$ spike waves and abnormalities fitting with partial epilepsy are botter localized than during the light N.REM 1-2 sleep. Because the amount of $\mathrm{FEM}$ sleep recorded in the foremon following one night sleep TSD does not differ substantialiy from the amount of REM sleep recorded during the first and second cycle of an all-night sleep recording (Chapter VII). It was checked whether the above hypothesis also accounted for the REM sleep following one night sleep deprivation.

Therefore, 100 sleep deprivation recordings of patients which have or were suspected of having primarily generalized epillepsy were investigated. In 83 of them generalized epileptic EEG phenomena were 
recorded during $N$. Rav sleep and in 13 also during REM sleep. of these 13 patients, 11 had EEG abnormalities consisting of typical $3 \mathrm{~b} / \mathrm{sec}$ spike waves, which in 8 cases clinically corresponded with an epllepsy of the absence type and 3 cases with an epilepsy of the tonicclonic type. In the two remaining patients, which also had a tonicclonic type of eplilepsy, the paroxysms consisted of LSW.

Further, 100 sleep deprivation recordings of patients which have or were suspected to have partial epilepsy were investigated. These had typical epileptic EEG abnomalities occurring auring N.REM $1-2$ sleep as well as during REM sleep. An example is represented in Figure IX.5.

The EEG abnormalities were more evident during N, REM $1-2$ sleep than during REM sleep in 29 patients. This was because they were seen over a larger brain area or because they occurred more frequent1y. In 22 patients the $\mathrm{EEG}$ abnormalities were localized in the left temporal region and in 6 in the right temporal region. The focus was better defined or the epileptic EEG abnomalities were better fonned during FEM sleep in 25 patients. In 22 patients the abnomalities were localized in the left temporal region and in 3 in the right temporal region.

From this limited evaluation it may be concluded that the REM sleep retained its characteristic influence on the eplleptic $\mathbb{E E G}$ abnomalities also during a sleep reconding following one night sleep deprivation.

\section{IX.3. POST ICTAL SLEEP PICTURES}

When a clinical fit occurs during sleep, the sleep can become irregular for a short period, however, often without a loss of cyclicity. In order to know to which degree a clinical seizure disturbs the sleep following one night sleep deprivation, it was investigated how many clinical seizures accurred during sleep following sleep depriwation in the 404 patients investigated during the period 1980 1981 (Table V.3.). Electroclinical seizures were recorded in 22 patients: 11 of the primarily generalized grand mal type, 6 of the secondarily generalized type, and 5 of the partial complex type. The time of occurrence was partitioned over the total sleep recording time. The earliest attack occurred $4 \mathrm{~min}$ after the start of the recording, the last occurred after $18.4 \mathrm{~min}$. They accurred 3 times during, wakefulness, 12 times duxing light $\mathrm{N}$.REM $1-2$ sleep, 5 times during N.REM 3-4 sleep and 2 times during feM sleep. The recording period after a seizure was divided into a postictal recovery perjod and a postictal sleep period. The recovery period is the period during which the EEG picture does not correspond to a $\mathbb{N}$. REM $I-4$ or REM sleep patterm, characterized by for instance the aboence of physiological sleep phenomena such as $K$-complexes, sharp vextex waves and spindles. An example of this is given in rigure IX.6.

The postictall sleep starts as soon as the EEG plcture can again be divided into light or deep N.REM or REM sleep. The duration of the recovery period as well as the characteristics of the postictal sleep are represented in Table IX.7.

of the 12 patients which had clinical seizures during N.REM 1-2 sleep, 7 belonged to the primarily generalized epllepsy type, and 4 


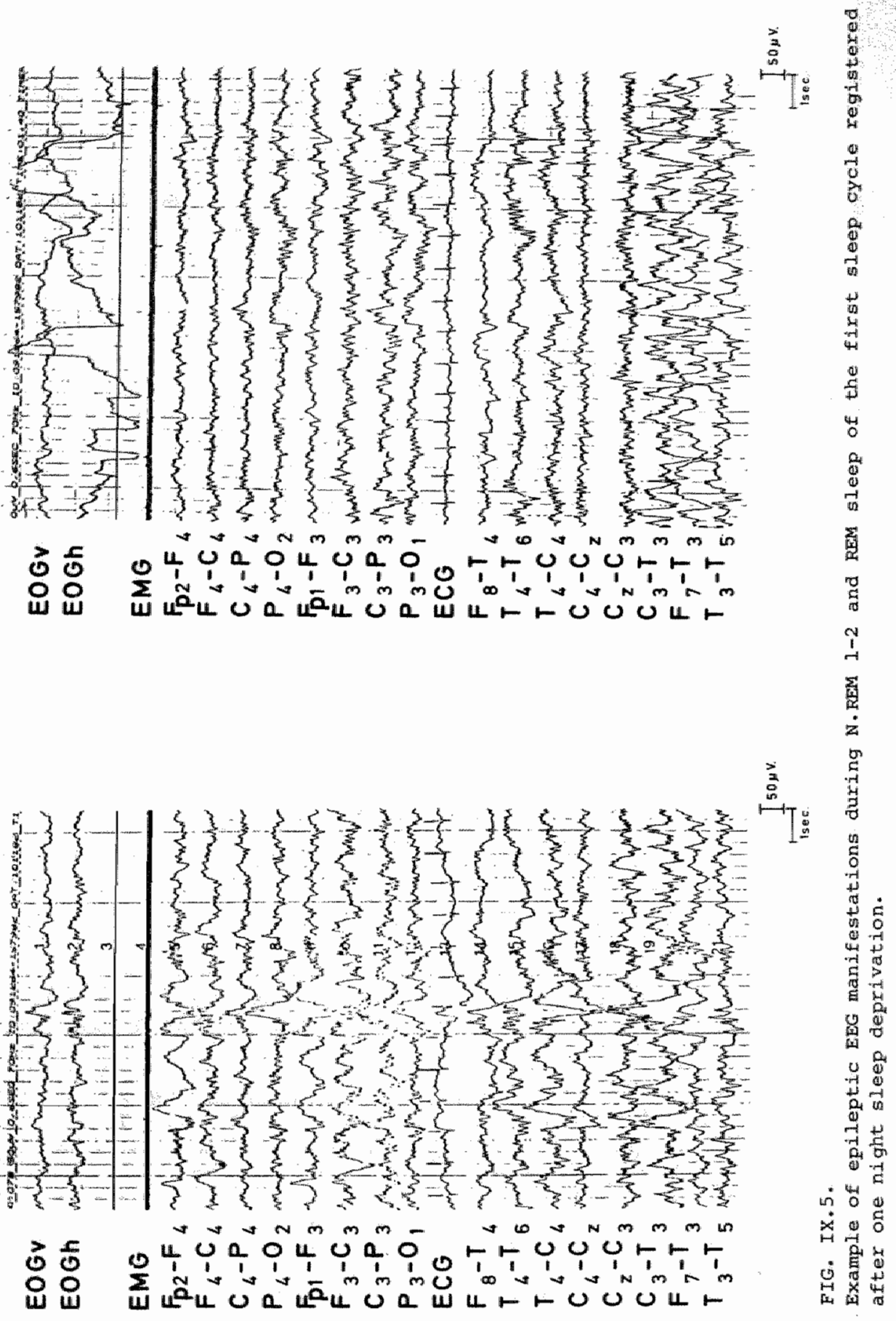



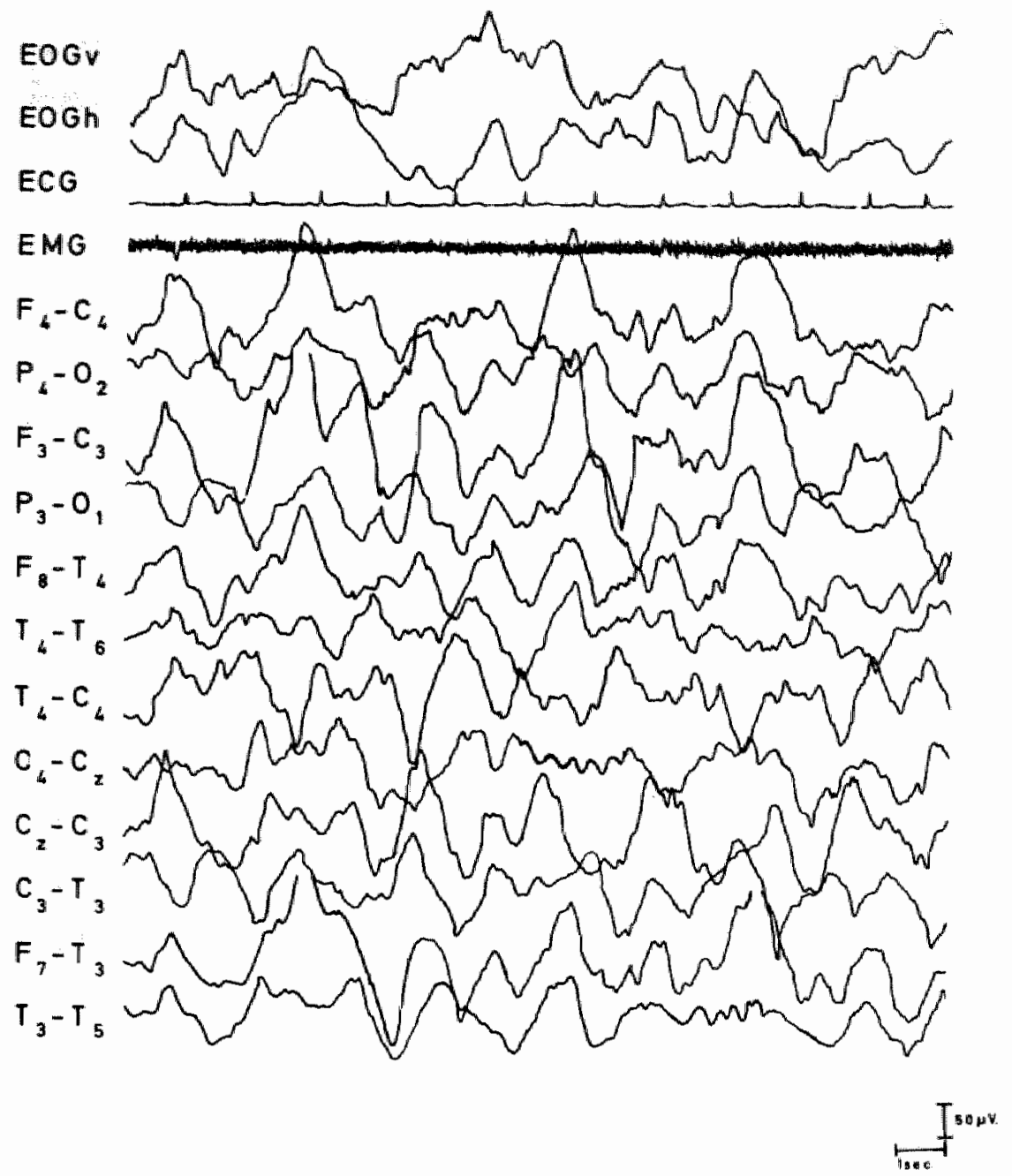

FIG. IX.6.

Example of a postictal period, two minutes after a generalized tonicclonic seizure;

to the paxtial complex type. The 4 cccurxing during N.REM 3-4 Bleep were all of the secondaxily generalized epliepsy type. The postictal recovery perjod lasted longer than 15 minutes in only 4 subjects. Following the postictal recovery period, in $11(50$ s) sleep continued as expected and in 8 only N. REM $1-2$ sleep was seen. Portictal aleep aiffered from pre-ictal sleep in 19 subjects, because of instability consisting of continuous transitions between the different stages of the slleep or because of long interruptions by arousal reaction ox by the occurrence of delta paroxysms. 


\begin{tabular}{|c|c|c|}
\hline 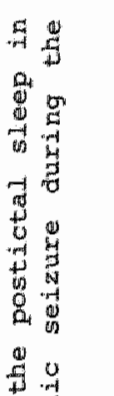 & 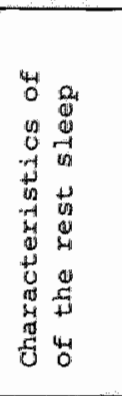 & 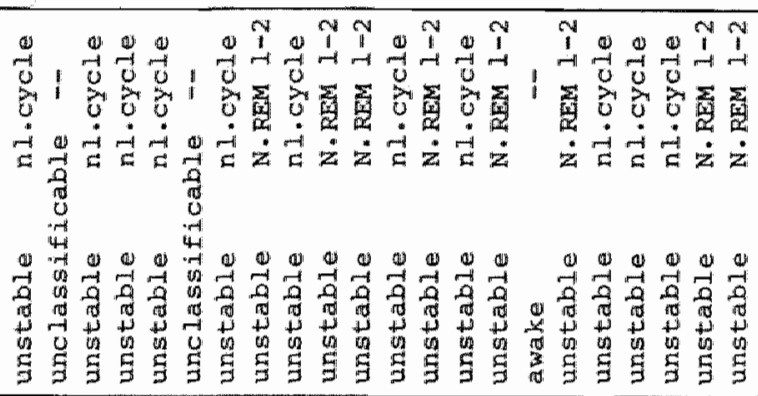 \\
\hline & 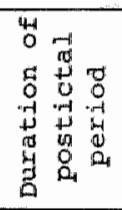 & 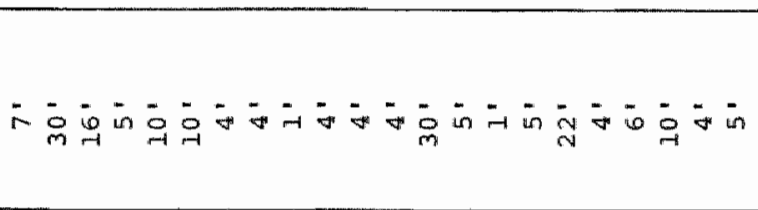 \\
\hline $\begin{array}{l}0.5 \\
0 \\
0.07 \\
0\end{array}$ & 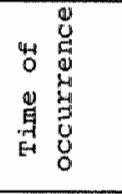 & 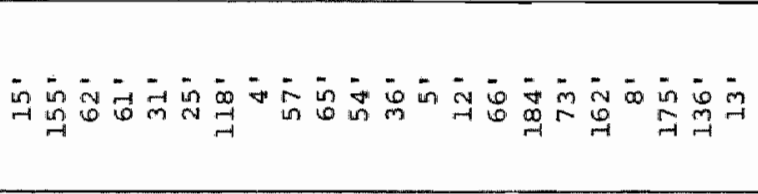 \\
\hline 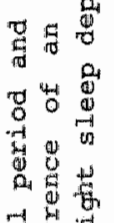 & 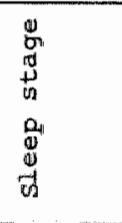 & 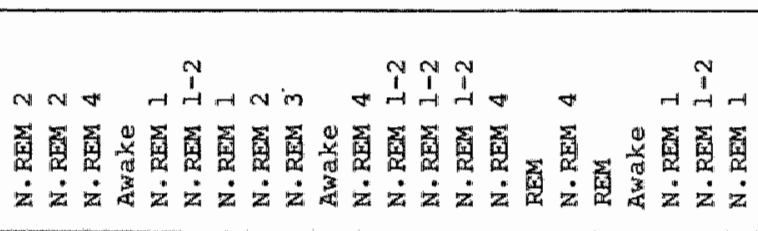 \\
\hline$\tilde{U}$ & 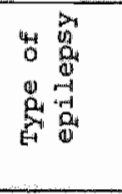 & 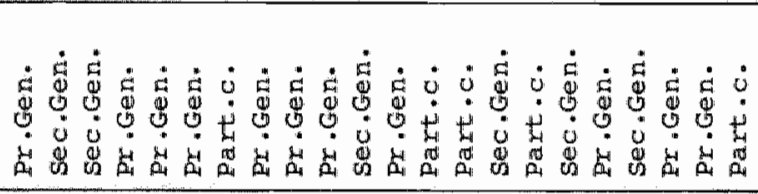 \\
\hline & 要 & 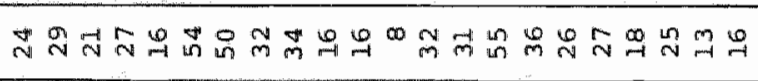 \\
\hline & $\underset{\Sigma}{\Sigma}$ & 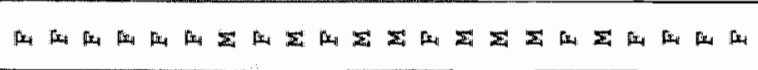 \\
\hline & $\dot{s}$ & 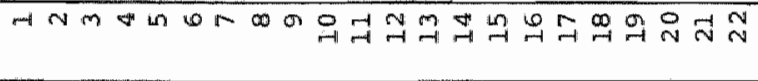 \\
\hline
\end{tabular}


our findings are in agreement with data from the ilterature concerning the changes of the all-night sleep recoralngs as a consequence of electroclinical seizures. Here too, seldom was a loss of cyclicity or difficulty to partition the sleep into sleep stages found, though sometimes a suppression or delay of REM sleep has been observed.

\section{IX.4. FRAGMWTAT ION OF THE SIEEP}

In about 10 of the sleep registrations recorded following one night sleep deprivation in subjects which have or are suspected to have epilepsy, the bypnograms are characterizea by a fragmentation of the sleep. This means that the sleep stages are repetitively interrupted for a short period (5 à $20 \mathrm{sec}$ ) by one or another sleep stage. An example of such interruption is shown in Figure IX.8.

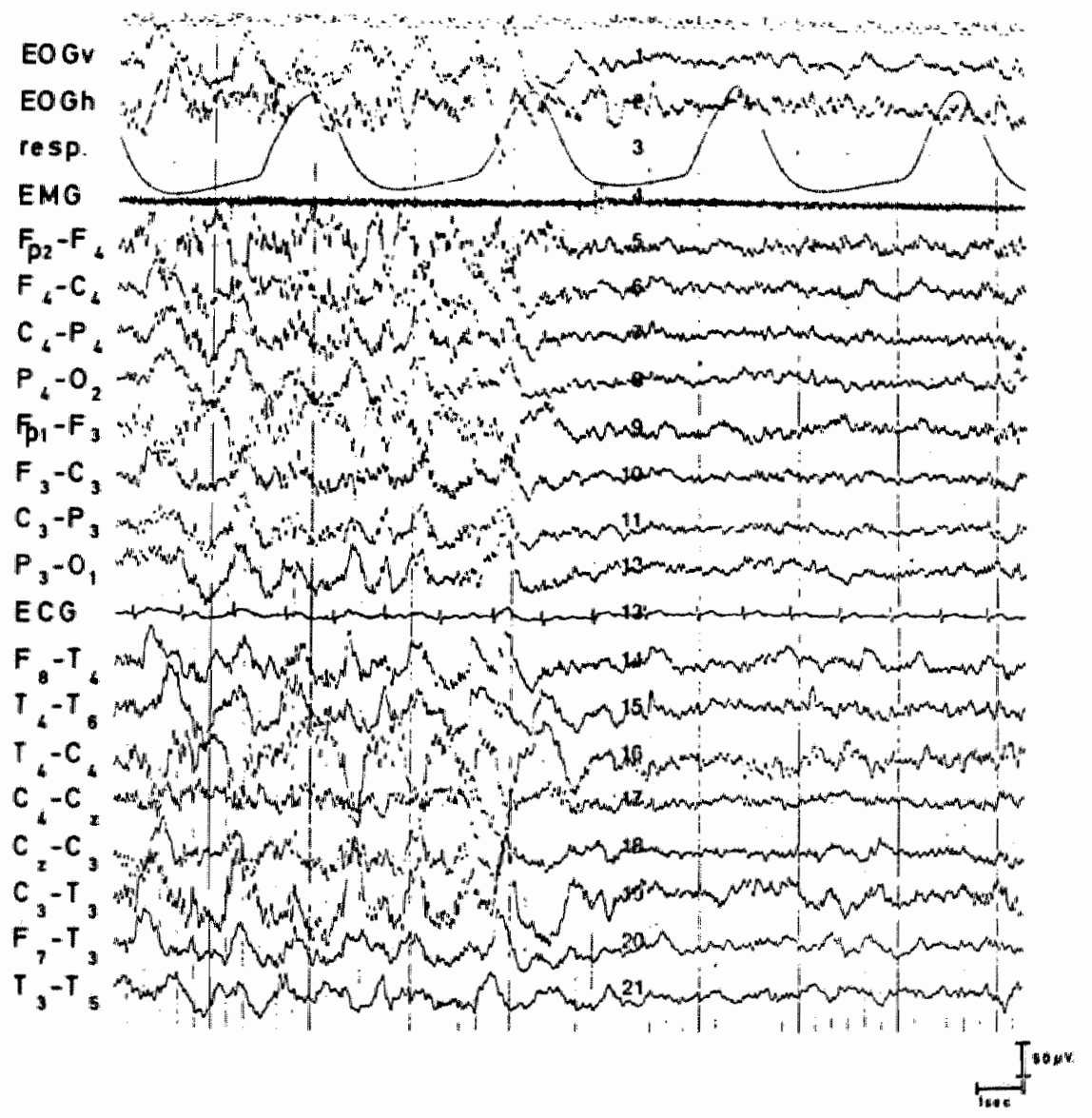

EIG. IX.B.

Example of sleep fragmentation. 
This very striking event was the instigation to examine whether these events are associated with clinical complaints af a non-epileptic nature. Therefore, we selected 50 recordings demonstrating thi charateristic sleep picture, from a total of 626 deprivation hypnograms recorded in the period 1979-1981 (Table v.6.). The population consisted of 26 males and 24 females, of which the age was respectively between $I 1$ and 57 (mean: 27.9) and between 17 and 47 (mean: 29.4). Since it wa known to us (Declerck et al., 1980) that the incidence of sleep fragmentation is higher in mentally retaraed patienta, patients were divided into 4 groups on the basis of the wechsler Adult Intelligence Scale (I.Q.: W.A.I.S.), respectively with an I.Q. above 95 , between 95 and 75 , between 75 and 50 , and less than 50. Of each of the 4 groups it was verified whether and in how many persons non-epileptic complaints were mentioned in their clinical dossier by the treating specialist. In addition, the number of patients in which the diagnosis of epilepsy could be confirmed and whether they were treated with antiepileptics (A.E.) or whether treated with other medication (N.A.E.) was examined. The data are summarized in Table IX.9.

TARLE IX.9.

The clinical and electroencephalographic findings of 50 patients, suspected of having epilepsy, with a typical pattern of sleep fragmentation in the sleep recorded after one night sleep deprivation, in relation with the intelifigence level.

\begin{tabular}{|c|c|c|c|c|c|c|c|c|}
\hline \multicolumn{2}{|c|}{$\begin{array}{c}\text { Intelligence } \\
\text { quotient }\end{array}$} & \multicolumn{2}{|c|}{ Clinical symptoms } & \multirow{2}{*}{$\begin{array}{l}\text { Ep11. par- } \\
\text { oxysms in } \\
\text { sleep EEG }\end{array}$} & \multicolumn{4}{|c|}{ Drug treatment } \\
\hline level & $n$ & epil. & other & & - & + A.E. & + & $\mathrm{N} \cdot \mathrm{A} \cdot \mathrm{E} \cdot$ \\
\hline$>95$ & 21 & 11 & 21 & 8 & 3 & 13 & & 5 \\
\hline $95-75$ & 14 & 10 & 7 & 1.2 & 4 & 10 & & - \\
\hline $75-50$ & 10 & 9 & 4 & 9 & 1 & 9 & & - \\
\hline$<50$ & 5 & 4 & 2 & 4 & 1 & 4 & & - \\
\hline
\end{tabular}

All 21 patients, which had an I.Q. above 95 suffered from addithonal complaints of neurovegetative orjgin such as headache, vertigo, symcopes of emotional or psychic instability. The clinical diagnosis of epliepsy was only certain in 11 subjects and only 8 of them had eplleptic EEG abnomalities. The diagnosis mas doubtful in the remining 10. Five of them were only treated with neuroleptics " because of complaints of a non-epileptic origin. of the 14 subjects which had an 1.0 . between 95 and 75 , 10 had a well-recogrisable form of epilepsy and the diagnosis was doubtful in 4 cases. Epileptic EEG abnomalities were recorded during the sleep in 12 patients of which 3 fitted with a combined fom of epilepsy, with characteristics of both partial and generalized epilepsy. In 7 patients important nonepileptic complaints were mentioned, especially learning and behavioural difficulties such as attacks of aggression and hot temper. 
of the 10 patients which had an $I .2$. between 75 and 50,9 suffered from a moderate to severe fom of epilepsy, confirmed during a slep recording. In 5 patients eplieptic paroxysms were registered fitting with a secondarily generalized form of epilepsy. Severe behavioural disturbances were found in 3 patients.

of the 5 patients which had an $\mathbb{I} \cdot \mathrm{Q}$. below 50,2 had a hemiparesis. othex complaints, except for epllepsy were not mentioned probably because of the predominance of the very severe mental retardation.

On the basis of these data it can be stated that, in the absence of severe mental or psychomotor handicaps, the fragmentation of the sleep is often associated with complaints of a non-epideptic nature. neurovegetative as well as psychic instability. Moreover, these complaints can persist in persons of which their eptiepsy is well controlled by antiepileptic medication.

IX.5. MORPHOLOGICAL CHANGES OF THE K-COMPLEXES IN EPILEPTIC SUBUECTS

The most evident EEG sign of arousal accurring during $\mathbb{N}$. REM $1-3$ sleep is the appearance of K-complexes (Fig. IX.10.). According Malasz et al. (1979) the number or density of $k$-complexes, would augment when the sleep becomes more profound. This tendency is absent when the sleep becomes lighter. They also found that the density is maximal duxing the first sleep cycle, and gradualy decreases during: subsequent sleep cycles. These changes do not accur in epileptios, because k-complexes exist during the whole sleep, often appearing in short series of 3 or more complexes.

In order to find out whether these changes are present in the sleep recorded following one night sleep deprivation, we calculated the density of the K-complexes in the sleep of 8 healthy persons and in 10 epileptios which had generalized spike or polyspike wave paroxysms during their sleep recordings. The transition of wakefulness via light to deep sleep and vice versa are respectively denoted as a descending and an ascemalng phase.

For each phase and for the first and second sleep cycle separately. we calculated the density of the K-complexes auring the $\mathrm{N} . \mathrm{REM} \mathbb{1}$, N. REM 2 and the N.REM 3 sleep, by taking the mean of $10 \times 1$ minute (in as far as the sleep stage lasted 10 minutes). An example of such calculation for a healthy and an epileptic patient is represented in respectively Tables IX.LI. and IX.12. All K-complexes ware counted, even if they had a deviant or epileptic apect, but they had to conform with the desctiption given by Chatrian et ll. (1974): "K-complex: a burst of somewhat variable appearance, consisting most comonly of a high valtage diphasic slow wave frequently associated with siep spindle. Amplitude is generally maximal in proximity of the vertex. K-complexes occur during sleep apparently spontaneously or in response to sudden sensory stimuli, and are not specific for ary individual sensory modlaility".

In healthy persons, the number of $\mathbb{K}$-complexes waried between 0-5 per minute and theix density was approximately equal during the descending and ascending phase and was somewhat smaller during the first sleep cycle than during the second sleep cycle. In epilleptica the density of $K$-complexes varied between 1 and $B$ and often appeared in short series of 2 or 3 subsequent $K$-complexes. There was no systematic difference between the first and second sleep aycle, netthex 

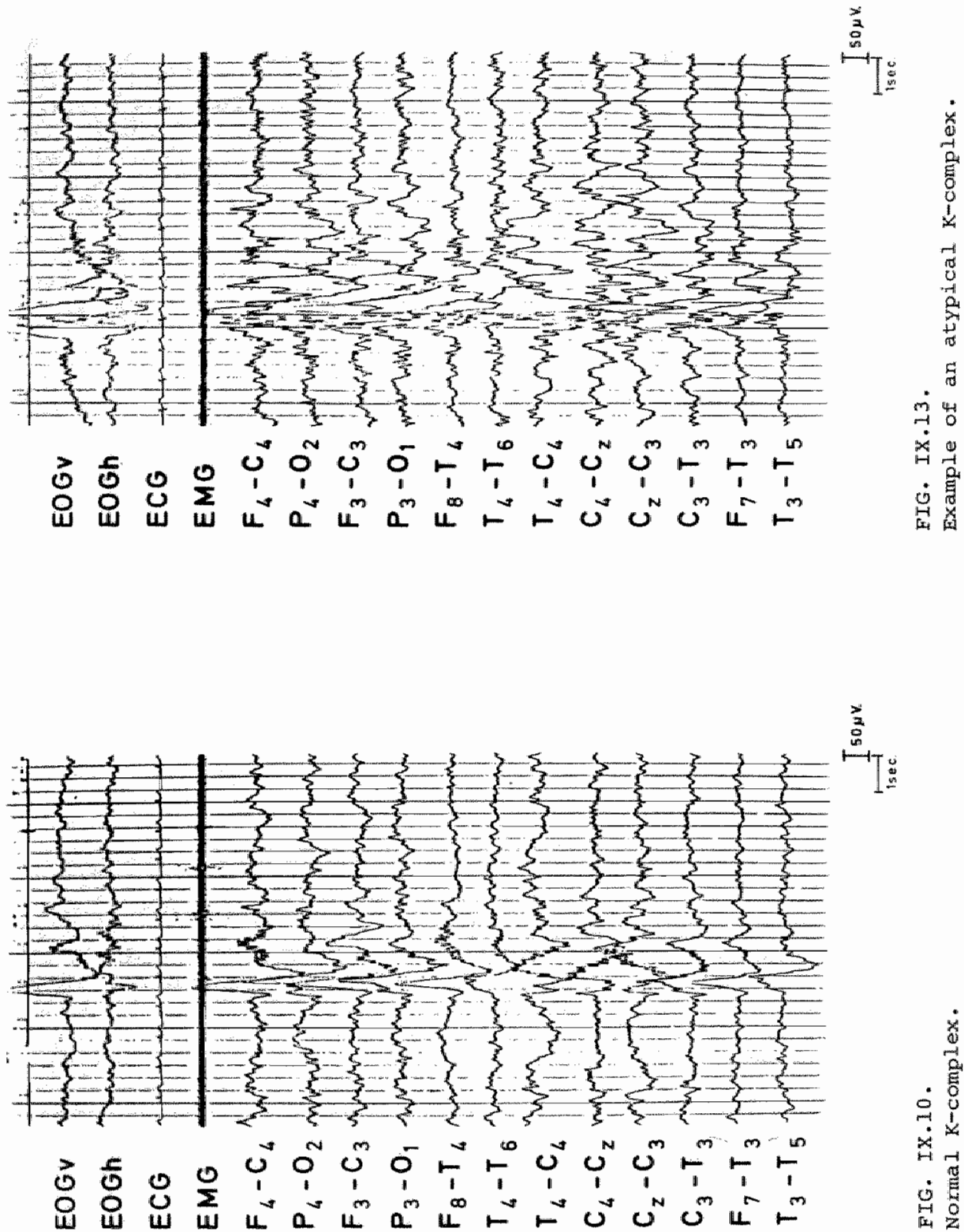
TABLE IX.11.

Density of K-complexes during the descending (D) and ascending (A) N. REM phases of the first and second sleep eycle of a healthy person after 1 night sleep deprivation.

\begin{tabular}{|l|cc|cc|}
\hline \multirow{2}{*}{$\begin{array}{l}\text { Density of } \\
\text { K-complexes }\end{array}$} & \multicolumn{2}{|c|}{ Ist cycle } & \multicolumn{2}{|c|}{ 2nd cycle } \\
\cline { 2 - 5 } & D1 & Al & D2 & A2 \\
\hline N. REM 1 & 1.2 & 1.1 & 1.5 & 1.5 \\
N. REM 2 & 1.8 & 2.1 & 2.6 & 3.1 \\
N. REM 3 & 1.6 & 1.8 & 1.8 & 2.8 \\
\hline
\end{tabular}

TABLE IX.12.

Density of $K$-complexes during the descending (D) and ascending (A) N. REM phases of the first and second sleep cycle of an eplieptic patient after 1 night sleep deprivation.

\begin{tabular}{|l|cc||cc|}
\hline \multirow{2}{*}{$\begin{array}{l}\text { Density of } \\
\text { K-complexes }\end{array}$} & \multicolumn{2}{|c|}{ lst cycle } & \multicolumn{2}{|c|}{ 2nd cycle } \\
\cline { 2 - 5 } & D1 & A1 & D2 & A2 \\
\hline N.REM 1 & 2.2 & 2.0 & 1.6 & 1.5 \\
N. REM 2 & 4.6 & 5.4 & 5.0 & 5.5 \\
N. REM 3 & 4.1 & 3.6 & 3.5 & 3.7 \\
\hline
\end{tabular}

between the descending and ascending phase. Except for a higher density, more abnomal k-complexes were found in epileptics, $i . e$. they were of a low amplitude and irregular ox of a very high amplitude and sharp. Examples of abnormal $\mathrm{K}$-complexes are represented in Figure IX.1.3.

In accordance with data from the literature on all-night sleep recordings more $k$-complexes, of whlch many had an abnormal character, were found in the sleep recorded following one night sleep deprivation in epileptics. In contrast to Halasz et a l. (1979) no differences were found neither in density during the first and second sleep cycle nor in the ascending and descending phase of the co group. This could go together with the sleep deprivation effect, through which sleep especially during the first sleep cycle mainly consista of deep $\mathrm{N}$. REM 4 sleep which also occurs faster after faling aleep.

IX.6. THE VALUE OF NON-EEG SLEEP PARAMETERS IN PATIENTS WHICH HAD OR WERE SUSPECTED TO HAYE EPILEPSY

As mentioned in the recoraing method (IV.2.) apart from recording EEG rhyths, also eye movements (EOG), chin muscle activity 
(1MG), the lectrocardiogram (ECG) and respiration (R) were registered. By these recordings a better differentiation can be made between the 4 stages of the N.REM sleep and REM sleep. The N.REM aleve, also termed quiet sleep, is characterized by the slowing and at some tage by a disappearance of eye movements, a decrease of muscle activity and a regular heart and respiration rhythm. Partiy In contrast herewith, during PEM sleep, heart and respiration rhythim becomes irregular, fast eye movements occur and a further decrease of miscle activity is seen. It appears to make sense to figure out to Which degree these physlological changes are also observed during the leep following leep depivation in subjects which have or are suspected of having epllepsy.

\subsection{The electro-oculogim} wakefulnes and sleep were recorded through skin electrodes positioned at the border of the eye. One pair of electrodes is positioned vertically, respectively with one electrode in the middle above and one electrode in the midale below the eye. Another pair of electrodes is postlioned horizontally with one electrode on either latexal side of the eye corner. Around the eye there exists an electrical field based on the potential difference within the eye, since the cornea is positively charged in comparison to the retina. Because the position of the cornea and the retina changes continuously during an eye movement, one measures the continuously changing potential difference at the electrodes. From these measures one can derive the direction, speed, size and density of the eye movements (in /min). Figures IX.I4. and IX.15. give examples of slow eye movements (SEM) during $N$. REM $1-2$ sleep of rapid eye movements (REM) of a high density during REM sleep.

Based on a visual evaluation of sleep recordings, the density of REM was scored as high, moderate and low. High means that minimally a mean of 20 R⿴囗十 were seen, low a maximal of 6 REMs and moderate from 7 to 20 REMs. It was found that in about 50 of the patients, REM sileep following sleep deprivation, consists of a low density and only in 5 of algh denstey. This is clearly different from the density of the eye movements in healthy persons of which 80 scored a moderate denslty. Between patients with a low and moderate density of RrM following differentiation could be established. In the group which had a low density there were relatively more mentally retarded patlents or patients with signs of a diffuse organic brain damage. In adiltion, there were more patients treated with the combination of more than 2 drugs, whether antiepileptics, especially high doses of diphenylhydantoin, or antiepileptics in combination with benzodiazepine dexivatives. In the 5 of patients which had a high density of eye movements relatively more patients had additional psychiatric complaints.

In 20 to 25 of the patients REM sleep was unstable and repetitively interrupted by short periods of light N.REM $1-2$ sleep or a wakening.

Finally, in patients as well as in non-patients fast eye movements appear in clusters. The density of REMs is smaller during the first sleep cycle than in the subsequent cycles. 
During sleep there is a general decrease of muscle activity and of large body mowements. Though this decrease is most pronounced during FaM sleep, precisely auring this sleep state small short-lasting twitches in the face and fingers appear. To measure thi general decrease in muscle activity and the characteristic twitches in the face, it is comon to measure chin muscle activity by means of skin electrodes. We also systematically applied this method, but often in combination th a second derivation placed on the neck, the cheek or the jaw muscles.

To check the validity of an EMG measure in the exaluation, three experienced EEG assistants working for at least 3 years in our laboratory and regularly carrying out sleep investigations were asked to clasilfy the sleep into deep $N$. REM and REM sleep exclusively based on the EMG signal. For this investigation 300 hypnograms of sleep recordings following sleep depxivation in epileptics were used. This independent evaluation provided following results:

1. Only in 1 patient, which had a serious sleep disturbance, was a high level of muscle activity registered during REM sleep.

2. In more than 40 of the patients no differentiation could be made between $N$. FEM and REM sleep only on the basis of the EMG. This was due to the fact that the muscle activity during N.REM sieep was as low as during REM sleep and because almost no muscle twitches occurred during REM sleep.

3. Following an arousal reaction occurring auring $\mathbb{N}$. REM $1-2$ sleep, the muscle activity could reach a 2 or 3 times higher level for about 5-1.0 minutes (Figure IX.16.). These long-lasting changes an muscle activity do not correlate with the short-lasting changes of the EEG picture or with changes in heart or respiration frequency, of which the oxiginal pattern is often re-established within 1 minute.

4. In many patients an extremely low muscle activity is seen from the beginning of sleep onwards, a phenomenon regularly observed in patients treated with antiepileptics in combination with benzodiazepine derivatives.

5. A sudden and very strong increase in muscle activity is often associated with a short period of wakefulness or with an epileptic discharge. The latter is mainly observed in patients with psychomotor attacks and in which a second derivation at the level of the che or jaw muscle is used.

6. Positioning electrodes in the neck or at muscles of the extremities is less meaningful since changes in posture may greatly alter the measured muscle activity.

In summary, it can be stated that measuring the muscle activity is a less valuable parameter for the partition of sleep in epileptics, especially when they are treated with antiepileptics in conjunction with benzodiazepine derivatives, than generaliy proposed in the 1 iterature.

\subsection{Resplration}

During $\mathbb{R E M}$ sleep respixation becomes irregular and periods of apnea may occur. A frequently applied method for recording the respiration is measuring air flow by placing a small 


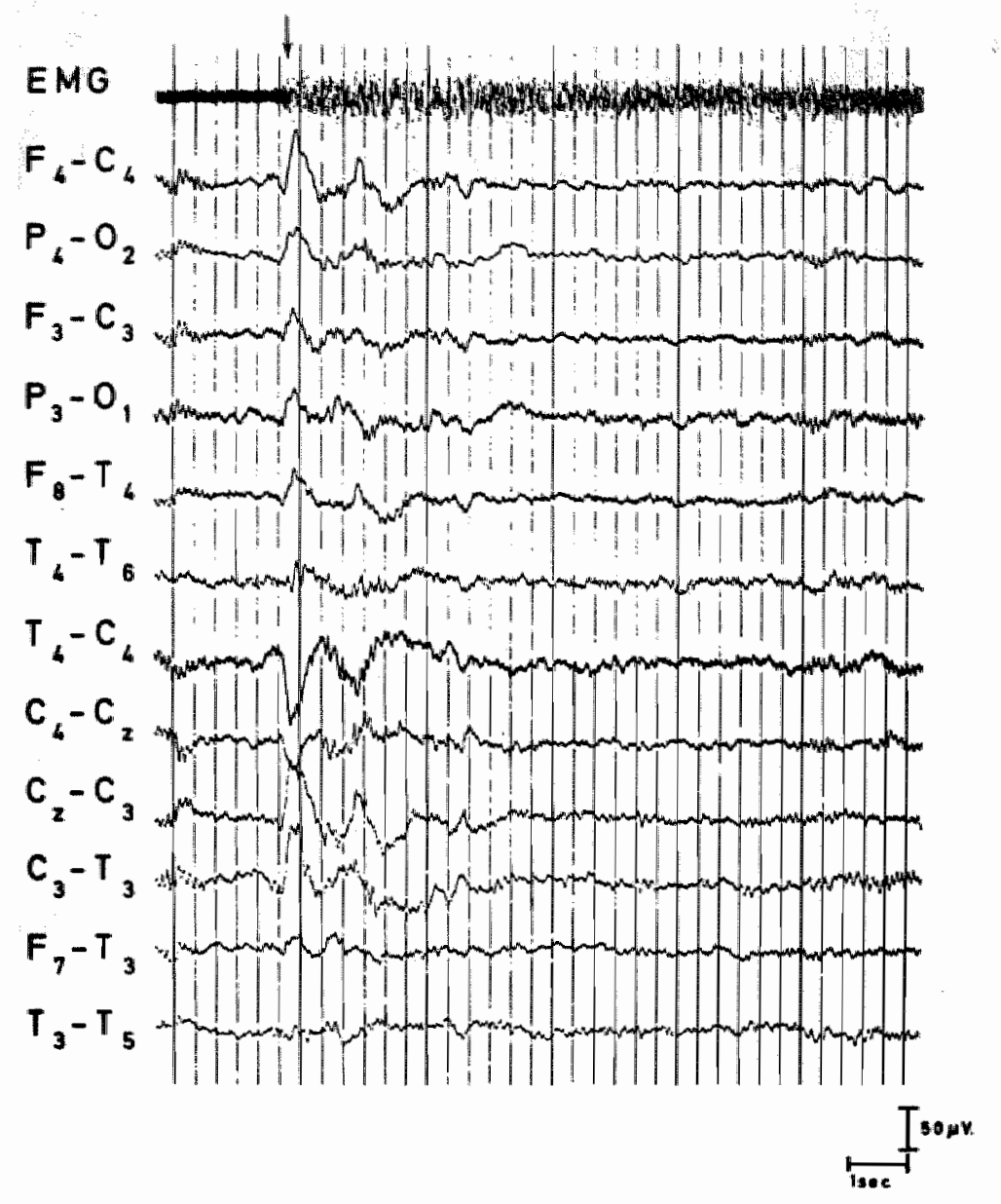

FIG. IX.16.

Level of chim muscle activity during $N . \mathbb{R E} 2$ aleep before and after an arousial reaction.

temperature- sensitive plate before the nose and mouth. This method (thermistor NTC - siemens) has also being applied by us.

A period of apnea is defined as an interruption of the air flow during minimally 10 see. According some authors (Guilleminault et al. 1980) periods of apnea cam give rise to sleep interruptions. owing to this a shortage of sleep may occur and in reverse a shortage of sleep can favour the occurrence of aprea periods*

It was of interest to check the regularity of resplration during REM and N.REM I-2 sleep and M. REM 3-4 sleep following sleep deprivation and how frequent apnea periods occurred in patients which had or were suspected of having epllepsy. 
A total of 40 sleep recordings were studied from patients recorded in 1981, in all of which an artifact free respiration recording was present and in whilch 2 complete sleep cyeles were found, consisting

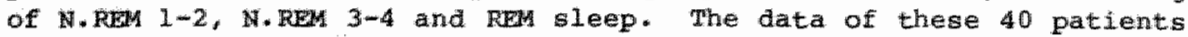
are sumarized in Table IX.17. The different columms contain following data: (1) age; (2) sex; (3) clinical form of epllepsy; (4) the EBG confirmation: (5) antieplleptic medication; (6) lowest and highest respiration frequency per minute respectively during $N$. REM $1-2$, N. REM 3-4 and REM sleep; (7) the maximal duration of apnea; (8) the maximal and minimal value of the heart frequency during $R$ sW sleep.

The population consisted of 17 males and 23 females, their age varied between 9 and 42 years, 26 were epileptics and 14 patients which were suspected to have epilepsy.

The magnitude and variability of the respiration frequency in the different bleep stages was relatively stable for each individual patient. In most patients, respiration was most regular and deepest during . FEM 3-4 sleep and superficial and irregular during N.REM I-2 leep and espectally during PEM sleep. There was no firm relationship between the respiration and heart frequency. Only in 3 patients were apmea periods found (case 11,16 and 28) with a maximal duration of respectively 15,22 and $30 \mathrm{sec}$. These occurred minly during the transition of deep $\mathrm{N}$. REM $3-4$ sleep to REM sleep or light $\mathrm{N}$.REM 1 leep. Most apnea periods give rise to al short-lasting lightening of the leep (or wakefulness), but in most cases for less than 1 minute. They never induced clinical seizures or increased electrical epileptic abnormalities.

For comparative purposes, an evaluation was made of 30 all night leep recordings in an analogous patient group. Apnea periods occurred in 2 patients lasting respectively 15 and 22 sec. These also occurred during the transition to REM or W.REM $1-2$ sleep following a deep sleep period. From these data one can conclude that there are no major differences between an all-night and a deprivation sleep recording, concerning the appearance of apnea periods and that apnea periods do not give rise to an increase in epileptic abnormalities. Therefore, sleep deprivation in epileptics does not yila an extra risk.

\subsection{The electrocardiogram \\ The $\mathbb{E C G}$ was derived from contact plate electrodes fixed} at both wrists by means of an elastic string. The ECG was systematicdiy recorded during a routine awake EEG as well as during the sleep recordings. Though a larger variability was found during REM sleep as compared to $N$. RRM sleep (Table IX.17.\%, these differences were too mall and varied to much to allow to differentiate between the different states of sleep on the basis of this parameter alone.

\section{IX.7. GENERAL SUMMARY}

During sleep following sleep deprivation spike wave paroxysms tend to change their form: $1 / 3$ of the typical spike waves changed 


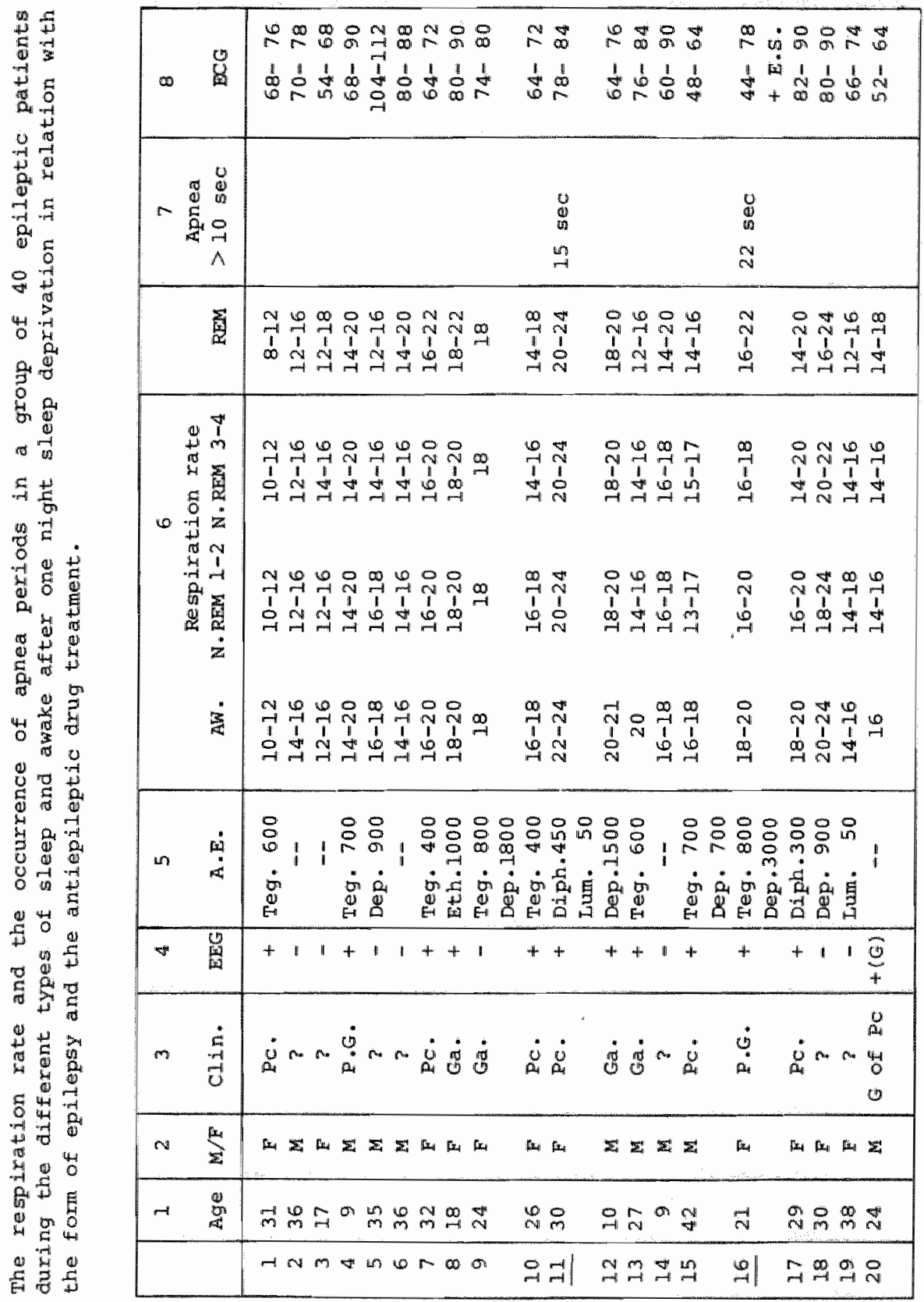




\begin{tabular}{|c|c|c|c|c|c|}
\hline 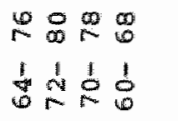 & $\begin{array}{ll}0 & \infty \\
0 & 0 \\
1 & 1 \\
0 & 0 \\
0 & 0\end{array}$ & $\begin{array}{l}\mathbb{4} 0 \\
00 \\
1 \\
40 \\
\text { in }\end{array}$ & 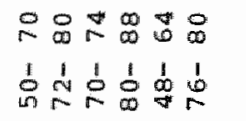 & 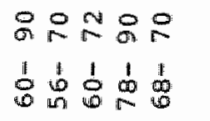 & $\begin{array}{l}N \\
\infty \\
1 \\
0 \\
0 \\
0\end{array}$ \\
\hline & & $\begin{array}{l}0 \\
0 \\
0 \\
0\end{array}$ & & & \\
\hline 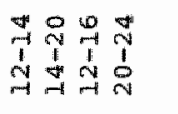 & 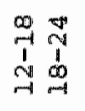 & 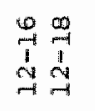 & 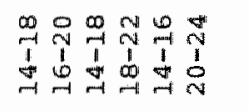 & 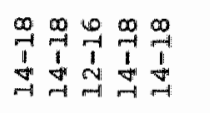 & $\begin{array}{c}0 \\
1 \\
1 \\
0 \\
-1\end{array}$ \\
\hline 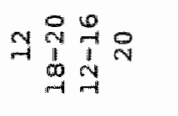 & $\stackrel{0}{\rightarrow}$ & 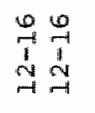 & 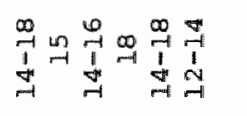 & 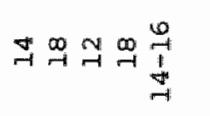 & $\begin{array}{l}\infty \\
-1 \\
1 \\
0 \\
-1\end{array}$ \\
\hline 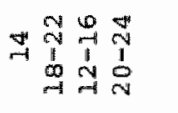 & 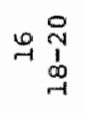 & $\begin{array}{cc}\infty & 0 \\
-1 & -1 \\
1 & b \\
-1 & 0 \\
-1 & 1\end{array}$ & 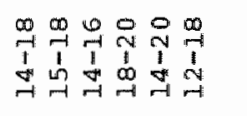 & 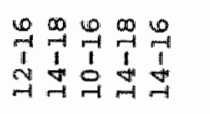 & $\begin{array}{l}0 \\
1 \\
1 \\
0 \\
-1\end{array}$ \\
\hline 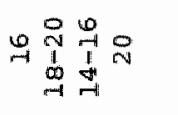 & $\underset{-1}{0} \underset{\substack{1 \\
0=1}}{9}$ & 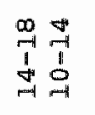 & 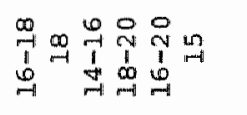 & 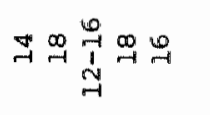 & $\begin{array}{c}0 \\
1 \\
1 \\
0 \\
0-1\end{array}$ \\
\hline $\begin{array}{l}0 \\
0\end{array}$ & $\begin{array}{l}0 \\
8 \\
0 \\
0 \\
8\end{array}$ & 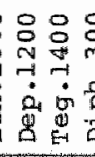 & 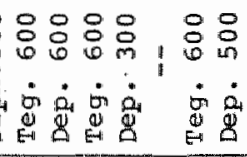 & 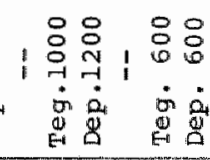 & 1 \\
\hline+111 & $\|+$ & ++ & $+11+1+$ & $1++1+$ & 1 \\
\hline 山密范 & $\infty \dot{0}$ & $0 \dot{0}$ & 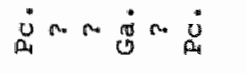 & 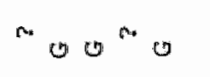 & n \\
\hline 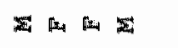 & $\Sigma \Sigma_{1}$ & 的 & 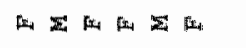 & $\Sigma \Sigma \Sigma$ 的 & $\omega_{4}$ \\
\hline 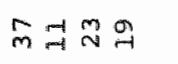 & $\stackrel{m}{\rightarrow-1} \prod_{\rightarrow}$ & $\stackrel{\infty}{\rightarrow}$ & $\underset{\sim}{\mathbb{N}} \underset{\sim}{\infty} \stackrel{0}{\sim} \stackrel{0}{\sim}$ & 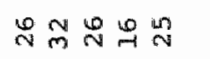 & $\stackrel{*}{N}$ \\
\hline $\overrightarrow{N N} \stackrel{m}{N}$ & un & $n \begin{array}{lll}n & \infty \\
n & 0\end{array}$ & ब임 & 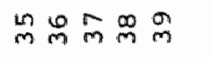 & $\stackrel{0}{*}$ \\
\hline
\end{tabular}


Into polyspike waves and $1 / 5$ of the polyspike waves to trplcal splke waves during $N . R E M ~ 1-2$ sleep. During $N$. REM $3-4$ sleep $1 / 3$ of the typical spike waves and $1 / 5$ of the polyspike waves changed to low frequency spike wave form. The latter demonstrated the most stable aspect, but these occurred especially in patients which have a diffuse brain damage.

The abnomalities fitting with partial epilepsy are better localized and bettex formed during REM sleep. This influence also occurs during REM sleep following sleep deprivation in epileptics*

With the occurrence of an electroclinical seizure during a sleep deprivation investigation, sleep can be partitioned only with dificulty, but such periods seldom last longer than 15 minutes. In the subsequent periods, sleep is often less stable than before the selizure.

When sleep following sleep deprivation is characterized by a striking fragmentation, especially in epileptics which have a normal intelligence (I.Q. W.A.I.S. $>95$ ) one often has to considex conplaints other than epilepsy, especially those of a neurovegetative or psychic origin. These complaints do not disappear after treatment with antlepileptics, even if these regulate the epilepsy.

A larger density of $K$-complexes is often seen in epileptics. They occur during light N. REM sleep or when sleep becomes deeper ox lighter, respectively at the start and at the end of a sleep cycle. In addition, these $\mathrm{K}$-complexes can take an abnormal form because they are blunt and have a low amplitude or because they are sharp and of a high amplitude or because they appear in short series. In these cases a differential diagnosis with aspecific spike waves can be extremely difficult.

Half of the patients treated for epilepsy have less than 6 fast eye movements per minute during REM sleep. such a low density is especially seen in eplleptics which have a subnormal I.Q. or when they are treated with more than 2 antiepileptics of which one is hydantoine or with antiepileptics in combination with benzodiazepine derivatives.

In 20 to 25 of the epileptios REM sleep is interrupted by short periods of light $\mathrm{N}$. REM $1-2$ sleep.

Many epileptics have a strikingly low chin muscle actiwity during all sleep stages, such that this is as low during N.REM as during REM sleep. This especially occurs in patients treated with the combination of antiepileptics and benzodiazepine dexivatives. otherwige, arousal reactions which shortly disturb the sleep plcture (less than 1. minute) can triple the muscle activity for several minutes.

The influence of $\mathrm{N}$. REM and $\mathrm{REM}$ sleep on the regularity and frequency of heart and respixation does not differ between eplleptics and healthy persons. of practical importance is the fact that sleep deprivation does not increase the frequency of periods of aprea. In addition, when these occurred they did not provoke cilnical or electro-encephalographic epileptic abnormalities. This mean that the sleep deprivation method is also a safe method for epileptics. 
In chapters IV-IX it was shown that the diagnostic yield of longtem polygraphic sleep registrations following one night TSD is detexinined by a multiplicity of factors Different procedures of TSD have been applied. Depending on the practical possibilities of an EEG department and the aims of the investigation, one can make a differentiation between the following:

1. A simple routine TsD procedure, with the sole aim of limproving the epllepsy diagnosis:

2. A complex long-term TSD procedure, to be carried out in those cases: where it is extremely difficult to make a differential diagnosis between the presence or absence of epilepsy, and in those cases where it is wished to study, not only the epileptic, but also the non-epileptic EEG abnormalities in relation to the compostion of the sleep.

3. A drected TSD procedure, where the recording and the processing is adapted in order to better analyze certain aspects of epilepsy during sleep, or sleep itself in epileptics.

\section{$\mathrm{X} .1$. THE SIMPLE ROUTINE TSD PROCEDU FE}

When on the basls of the clinical investigation and of a routine EEG examination it is desirable to carry out a sleep recording after sleep deprivation, the following procedure can be proposed:

1. Preceding the investigation the patient, preferentially under guidance, remalins awake for the whole night.

2. The patient is present in the EEG department in the morning. The recording has to be caxried out in the forenoon, since the opportunity to record a sufficient amount of REM sleep decreases towards the end of the day (Fukuda et a l.., 1981).

3. Normally a 12-, but preferentially a 16 (or moxe)-channel electroencephalograph is used for the polygraphic sleep recording. Three or 4 channels are used for the recording of non-EEG parameters, the other channels serve for recording EEG rhythms. The electrodes have to be positioned in a configuration by which epileptic EEG as well s leep phenomena can be recorded optimally (chapter IV). During the technical preparation the patient has to be kept awake.

4. After the start of the recording, the patient has to be kept awake for minimally 10 minutes, for this purpose external stimuli are often necessary. This period of lowered alextness continuously interrupted by arousal reactions, is considered as very provocative for the appearance of epileptic EEG abnormalities. Moreover, duxing this period, it is ideal to check whether all EEG and non-EEG parameters are recorded artifact free. A correction is then feasible without having to additionally awaken the patient.

5. After the sleep onset minimally one sleep cycle is recorded. In epileptics, the first sleep cycle lasts between 80 and 110 minutes, often containing somewhat more deep $\mathbb{N}$. REM $3-4$ sileep than light. N. REM 1-2 sleep and a short REM period at the end of it. 
6. If by the ena of the first sleep cycle no epileptic EEG abmomalities have beer recorded, than it is meaningtul to prolong the recording for minimally 15 minutes in order to find out whether epileptic EEG abnomalities occur during the initial phase of the second sleep cycle, i.e. the transition of REM sleep to N. KEM 1-2 sleep.

7. Whe recording has to continue for an adaitional 10 to 15 minutes after awakening the patient. Most patients have difficulties in remaining awake. The variations in the degree of vigilance favour the occurrence of epileptic EEG manifestations.

8. In patients suspected of having a form of epilepsy senisitive to light stimuli or hyperventilation, the investigation can be conplemented by one or both provocation tests.

In applying this procedure, the duration of the registration lasts 120-150 minutes. With this recording procedure we achileve more than 90 of the total positive diagnosis, which conld be attained by prolonging the recording to two sleep cycles or about 4 hours recoraing. The most obvious reason responsible for an insufficient sleep, apart from ather demonstrable causes of sleep disturbances (for example organic brain damagel, is an insufficlent sleep deprivation.

\section{$\mathrm{X} .2$. THE COMPLEX LONG-TERM TSD PROCEDURE}

During short-1asting observations allowing to confixm, differentiate, or exclude the existence of epilepsy, the following neurophysiological procedures can be proposed:

1. Carrying out a routine and specific EEG investigation on the basis of clinical and anamestic findings, preferentialiy during the morning.

2. Linking-up with this routine EEG investigation and based an the recorded findings, the patient is further irvestigated with the ald of a continuous ambulatory EEG registration, using a minitape recorder. Herewith one can find out whether the patient remains awake at night and whether epileptic EEG abnormalities occur during this period. Keeping the patient awake is done in the clinic under the guidance of the nursing staff. The day/night activities are noted by the patient or by the staff.

3. During the mext morning a polygraphic sleep investigation is carried out, confoming to the procedure proposed for the omple routine TSD procedure. The duration of the recording, however, ts prolonged to two sleep cycles or when there lis an insufficient cyclicity of the sleep to minimally 4 hours

4. Following the sleep investigation again an anbulatory EEG recording is carried out during the next 24 hours. When necessary, the electrode position is adapted according to the epileptio beg findings established during the sleep investigation. By this means it is possible to check whether the effects of the sleep deprivation persist because the appearance of day sleep, through which the sleep in the subsequent night becomes superficlal and less stable.

Such registration continued during 48 to 60 hours is not burdensome to most patients. 
Many Investigators mentioned that during the sleep in epileptics more sharp vertex waves (Fassouant, 1975) and $x$-complexes (Halasz et al., 1979) are present, eventually eqen with the appearance of epileptic K-complexes (Miedermeyer et al. 1981). An increase of well-formed spindle activity would otherwise point at a better regulation of the epdlepsy (sterman et a1., 1979). Recently waitoh et al. (1982) pointed at the antagonism which would exist between brain mechanisms responsible for the production of sleep spindles and the synchronizing mechanisms responsible for the appearance of sharp. vertex waves, $K$-complexes and delta sleep. Ar inhibitory function is assigned to leep spinales (Johnson et al., 1976) giving rise to an increase of the arousal threshold and stability of the sleep. Sharp vertex waves and $k$-complexes, on the other hand, are considered as an expression of enhanced cortical exitability (Faynal et al., 1974), by which arousal reactions interrupting the sleep are facilitated. According Gaillard and Tissot (1976) one may expect that an increase of spinale activity is associated with a decrease of vertex waves, $K$-complexes and delta sleep.

If it is desirable to study such associations, it is necessary to derive these specific EEG phenomena from those regions where they are maximally present. For an adequate detection of K-complexes, recordings have to be made not only from the vertex but also from more frontal, medial, and parasagittal cortical regions. For the detection of the spindle activity recordings have to be made precentrally as well as central-temporally and parieto-occipitally. These are the regions where these rhythms may differ largely from each other during the N. FREM sileep.

Though such investigation offers perspectives for an improved evaluation of brain functioning and antiepileptic treatment, adequate soft-ware methods are required for an optimal processing of the EEG sigmals 
This study was designed to find the optimal method of carrying-out a polygraphic sleep recording following one night total sleep deprivation (TSD) in epileptics, in order to obtain a maximum in alagnostic galin. By this we not only mean the recording of epileptic EEG abnomalities, but also the sleep changes which can originate from having epilepsy or from the intake of antiepileptics. Therefore, we carried out a literature survey and an investigation in which seep of epileptics and healthy subjects, whether during the night, or during the day following one night total sleep deprivation were registered and subsequently analyzed. By comparing the obtained results, it became possible to judge the diagnostic validity of our TSD method. In order to better understand the differences in the diagnostic gain depending on the applied sleep procedure, first a short description of the neurophysiological background, which might be of importance in epilepsy and sleep, will be considered.

XI.1. NEUROPHYSIOLOGICAL BACKGROUND OF THE INTERACTION SLEEP AND EPILEPSY

Nearly all investigators (II.3.) agree that epileptic EEG abnormalities are mostly seen during the light N.REM I-2 sleep. Also, during $N$. REM $1-2$ sleep the probability of developing polyspike waves increases and the spread of focal discharges from the focus increases. This does not occur duxing REM sleep and a decrease in generalized epileptic discharges and a better circumscription of partial epll.eptic discharges is better observed. These apparently contradictory influences show that cortical functioning during N.REM and REM sleep aiffers and further, that both types of sleep are differently controlled.

The activity of neurons, localized in the brain stem, are responsible for the neurophysiological. organization of wakefulness and sleep. They can be divided into two systems on the basis of their antagonistic function. One system i.s responsible for wakefulness and arousal, the other one for the induction of sleep and between both systems a continuous reciprocal interaction exists (Hobson et al. 1975). The first or activation system is responsible for a continuous activation and control, through an adequate inhibition of cortical neurons. Herein the ascending reticular activating system fulflis an important role. This system is also responsible for a high cerebral catecholaminergic activity; an action which is also expressed in a desynchronized EEG picture and a high level of muscie activity. In the second or sleep inducing system, the midine nuclel of the thalamus and raphe nuclel play an important role, whether by a drect influence on cortical neurons, or indirectly by suppressing the subcortical activating systems. This influence is associated with an increase in cerebral serotonexgic activity, which is especially expressed during N. REM 3-4 sleep (Hartmann, 1967) and give rise to a synchronized EEG picture consisting of high delta waveg. The organization of the REM sleep is sustained by a complex mechanism in whilch the locus coeruleus plays an important role. similarly, as durtng 
wakefulnes though les pronounced, auring FEM sleep the catecholaminergic activity is high (Galliard, 1979) by which this desynchronized EEG picture can be explained. Further during REM sleep there is a low secotonergic activity and a high cholinergic activity. Finally the EMG picture is characterized by low level of muscie activity, which is ascribed to an inhibition of alpha-motor neurors. Although the cited regulatory mechanisms are very simplified it is possible to better understand the similarity between wakefulness and REM Leep, both typlfied by a desynchronized EEG, and deep N. REM 3-4 Bleep with a bychxonized EEG. Wakefulness and REM sleep as well as deep N. R 3-4 sleep axe considered as actively induced states (Hess, 1925, Monnier and schönenberger, 1977) whereas 11ght $\mathrm{N}$. REM 1-2 sleep is often considered as a pasive condition, which originates from a decreased or even suppression of the functioning of activating systens (Bremer, 1935; Koella, 1981). In this conception, light N. REM 1-2 sleep can be viewed as a passive transition phase between the Inability to maintain the conditions of wakefulness and PEM sleep and the inability to induce a stable deep $N$. REM 3-4 sleep. During this activation, the control of contical neurons is lessened, however, the thalamo-cortical activity is maintained. Due to the decreased inhibition, afferent stimuli produce a more pronounced cortical reaction which 1.9 expressed in the EEG by the appearance of sharp vertex waves and $\mathrm{K}$-complexes (Natoh et al., 1982). Because of the existence of large physlological differences at cortical and subcortical level during the conditions of wakefulness, light and deep N.REM sleep and REM sleep, it 1 s likely that epileptic discharges will occur more easily during conditions which promote their origin.

Gastaut and Tassinari (1975) defined an epileptic EEG discharge as "a neuronal discharge characterized by the simultaneous excessive activation of a large number of cells which may be recorded by electroencephalographic techniques as a paroxysmal wave form, usually in the form of a spike (S), sharp wave (SH) and spike and wave (SW) or other wuch complex". The spike is considered as "a sign of neuronall membrane depolarization and unit activity facilitation under conditions of enhanced positive pyramidal cell feedback and increased activity of excitatory interneurons". The slow wave is described as "a hyperpolarization with inhibition of pyramidal cell unit activity" (steriade, 1974). Conditions of an enhanced cortical excitability which allow the appearance of excessive neuronal discharges, may be based on a congenital predisposition (Metrakos and Metrakos, 1961) or an acquired pathological condition of the gray brain matter (Gloor, 1969). This disturbs the normal thythmic interplay between excitatory and inhibitory postsynaptic potentlals, which are the basis of the EEG rhythm (Pollen et al, 1964), and give rise to abnormal EEG phenomena.

Gloor (1979) differentiates between epileptogenesis of the first and second order, depending on the degree of the disturbance. In the first degree the rhythic interplay between excitatory and inhibitory postsynaptic potentials is disturbed without instigating an increasing depolarization of the cell membrane potential. This disturbance is clinically expressed malnly in genermized epilepsy of the absence type and electroencephalographically in generalized spike wave paroxyams. During the second degree the neuronal discharges give rise to a further depolarization by which the discharge frequency of cells 
Further Increases. This disturbance is electroencephalographically expressed by the appearance of series of spikes. shaxp waves or polyspike waves. Clinically, this is expressed in generalized epilepsy of the grand mal type or partial epllepsy if the disturbance is restricted to a part of the brain cortex. These excessixe fockl discharges however, can invade neighbouring nomal neurons. Calvin (1972) showed that "even a notmal neuron can become eplleptic if more than 1 of the synaptic input receives high frequency discharges from other epileptic neurons".

When as described above, epilepsy is basiea on a too high ana simultaneous discharge frequency of large groups of cortical neurons. this tendency will be further reinforced by physiological conditions of dininished cortical intibition ( $N$. REM $1-2$ sleep) or by pathophysiological conditions of enhanced cortical excitability (postanoxic or metabolic). As a consequence of this it is comprehensible that epileptic EEG abnomalities will more easily appear during N. REM $1-2$ sleep with an enhanced possibility for the formation of polyspikes and a spread to adjacent neurons. Due to the high activation and control of cortical neurons during REM sleep an opposite effect can be understood. These are the reasons why in the literature REM sleep is sometimes assigned anticonvalsant properties and the N. RFM sleep convulsant properties. This claim cannot fully be sustained because focal discharges though sharply circumscribed sometimes occur more frequently during REM sleep than during wakefulness or N.REM sleep. This might be connected with the finding that focal epileptic saurces, localized in the limbic system or in the supplementary motor area, show a higher incidence of spiking during ReM sleep, this is in contrast to other cortical areas (wieser, 1982). The enhanced cerebral cholinergic activity curing REM sieep might play a role in this according to some authors (Celesia and Jasper, 1966).

If one accepts that one of the basic mechanlsms for the origin of epilepsy is an acquired or innate enhanced cortical excitability and that the degree of cortical excitation differs depending on the kind and depth of sleep, then it is acceptable that this can change the structure of the sileep in epileptics.

During N.REM $1-2$ sleep many authors observed more sharp vertex waves in patients with a generalized form of epilepsy (Clemens and Mezey, 1980). Similarly, more sharp to epileptic K-complexes (Niedemeyer, 1981) which may even occur in series (Halasz, 1979) or which nay be expressions of excitation and synohronization have been reportied (Naitoh et al., 1982). This enhanced coxtical excitation can give rise to a tao strong arousal reaction resulting in frequent and long-lasting awakenings from light N. REM $1-2$ sleep, which hamper the induction of a stable $\mathrm{KEM} 3-4$ and REM sleep. Thirough this one can explain the mary transitions and even interruptions seen during N. REM 3-4 sleep and REM sleep in eplleptics. These stages of leep can then be replaced by light $N . R E M \quad 1-2$ sleep and even by awakening (Passouant, 1975).

Taking into account, that according to certain authors (chadwick et al." 1978; Rolf et a 1., 1982) epileptlcs, especialiy those which suffer from a grand mal. type, produce few blogenic amines such as serotonin (activity engaged in the induction of deep $N$ RBM 3-4 sleep) a deviant sleep structure can be understood. 
On the basis of the outined interactions between epilepsy and sleep, we will discuss hereafter the investigation procedures we applied and the results obtained. Where our findings deviate from the ilterature we attempt to explain then.

\subsection{The TSD procedure (Chapter IV)}

The most important differences between our prociedure and those mentioned in the literature ane the followng:

- The syatematic utilization of 26 or 21 recording channels through which the epileptic and sleep phenomena can be described and classified precisely:

b. Controlling, by the nursing staff alded by the members of the family or relatives, that the patients remain continuously awake during the night preceding the investigation. By this, one prevents the occurrence of "microsleeps" through which the aimed deprivation effect can be mitigated;

c. Starting the sleep recording in the morning between 7.00 and 8.00 hours because the opportunity to record REM sleep is greater during the forenoon than in the afternoon or evening (Fukuda et a.., 198:):

d. A 3 to 6 times longer recording time than the 30-60 minutes recording used in the literature;

e. Mentioning the type, localization and the quantity of epileptic EEG abnomalities depending on the sleep stage and depth, with in addition, mentioning the sleep partition in a hypnogxam and the most striking sleep phenomena, such as K-complexes, sleep spindles, and of sleep patterns of delta and FEM sleep.

Thanks to the measures mentioned in $b, c$, d the recording period was often sufficiently long to obtain two complete sleep cycles and to record $\mathrm{REM}$ sleep and all stages of N.REM sleep in patients. This provided the opportunity to relate the epileptic EEG abnormalities with the kind and depth of sleep during the first and second cycle and to compare the two sleep cycles with each othex and with the allnight sleep, which allowed the deprivation effect in epileptics to be studied.

The measures mentioned in and ade it possible to analyze the changes in the aspect of eplleptic EEG phenomena with respect to the sleep and of the sleep phenomena with respect to the epllepsy, or the intake of antieplieptics.

\subsection{The value of TSD for the electroencepinalographic diagnosis of epilepsy (Chapter v) \\ This discussion is restricted to some differences which} are mainly of practical importance.

a. The percentage sleep recordings in which epileptic EEG abnormalithes were found in an aselective group of patients suspected of having epllepsy was 63.7 in 1977 and 70.9 in 1981. During the of 3-4 hours following TSD, this percentage was 4 to 5 io lower than during an all-night sleep recording lasting $7-9$ hours. The percentage of 60 to 65 is 5 to 10 higher than those found in 
most of the literature (Degen and Degen, 1980), This gain can be ascribed to the longer duration of the reconding time and to a strict control of wakefulness during the periad preceding a sleep recoriling.

b. Besides the percentage diagnostic affirmation depending on the clinical form of epliepsy we almed to determine the diagnostic gain in function of (I) the probability by which the referring specialist (neurologist of pedatrician) could confirm or deny the existence of epilepsy on the basis of anamestic and clinical data and (2) the specificity by which the epileptic EEG abnomalitie were seen during the sleep recording.

When the existence of epilepsy was clinically considered as certain, then the percentage of recordings with speciflc epileptic EEG abnomalities increased from 35.1 during wakefulnes to 8.4.2 during sleep. When however the diagnosis of epilepsy was clinically rejected than only $3(0.75$ of the 395 patients had specific epileptic abnomalities during the sleep. Such a differentiated comparison of such a large patient population has not been reported in the literature (Deisenhamer and Klingler, 1978). This also points at the importance of precisely observing and describing the clinical as well as the electroencephalographically recorded epileptic phenomena.

c. In accordance with the literature (Marosfi, 1980) most eplieptic EEG abnormalities were determined during the first sleep cycle. Though it has to be mentioned that 13.4 of the positive findings were only seen auring the second sleep cycle. This can be the consequence of the sleep changes which may occur during the first cycle following one night Tso and which consist of a much shorter onset of sleep and a decrease in the 1 light $N$. REM $1-2$ sleep.

d. The mean sleep latency was $6.3 \mathrm{~min}$ in our population. During this short perilod wakefulness was characterized by a low and instable vigillance, which favours the occurrence of epileptic EEG abnomalities (Faber, 1978). Some data from the literature suggest that recording only the wakefulness following one night TSD without sleep is sufficient to determine the epileptic EEG abnormalties. In onder to evaluate this we systematically kept 100 patients awake for 30 minutes during TSD recordings. The number of registrations with epileptic EEG abnormalities during this wakefulness period was $29 \%$. This is 17 lower than the percentage established durdng the first $30-\mathrm{m} 1 \mathrm{n}$ period of recordings following TSD when patients were allowed to fall asleep spontaneously. This higher percentage makes a sleep recording desirable. Furthermore, artiflcially keepling patients awake is unpleasant for the patint.

e. Because of the long recording time we were able to calculate the percentage diagnostic gain in relation to time The diagnostic gain was 57.3 following one hour recording time, this increased to 69.4 after 2 hours and to 74.5 after 4 hours. The adaltional gain of 5.1 achieved during the third and fourth recording hour was independent of the type of epilepsy.

f. The higher percentage positive diagnostic findings using our TSD procedure is in our opintion not only the consequence of a longex duration of the recording but also of the changes in wakefulness and sleep which result from the preceding sleep deprivation. Thus during the sleep latency periad, wakefulness is charactexized by a 
changing and often low degree of vigilance, whereby "microarousd ${ }^{\text {m }}$ need to be continuously given to prevent the occurrence of lieep. It is krown that such variations in wiglance (Faber, 1978) favour the occurrence of epileptic EEG abnormalities. Apart frow this, we observed during the sleep following wsD in epileptics larger varlations and more series of sharp vertex waves and sharp to eplleptic k-complexes as compared to an all-night 1eep. These findings point respectiwely at an increased instability of the sleep, through which more intermediate sleep stages occur (Halasz, 1982) and to an increase of cortical excitability during Ifght N.REM $1-2$ sleep (Niedermeyer, 1981) or changes which favoux the occurrence of epileptic EEG abnormalities.

2.3. Sleep structure of the all-night sleep in epileptics (Chapter VI)

According to the literature the presence of eplileptlic EEG abnormalities hardly changes the sleep structure. In our investigathons which were restrlcted to do the first and second sleep cycle of an ald night sleep some differences between epileptics and a control. group were found.

a. Eplleptics often have a longer-lasting first and second sleep cycle, almost completely due to an increase in light N. REM 1-2 sleep. Further, epileptics become more frequently awake and sleep fractionations often occur. This might be associated with the existence of a high degree of cortical hyperexcitability during lifht N.FEM 1-2 sleep, through which the arousal reactions are more violent and can easily give rise to more awakenings and by which deep sleep is less easily induced and maintained.

b. The mentioned differences are less pronounced when antiepileptic medication is taken. From this one can derive that these medicines carry out their action by reducing the cortical hyperexcitability through whilch the sleep stabilizes and epileptic EEG abnormalities diminish. This is linked up with the experience that the sleep abnormalities of the epileptics which have epileptic EEG abnomalities are often larger than in those which do not have epileptic EEG phenomena.

c. When the sleep is not disturbed by other diseases (e.g. severe organic brain damage, depression, etc.) then the sleep changes are only moderately dependent on the type of epliepsy. There is somewhat more N.REM 1-2 sleep in patients having a generalized form of epilepsy, somewhat more FEM sleep in those having a partial form of epllepsy and when both forms of epilepsy exist, both forms of sleep increase.

a. In contrast to some findings in the literature ifindji et al. 1978) we did not find an absolute, but a relative decrease, of deep N. Pry 3-4 sleep, due to a prolongation of the cycle length. In many epileptics, the delta activity during deep $\mathrm{N}$. $R$ EM 3-4 sleep had a strikingly low amplitude or there was a strong spread in the frequency with more fast delta waves of $2-3 \mathrm{c} / \mathrm{sec}$. This can be associated with an insufficient functioning of sleep mechanisms, which induce deep N. REM 3-4 sleep, and which can be based om epilepsy, or the intake of antiepileptic medication. 


\subsection{The sleep structure of TSD sleep in eplleptios lchaptex VIII \\ There is: a consensus in the literature that the changes in}

sleep following one night TsD are mainly restricted to the furst sieep cycle, which consists of a decrease in light N. REM $1-2$ gleep ox an increase in N.REM 3-4 sleep, sometimes associated with decrease of the REM sleep. We found similar changes in our control population, but some of these changes were different in epileptics.

a. As comparea to an ali-night sleep, in both control and the cilnical group, there was a shortening of the cycle length during the sleep following TSD. In the control group, the effect was restricted to the first cycle in wich thexe was a relatively larger decrease of N. REM I-2 sleep. In epileptics, there was a shortening of the first cycle and to a lesser extent of the second cycle. In the first cycle, this was mainly due to a decrease of $\mathbb{N}$. REM $1-2$ sleep. and a less strong increase of $N$. REM $3-4$ sleep as compared to the control group and in the second cycle due to less REM sleep. It seems as if epileptics can only move slowly and less effectively recuperate fxom the consequences of a one night wakefulness. This is not surprising, since the changes induced by sleep deprivition are opposite to the changes established during an all-night sleep in epileptics. Wherefore, these sleep changes need to be neutralized before the deprivation effect can be expressed.

b. All patients, except for the clinical group treated with the combination of fixst choice antiepileptics and benzodiazepine derivatives, had a longer sleep cycle following TSD than in the control group. Though this was also established during spontaneous nooturnal sileep, whereby the prolongation was only due to an increase of $N . R E M \quad 1-2$ sleep, this was mainly due to an increase of light and deep $N$. REM sleep following TSD.

Further, the differences in sleep structure of the first sleep cycle following one night TSD are much less than during the spontaneous nocturnal sleep. It is reasonable to assume that precisely the strong decrease of 1 ight $\mathrm{N}$. REM $1-2$ sleep following $\mathbb{L} \mathrm{D}$, or the sleep wich is most sensitive to different influences, is therefore responsible.

However, in conformity with the all-night sleep, also during sleep following TSD, we found small differences in the composition of the sleep between the clindcal groups which heve elther generalized or partial epileptic EEG abnormalities, or which have phenoniena of both. In the patient group between $20-40$ year there was rellatively somewhat more light $\mathrm{N}$. REM 1-2 sleep in the presience of generalized epliepsy and somewhat more REM sleep in the presence of partial epleptic EEG abnormalities and an increase of $\mathrm{N}$. REM $1-2$ sleep well as RFM sleep when both forms of epliepsy co-exist. The lattex pattern was not Eound in patlents younger than 20 years, whil ch had both forms of epilepsy. In comparison, with patients which have generalized epilepsy " they only had more light N. REM $1-2$ sleep. Thls finding fits with the clinical data that certain forms of generalized epllepsy preferentially occur at an early age. The preponderance of this form of epilepsy would then explain the observed sileep pattern. 
c. The sleep structure following one night TSD is age-dependent and can be influenced strongly by the intake of benzodiazepine derivatives. When these factors are excluded, then one can state that one night TSD also affects the sleep in epileptics in a stereotyped way. The absence of this influencing pattern, appears to be based riatily on an incomplete sleep deprivation (for instance a not well-controlled total sleep deprivation during the night) or the existerce of a cerious slexp alsturbance caused by a non-epiLeptio disease.

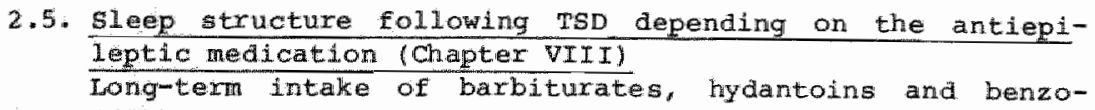
diazepine derivatives can give rise to an increase in N. REM I-2 sleep, a decrease of N. REM 3-4 sleep and REM sleep, and a prolongation of the cycle length (II.2.4.). This can be accompanied with an increased need for sleep which according to Feinberg et al. (1979) originates "by slowing the metabollc processes of sleep so that longer sleep duration is required for the same biological effects". Hitherto, no extensive studies have been carried out on how sieep in eplleptics is affected by long-term intake of carbamazepine and valproate, and of antiepileptics in combination with benzodiazepine derlvatives (Johnson, 1982). In order to evaluate this we sampled a patient group in which a sleep recording following TSD was performed and whilch had a well-partitioned first sleep cycle. Further, the patients were treated only with carbanazepine, sodium valproate, diphenylhydantoln, or with two of these antiepileptics, or first cholce antiepileptics in conjunction with the benzodiazepine derivatives chloxazepate or clonazepam. An advantage of this study appeared to be the fact that the interindividual differences in the composition of the first sleep cycle largely disappear following one night TSD. This increases the likelihood that the measured differences are medication-dependerit.

a. The effects of first cholce antiepileptics on the sleep structure. such a study appeared reasonable since most data from the Iiterature concern the chronic use of barbiturates. These drugs, together with benzodiazepine derivatives, are often prescribed for thel hypnogedative effects and less frequently because of their antlconvilsant properties. Our investigation concerns those drugs which are taken in the first place for their anticonulsant properties. In accordance with the structure of the all-night sleep in patients taking only diphenylhydantoin (Sengoku and wolf, 1981) we found the following changes in the sleep aftex ISD: a prolongation of the oycle length caused by an increase in N.RFM $1-2$ sleep. deep N.REM 3-4 sleep stays the same, however, the patients become awake for shorter periods. Also the intake of sodium valproate gave rise to a longer cycle length caused by an increase in N. REM 1-2 sleep and an even more pronounced increase in deep M. REM 3-4 sleep. The effects of the intake of carbamazepine on sleep differed in that a stronger lincrease in $\mathrm{N} . \mathrm{REM} 3-4$ sleep was compensated by an equal decrease in the amount of $N$. REM $1-2$ and REM sleep, through which the eycle length remained the same. Such differential influences on the structure of the sleep suggest that the mechanisms of action of these antiepileptics differ. 
Hydantoin derivatives are known as arugs which raise the meuronal firing threshold at thalamocortical level and whlch stablilue the cell membrane potential (Englander et a 1. 1977). By this they are able to suppress the chance of, or the presence of increasing cortical hyperexcitability. Long-term usage of these arugs can by continuously suppressing hyperexcitability lead to a slowing of brain functioning. This is clinically expressed durlng the day by a lower degree of vigilance and electroencephalographically in a diminishing of the frequency of the EEG rhythms or with a mixing of slow waves (Longo, 1977). During the night there is a slower recovery, through which the need for sleep increases and the cycle length increases (Feinberg et al. 1979).

Sodium valproate derivatives are compounds which erhance the cerebral GABAergic activity, a neurotransmitter which has inhibitory properties. This drug is indicated in conditions of a lowered cortical inhibition. This can exist in patients which have a generalized form of epilepsy (Metrakos and Metrakos, 1961). It might be that this medical readjustment of the brain can also be responsible for an effective recuperation following TSD, which is expressed in a stronger increase of the deep than the Iight N.REM sileep.

The influence of carbamazepine on the sleep pattern is somewhat more than the influence of TSD itself in the control group. It seems as if carbamazepine activates the compensatory mechanisms in patients, which result in a recuperation within the first slevp cycle, just as is seen in healthy persons. From many investigations (e.g. Ballenger and post, 1980) it appears that carbamazepine is able to suppress the cortical epileptic discharges originating in the limbic system and spreading to the diencephalon. Recently (Sillanpää, 1981) it has been suggested that the specific mechanism could be attributed to the anticholinergic properties of carbamazepine. Therefore, it is not surprising that this antiepileptic is especially useful for partial epllepsy of temporal origin. The mechanism of action can be partially understood from the fact that carbamazeptne resembles imipramine, a tricyclic amine known to cause comparable EEG changes (Jovanovic, 1974).

As mentioned earlier it is not excluded that the differences are partially connected with the form of epllepsy for which these antiepileptics are prescribed. The group only treated with carbamazepine in oux population, are almost exclusively normal to sightiy subnormal functioning subjects which have a psychomotox form of epilepsy. This signifies that only a small part of the cortex is disregulated and that the majority can be conisidered as normal. This might also be the reason why the sleep structure in these patients hardly aiffers from those in the control group.

patients treated with valproic acid derlvatives suffered almost exclusively from a generalized form of epilepsy and had a nomal to subnormal (I.Q. $>75)$ functioning level. This means that all parts of the brain cortex are subject to epileptlo discharges, through which sleep can be more affected.

Finaliy, the diphenylhydantoin group consists of subjects which have a severe form of epilepsy (mostly partial epillepsy with secondary generalization), and of which the epileptic abnomalities are only part of more generalized disturbances in cerebral functioning * 
When the treatment ith antiepileptics was unable to control the epllepey, patiente mere treated with two antiepileptics. From our intestgations it appeared that both antiepileptics affected the sleep though unequally. With the combination of carbamazepine and sodium valproate there was a predominant carbamazepine effect and wth the combination of hydantoin and sodium valproate, there was a predominant hydantoin effect.

Becaluse antiepileptic can affect the epileptic EEG manifestations as well as the sleep, it is not surprising that some authors axe of the opinion that better adjustment of the epilepsy is accomplished also by an improved sleep regulation (Röder and Wolf. 1980 and further, that a disregulation of the sleep can precede a deterioration of the eplilepsy (Arguner, 1977).

b. The influence of a combined therapy of antiepileptics and benzodiazepine deriwative on the sleep structure.

It is now generally accepted that part of the activity of benzodiazepines is brought about by an activation of a GABA system and through an influence on the limbic system (McCarley, 1982; Gallager, 1982). Most benzodiazepine derivatives give rise to an increase of the light $\mathbb{N}$.REM $1-2$ sleep and a prolongation of the first cycle length (Johnson and spinweber, 1981). We found similar effects in epileptics treated with antiepileptics in combination with chlorazepate and clomazepam on the sleep following one night TSD. Both groups, however, differed clearly from each other. The expected rise in the deep N.RFM $3-4$ sleep as a consequence of sleep deprivation, was seen when chlorazepate was taken, but not following the intake of clonazepam. There too the problem exists that patient treated with clonazepam often had a more severe form of epilepsy, mainly based on generalized organic brain damage.

one could wonder whether the sleep changes are directly the consequence of the action of antiepileptics and benzodiazepine derivatives on cortical neurons, or to which degree they are based on a suppression of the regulatory mechanisms and the release of neurotransmitters (e.g. serotonin), which are of importance for the induction of deep N.RFM sleep and RFM sleep. However, it remains of interest that benzodiazepine derivatives, given in therapeutic doses and even in combination with high doses of antiepileptics, change the sleep following TSD in epileptics in such a way that one can derlve their mechanism of action from these.

\subsection{Age and the influence on sleep (Chapter VI-VII)}

Brain maturation is a gradual process which can proceed tili. the age of 1.5-20 years. An age-dependent effect on the sleep structure is known (Fischgold et al, 1959) as well as the agedependent occurrence of certaln forms of epilepsy (van Heycop ten Ham, 1974; Jeawons, 1977; Matthe:s, 1969).

The first and second sleep cycle of an all-night sleep is on the average longer in patients below the age of 20 years than in healthy subjects of the same age. This prolongation is due to an increase of N. RaM sleep which in subjects below the age of 20 years is predominantiy aue to a very strong rise in the amount of deep N. REM 3-4 sleep. This increase can be associated with a pronounced somatic growth during this age period in which there is a greater need of 
substances stch as the growth hormone matnly released during N.REM 3-4 sleep (Monnier and Gailiard, 1980).

The deprivation effect following one night TSD was more pronounced in patients below the age of 20 years. Below the age of 20 years, and when no antiepileptics were taken, the depriwation effect was age-independent. When antiepileptics were taken, there wia seinforcement of the deprivation effect (more deep N.REM 3-4 sleep), but this effect diminished with aging. The patient group between 5 and 9 years old differed, but this population group consists of severe brain damaged children which often have multiple handicaps. It seens as if the treatment with antiepileptics allows young eplleptics to compensate faster for the deprivation effect.

The effect of benzodiazepine derivatives is strikingly age-dependent. The deprivation effect is reinforced below the age of 20 years, but above 20 years it is complemented by a benzodiazepine effect. This gave rise to a strong prolongation of the cycle length, respectively due to an increase of deep $\mathrm{N}$. REM $3-4$ sleep with respect to the deprivation and an increase of $\mathrm{N}$. REM $1-2$ sleep and a decrease of the REM sleep with respect to the benzodiazepine derivatives.

our data show that the age limit of 20 years is important for the way the brain reacts to the medication as well as to the sleep deprivation. The latter $1 \mathrm{~s}$ in agreement with the findings in the literature (Ritter et al., 1977). The age factor has, therefore, to be taken into account in evaluating sleep structure.

2.7. Changes of the morphological aspects of the EEG fitting with epilepsy and sleep (Chapter IX)

It is known since a long time that sleep can change the electroencephalographic configuration of epileptic EEG abromalities and that certain sleep patterns and phenomena in epileptics have aspecific characteristics. We found analogous changes during the sleep in epileptics following one night TSD.

a. Changes of the epileptic EEG phenomena.

Since brain functioning during $N$. REM and REM sleep differs from each other in many aspects, it is not surprising that both forms of sleep differentially affect the epileptic EEG phenomena During light $N$. REM $1-2$ sleep, a stage considered as a condition of deactivation and diminished cortical inhibition, spikes developed to polyspike wave paroxysms and focal discharges spread to other areas in many patients.

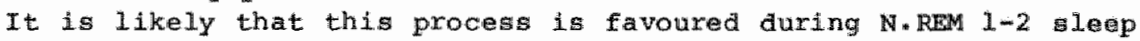
If one accepts that the spike is based on a summation of a large number of excitatory postsynaptic potentials occurring simultaneously in large groups of cortical nevrons. One car state that when these changes occur to a moderate extent they point at an adequate functioning of cortical neurons. For a clinical interpretation it is of great importance to take these changes into consideration. In our own investigations (Declerck et al., 1982) we found that in 32 of the patients, which had generalized splke wave paroxysms during a routine EEG recording, only had spike wave paroxysms during N. REM $1-2$ sleep. Further, when eplieptic EEG abnormalities were present only during N.RFM $1-2$ sleep, 70 of the PSW paroxysms correlated clinically with a primaxily generalized form of epilepsy. 
We often observed that the epileptic focus was better circumscribed during reM aleep in accordance with the literaturel, but also an increment in the guantity and specificity of the epileptic abnomalities was found. The latter almost exclusively concerned temporarily localized foci. This finding agrees with findings of Weser (1982) which established a decrease of cortical spiking during REM sleep, except in foct locilized in the limbic system and the supplementary motor area. Though not yet statistically confirmed in our material, these changes appear to correlate with the stablilty and density of REM sleep.

b. Changes of the sleep parameters.

Apart from the epileptic EEG abnomallties also the sleep parameters can undergo changes. To the most cited ones belong an increase in tharp vertex waves and sharp $K$-complexes, $E E G$ phenomena which can be present to an even moxe frequentily during sleep fallowling one night TSD (Klingler et al. 1982). We can confirm this finding. In addition, we found that when the epilepsy was weilcontrolled the sleep became more stable and this was associated wh an increase in sleep spindles (Sengoku and wolf, 1981; Declexck et al. (1982).

Except for an increased number in K-complexes we would like to draw attention also to the sharp aspect of the k-complexes found in epileptics. It is often difficult to differentiate these from the very short generalized aspecific splike wave paroxysms especially when they occur in short series. We have as yet been unable to investigate whether both phenomena are based on a similar hypersynch ronous mechanism (Miledermeyer, 1981).

2.8. The value of the total sleep deprivation method (chaptex $\mathrm{x}$ ) Within the scope of supplementary epilepsy investigations we studied whether the sleep recording following one night TSD is an effective and practical aiagnostic method. On the basis of our experience we proposed three procedures which, depending on the indication, were sufficient to study the epileptic EEG and the sleep changes in relation to each other as well as with respect to the treatment.

The first or simple procedure was especially focussed on the diagnosid of eptleptic EEG abnormalities. During this procedure a sleep cycle fis recorded during which all sleep stages are nomally present. These are required to promote the occurrence of epileptic EEG abrormalities and changes in their moxphology. In addition, their accurrence is promoted by the changes of wakefulness occurring during the seep latency period as well as of the sleep occurring during the flrst sleep cycle, as a consequence of the sleep deprivation. Following TSD, wakefulness is characterized by continuous fluctuations of wigilance, during which continuous microarousals are necessary to keep awake. These arousal reactions are based on hypersynchronization of mechaniams: which mainly favour the accurrence of generalized epileptic discharges. Similar fluctuations occur in a more pronounced way during the sleep following ISD and give rise to the appearance of more sharp vertex waves (wittenbecher and kubicki, 1982), more sharp and eplleptic K-complexes (Niedermeyer, 1981) and delta paroxysms (Nitoh et al. 1982) or phenomena which are also based on hypersynchronization. 
Although the mentioned morphological changes following sleep deprivation can also occur in subjects which do not have eplilepsy (kinglex et al., 1982) especially in young people (Ritter et alm, 1977), we never observed specific epileptic $\mathrm{EEG}$ phonona in patients which do not have epilepsy (Arnë-Bess et al., 1982). It lis therefore of utmost practical importance to clearly differentiate both types of EEG abnomalities in order to avold a wrong diagnosis. If we applied only this simple method, then the percentage diagnostic confinmaton would have been about 80 of the results achieved from a long-term. investigation consisting of two or more sleep cyeles.

The second or complex method is focussed on the one hand on forms of epilepsy which can only be diagnosed and differentiated with difficulty and on the other hand, on evaluation of the sleep in relation to the epileptic EEG abnomalities present and the arug treatment.

The results obtained during the sleep latency period and the ftrat sleep cycle are obviously equal to those obtained using the simple procedure. The absence of the expected sleep deprivation effect during the first sleep cycle can point at a severe brain disturbance or at the presence of a non-epileptic disturbance of the sleep or at the intake of antiepileptics. Especially the second sleep cycle following TSD is very useful for the study of sleep since 1 ts structure hardly differs from the second sleep cycle of an all-night sleep. on the basis of the composition of second sleep cycle it is possible to find out how and to what degree sleep in epileptics differs from that in healthy subjects of the same age, depending on the kind and degree of the epilepsy and its treatment.

Such an analysis is not only of importance for quantifying the sleep but also for determining the epilepsy. It has been established that a deterioration of epilepsy can be preceded by a disregulation of the sleep (Arguner, 1977) and that normalization of sleep can be an early sign of an effective treatment with antiepileptics (sterman and Shouse, 1980).

The third or directed method is required especially for a detailed study of EEG phenomena which can help in making a bettex differential diagnosis, or to better evaluate a therapeutic effect. Therefore it can be necessary to extend the method of recording (number and localization of skull electrodes) and of the methods of andysis (automatic). By way of example we mention the evaluation of shaxp $\mathrm{K}$-complexes, which may occur in youths or in epileptics. In youths "these physiological sharp $\mathrm{K}$-complexes are maximally localized on the vertex region whereas in epileptics they appear more in the frontal area (Wledermeyer et a l., 1981). One could also study the relationship between $\mathrm{K}$-complexes and sleep spindles, two phemomena occurring during the light $N$. REM $1-2$ sleep, but which are based respectively on an excltatory and an inhibitory mechanism (Naltoh et al., 1982).

\section{XI.3. CONCLUSIONS AND PERSPECTIVES}

From our study we can conclude that a sleep recording following one night TsD, under certain conditions, is a very suitable method to establish epileptic EEG abnormalities and to evaluate these in xelation to sleep in epileptics and, to evaluate the sleep in function of the presence or absence of epileptic EEG abnormalities and the medi- 
cation taken. We considex that the following conditions are very important: (1) afficient control on the efficacy of remaining awake durling the TsD period, (2) carrying out a sleep recording according one of the three procedures proposed (Chapter $x$ ) depending on the indication made, (3) describling and analyzing in a standaraized way the eplieptic and non-epileptic EEG abnomalities, (4) being familiar with the EEG changes which may occur with respect to the interaction between epilepsy, sleep, sleep deprivation and antiepileptlas and (5) taking the age into account (especially younger or older than 20 years) and the existence of severe non-epileptic dilseases.

To understand the interaction between sleep and epilepsy some knowledge of the phyiological and pathophysiological mechanisms of origin is required, in addition to the way by which diffexent antiepileptics can affect these mechanisms. This mutual influence can be expressed both in a change of the epileptic EEG pictures and in the change of the polygraphic sleep patterns. It is therefore of importance to study both aspects in relation to each othex. According our optinion the procedures mentioned would improve the diagnosis of epilepsy as well as the cholice of treatment and guidance of the epileptlo patients. In order to reallze this it is required to complement the visual analysis by automatic methods of analysis of which a number of examples are mentioned in Addendum 1 . It is therefore necessary to extend our investigations in the future in order to answer the following questions.

Question 1: If there an antagonism between sharp vertex waves and K-complexes on the one hand or sileep spindles on the other hand? Is their mutual relationshlp predictive for the probabdlity that epileptic EEG discharges occur and for the therapeutic effect of the medication given?

In our investigation we repetitively found that a normalization of the quantity of spindle activity is coincident with an improved regulation of epileptic and sleep abnomalities (Declerck et al.. $1982 \mathrm{a}, \mathrm{b})$.

question 2: To which degree are the changes in the sleep of epileptios useful as an additional parameter to bettex treat the epileptic and for the overall functioning of the patients?

Duxing our investigations we found that an improved sleep pattern colnaided with a better ajustment of the epilepsy, but also with a much better functioning of the patient. In addition we regularly found that due to the medication there were clear qualitative changes of the delta sleep.

Question 3: Is it possible to improve the quality of the $24-\mathrm{h}$ ambulatory EEG recordings to such extent that they are suited for an automatic and quantitative andysis such that the gradation and fluctuation of the vigilance during day time can be determined precisely and in relation to the sleep? 
The present study dealt ith the interactions between epilepsy. sleep and antiepileptics as based on dinical neurophysiological investigations.

In chapter I, the question discussed was whether a polygraphic sleep registration following one night total sleep deprivation (TSD) is a suitable method for the investigation of these interactions and whet criteria needed to be fulfilled in order to optimalize such a recording.

In chapter II the findings from the literature are sumarized and are divided into two parts. Part 1 treats the generally applied definitions of the EEG phenomena fitting with sleep and epilepsy and the criteria employed to classify the different forms of sleep and epilepsy. Part 2 surveys the different sleep methods which have been applied in oxder to register epileptic EEG phenomena and the sleep changes which may occur in epileptics in relation to the epilepsy and the intake of antiepileptics.

There exists an overall consensus that epileptic EEG abnomadities, of both the generalized and partial type, increase mostly during light N. REM 1-2 sleep. In contrast to REM sleep, during N.REM $1-2$ sleep more polyspike wave formation accurs, and these show a greater anatomical spread. It is generally accepted that sleep is not affected by epileptic discharges except for the occurrence of some morphological changes. However, sleep can be affected by the prolonged intake of antiepileptics.

In chapter III questions are formulated which could not be answered by studying the $\mathbb{l}$ iterature. These questions are necessaxy to determine the advantages and disadvantages of sleep recordings following one right TSD. Our own investigations aimed at answering these questions.

Chapter IV describes matexials and methods. The material consisted of more than 1500 polygraphic sleep recordings carried out during the period 1976-1981, in subjects which have or were suspected of having epilepsy. Of these $70 \%$ are recorded following one night TSD each lasting $3-5 \mathrm{~h}$ and 30 are recordings from the normal nocturnali sleep. All recordings were carried out with a 16- or 21-channel electroencephalograph of which minimaly 12 channels were used for recording $\mathrm{EEG}$ potentialis.

on the basis of the visual analysis, the sleep structure is represented in a hypnogram and underneath the following data are dascribed: the quantitative composition and the qualitative aspects of the sleep; type, duration and quantity of epileptic abnormalitie in relation to the kind and depth of sleep. Since 1979 the vilual analysls of sleep is complemented by an automatic computerized sleep analysilis and classification method.

Chapter $v$ describes the extent of the confirmation of epllepsy achieved during sleep. In an unselected population of patients suspected of having epilepsy, the dignostic gain reached 25 to 32 on the basis of a sleep investigation as compared to a routine EEG investigation carried out during day time. This gain amounts up to 50 for patients of whom, on a clinical basts, the diagnosis af epilepsy was vexy likely. of the 395 patients which olinically very 
probably had no epilepsy, in only 3 patients were specific epileptic EBG abnomalities observed during the sleep as opposed to 2 during a routine EsG investigation. Of the patients in whom clinical diagnosis of epilepsy was certain, specific epileptic EEG abrormalities were found in more than 3 w turing sleep.

The percentage gain obtained by recording an all-night sleep is for the generalized epilepsy 6 bigher than during a sleep recorang following one night TSD and equal for the partial epilepsy. In accordance with the literature most epileptic EEG abnomalities occur during N.RFM $1-2$ sleep and during the beginning of the sleep recording. Important is the finding that in about 13 of the patients eplieptic EEG abnomalities are only seen during the second sleep cycle, and in about 7 only aftex a recording lasting more than $2 \mathrm{~h}$. In adcition, for a number of patients suffering from generalized epilepsy recording of deep We Rew $3-4$ sleep is necessary.

Complementing the long term sleep recording following TSD which normally has at least two sleep cycles, with hyperventilation and/or intemittent light flashes, has only a very limited value. In addition, wch investigations are burdensome for some of the patients.

The general conclusion is that the sleep recording of two sieep cycles following one night TsD are considered as optimal for the establishment of epileptic EEG phenomena.

Chapter VI deals with the quantitative changes of the composition of the first and second sleep cycle during the habitual nocturnal sleep in eplleptics in comparison with a healthy control group. All patients have a longer cycle duration, due to more N.REM sleep, especially light N.REM $1-2$ sleep. The differences are smallest for those patients which have eplleptic EEG abnomalities during the sleep and which take antiepileptics. By adding benzodiazepine derivatives to the antiepileptics, N. REM $1-2$ sleep increased. Depending on the type of epilepsy, only small diffexences were seen: more N. REM 1-2 sleep in the category with generalized forms of epilepsy, more REM sleep for the partial form of epilepsy and an increase of N. REM $1-2$ as well as REM sleep when both forms of epilepsy co-exist.

In chapter VII the composition of the first and second sleep cycle following one night TSD in epileptics as compared to that of healthy subjects is described. The presence or absence of epileptic EEG abnomalities during sleep and the differences in sleep structure depending on whether antiepileptic medication is taken or whether antiepileptics are combined with benzodiazepine derivatives was investigated. The results show that during the first sleep cycle in epileptids well as in healthy subjects the sleep deprivation eftect. dominates over other influences cited for the ali-night sleep. The sleep pattern following TSD is affected in a stereotyped way there 1 a shortening of the sleep latency and of the total duration of the first sleep cycle. This is due to a decrease in $\mathrm{N}$. REM sleep in which there 1 is a relatively increased deep $\mathrm{N} . \mathrm{Rr}$. $3-4$ sileep as opposed to light $N$. REM $1-2$ sleep. These effects almost disappear during the second cycle, which resembles in many aspects, the second sleep cycle of ali-night sleep. In this chapter the importance of the age factor, especially the 20-yeax limit is stressed. The deprivation effect is more pronounced below the age of 20 years and this is further accentuated in patients taking benzodiazepine derivatives. Above the age of 20 years the deprivation effect is less pronounced, but is 
complemented by a benzodiazepine efrect which expresses itsedf by a lengthening of N. REM $1-2$ sleep.

In chapter VIII it is described that the sleep composition of the first sleep cycle following one night TSD in eplleptios treated with one or with maximally two antiepileptics, depended on the type of the antiepileptic medication taken. The effect of the deprivation $1 \mathrm{~s}$ reinforced by the intake of carbamazepine and to a lesser extent by the intake of sodium valproate, but is neutralized by the intake of hydantoin derivatives. As compared to healthy subjects, the total cycle length of the first sleep cycle is prolonged by the intake of hydantoins and valproate derivatives. The prolongation seen after lydantoin derivatives is mainly due to an increase in Iight N. REM $1-2$ sleep and with the intake of valproate, due to a smaller increase in light $\mathrm{N}$. REM $1-2$ sleep and a more pronounced increase of deep N.REM 3-4 sleep. We could also demonstrate that benzodiazepine derivatives given in combination with antiepileptics affect the composition of the furst sleep cycle following TSD and that the kind and size of these changes depended on the benzodiazepine derivative taken. In addition, it is pointed out that the registered differences in the sleep composition as a consequence of the intake of antiepileptics or benzodiazepines are also dependent on the type and the intensity of the brain disturbances, responsible for the existence of epilepsy.

Chapter IX is composed of a series of investigations dealing with an the one hand the changes in the form of the epileptic EBG phenomena which may accur during the sleep and on the other hand the changes in the polygraphic sleep phenomena as a consequence of the epilepsy and its treatment. It is important to be aware of these changes as well as of their clinical significance in order to adequately intexpret the epileptic EEG abnormalitles aring the sleep.

Further, we also show that certain changes seen during an alinight sleep recording in epileptics occur in ai similar way, e.g* periods of apnea or even in a more pronounced way e.g. sharp $K$-complexes during the sleep following one night TSD. Certain changes which may be associated with the medication taken, such as a decrease in fast eye movements or muscle activity make these parameters less suitable as criteria to differentiate the kinds of sleep. This objection is mast important when automatic sleep classifications are used.

In chapter $x, 3$ sleep procedures following one night TSD differs, according to the aim of the study. The first or simple procedure mainly serves for the diagnosis of epilepsy. The second or complex and more elaboxate procedure is aimed at studying epllepsy, sleep and the influence of antiepileptics. Finally, the thixd or specific procedure denotes that it can be necessary to adapt the recording and analysis due to the aims of the investigation.

Chapter XI is the general discussion and consists of 3 parts. In the first part we aiscussed the physiological and pathophysiological regulatory mechanisms of sleep and epilepsy, by which we galln gome insight into the way they may affect each othex.

In the second part we discussed the results of our own investigations on the basis of these insights, and show how our results differ in certain aspects from the data in the literatuxe. We also alm to explain the differences in the sleep structure of the first sleep 
cycle following one night TSD depending on the type of antlepileptic medication taken, on the basis of their postulated mechanisms of action.

In the third paxt some of the important conditions of the TSD procedure which need to be fulfilled in order to achieve an optimal diagnostle gain are described. Further, some recomendations for further investigations are given.

The addenda containi a discussion of the automatic sleep stage classification (Add. I) and the statistical method applied (Add. 2). Thereafter, follow a series of tables which contain supplementary data concerning differences in the compostion of the first and second sleep cycle of the all-night sleep, the sleep following one night TSD (Add. 3) and finally, a list of all figures and tables is given (Ada. 4 ). 
CHAPTER XIII: ADDENDA

Addendum 1: Experiences with utomated sleep analysis.

Addendum 2: Statistical method.

Addendum 3: Tables with complementary data, corxesponding with the simplified tables mentioned in the chapters VI, VII and VIII.

Addendum 4: Iust of tables and figures. 
(H.I.J. Haxtens) *

AdA. 1.1. STEEP CLAS SIFICAT TON

The first (watugier et al., 1979) and the second method (Matens et a 1*, 1981) of atitomated sleep analysis, as described previously (IV.2.2.) are based on an on-line procedure wh which a set of parameters is extracted from the runing EEG, and an off-line procedure, to classify the leep, which is the same for both methods.

In the off-line procedure (wauquier et al., 1979) the parameters are displayed over the whole registration time up to 8 hours. Then their validity is evaluated and a selection is made of those parameters which could be useful to classify sleep. Thereafter, 5 epochs are chosen visually as being representative examples of the various s leep stages for each individual patient. Finally the classification is carried out automatically by calculation of the "distances" of each consecutive epoch to the different sleep stages and labelling the epoch with the sleep sitage.

whe most relevant parameters appear to be: (I) the delta timecourse for all the sleep stages, (2) the sleep spindle time-course of the N. REM 2 sleep, (3) the alpha time-couxse for the detection of awake periods and for discrimination between awake and REM sleep, (4) muscle activity to detect movement artefacts, and (5) the time-course of rapid eye movements.

Using the first method, there was a good agreement between the visually and the automatically scored hypnograms for the N.REM 2 and N. $R E M$ (more than 908 ) and the REM sleep (more than $80 \%$ ), but the correlation was rather poor (Less than 70 ) for the $\mathrm{N}$. REM $\mathbb{1}$ and the N. REM 3 sleep stages. This can be caused by the fact that the criteria of Rechtschaffen and Kales axe not completely covered by the parameters used for the automatic classification (e.g. sharp vertex waves and $\mathrm{K}$-complexes axe not estimated and by the method of quantification based on power density spectra (one does not know in which percentage of time an EEG $x$ hythm is present within a certain epoch). In the second method the agreement between the visual and the automated sleep classification could be improved by (1) a reduction of the variance of the different time courses of the parameters measured; (2) conpenation for the interaction of some parameters; (3) an appropriate recognition of artefacts and (4) an extension of the set of parameters.

Add. 1.2. QUAMTIFICATION OF THE PARAMETERS

In the on-line procedures of both methods the time signals are segmented into epochis of 30 seconds and power diensity spectrum analysis is carried out on the $\mathrm{I}_{4}-\mathrm{C} 4$ and the P4-O2 EEG derivations.

* Medical Physidist, staff coworker of the Department of EEG and Clinical Neurophystology. 
In the first method an estimation of the activty of the various EEG xhythms is obtained by integration of the power density trom 0.5 to $3.5 \mathrm{~Hz}$, from 3.5 to $7.5 \mathrm{~Hz}$, from 7.5 to $11.5 \mathrm{~Hz}$ and from 11.5 to $20.5 \mathrm{~Hz}$. In the second method the integration of the powex density is restricted to peaks, with as a resuit a reduced variance in the delta theta and alpha time courses. Besides, by displaying the two frequencies of these rhythm where the power density is decreased to half the maximal powex density of the peak, it is possible to get an impression not only of the peak frequency of the rhythms (or low frequency artefacts) but also of their time behaviour. A narrow "double" trace as shown in Figure IV.6. (IV.2.2.) corresponds to a stable rhythm within an epoch (e.g. a pure sine wave) while somewhat broadened tracings reflect stochastic vaxiability. These traelngs: axe only indicated if they exceed the visualiy detexmined levels.

In the first method sleep spindles are detected after a further segmentation of a 30-second epoch into time segments of 0.8 seconds, followed by spectral analysis and evaluation of the 11.25 to $15 \mathrm{~Hz}$ frequency band. In the second method a matched filter with adjustable peak frequency and bandwidth is calculated from the spectrum of each epoch and thereafter this fidter is applied to the corresponding EEG sigmal. The resulting impravement of the signal to noise ratio facilltates detection of sleep spindles and calculation of their duration. Peak frequency and time duration of sleep spindles are also indicated as time courses. The bandwidth of the filter, matched to sleep spindles, appears to be about $1 \mathrm{~Hz}$ on average; as a result, detection is much less sensitive to disturbing activities compared to a more conventional approach considering the 11-15 $\mathrm{Hz}$ frequency band.

If sleep spindles have been detected, the corresponding part of the spectrum is set to zero; also the fixst harmonic of the alpha rhythm is removed from the spectrum and then the beta activity is estimated by integration of the power density from 11.5 to $25 \mathrm{~Hz}$. As. a result, the alpha, beta and sleep spindle time courses appear to have independent behavilour over time, which has benefictal effects for the sleep classification.

In the first method the mean amplitude of the EMG and EOG derivations are calculated for each epoch. In the second method, rapid eye movements are detected using a filter, matched to REM's and an inverse filter, to reduce the influence of EEG activity.

In Figure IV.6. (IV.2.2.) the various parameters show a rather smooth behaviour over time. This is caused by thelir more optimal quantification and by application of off-line amoothing to the various parameters. By this procedure ("Wiener" filtering, described by de Weerd and Martens, 1978), a slowly changing parameter is smoothed heavily and a quickly changing parameter only silghtly " Ihis leads to a better estimation of the various time course parameters by combining a maximal reduction of variance to a minimal distartion.

A Euture extension of the method will concentrate on quantiflcation of phenomena such a sharp vertex waves, $K$-complexes and paroxysmal discharges. However, although all the refinements, as mentioned, wil improve the agreement between the automatically and visually scored sleep classification, one may wonder if this is the only goall of the automated EEG analysis. In our department, the rough plot of the different parameters without classification are presented to the physician as a pre-screening. It can help him to interpret the EIG 
In more objective and faster way. Afterwards, with the visual andysig as gulde Iine, one can select from the parameter plot well-deflned periods of neurophyslological stability as e.g. the W. FEM 2 and 4 tage. The great number of objective measurements now allow valid statistics on these periods to be made and allow interarell as intra-individial comparisons (Declerck et al., 1982).

The author wishes to thank Dr. A. Wauquier, J.L. Verheyen, W.A.E. Van den Broeck and Dr. P.A.J. Janssen fox getting the disposal of their software sleep analysing method. 


\section{INTRODLCIION}

In this study the aim was to get an idea of the sleep composition of various groups of patients showing different forms of epilepsy and $/$ medication. Therefore from the total patient group various subgroups were formed and the composition of their first and second sleep cycle was calculated. The only purpose of the statistics, as used in this study, was to indicate to what extent clear, clinically relevant findings could be relied upon in extrapolating the findings from a certain subgroup (a sample, e.g. 50 patients having partial. epilepsy) to the corresponding population (all patients in the world having partial epilepsy). Therefore, so-called confidence intervals for the means were calculated; apaxt from the extrapolating power of such intervals they also can easily be compared to another in direct graphical representations (see e.g. Figure VI.16.), thus yielding a procedure of testing for significance of differences between sample means. Compared to the classical t-testing for significance of difference between two sample means (which is equivalent to testing, whether the confidence interval for the difference of two sample means includes zero and which therefore is focussed on the rejection of the hypothesis, that there is no difference) the comparison of the confidence intervals of two sample means will result into lower levels of significance, especially when these samples show different sizes and variances, which was often the case in this study.

\section{CRITERIA FOR A SLEEP CYCLE}

In Figure Add. 2.1. histograms are shown of the minutes awake, N. REM 1-2, N. REM 3-4 and REM sleep of the first cycle after one night sleep deprivation as derived from the total patient group ( $n$ : 548 ) who showed an appropriate first cycle. A first sleep cycle was rejected if it contained:

$>60$ minutes awake or

$>120$ minutes N. REM $1-2$ or

$>120$ minutes N. REM $3-4$ or

$>60$ minutes REM sleep.

The second cycle was rejected according to the game criterian or in case of an inappropriate first cycle.

\section{CONSTRUCTION AND USE OF CONFIDENCE INTEEVALS FOR THE MEAN}

By defining

$\bar{x}=\frac{1}{n} \sum_{i=1}^{n} \quad x_{i}=\frac{1}{n} \Sigma x$

as the mean of a parameter $x$ of a certain sample with size $n$ (e.g. 50 patients having partial epilepsy), this $\bar{x}$ is an estimate of the true mear $\mu$ of the population (ali patients in the world having partial epilepsy). 

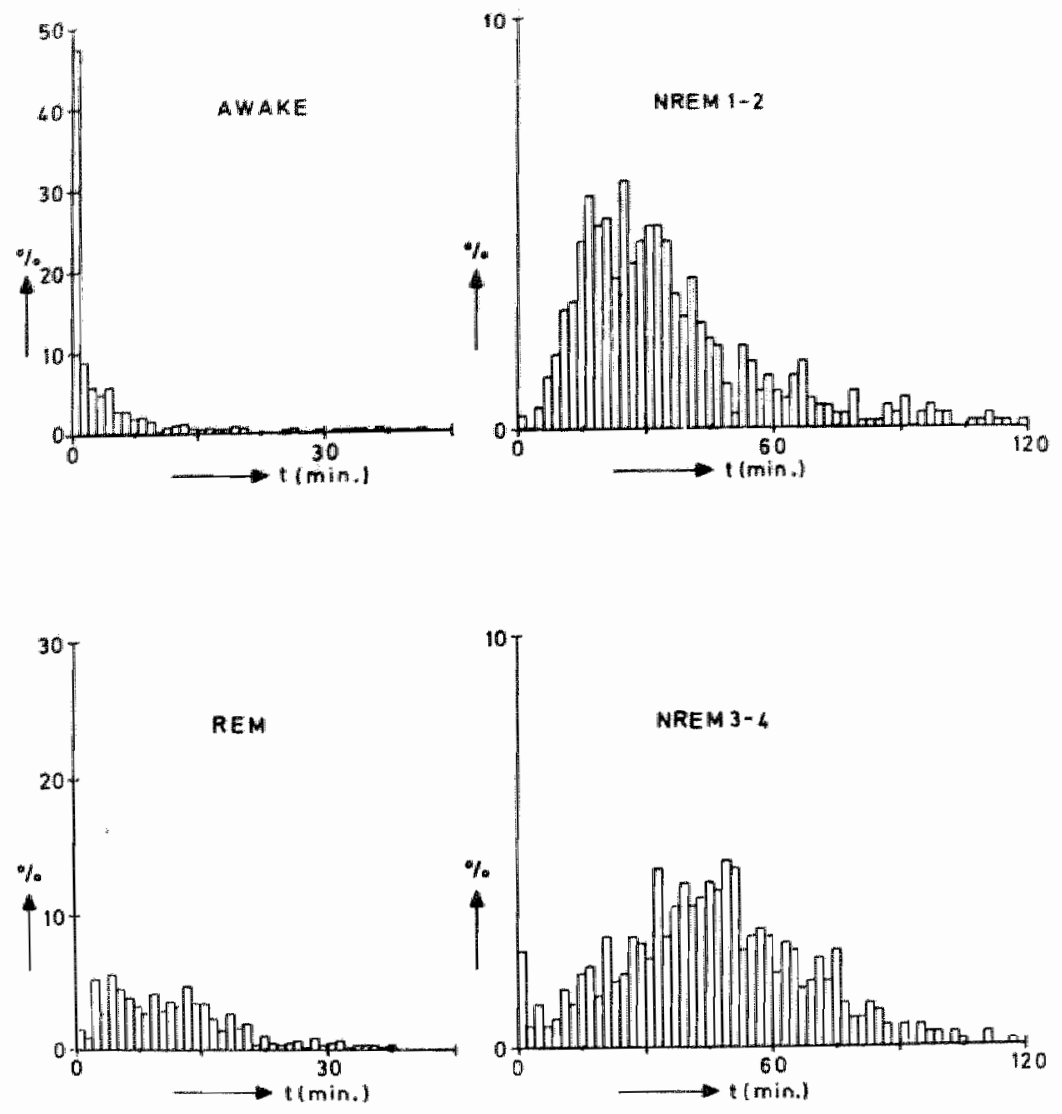

FIG. ADD. 2.1.

Histograms of minutes awake, N.REM 1 -2, REM and N.REM 3-4 sleep of the first cycle after one night sleep deprivation of the total patient group $(\mathrm{n}: 548)$.

By defining:

$=\sqrt{\left\{\frac{1}{n-1} \quad \Sigma(x-\bar{x})^{2}\right\}}$

as the standard deviation of the parameter $x$ of the sample this $s$ is an estimate of the true standard deviation of the population.

Iuet us define:

$u=\mathrm{n}-\mathrm{L}$

is the number of degrees of Exeedom of the sample.

By considexing another sample, of course another $\bar{x}$ and $s$ will be found; $\bar{x}$ and $s$ can be considered as stochastic variables. For the mean of the means of ald possible samples it yields:

$\mu_{\vec{x}}=\frac{1}{n} n_{n}=\mu$ 
If the size $n$ of the samples is not too small then for the atandard deviation of the means of all samples it yields:

$\sigma_{\bar{x}}=\frac{d}{\sqrt{n}}$

This $\sigma_{\bar{x}}$ is called the standard error of the mean (S.E.M.). If the aistribution of the parameter $x$ is about Gaussian, the means of the samples with size $n$ appeax to vary around the real mean $\mu$ accorang to a Gaussian distribution having a standand deviation $\sigma / \sqrt{n}$ (see Figure Add. 2.2.).

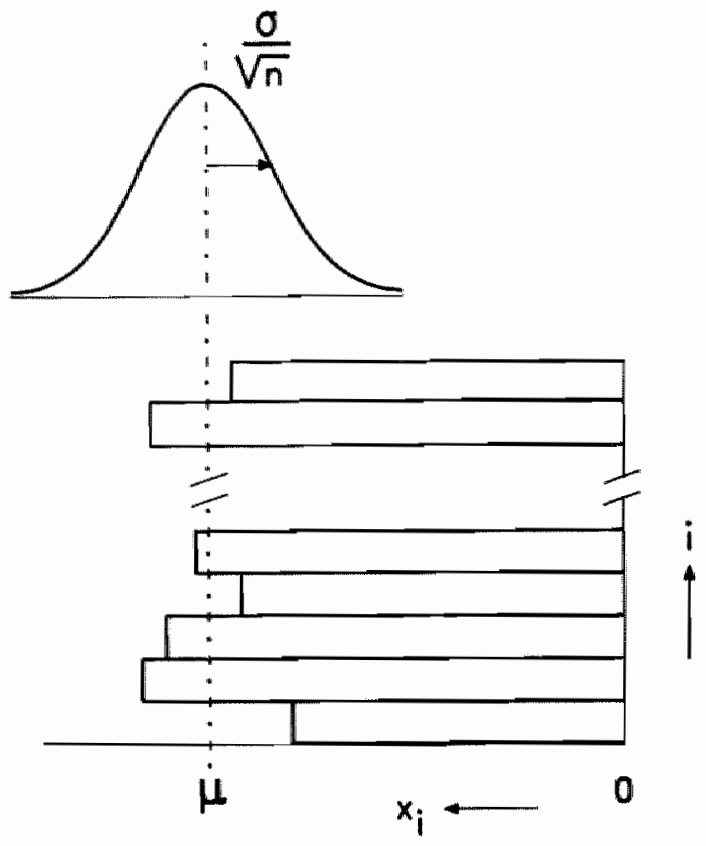

FIG. ADD. 2.2 .

Distribution of the sample means with size $n$.

However, o is unknown mostly; now one can use the standaxd deval tion, as measured from a sample, for an estimated S.E.M.

$s_{\bar{x}}=\frac{s}{\sqrt{\pi}}$

By subtraction of the mean and division by the estimated s.R.M., one arrives at the quantity:

$t=\frac{\bar{x}-\mu}{s / \sqrt{n}}$

which follows a so-called STUDENT-distribution with a number of n-1 degrees of freedom; the distribution is symetrlcally around the mean Hit with: 
$\mu$

and

$\sigma_{t}=\sqrt{\{u(v-2)\}}$
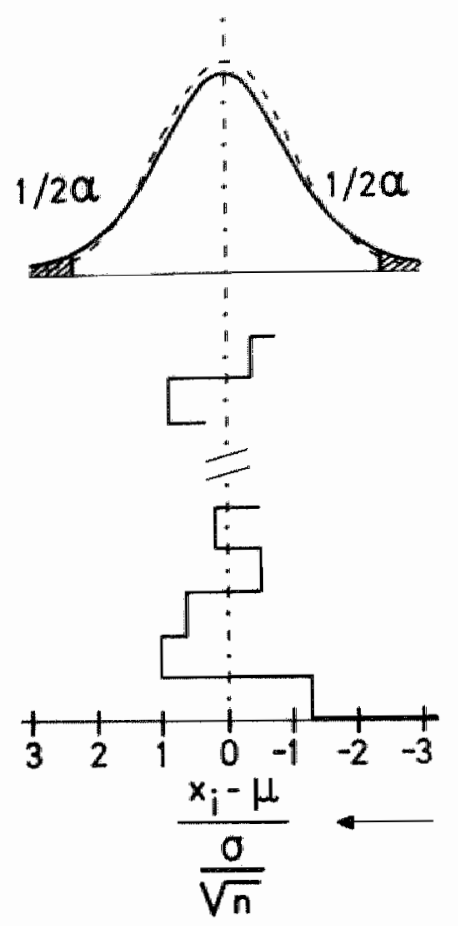

EIG. ADD. $2 \cdot 3$.

Dlstribution of normalized sample means with size 6 .

In Figure Aad. 2.3. the STUDENT-distribution is depicted for $u=5:$ the dashed 1Hne indicates a Gaussian distribution having zero mean and standard deviation 1 . With an increasing number of degrees of freedom - so with increasing sample size - the STuDENT-distribution approximates the Gaussian.

The $1 / 2$ a percentlles of both these distributions are listed in almost any statistical handbook.

Without exact knowledge of $\mu$ and $\sigma$ of the population, one can construct a so-called $(2-a) \times 100$ confidence interval for the mean of an ad random sample with size $n$ by taking:

$\bar{x} \pm t_{1 / 2 \alpha} \frac{s}{\sqrt{n}}$ 
This interval is determined by:

1. the sample mean $\bar{x}$

2. the sample standard deviation s

3. the sample size $n$

4. the $1 / 2 \alpha$ percentile of a stuDENT-aistribution with $n-1$ numbers of freedom

5. the required level of confidence (95.99, etc.).

Apparently the confidence intervals are increasing with a higher level of confidence and decreasing with an increasing sample size. Considering confidence intervals for the means of several ad random samples from the population, the population mean $\mu$ will be within these intervals in an $(1-a) \times 100$ percentage.

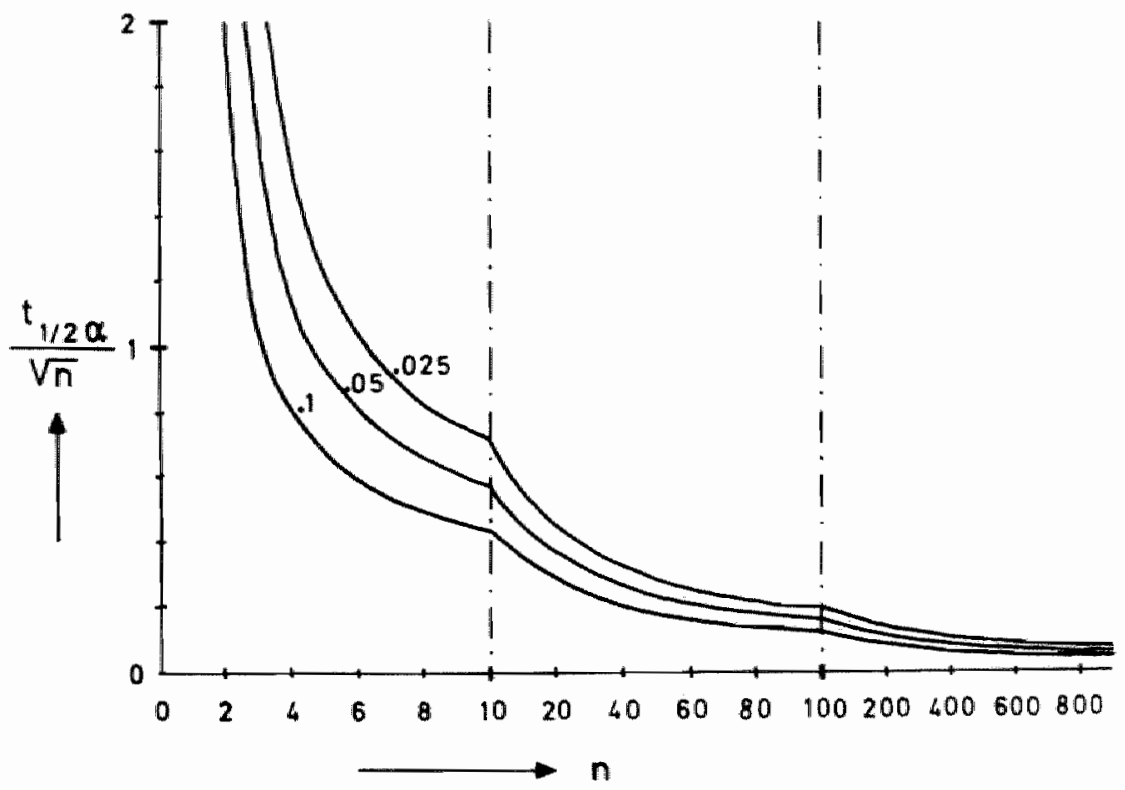

FIG. ADD. $2 * 4$.

The quantity $u$ as a function of the sample size $n$ for $1 / 2 \alpha=0.1$, 0.05 and 0.025 .

In Figure Ada. 2.4. the quantity

$u=\frac{t_{1 / 2} \alpha}{\sqrt{n}}$

is depicted for $1 / 2 a=0.1,0.05$, and 0.025 .

This quantity indicates, which portion of a measured standard de viation of a sample - having size $n$ - has to be taken into account for the construction of the confidence interval around the measured mean of the sample. 
Example

Suppose, sample 1 with size 5 has a mean $\bar{x}_{1}$ and standard deviation $s_{1}$ and arother sample 2 with size 8 has a mear $\bar{x}_{2}$ and $s_{2}$. From Figure Ada. 2.4. it follows for both 90 w 95 and 97.5 onesided confidence intervals:

90 皮

Sample 1 . $\bar{x}_{1}+0.68 \%$.

Sample $2 \quad \mathrm{x}_{2} \neq 0.5$ x $\mathrm{s}_{2}$
958

$\bar{x}_{1} \pm 0.94 \times s_{1}$

$\bar{x}_{2}+0.66 \times 52$
97.5

$\overrightarrow{\mathrm{x}}_{1}+1.24 \times \mathrm{s}_{1}$

$\bar{x}_{2} \pm 0.82 \times 52$

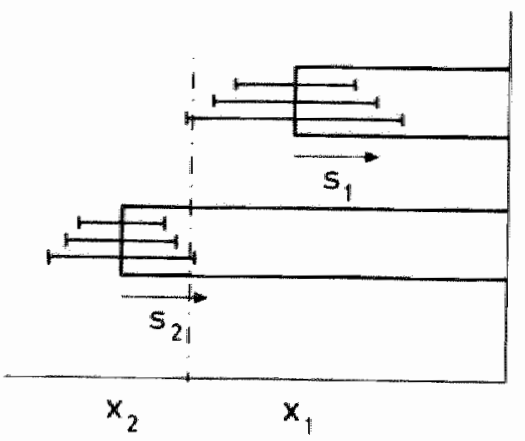

FIG. ADD. 2.5.

Two-sided confidence intervals for $\bar{x}_{1}$ and $\bar{x}_{2} ; 1 / 2 a=0.1,0.05$ and 0.025 .

By comparing lower and upper bounds of the confidence intervals (Fig. Add. 2.5.) of the two samples at the same confidence level, it will be clear that in this case the conclusion is:

sample 2 has a laxger mean than sample 1 at a significance level of at least $0.05(\mathrm{p}<0.05)$.

once the confidence intervals for the means of vaxious samples, having various sizes, have been constructed at various levels of confidence, all these sample means can be compared one to another on warlous levels of significance.

We are very grateful to $\mathrm{Dr}$. A. Clincke for his valuable advice and discussion. 
ADDENDUM 3: TABLES (bis) WITH COMPLEAENTARY DATA, CORRESPONDING TO THE SIMPLIFIED TABLES MENTIONED IN TWE CHAPTERS VI, VII, AND VIII 
THBUE VI.12. bis

Comparison of the sleep pattem of the first all night cycle: contral group versus the different clinical groups (mean, standard deviation (sD), confidence intervals for the mean $(1 / 2 a=0.05,0.025)$.

\begin{tabular}{|c|c|c|c|c|c|c|c|}
\hline $\mathrm{Cy} \cdot 1$ & $\begin{array}{l}\text { Total } \\
\text { cycle }\end{array}$ & $\begin{array}{l}\text { Time } \\
\text { awake }\end{array}$ & $\begin{array}{r}\text { Effective } \\
\text { sleep time }\end{array}$ & $\begin{array}{l}\text { A. REM } \\
\text { sleep }\end{array}$ & $\begin{array}{c}\text { REM } \\
\text { sleep }\end{array}$ & $\begin{array}{c}\text { N } P \text { PEM } \\
1-2\end{array}$ & $\begin{array}{c}\text { N. REM } \\
3-4\end{array}$ \\
\hline \multirow[t]{2}{*}{$\begin{array}{l}\text { CO } \\
\text { Hoen } \\
\text { SD } \\
0.8 \\
0.9 \\
0.95\end{array}$} & \multirow[t]{2}{*}{$\begin{array}{r}85.5 \\
13.6 \\
\pm \quad 6.4 \\
\pm \quad 8.4 \\
\pm \quad 10.5\end{array}$} & \multirow[t]{2}{*}{$\begin{array}{r}7.7 \\
8.9 \\
\pm \quad 4.2 \\
\pm \quad 5.5 \\
\pm \quad 6.9\end{array}$} & \multirow[t]{2}{*}{$\begin{array}{r}77.8 \\
14.1 \\
+\quad 6.6 \\
\pm \quad 8.8 \\
\pm 10.9\end{array}$} & $\begin{array}{r}70.4 \\
10.2 \\
+\quad 4.8 \\
\pm \quad 6.3 \\
\pm \quad 7.9\end{array}$ & $\begin{array}{r}7.4 \\
8.7 \\
+\quad 4.1 \\
\pm \quad 5.4 \\
\pm \quad 6.7\end{array}$ & $\begin{array}{r}39.2 \\
14.2 \\
+\quad 6.6 \\
\pm \quad 8.8 \\
\pm \quad 10.9\end{array}$ & $\begin{array}{r}31.2 \\
11.4 \\
+\quad 5.3 \\
\pm \quad 7.2 \\
\pm \quad 8.8\end{array}$ \\
\hline & & & & \multicolumn{2}{|c|}{ Ni . REM/REM: 9.5} & \multicolumn{2}{|c|}{ N. REMI-2/3-4:1.26 } \\
\hline \multirow[t]{2}{*}{$\begin{array}{l}\text { N.E. } \\
\text { mean } \\
\text { SD } \\
0.8 \\
0.9 \\
0.95\end{array}$} & \multirow[t]{2}{*}{$\begin{array}{r}115.9 \\
32.7 \\
+10.6 \\
\pm 13.9 \\
\pm 16.9\end{array}$} & \multirow[t]{2}{*}{$\begin{array}{r}16.8 \\
19.3 \\
\pm \quad 6.3 \\
\pm \quad 8.2 \\
\pm \quad 9.9\end{array}$} & \multirow[t]{2}{*}{$\begin{array}{r}99.1 \\
33.6 \\
+10.9 \\
\pm 14.2 \\
\pm \quad 17.3\end{array}$} & $\begin{array}{r}87.1 \\
29.3 \\
\pm \quad 9.5 \\
\pm \quad 12.2 \\
\pm 15.1\end{array}$ & $\begin{array}{r}12.0 \\
7.8 \\
+\quad 2.5 \\
\# \quad 3.3 \\
\pm \quad 4.0\end{array}$ & $\begin{array}{r}56.4 \\
25.4 \\
+\quad 8.2 \\
\pm 10.7 \\
\pm \quad 13.1\end{array}$ & $\begin{array}{r}30.7 \\
24.1 \\
\pm \quad 7.8 \\
\pm \quad 10.2 \\
\pm 12.4\end{array}$ \\
\hline & & & & \multicolumn{2}{|c|}{ N.REM/REM: 7.3} & \multicolumn{2}{|c|}{ N. REMI $-2 / 3-4: 1.84$} \\
\hline \multirow[t]{2}{*}{$\begin{array}{l}\mathrm{N} . \mathrm{E} .+ \\
\text { mean } \\
\mathrm{SD} \\
0.8 \\
0.9 \\
0.95\end{array}$} & \multirow[t]{2}{*}{$\begin{array}{r}94.5 \\
24.4 \\
+\quad 7.5 \\
+\quad 9.7 \\
\pm \quad 11.8\end{array}$} & \multirow[t]{2}{*}{$\begin{array}{r}9.5 \\
11.2 \\
\pm \quad 3.4 \\
\pm \quad 4.4 \\
\pm \quad 5.4\end{array}$} & \multirow[t]{2}{*}{$\begin{array}{r}85.0 \\
26.3 \\
+\quad 8.1 \\
+\quad 10.5 \\
+\quad 12.7\end{array}$} & $\begin{array}{r}72.8 \\
22.1 \\
+\quad 6.8 \\
\pm \quad 8.8 \\
\pm 10.7\end{array}$ & $\begin{array}{r}12.2 \\
10.9 \\
+\quad 3.4 \\
\pm \quad 4.3 \\
\pm \quad 5.3\end{array}$ & $\begin{array}{r}43.8 \\
24.2 \\
+\quad 7.4 \\
\pm \quad 9.6 \\
\pm 11.7\end{array}$ & $\begin{array}{r}29.0 \\
16.6 \\
+\quad 5.1 \\
\pm \quad 6.6 \\
\pm \quad 8.0\end{array}$ \\
\hline & & & & \multicolumn{2}{|c|}{ N.REM/REM: 6.0} & \multicolumn{2}{|c|}{ W. REMI-2/3-4:1.51 } \\
\hline \multirow[t]{2}{*}{$\begin{array}{l}\mathrm{E} . \mathrm{A} . \\
\text { mean } \\
\mathrm{SD} \\
0.8 \\
0.9 \\
0.95\end{array}$} & \multirow[t]{2}{*}{$\begin{array}{l}8 \\
5 \\
7 \\
2 \\
5\end{array}$} & \multirow[t]{2}{*}{$\begin{array}{r}7.3 \\
12.2 \\
2.6 \\
3.3 \\
4.0\end{array}$} & \multirow[t]{2}{*}{$\begin{array}{r}100.5 \\
36.0 \\
+\quad 7.5 \\
\pm \quad 9.7 \\
\pm 11.7\end{array}$} & $\begin{array}{r}89.8 \\
36.5 \\
+\quad 7.6 \\
\pm \quad 9.9 \\
\pm 11.8\end{array}$ & $\begin{array}{r}10.7 \\
8.6 \\
+\quad 1.8 \\
\pm \quad 2.3 \\
\pm \quad 2.1\end{array}$ & $\begin{array}{r}45.8 \\
27.4 \\
+\quad 5.7 \\
\pm \quad 7.4 \\
\pm \quad 8.9\end{array}$ & $\begin{array}{r}44.0 \\
27.9 \\
+\quad 5.8 \\
\pm \quad 7.5 \\
\pm \quad 9.1\end{array}$ \\
\hline & & & & \multicolumn{2}{|c|}{ N. REM/ REM: 8.4} & \multicolumn{2}{|c|}{ N. REML $-2 / 3-4: 1.04$} \\
\hline \multirow[t]{2}{*}{$\begin{array}{l}\text { A.E.4 } \\
\text { mean } \\
S D \\
0.8 \\
0.9 \\
0.95\end{array}$} & \multirow[t]{2}{*}{$\begin{array}{r}101.8 \\
31.5 \\
+21.5 \\
\pm 30.0 \\
\pm 39.1\end{array}$} & \multirow[t]{2}{*}{$\begin{array}{r}4.4 \\
2.9 \\
+\quad 2.0 \\
\pm \quad 2.8 \\
\pm \quad 3.6\end{array}$} & \multirow[t]{2}{*}{$\begin{array}{r}97.4 \\
31.4 \\
+\quad 21.5 \\
\pm 29.9 \\
\pm \quad 39.0\end{array}$} & $\begin{array}{r}83.8 \\
27.9 \\
+\quad 19.1 \\
\pm 26.6 \\
\pm 34.7\end{array}$ & $\begin{array}{r}13.6 \\
9.0 \\
\pm \quad 6.2 \\
\pm \quad 8.6 \\
\pm 11.3\end{array}$ & $\begin{array}{r}52.2 \\
14.3 \\
+\quad 9.8 \\
\pm 13.6 \\
\pm 17.8\end{array}$ & $\begin{array}{r}31.6 \\
17.5 \\
+\quad 12.0 \\
\# \quad 16.7 \\
\# \quad 21.7\end{array}$ \\
\hline & & & & N. REM/E & $M: 6.2$ & M . REMI- & $(3-4: 1.65$ \\
\hline
\end{tabular}

These values correspond with Table VI.8. 
TABLE VI.13.bis

Comparison of the second all-night cycle: control group versus aifferent clinical groups (mean, standard deviation (SD), confidence intervals for the mean $(1 / 20=0.05,0.025)$.

\begin{tabular}{|c|c|c|c|c|c|c|c|}
\hline$C y * 2$ & $\begin{array}{l}\text { Total } \\
\text { cycle }\end{array}$ & $\begin{array}{l}\text { Time } \\
\text { awake }\end{array}$ & $\begin{array}{l}\text { Effectivio } \\
\text { sileep time }\end{array}$ & $\begin{array}{l}\text { N. REM } \\
\text { sieep }\end{array}$ & $\begin{array}{c}\text { REM } \\
\text { sleep }\end{array}$ & $\begin{array}{c}\mathbb{M} \cdot \operatorname{REM} \\
1-2\end{array}$ & $\begin{array}{c}N \cdot \operatorname{REM} \\
3-4\end{array}$ \\
\hline \multirow[t]{2}{*}{$\begin{array}{l}C 0 \\
\text { meam } \\
S D \\
0.8 \\
0.9 \\
0.95\end{array}$} & \multirow[t]{2}{*}{$\begin{array}{r}90.1 \\
17.35 \\
+\quad 8.1 \\
\pm \quad 10.8 \\
\pm \quad 13.4\end{array}$} & \multirow[t]{2}{*}{$\begin{array}{r}3.9 \\
4.3 \\
+\quad 2.0 \\
\pm \quad 2.7 \\
\pm \quad 3.3\end{array}$} & \multirow[t]{2}{*}{$\begin{array}{r}86.2 \\
15.2 \\
+\quad 7.1 \\
+\quad 9.4 \\
+\quad 11.7\end{array}$} & $\begin{array}{r}70.4 \\
12.3 \\
+\quad 5.8 \\
\pm \quad 7.6 \\
\pm \quad 9.5\end{array}$ & $\begin{array}{r}15.8 \\
6.6 \\
\pm \quad 3.1 \\
\pm \quad 4.1 \\
\pm \quad 5.1\end{array}$ & $\begin{array}{r}40.6 \\
14.6 \\
+\quad 6.8 \\
\pm \quad 9.1 \\
\pm \quad 11.3\end{array}$ & $\begin{array}{r}29.8 \\
14.1 \\
+\quad 6.6 \\
\pm \quad 8.8 \\
\pm \quad 10.9\end{array}$ \\
\hline & & & & \multicolumn{2}{|c|}{ N.REM/REM: 4.5} & \multicolumn{2}{|c|}{ N. REML $-2 / 3-4: 1 \cdot 36$} \\
\hline \multirow[t]{2}{*}{$\begin{array}{l}\text { N.E. }-7 \\
\text { mean } \\
\text { SD } \\
0.8 \\
0.9 \\
0.95\end{array}$} & \multirow[t]{2}{*}{$\begin{array}{r}106.6 \\
20.8 \\
+\quad 7.0 \\
\pm \quad 9.1 \\
\pm \quad 11.1\end{array}$} & \multirow[t]{2}{*}{$\begin{array}{r}10.6 \\
8.9 \\
\pm \quad 3.0 \\
\pm \quad 3.9 \\
\pm \quad 4.7\end{array}$} & \multirow[t]{2}{*}{$\begin{array}{r}96.0 \\
20.6 \\
6.9 \\
9.0 \\
10.7\end{array}$} & $\begin{array}{r}76.1 \\
19.5 \\
+\quad 6.5 \\
\pm \quad 8.5 \\
\pm 10.4\end{array}$ & $\begin{array}{l}2 \cdot 7 \\
3 \cdot 5 \\
4 \cdot 3\end{array}$ & $\begin{array}{r}47.7 \\
21.3 \\
+\quad 7.1 \\
\pm \quad 9.3 \\
\pm 11.3\end{array}$ & $\begin{array}{r}20.1 \\
+\quad 6.7 \\
\pm \quad 8.8 \\
\pm \quad 10.7\end{array}$ \\
\hline & & & & \multicolumn{2}{|c|}{ N. REM/REM: 3.8} & \multicolumn{2}{|c|}{ N. REML $-2 / 3-4: 1.68$} \\
\hline \multirow[t]{2}{*}{$\begin{array}{l}\text { N.E.+t } \\
\text { mean } \\
\text { SD } \\
0.8 \\
0.9 \\
0.95\end{array}$} & \multirow[t]{2}{*}{$\begin{array}{r}98.6 \\
18.9 \\
+\quad 6.3 \\
\pm \quad 8.3 \\
\pm \quad 10.1\end{array}$} & \multirow[t]{2}{*}{$\begin{array}{r}3.1 \\
3.7 \\
+\quad 1.3 \\
\pm \quad 1.6 \\
\pm \quad 2.0\end{array}$} & \multirow[t]{2}{*}{$\begin{array}{r}95.5 \\
19.2 \\
+\quad 6.5 \\
\pm \quad 8.4 \\
\pm 10.2\end{array}$} & \multirow{2}{*}{\multicolumn{2}{|c|}{ 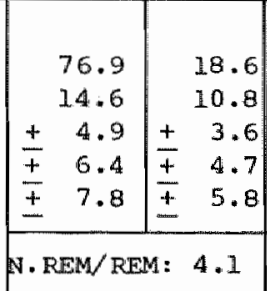 }} & $\begin{array}{r}45.3 \\
21.7 \\
+\quad 7.3 \\
\pm \quad 9.5 \\
\pm 11.6\end{array}$ & $\begin{array}{r}31.6 \\
22.4 \\
+\quad 7.5 \\
\pm \quad 9.8 \\
\pm \quad 11.9\end{array}$ \\
\hline & & & & & & \multicolumn{2}{|c|}{$N \cdot \mathbb{R E M I}-2 / 3-4: 1.43$} \\
\hline \multirow[t]{2}{*}{$\begin{array}{l}\mathrm{E} .+\mathrm{A} . \\
\text { mean } \\
\mathrm{SD} \\
0.8 \\
0.9 \\
0.95\end{array}$} & \multirow[t]{2}{*}{$\begin{array}{r}101.9 \\
36.6 \\
\pm \quad 7.9 \\
\pm \quad 10.2 \\
\pm \quad 12.2\end{array}$} & \multirow[t]{2}{*}{$\begin{array}{l}5.5 \\
8.0 \\
1.7 \\
2.2 \\
2.7\end{array}$} & \multirow[t]{2}{*}{$\begin{aligned} & 96.4 \\
& 376 \\
&+\quad 8.0 \\
& \pm 10.4 \\
& \pm 12.5\end{aligned}$} & $\begin{array}{r}79.9 \\
34.8 \\
+\quad 7.5 \\
\pm \quad 9.7 \\
\pm \quad 11.6\end{array}$ & $\begin{array}{r}16.5 \\
11.7 \\
+\quad 2.5 \\
\pm \quad 3.3 \\
\pm \quad 3.9\end{array}$ & $\begin{array}{r}50.7 \\
25.7 \\
+\quad 5.5 \\
\pm \quad 7.1 \\
\pm \quad 8.6\end{array}$ & $\begin{array}{r}29.2 \\
21.4 \\
+\quad 4.6 \\
+\quad 5.9 \\
\pm \quad 7.1\end{array}$ \\
\hline & & & & N. REM $/$ RI & $M: 4.8$ & N. REML - & $13-4: 1 \cdot 74$ \\
\hline $\begin{array}{l}A \cdot E \cdot+B \cdot D \cdot 5 \\
\text { mean } \\
\text { SD } \\
0.8 \\
0.9 \\
0.95\end{array}$ & $\begin{array}{r}92.8 \\
36.3 \\
+24.9 \\
\pm \quad 34.6 \\
\pm \quad 45.1\end{array}$ & $\begin{array}{r}9.0 \\
7.7 \\
+\quad 5.2 \\
\pm \quad 7.3 \\
\pm \quad 9.5\end{array}$ & $\begin{array}{r}83.8 \\
39.6 \\
+27.1 \\
+37.8 \\
+49.3\end{array}$ & $\begin{array}{r}73.8 \\
40.9 \\
+28.0 \\
\pm \quad 39.0 \\
\pm \quad 50.1\end{array}$ & $\begin{array}{r}10.0 \\
9.4 \\
+\quad 6.5 \\
\pm \quad 9.0 \\
\pm \quad 11.7\end{array}$ & $\begin{array}{r}51.8 \\
31.2 \\
+21.3 \\
\pm 29.7 \\
\pm \quad 30.8\end{array}$ & $\begin{array}{r}22.0 \\
26.5 \\
+18.2 \\
+25.3 \\
\pm 33.0\end{array}$ \\
\hline & & & & N. RE & $1: 7$. & N. REMI - & $3-4$ \\
\hline
\end{tabular}

These values correspond with Table VI.9. 
MABLE VII.12. bIS

Comparison of the sleep pattern of the first sleep deprivation cycle: control group versus the different clinical groups of patients between 20 and 40 years old (mean, standard deviation (SD), confidence interval for the mean $(\mathbb{1} / 2 a=0.05,0.025)$.

\begin{tabular}{|c|c|c|c|c|c|c|c|}
\hline $\mathrm{Cy} \cdot 1$ & $\begin{array}{l}\text { Total } \\
\text { cycle }\end{array}$ & $\begin{array}{l}\text { Time } \\
\text { ewake }\end{array}$ & $\begin{array}{l}\text { Effective } \\
\text { sleep time }\end{array}$ & $\begin{array}{l}\text { N. FEM } \\
\text { s.leep }\end{array}$ & $\begin{array}{c}\text { REM } \\
\text { sleep }\end{array}$ & $\begin{array}{c}\text { N REM } \\
1-2\end{array}$ & $\begin{array}{c}\text { N. } \\
3-4\end{array}$ \\
\hline \multirow[t]{2}{*}{$\begin{array}{l}c 0 \\
\text { mean } \\
\text { sD } \\
0.8 \\
0.9 \\
0.95\end{array}$} & \multirow[t]{2}{*}{$\begin{array}{r}77.1 \\
15.2 \\
+\quad 5.3 \\
\pm \quad 6.9 \\
\pm \quad 8.4\end{array}$} & \multirow[t]{2}{*}{$\begin{array}{r}5.1 \\
7.3 \\
+\quad 2.5 \\
\pm \quad 3.3 \\
\pm \quad 4.1\end{array}$} & \multirow[t]{2}{*}{$\begin{array}{r}72.0 \\
18.1 \\
+\quad 6.3 \\
+\quad 8.2 \\
+\quad 10.0\end{array}$} & $\begin{array}{r}63.3 \\
16.0 \\
\pm \quad 5.5 \\
\pm \quad 7.3 \\
\pm \quad 8.5\end{array}$ & $\begin{array}{r}8.7 \\
6.5 \\
\pm \quad 2.3 \\
\pm \quad 3.0 \\
\pm \quad 3.6\end{array}$ & $\begin{array}{r}28.5 \\
11.3 \\
\pm \quad 3.9 \\
\pm \quad 5.2 \\
\pm \quad 6.3\end{array}$ & $\begin{array}{r}34.8 \\
18.6 \\
+\quad 6.5 \\
\pm \quad 8.5 \\
\pm 10.3\end{array}$ \\
\hline & & & & \multicolumn{2}{|c|}{ H. REM REM: 7.3} & \multicolumn{2}{|c|}{ N. REMI-2/3-4:0.82 } \\
\hline \multirow[t]{2}{*}{$\begin{array}{l}\text { N.E. }-7 \\
\text { mean } \\
\text { SD } \\
0.8 \\
0.9 \\
0.95\end{array}$} & \multirow[t]{2}{*}{$\begin{array}{r}94.7 \\
32.2 \\
\pm \quad 6.1 \\
\pm \quad 7.8 \\
\pm \quad 9.4\end{array}$} & \multirow[t]{2}{*}{$\begin{array}{r}5.2 \\
7.6 \\
+\quad 1.5 \\
\pm \quad 1.9 \\
\pm \quad 2.2\end{array}$} & \multirow[t]{2}{*}{$\begin{array}{r}89.5 \\
30.0 \\
+\quad 5.6 \\
\pm \quad 7.3 \\
\pm \quad 8.7\end{array}$} & $\begin{array}{r}77.2 \\
26.2 \\
+\quad 4.9 \\
\pm \quad 6.4 \\
\pm \quad 7.6 \\
\end{array}$ & $\begin{array}{r}12.3 \\
10.2 \\
+\quad 1.9 \\
\pm \quad 2.5 \\
\pm \quad 3.0 \\
\end{array}$ & $\begin{array}{r}34.5 \\
19.8 \\
+\quad 3.7 \\
\pm \quad 4.8 \\
\pm \quad 5.8\end{array}$ & $\begin{array}{r}42.7 \\
20.6 \\
+\quad 3.9 \\
\pm \quad 5.0 \\
\pm \quad 6.0\end{array}$ \\
\hline & & & & \multicolumn{2}{|c|}{ N. REM REM: 6.3} & \multicolumn{2}{|c|}{ N. REMI-2/3-4:0.81 } \\
\hline \multirow[t]{2}{*}{$\begin{array}{l}\text { N.E.+ } \\
\text { mean } \\
\text { SD } \\
0.8 \\
0.9 \\
0.95\end{array}$} & \multirow[t]{2}{*}{$\begin{array}{r}97.2 \\
28.2 \\
+\quad 5.2 \\
\pm \quad 6.8 \\
\pm \quad 8.1\end{array}$} & \multirow[t]{2}{*}{$\begin{array}{r}4.0 \\
6.5 \\
+\quad 1.2 \\
\pm \quad 1.6 \\
\pm \quad 1.9\end{array}$} & \multirow[t]{2}{*}{$\begin{array}{r}93.2 \\
25.7 \\
+\quad 4.8 \\
\pm \quad 6.2 \\
\pm \quad 7.4\end{array}$} & $\begin{array}{r}82.5 \\
25.5 \\
+\quad 4.7 \\
\pm \quad 6.1 \\
\pm \quad 7.3\end{array}$ & $\begin{array}{r}10.7 \\
11.8 \\
+\quad 2.2 \\
\pm \quad 2.8 \\
\pm \quad 3.4\end{array}$ & $\begin{array}{r}39.6 \\
20.7 \\
+\quad 3.9 \\
\pm \quad 5.0 \\
\pm \quad 6.0\end{array}$ & $\begin{array}{r}42.9 \\
20.7 \\
\pm \quad 3.9 \\
\pm \quad 5.0 \\
\pm \quad 6.0\end{array}$ \\
\hline & & & & \multicolumn{2}{|c|}{ N. REM/REM: 7.7} & \multicolumn{2}{|c|}{$N \cdot R E M 1-2 / 3-4: 0.92$} \\
\hline \multirow[t]{2}{*}{$\begin{array}{l}\text { E. }+A . \\
\text { mean } \\
\text { SD } \\
0.8 \\
0.9 \\
0.95\end{array}$} & \multirow[t]{2}{*}{$\begin{array}{r}92.7 \\
29.0 \\
+\quad 3.9 \\
\pm \quad 5.0 \\
\pm \quad 6.0\end{array}$} & \multirow[t]{2}{*}{$\begin{array}{r}5.4 \\
10.5 \\
1.4 \\
1.8 \\
2.2\end{array}$} & \multirow[t]{2}{*}{$\begin{array}{r}87.3 \\
25.0 \\
+\quad 3.4 \\
\pm \quad 4.3 \\
\pm \quad 5.1\end{array}$} & $\begin{array}{r}76.5 \\
24.5 \\
+\quad 3.3 \\
\pm \quad 4.2 \\
\pm \quad 5.0\end{array}$ & $\begin{array}{r}10.8 \\
10.6 \\
\pm \quad 1.5 \\
\pm \quad 1.9 \\
\pm \quad 2.2\end{array}$ & $\begin{array}{r}33.4 \\
19.3 \\
+\quad 2.6 \\
\pm \quad 3.3 \\
\pm \quad 4.0\end{array}$ & $\begin{array}{r}23.1 \\
20.0 \\
+\quad 2.8 \\
\pm \quad 3.6 \\
\pm \quad 4.3\end{array}$ \\
\hline & & & & N. REM/RE & $M: 7.1$ & N. REML -2 & $/ 3-4: 0.77$ \\
\hline $\begin{array}{l}A \cdot E \cdot+B \cdot D \cdot 11 \\
\text { mean } \\
\text { SD } \\
0.8 \\
0.9 \\
0.95\end{array}$ & $\begin{array}{r}108.6 \\
27.1 \\
+11.2 \\
+14.8 \\
\pm 18.2\end{array}$ & $\begin{array}{r}3.5 \\
5.3 \\
+\quad 2.2 \\
+\quad 2.9 \\
+\quad 3.5\end{array}$ & $\begin{array}{r}105.1 \\
23.9 \\
+\quad 9.9 \\
+13.1 \\
+16.1\end{array}$ & $\begin{array}{r}99.9 \\
24.7 \\
+10.2 \\
+13.5 \\
+16.6\end{array}$ & $\begin{array}{r}5.2 \\
6.4 \\
\pm \quad 2.6 \\
\pm \quad 3.5 \\
\pm \quad 4.3\end{array}$ & $\begin{aligned} & 65.1 \\
& 29.7 \\
+ & 123 \\
\pm & 16.2 \\
\pm & 19.9\end{aligned}$ & $\begin{array}{r}34.8 \\
26.5 \\
+10.9 \\
\pm 14.5 \\
\pm 17.8\end{array}$ \\
\hline & & & & N.REM/R & $M: 19.2$ & N. REMI - & $/ 3-4: 1.8$ \\
\hline
\end{tabular}

* These values correspond with Table VII.8. (S). 
THBLE VII.13, bis

Comparison of the sleep pattern of the second sleep deprivation eycle: control group versus the different clinical groups in patients between 20 and 40 years old (mean, standard deviation (SD), confidence intervals for the mean $(1 / 2 \alpha=0.05,0.025)$.

\begin{tabular}{|c|c|c|c|c|c|c|c|}
\hline $\mathrm{CY}=2$ & $\begin{array}{l}\text { Total } \\
\text { cycle }\end{array}$ & $\begin{array}{l}\text { Time } \\
\text { awake }\end{array}$ & $\begin{array}{l}\text { Effective } \\
\text { sleep time }\end{array}$ & $\begin{array}{l}\text { N. REM } \\
\text { sleep }\end{array}$ & $\begin{array}{c}\text { REM } \\
\text { sileep }\end{array}$ & $\begin{array}{c}\text { N. REM } \\
1-2\end{array}$ & $\begin{array}{c}\text { N. } \text {. } \\
3-4\end{array}$ \\
\hline \multirow[t]{2}{*}{$\begin{array}{l}\mathrm{CO} \\
\text { mean } \\
\mathrm{SD} \\
0.8 \\
0.9 \\
0.95\end{array}$} & \multirow[t]{2}{*}{$\begin{array}{r}84.4 \\
26.1 \\
+\quad 9.4 \\
\pm \quad 12.4 \\
\pm \quad 15.1\end{array}$} & \multirow[t]{2}{*}{$\begin{array}{r}2.8 \\
3.0 \\
+\quad 1.1 \\
+\quad 1.4 \\
\quad 1.7\end{array}$} & \multirow[t]{2}{*}{$\begin{array}{r}81.6 \\
24.5 \\
+\quad 8.8 \\
+11.6 \\
+\quad 14.1\end{array}$} & $\begin{array}{r}69.2 \\
18.5 \\
+\quad 6.7 \\
\pm \quad 8.8 \\
\pm 10.7\end{array}$ & $\begin{array}{r}12.4 \\
10.7 \\
+\quad 3.9 \\
\pm \quad 5.1 \\
\pm \quad 6.2\end{array}$ & $\begin{array}{r}38.8 \\
21.1 \\
+\quad 7.6 \\
\pm 10.0 \\
\pm \quad 12.2\end{array}$ & $\begin{array}{r}30.4 \\
11.5 \\
+\quad 4.2 \\
\pm \quad 5.4 \\
\pm \quad 6.6\end{array}$ \\
\hline & & & & \multicolumn{2}{|c|}{ N.REM/REM: 5.6} & \multicolumn{2}{|c|}{$\mathbb{N} \cdot$ REMI-2/3-4:1.28 } \\
\hline \multirow[t]{2}{*}{$\begin{array}{l}N . E \\
\text { mean } \\
S D \\
0.8 \\
0.9 \\
0.95\end{array}$} & \multirow[t]{2}{*}{$\begin{array}{r}80.9 \\
25.3 \\
+\quad 5.0 \\
\pm \quad 6.4 \\
\pm \quad 7.7\end{array}$} & \multirow[t]{2}{*}{$\begin{array}{l}5.4 \\
5.8 \\
1.2 \\
1.5 \\
1.8\end{array}$} & \multirow[t]{2}{*}{$\begin{array}{r}75.5 \\
26.7 \\
+\quad 5.2 \\
\pm \quad 6.8 \\
\pm \quad 8.1\end{array}$} & $\begin{array}{r}61.8 \\
20.6 \\
+\quad 4.1 \\
\pm \quad 5.2 \\
\pm \quad 6.3\end{array}$ & $\begin{array}{r}13.7 \\
12.9 \\
\pm \quad 2.5 \\
\pm \quad 3.3 \\
\pm \quad 3.9\end{array}$ & $\begin{array}{r}35.5 \\
16.4 \\
+\quad 3.2 \\
\pm \quad 4.2 \\
\pm \quad 5.0\end{array}$ & $\begin{array}{r}26.3 \\
17.8 \\
+\quad 3.5 \\
\pm \quad 4.5 \\
\pm \quad 5.4\end{array}$ \\
\hline & & & & \multicolumn{2}{|c|}{ N.REM/REM: 4.5} & \multicolumn{2}{|c|}{ N. REMI - 2/3-4:1.35 } \\
\hline \multirow[t]{2}{*}{$\begin{array}{l}\text { N. E. } \\
\text { mean } \\
S D \\
0.8 \\
0.9 \\
0.95\end{array}$} & \multirow[t]{2}{*}{$\begin{array}{r}91.0 \\
22.6 \\
+\quad 4.5 \\
+\quad 5.8 \\
+\quad 7.0\end{array}$} & \multirow[t]{2}{*}{$\begin{array}{l}5.4 \\
6.7 \\
1.3 \\
1.7 \\
2.1\end{array}$} & \multirow[t]{2}{*}{$\begin{array}{r}85.6 \\
23.0 \\
+\quad 4.6 \\
+\quad 5.9 \\
\pm \quad 7.1\end{array}$} & $\begin{array}{r}74.6 \\
18.2 \\
+\quad 3.6 \\
\pm \quad 4.7 \\
\pm \quad 5.6\end{array}$ & $\begin{array}{r}11.0 \\
9.7 \\
+\quad 1.9 \\
\pm \quad 2.5 \\
\pm \quad 3.0\end{array}$ & $\begin{array}{r}39.3 \\
17.3 \\
+\quad 3.4 \\
\quad 4.4 \\
\pm \quad 5.4\end{array}$ & $\begin{array}{r}35.3 \\
18.5 \\
+\quad 3.7 \\
\pm \quad 4.7 \\
\pm \quad 5.7\end{array}$ \\
\hline & & & & \multicolumn{2}{|c|}{ M.REM/REM: 6.8} & \multicolumn{2}{|c|}{ N. REMI $-2 / 3-4: 1.11$} \\
\hline \multirow[t]{2}{*}{$\begin{array}{l}\text { E. A. } \\
\text { mean } \\
S 0 \\
0.8 \\
0.9 \\
0.95\end{array}$} & \multirow[t]{2}{*}{$\begin{array}{r}87.6 \\
21.3 \\
+\quad 3.0 \\
\pm \quad 3.9 \\
\pm \quad 4.7\end{array}$} & \multirow[t]{2}{*}{$\begin{array}{r}7.0 \\
11.0 \\
1.6 \\
2.0 \\
2.4\end{array}$} & \multirow[t]{2}{*}{$\begin{array}{r}80.6 \\
23.2 \\
+\quad 3.3 \\
\pm \quad 4.2 \\
\pm \quad 5.1\end{array}$} & $\begin{array}{r}70.1 \\
20.7 \\
+\quad 2.9 \\
\pm \quad 3.8 \\
+\quad 4.5\end{array}$ & $\begin{array}{r}10.5 \\
10.6 \\
\pm \quad 1.5 \\
\pm \quad 2.0 \\
\pm \quad 2.3\end{array}$ & $\begin{array}{r}35.9 \\
16.8 \\
+\quad 2.4 \\
\pm \quad 3.1 \\
\pm \quad 3.7\end{array}$ & $\begin{array}{r}34.2 \\
19.5 \\
+\quad 2.8 \\
\pm \quad 3.6 \\
\pm \quad 4.3\end{array}$ \\
\hline & & & & \multicolumn{2}{|c|}{ N. REM/REM: 6.7} & \multicolumn{2}{|c|}{ N. REML $-2 / 3-4: 1.05$} \\
\hline $\begin{array}{l}\mathrm{A} \cdot \mathrm{E} \cdot \mathrm{AB} \cdot \mathrm{D} \cdot \mathrm{B} \\
\text { mean } \\
\mathrm{SD} \\
0.8 \\
0.9 \\
0.95\end{array}$ & $\begin{array}{r}79.0 \\
23.5 \\
+\quad 11.7 \\
+\quad 15.7 \\
+\quad 19.6\end{array}$ & $\begin{array}{r}5.2 \\
6.6 \\
\pm \quad 3.3 \\
\pm \quad 4.4 \\
\pm \quad 5.5\end{array}$ & $\begin{array}{r}73.8 \\
26.5 \\
+\quad 13.2 \\
\pm \quad 17.7 \\
\pm \quad 22.1\end{array}$ & $\begin{array}{r}65.0 \\
24.9 \\
+12.4 \\
\pm 16.7 \\
\pm \quad 20.8\end{array}$ & $\begin{array}{r}8.8 \\
8.0 \\
\pm \quad 4.0 \\
\pm \quad 5.3 \\
\pm \quad 6.7\end{array}$ & $\begin{array}{r}34.1 \\
18.4 \\
+\quad 9.2 \\
+12.3 \\
+15.3\end{array}$ & $\begin{array}{r}30.9 \\
27.4 \\
+13.7 \\
+18.3 \\
\quad 22.9\end{array}$ \\
\hline & & & & N. REM/RE & $M: 7.4$ & N. REML - 2 & $(3-4: 1 \cdot 10$ \\
\hline
\end{tabular}

These values correspond with Table VII.9. (S). 
THBLE VIIT.7. big

Composition of the first cycle after one night sleep deprivation of aleep pattexns without eplleptic EEG phenomena in patients treated with one or two antiepileptic drugs (mean, standard dewiation (SD), confidence intervals for the mean $(1 / 2 a=0.05,0.025)$.

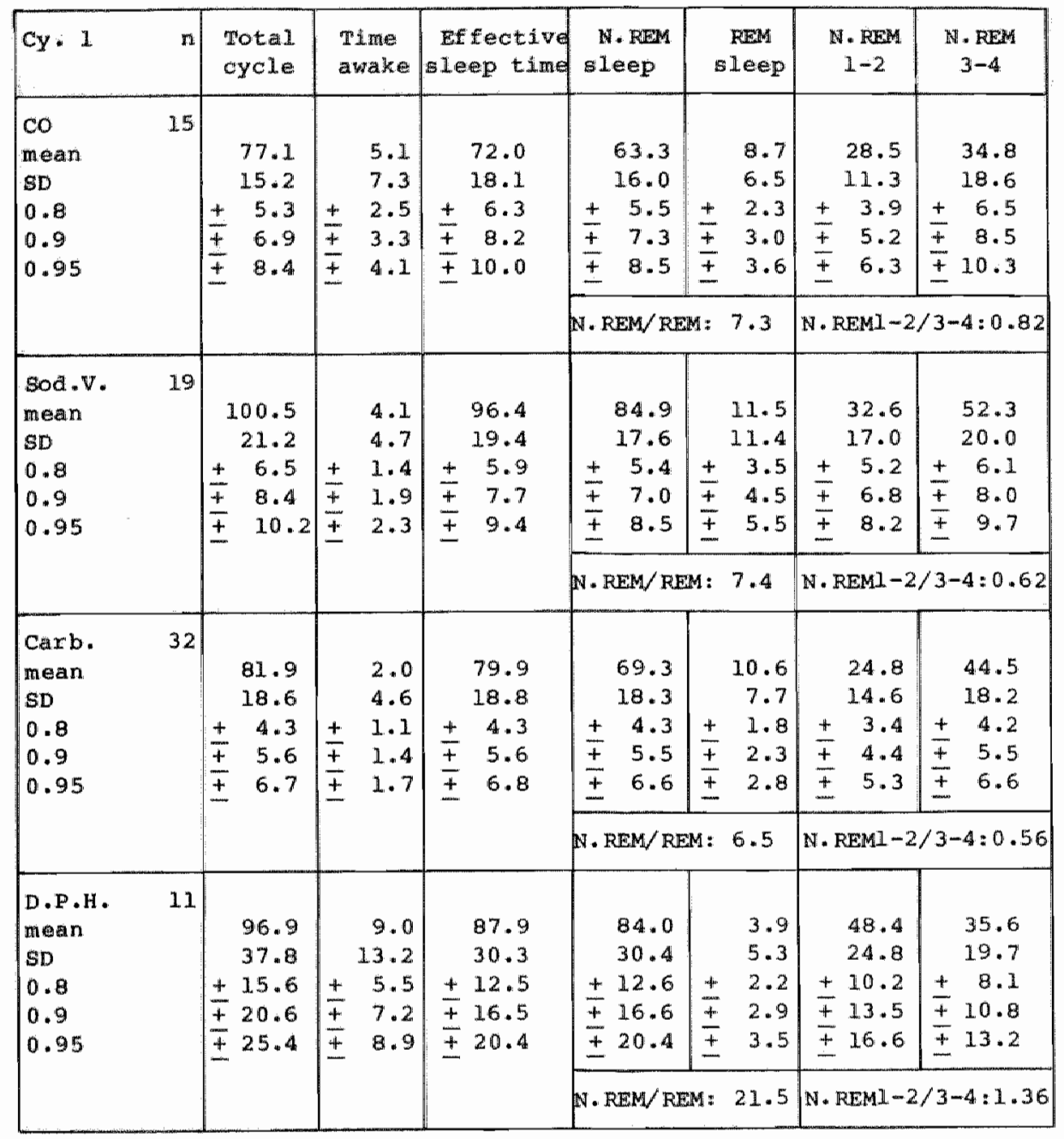


TARLE VIII. 7 . bis (continued).

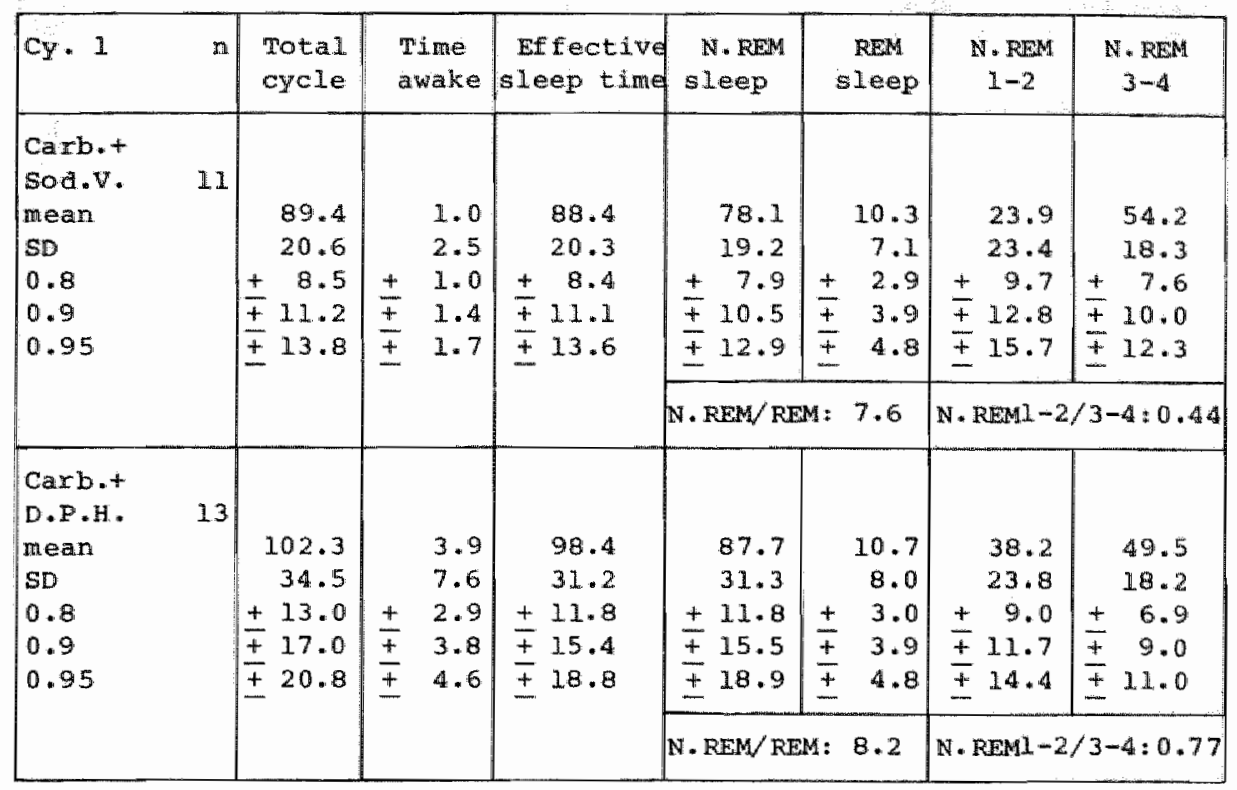


TARE VIII.B. BIS

Compostion of the first cycle after one night sleep deprivation of sleep patterns with eplieptic EEG phenomena in patients treated with one or two antieplleptic drugs (mean, stardard deviation (SD), confidence intervals for the mean $(1 / 2 a=0.05,0.025)$.

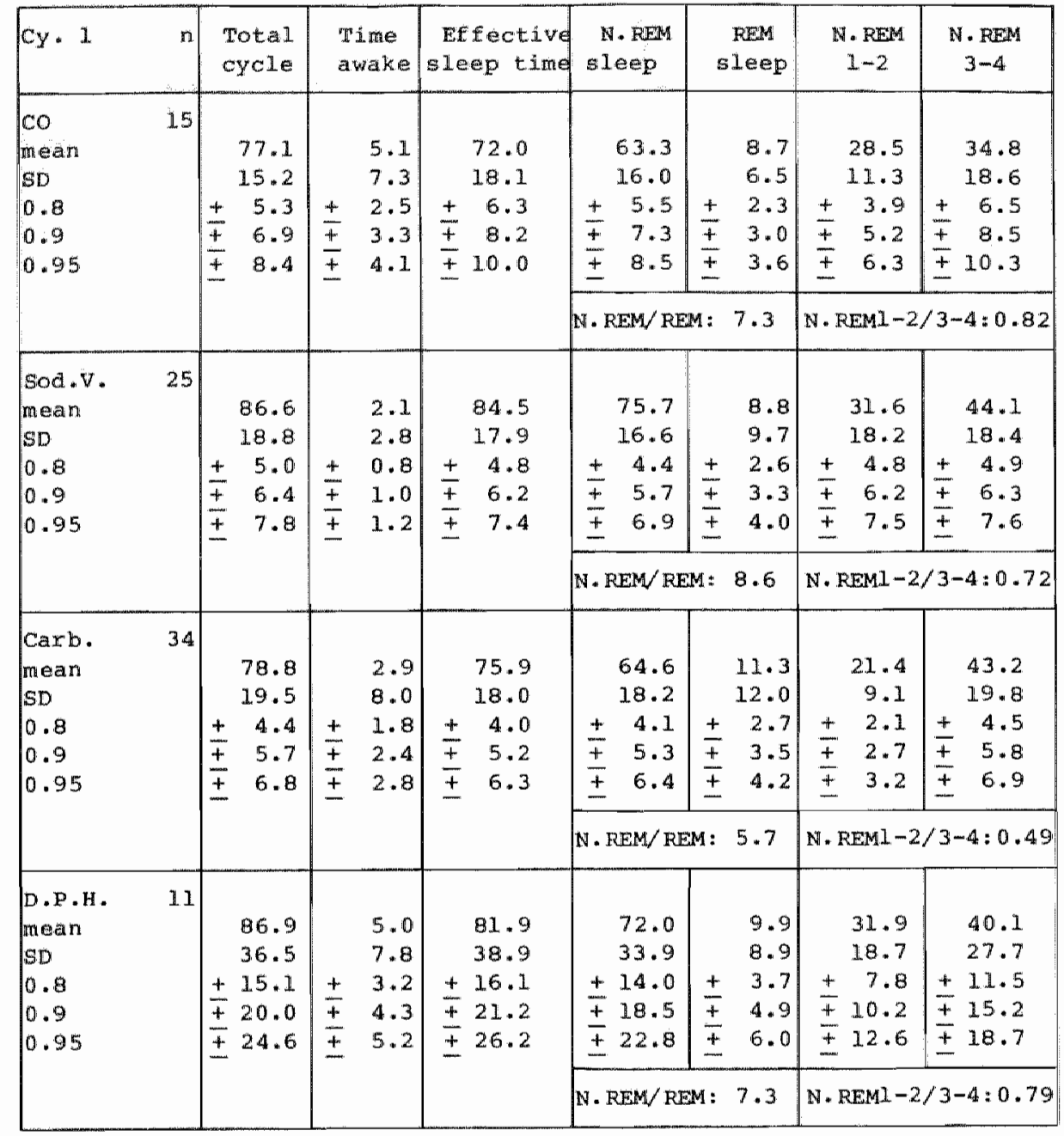


TAELE VII.8. bis (continued)

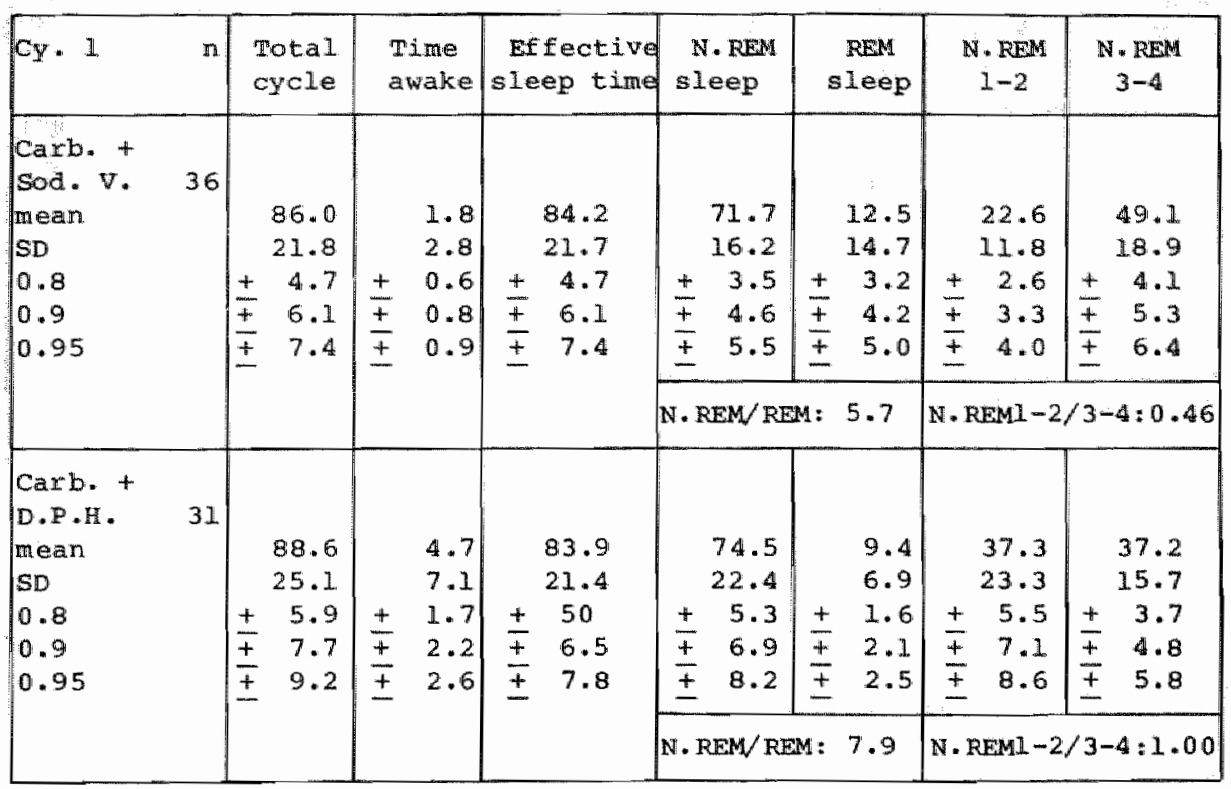


THERE VIII.9. DIE

Composition of the firet cycle ater one night sleep deprivation in patients treated with antiepileptic drugs in combination with chlorazepte (chlor.) or clonazepam (clon.) " (mean. standard deviation (sD), comfidence intervals for the mean $(1 / 2 a=0.05,0.025)$.

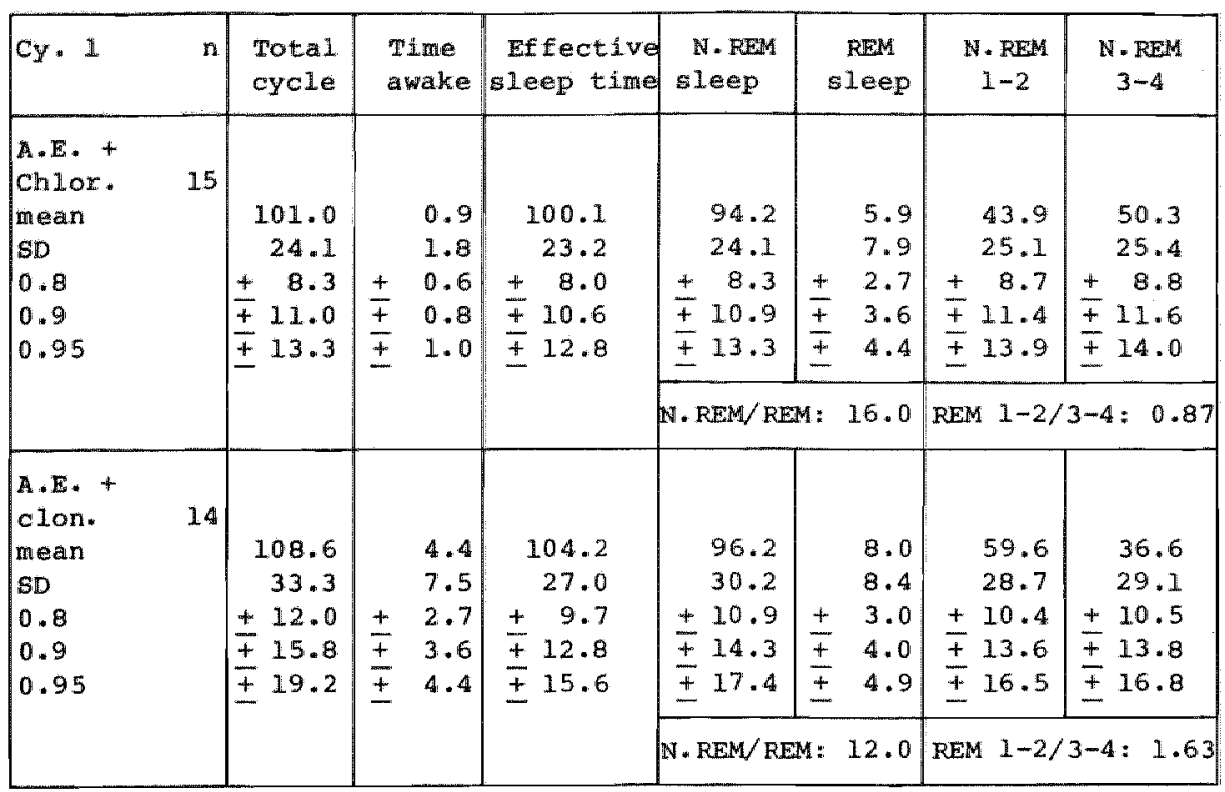


Fig. II.1. EEG patterns according to the alferent human sleep stages and states (from Havri, 1977).

Fig. II.2. Example of a hyprogram.

Fig. II.3. Example of primary generalized epilepsy $(3 \mathrm{c} / \mathrm{sec})$ *

Fig. II.4. Example of secondary generalized epilepsy (hypsarrhythmia).

Fig. II.5. Example of complex partial epilepsy (psychomotor type).

Table II.6. Sumary of some literature findings concerning the influence of the different sleep states and stages on epileptic EEG phenomena.

Table IV.1. Diagnostic procedures.

Fig. IV.2. Position of electrodes by using a 16-channel recorder.

Fig. IV.3. Position of electrodes by using a 21-channel recorder.

Flg. IV.4. Standard report of a polygraphic sleep recording carried out in an epileptic patient.

Fig. IV.5. Example of automatic sleep analysis with sleep classification (Wauquier et a1., 1978).

Fl.g. IV.6. Example of automatic sleep analysis with sleep classification (Maxtens et a l., 1981).

Table V.1. Number $(n)$ and percentage ( $(2)$ of routine and sleep EEG recordings during the period 1976-1981 with epileptic $\mathbb{E E G}$ phenomena.

Table V.2. Electroencephalographic confirmation of epilepsy according to the clinical aiagnosis.

Table v.3. Gain of electroencephalographic epilepsy diagnosio depending on the sleep recording method versus the clinical form of epilepsy.

Table V.4. Diagnosis of epliepsy according to the sleep states and stages during sleep deprivation registration. 
male V.5.5.

Tale

Fig. $\quad y .7$

Thabe V.

Table W.9.

Table W.10.

Positive diagrostic findings of epilepsy during the first M. FFM $1-2$ and N.PEM 3-4 periods: allnight versus sleep deprivation method.

Eig. VI.1. Age alotribution in years of the 55 male patients.

Fig. Age distribution in years of the 38 female patHents.

Table VI.3. Quantitative composition of the first and second cycle during all-night sleep recordings of the control population.

Table VI.4. Composition of the first cycle of all-night sleep reconding of patients, respectively without (N.E.) and ith (E.) epileptic EEG phenomena, in comparigon with the co growp.

Table VI.S. Composition of the second cycle in all-night sleep recordings of the patients without $(\mathrm{N} \cdot \mathrm{E} \cdot)$ and with (E.) plleptic EEG phenomena.

Table W1.6. Composition of the first cycle of all-night sleep recoxdings without epileptic EEG phenomena and without or with antiepileptic drug treatment.

Table VI.7. Composition of the second cycle of all-night sleep recondings without epileptic EEG phenomena and without or with antiepileptic arug treatment. 
Table VI.B.

Sleep composition of the first all-night cycle in recordings with epileptic $\mathrm{EEG}$ phenomena; traated with antiepileptic arugs, with $\left(E_{*}+\right.$ A.E.+B.D.) or without combination with benzodiazepine dexivatives $(E \cdot+A \cdot E *-B \cdot D \cdot)$.

Table VI.9.

Composition of the second allmight sleep cycle in recordings with epileptic EEG phenomena, treated with antiepileptic drugs, with $\left(E_{.+A .+E .+D .)}\right.$ or without combination with benzodiazepine derivatives $(E,+$ A.E. -B.D.).

Table VI.10. Sleep composition of the first all-night cycle in recordings with interictal epileptic EEG paxoxysms belonging to Generalized, Partial or Generallued with Paxtial epilepsy.

Table VI.11. Sleep composition of the second all-night cycle in recordings with epileptic EEG paroxysms belonging to generalized, partial or generalized with partial epilepsy.

Table VI.12. Comparison of the sleep patterns of the first all-night cycle: control group versus the different: clinical groups.

Table VI.13. Comparison of the second all-night cycle: control group versus different clinical groups.

Table vI.14. Comparison of the sleep pattern of the first allnight cycle in patients with epileptic EEG paroxysms and treated with antieplileptic drugs: control group versus 3 clinical groups, respectively between the age of $3-10,11-20$ and $21-30$ years.

Table VI.25. Comparison of the sleep pattern of the second all-night cycle in patients with eplleptic EEG paroxysms and treated with antiepileptic drugs: control group versus 3 clinical groups, respect1 vely between the age of $3-10,11-20$ and $21-30$ years.

Fig. VI.26. Mean values, in minutes, of the total feep cycle, the time awake, and the effective sleep time during the first and the second sleep cycle of the control and the different clinical categories.

Fig. VI.17. Percentage of effective sleep time in the control and different clinical categories during the first and second al1-night cyclue.

Fig. VI.18. Mean values, in minutes, of N. REM and REM sleep during the first and second all-night cycle of the control and the different clinical categories. 
Yig. VI.19. Mean values of $\mathrm{N}$. REM $1-2$ and N.REM 3-4 sleep during the first and second all-night cycle of the control and the different clinical categories.

Fig. VI.20. Whio of the H.RM $1-2 / \mathrm{M}$. REM $3-4$ sleep during the fIrst and second all-night sleep cycle of the control and the different clinical categories.

Fig. VII.1. Age distribution in years of the 295 male patients. Fig. VII.2. Age distribution in yeaxs of the 253 female patients.

Table VII.3. Quantitative composition of the first and second oycle during the sleep deprivation recordings of the control group.

Table VII.4. Composition of the first cycle during sleep deprivation recordings of patients without (N.E.) and wth (E.) epileptic EEG phenomena, for the total group ( $T$ ) and for the selective group (S).

Tablie VII.5. Composition of the second cycle during sleep deprivation recordings of patients without (N.E.) and with (E.) epileptic EEG phemomena ( $T$ = total group; $s=$ selective group).

Table VII.6. Composition of the first cycle during sleep deprivation recordings of patients, without epileptic EEG phenomena (N.E.) and without (-A.E*) or with $(+$ A.E.) antilepileptic drug treatment $(T=$ total group; $s$ = selective group).

Mable VII.7. Composition of the second cycle during sleep deprivation recordings of patients without epileptic EEG phenomena (N.E.) and without (-A.E.) or with (+A.E.) antiepileptic drug treatment $(\mathbb{T}=$ total group: $s=$ selective group).

Table VII.8. Composition of the first sleep deprivation cycle in patients with epileptic EEG phenomena (E.) treated with antieplieptic drugs, in combination with $\left(+\mathrm{A} \cdot \mathrm{E}_{*}-\mathrm{B} \cdot \mathrm{D}.\right)$ or without $(+\mathrm{A} \cdot \mathrm{E} \cdot+\mathrm{B} \cdot \mathrm{D}$.$) benzo-$ alazepine derivatives $(T=$ total group; $s=$ selective groupl.

Table VII.9. Composition of the second sleep deprivation cycle in recordings with epileptic EEG phenomena (E.) with antiepileptic drug treatment, in combination with (+A.E.+B.D.) or without (+A.E.-B.D.) benzodiazepine derivatives $(\mathrm{T}=$ total group: $\mathrm{S}=$ selective group) 
Table VII.10. Composition of the first sleep deprivation cycle in recordings with epileptic EEG paroxysms belonging to generalized, partial or generalized with partial epllepsy $(T=$ total groupi $s=$ selective group).

Table VII.1. Composition of the second sleep deprivation cycle in recordings with eplieptic EEG paroxysms belonging to generalized, partial or generalized with partial epilepsy ( $\mathrm{T}$ = total group; $\mathrm{S}=$ selective group).

Table VII.12. Comparison of the sleep pattern of the first sleep deprivation cycle: control group versus the different clinical groups of patients between 20 and 40 years old.

Table VII.13. Comparison of the sleep pattern of the second sleep deprivation cycle: control group versus the different clinical growps in patients between 20 and 40 years old.

Table VII.14. Comparison of the first sleep deprivation cycle: control group versus the different clinical groups depending on the age (5-20 versus $20-40$ years).

Table VII.15. Comparison of the second sleep deprivation cycle: control group versus the different clinical groups depending on the age (5-20 versus $20-40$ years).

Table VII.16. Composition of the first sleep deprivation cycle in patients of different age group, without antiepileptic drug treatment (-A.E., $\mathrm{n}=100$ ).

Table VII.17. Composition of the first sleep deprivation cycle in patients of different age only treated with antiepileptic drugs ( + A.E., $n=195$ ).

Table VII.18. Composition of the first sleep deprivation cycle in patients of different age, treated with antieplleptic drugs in combination with benzodiazepine derivatives $(+$ A.E. + B.D., $n=24)$.

Fig. VII.19. Mean values, in minutes, of the total sleep cycle, the time awake and the effective sleep time during the first and second sleep deprivation cycle of the control and the different clinical categories $(20-40$ years).

Fig. VII.20. Percentage of effective sleep time in the control and the different clinical categories during the first and second sleep deprivation cycle. 
Fig. VII.21. Mean values, in mutes, of the ReM and the N.REM sleep during the first and second sleep deprivation cycle of the control and the different clinical categories.

Fig. VII.22. Mean values, in minutes, of the M.REM $1-2$ and the N. FEM 3-4 sleep during the first and second sleep deprivation cycle of the control and the different clinical categorleg $(20-40$ years).

F1.g. VII.23. The N.REM 1-2/N. REM 3-4 ratio during the first and second sleep deprivation and all-night cycles of the control and the different clinical categrories.

Table VIII.1. Number and mean age of patients treated with different types of antiepileptic drugs ox benzodiazepine derivatives*

Table VIII.2. Composition of the first and siecond sleep cycle after one night sleep deprivation in patients only treated with sodium valproate.

Table VIII.3. Composition of the first and second sleep cycle after one night sileep deprivation in patients only treated with carbamazepine.

Table VIII.4. Composition of the first and second sleep cycle after one night sleep deprivation in patients only treated with diphenylhydantoin.

Table VIII.5. Composition of the first and second cycle of one night sleep deprivation in patients treated with carbamazepine and sodium valproate.

Table VIII.6. Composition of the first and second cycle after one night sleep deprivation in patients treated with carbamazepine and diphemylhydantoin.

Table VIII.7. Composition of the first cycle after one night sleep deprivation of sleep patterns without epileptic EEG phenomena in patients txeated with one or two antiepileptic drugs.

Table VIrI.8. Composition of the first cycle after one night sleep deprivation of sleep patterns with epileptic IEEG phenomena in patients treated with one or two antiepileptic drugs.

Table VIII.9. Composition of the first and second cycle after one night sleep deprivation in patients treated Wh antiepileptic arugs in combination with chlorazepate (Chlor.) or clonazepam (clon.). 
Fig. VIII.10. Mean values, in minutes, of the total sileep time. the time awake, and the effective sleep time of the first sleep deprivation cycle in patients with (E.) or without (N.E.) epileptic EEG phenomena treated with one or two diffexent antieplieptic drugs.

Fig. VIII.II. Percentage of the effective sleep time in the first sleep deprivation cycle of patients with (E.) or without (N.E.) epilleptic EEG paxoxysms treated ith different antiepileptic drugs.

Fig. VIII.12. Mean values, in minutes, of the REM and the N.REM sleep during the first sleep deprivation cycle of patients treated with different types of antiepileptic drugs.

Fig. VIII.13. Mean values, in minutes, of the N.REM $1-2$ and the N. REM 3-4 sleep during the first sleep deprivation cycle of patients treated with three different types of antiepileptic drugs.

F19. VIII.14. N. REM 1-2/N. REM 3-4 ratio of the first deprivation sleep cycle for 3 different types of antiepileptic drugs (sodium valproate, carbamazepine and diphenylinydantoin).

Fig. VIII.15. The mean values, in minutes, of the total cycle, alvided in time awake and effective sleep time, of the effective sleep time divided in REM and N.REM sleep and the N.REM sleep divided in N.REM $1-2$ and N. REM 3-4 sleep in patients treated with antieplleptic arugs, or in combination with or without chlorazepate or clonazepam.

Fig. IX.1. Example of typical spike wave complexes (SW).

Fig. IX.2. Example of polyspike wave complexes (PSW).

Fig. IX.3. Example of low frequent spike wave complexes (LSW).

Table IX.4. Percentage of typical spike wave (sW), polygpike wave (PSW) and low Exequent spike wave (ISW) paraxysms during the sleep stages N. REM $1-2$ and N.REM 3-4 sleep after one night sleep deprivation, and the registrations without epileptic EEG manifestations (N.E.), in comparison with the routine awake EEG.

Fig. IX.5. Example of epileptic EEG manifestations during W. REM $1-2$ and REM sleep of the first sleep cycle registered after one night sleep deprivation. 
FIg. IX.6. Example of a postictal period, two minutes after a generalized tonic-clonic selzure.

Table IX.7. Duration of the postictal period and the characteristics of the postictal sleep in patients with the occurrence of an electroclinical epileptic seizuxe during the registration after one night sleep deprivation.

Fig. IX.8. Example of sleep fragmentation.

Table IX.9. The clinical and electroencephalographic findings of 50 patients, suspected of having epilepsy, with a typlcal pattexn of sleep fragmentation in the sleep recorded after one night sleep deprivation, in relation with the inteligence level.

Fig. IX.10. Normal K-complex.

Table IX.1.1. Density of K-complexes during the descending (D) and ascending (A) N.REM phases of the first and second sleep cycle of a healthy person after 1 night sleep deprivation.

Table IX.12. Density of K-complexes during the descending (D) and ascending (A) N. FEM phases of the first and second sleep cycle of an eplleptic patient after 1 night sleep deprivation.

F1g. IX.13. Example of an atypical K-complex.

Fig. IX.14. Example of slow eye movements during N. REM I sleep.

F1g. IX.15. Example of rapid eye movements of high density during REM sleep.

Fig. IX.16. Level of chin muscle activity during N.PEM 2 sleep before and after an arousal reaction.

Table IX.17. The resplration rate and the accurrence of aprea periods in a group of 40 epileptic patients during the alfferent types of sleep and awake after one night sleep deprivation in relation with the form of epilepsy and the antiepileptic drug treatment.

Fig. Add.2.1. Histograms of minutes awake, N.REM 1-2, FEM and N. REM 3-4 sleep of the first cycle after one night sleep deprivation of the total patient group $(\mathrm{n}$ : $548)$.

Fig. Ada.2.2. Distribution of the sample means with size $\mathrm{n}$.

Fig. Add.2.3. Distribution of normalized sample means with size 6. 
Fig. Ada.2.4. The quantity u as a function of the sample size $\mathrm{n}$ for $1 / 2 a=0.1,0.05$ and 0.025 .

Fig. Add.2.5. Two-sided confidence intervals for $\bar{x}_{1}$ and $\bar{x}_{2}$; $1 / 2 a=0.1,0.05$ and 0.025 .

Table VI.12. Comparison of the sleep pattern of the first al1bis night cycle: control group versus the different clinical groups [mean, standara deviation (SD). confidence intervals for the mean $(1 / 2 \alpha=0.05$, $0.025) 1$.

Table VI.13. Comparison of the second all-night cycle: control bis group versus different clinical groups [mean, standard deviation (SD), confidence intervals for the mean $(1 / 2 a=0.05,0.025)]$.

Table VII.12, Comparison of the sleep pattern of the first sleep bis deprivation cycle: control group versus the different clinical groups of patients between 20 and 40 years old [mean, standard deviation (SD), confidence intervals for the mean $(1 / 2 \propto=0.05$, $0.025)]$.

Table VII.13. Compaxison of the sleep pattern of the second sleep bisi deprivation cycle: control group versus the different clinical groups in patients between 20 and 40 years old [mean, standard deviation (SD) , confidence intervals for the mean $(1 / 2 \alpha=0.05$, $0.025)]$.

Table VIII.7. Composition of the first cycle after one night bis sleep deprivation of sleep patterns without epileptic EEG phenomena in patients treated with one or two antiepileptic drugs Imean, standard deviation (SD), confidence intervals for the mean $(1 / 2 \alpha=0.05,0.025)]$.

Table VIII.8. Composition of the fixst cycle after one night bis sleep depriwation of sleep patterns with epileptic EEG phenomena in patients treated with one ox two antiepileptic drugs [mean, standard deviation (SD). confidence intervals for the mean $(1 / 2 \alpha=0.05$. $0.025) 1$.

Table VIII.9. Composition of the Eirst cycle after one right bis sleep deprivation in patients treated with antiepileptic drugs in combination with chlorazepate (Chlor.) or clonazepam (clon.), [mean, standard deviation (SD), confidence intervals for the mean $(1 / 2 a=0.05,0.025)]$. 
Dit proefschrift behandelt de interacties tussen eplepsie, slaap en anti-epileptica, gebaseerd op klinisch neurofyslologisch onderzoek.

In hoofdstuk I komt de vraag an de orde of polygrafische slaapregistratie na 1 nacht totale slaapdeprivatie (TSD) en geschikte methode is voor onderzoek van deze interakties en aan welke voorwaarden die dan moet voldoen.

In hoofdstuk II zijn de literaturgegevens samengevat en opgesplitst in twee delen.

In het eerste deel werden de algemeen geldende definities vermela om EEG fenomenen, passend bij slaap en epilepsie, te beschrifven alsmede de criteria die worden gehanteerd om de verschillende soorten slaap en epilepsie te classificeren.

In het tweede deel wordt een overzicht gegeven van de verschillende slaapmethoden die toegepast worden om epileptische EEG verschijnselen te registreren en de slaapveranderingen die kunnen optreden bij de epilepsie ten gevolge van de epilepsie of de imname van anti-epileptica. Er bestaat een algemene consensus over het felt dat de epileptische $\mathbb{E E G}$ verschijnselen, zowel van het gegeneraliseerde als van het partiële type, het meest toenemen tijdens de oppervlakkige $N$. REM 1-2 slaap, een slaap die ook aanleiding geett tot meer polypiekvoming en spreiding var de epileptische EEG verschijnselen, dit in tegenstelling tot de REM slap. Algemeen wordt aangenomen dat de slap niet wezenlijk wordt beinvloed door het optreden van epileptische EEG ontladingen, met uitzondering van het optreden van enkele morfologische veranderingen, maar dat de slaap wel gewijzigd kan worden door langdurige inname van anti-epileptica.

In hoofdstuk III worden de wragen geformuleerd die aan de hand van literatuurstudie onvoldoende beantwoord konden worden, antwoorden nodig om de voor- en nadelen van de slaapregistratie na 1 nacht TSD methode te bepalen. Met behulp van eigen onderzoek is geprobeerd deze vragen te beantwoorden.

In hoofdstuk IV wordt dieper op het gebruikte materiaal en de methoden ingegaan. Het materiaal bestond uit ruim 1500 polygrafische slaapregistraties die in de periode 1976-1981 werden verricht bij personen met of verdacht van epilepsie. Hierim is 70 opgenomen na 1 nacht TSD, met een registratiedur wan 3 tot 5 uur en 30 tijders de gewone nachtelijke slaap. Alle opnamen werden verricht met ean 16- of 21-kanats elektroencephalograaf waarvan minimal 12 kanalen werden gebruikt voor het reglstreren van EG potentialen.

wa visuele beoordelling werd de samentelling van de slaap weexgegeven in een hypnogram, met daaronder vermelding van de kwantitatleve samenstelling en de kwalitatieve aspecten van de blipap en tevens van de soort, dur en hoeverheld eplleptische EEG afwijkingen in relatele tot de slaapsoort en diepte. Sinds 1979 werd de visuele analyse angevuld met een automatische slapanalyse en classificatie.

In hoofastuk $V$ wordt de registratio van epileptische EEg fenomenen tijdens de slaap besproken. In een aselecte populati van patienten, verdacht van epilepsie wordt in vergelijking met de routine en de diagnostische EEG onderzoekingen overdag een diagnostische winst van 25 tot 32 geboekt. Deze winst loopt op tot ca. 50 voor de patiënten bij wie op klinische gronden epilepsie zeer warachijniljk 
1.5. Slecht bij 3 van de 395 patienten, klinisch zeer waarschijnijk zonder eplepeie, werden tijdens de slaap specifieke epileptische ErG afwijkingen vastgesteld in vergelijking met 2 personen tijdens het routine EEG onderzoek overdag. Het antal patienten met specifieke epileptische EEG afwijkingen tljdens de slaap was ruin 84 bij patienten bij wie de kinische dilagnose van epilepsie als zeker werd beschouvd. Het percentage inst verkregen door registratie van slaap gedurende en hele nacht is voor gegenerallsecrde epilepsie 6 hoger dan tijdens de slap na TSD en voor partiële epilepsie gelijk. Conform de literatuur werden de meeste eplleptische EEG verschijnselen tijdens de AFM $^{1-2}$ slaap en tijdens de beginperiode van de slaapregistratie gezien. Belangrijk is echter de bevinding dat bij ca. 13 de epileptische EEG afwijkingen slechts aanwezig waren tijdens de 2e slapcyclus en bij ca. 7 t enkel na een registratieduur van meer dan 2 uur. Daarenboven 1 voor een aantal patiënten met gegenerallieerde epliepsie de aanwezigheid van diepe $\mathbb{N}$. REM 3-4 slaap noodzakelijk.

Bij het ultwoeren van langdurige slaapregistraties na $\mathrm{mSD}$, met gemidald 2 slapcyclussen, heft het completeren van het onderzok met hyperventilatie en/of intermitterend lichtflitsen slechts een beperkte warde en vormt voor de patient een extra belasting.

De algemene conclusie 1 widt dat na 1 nacht $T S D$, een slaapregistratie van 2 slaapcylussen als optimaal beschouwd kan woxden voor het reglstreren van epileptische EEG fenomenen.

Hoofdstuk VI behandelt de kwantitatieve veranderingen in slaapsamenstelling van de le en $2 e$ slaapcyclus tijdens de gewone nachtelijke slaap bij eplleptici in vergelijking met een controlegroep gezonden. Alle patiënten hebben en langere cyclusduur, te wijten aan meer N.REM slaap vooral van de oppervlakkige N. REM $1-2$ slaap. De verschillen zijn het kleinst bij de patiënten met epileptische $\mathrm{EEG}_{\mathrm{j}}$ afwijkingen tijdens de slaap en met inname van anti-epileptica. Bij toevoeging van benzodiazepine derivaten aan de anti-epileptical ziet men een toename van de N.REM 1-2 slaap. Afhankelijk van het type epilepsie zijn er silechts lichte verschillen, bestaande uit: meer N. REM $1-2$ slaap bij de gegeneraliseerde vormen van epilepsie, meer REM slaap bij de partiële vomen en vooral meer $N$. REM $1-2$ als $N$. REM slaap bij epilepsie met zowel gegeneraliseerde als partiële aanvallen.

In hoofdstuk VII wordt, naar analogie van de doorslaapregistratie, angegeven hoe de slaapsamensteling van de le en $2 \mathrm{e}$ sla apcyclus na een nacht slapdeprivatie bij eplleptici verschilt van die bij gezonden. Bij epilepticl biljkt de slapsamensteling minder afhankelijk te zijn wan het wel of niet arnwezig zijn van epileptische afwijkingen dan het wel of niet innemen van anti-epileptica, hetzij alleen, hetzij in kombinatie met benzodiazepine derivaten.

Onze resultaten tonen aan dat tijdens de le cyclus zowel bij gezonden als bij patiënten het slaapdeprivatie-effect overweegt boven andere invloeden zoals geciteerd bij de doarslap.

Ten gevolge van de slaaponthouding wordt het slaappatroon op stereotype wijze beinvloed, en wel door een verkorting van de inslaaptijd en van de totale le cyclusduux. Dit is te wijten a an een aframe van de N.REM slaap. Binnen de N. REM slaap is er verhoudingsgewijze meer diepe dan oppervlakkige $N$. REM slaap. Deze effecten zijn nagenoeg verdwenen tijdens de $2 e$ cyclus die daardoor in vele opzichten grote gelijkenis vertoont met de 2 e doorslaapcyclus. 
In dit hoofdstuk wordt gewezen op het belang van de leeftijd en met name de leeftijasgrens van 20 jaax. Onder de 20 jaax is het deprivatie-effekt sterker dan darboven, en wordt nog geaccentueerd door benzodiazepine derivaten. Boven de 20 jaar wordt het deprivatileeffekt gecompleteerd met een benzodiazepine effekt, waardoor nog sterkere verlenging van de cyclusduur optreedt.

In hoofdstuk VIII wordt aangetoond dat de samenstelling van de le slaapcyclus na 1 nacht TSD, bij epileptici die slechts inet 1 antiepilepticum of een combinatie van 2 anti-epileptica worden behandeld, verschilt per type anti-epliepticum. Het deprivatie-effekt wordt versterkt bij inname van carbamazepine en in lets mindere mate door inname van natriumvalproaat, mar daarentegen geneutraliseerd bij toediening van hydantoine derivaten. In vergelijking met de slaap bij gezonde proefpersonen is de totale le cyclusauur verlengd bij: inname van hydantoine of valproat derivaten. Die verlenging is bij de hydantoine derivaten wooral te wijten an meer oppervlakkige N. REM 1-2 slaap en bij valproaat an geringe vemeerdering van de oppervlakkige N.REM $1-2$ en iets sterkere toename van de diepe N. REM 3-4 slaap.

ook kon worden angetoond dat benzodiazeplne derivaten, gegeven in combinatie met anti-epileptica, conform hun werkingsprofiel, de samenstelling van de le slaapcyclus na 1 nacht TSD wijzigen. De soort: en grootte van de wijziging verschilt per benzodiazepine dexivat.

Tevens wordt erop gewezen dat de geregistreerde verschilien in slaapsamenstelling per soort anti-epilepticum of benzodiazepine derivaat mede afhankelijk kunnen zijn van de soort en ernst van hersenfunctiestoornis die voor het optreden van epilepsie verantwoordelijk 1.s.

Hoofdstuk IX bestaat uit een reeks evaluatieonderzoeken waarbij vooral de aspectveranderingen worden belicht die enerzijas de epileptische EEG afwijkingen kunnen ondergaan ten gevolge van de slaap en anderzijds de polygrafische slaapfenomenen ten gevolge van de epilepsie met de hiervoor ingestelde behandeling. Voor een goede interpretatie van de epileptische EEG afwijkingen tijdens de slaap moet men van die vexanderingen op de hoogte zijn alsmede van hun klinische betekenis.

zowel tijdens de doorslaap als tijdens de slaap na TSD hebben epileptici green abnomal lange apnoeperioden. Wel zijn er meer scherpe k-complexen dan bij de controlepersonen en na TSD nog meer dan tijdens de nachtelijke slaap. Sommige veranderingen, zoals de afname vam snelle oogbewegingen of niveau van splexactiviteit, veranderingen die kunnen samenhangen met de ingenomen medicatie, maken deze parameters minder bruikbaar als criteria or de slapsoorten van elkater te onderscheiden. Dit bezwaax is vooral van belang bij het gebruik van automatische slapanalyse en classificatie.

In hoofdstuk $\$$ worden 3 slapprocedures voorgesteld die na 1 nacht ISD, afhankelijk van de beoogde doelstelling, bij voorkeur worden toegepast. De le of eenvoudige procedure richt zich hoofdzakelijk op de epilepsiediagnostiek.

De $2 e$ of complexe en meer uitvoerige procedure richt wich zowel op bestudering van de epilepsie als slaap en beïvloeding van elk van belide door anti-epileptica.

De $3 e$ of gerichte procedure geeft an dat het noodzakelifk kan zijn de registratie en de verwerkingswijzen an te passen aan de 
Indicatiestelling van het onderzoek.

Hoofdstuk XI of de bespreking onvat 3 onderdelen. In het le deel worden de fydiologische en pathofysiologische regulatie en ontstaassmechanimeri van slaap en epilepsie besproken, waardoox enig inzicht wordt vexkregen van de wijze warop deze elkaar kunnen beinwloeden.

In het $2 e$ deel worden an de hand van deze inzichten de bevindingen van eigen onderzoek besproken en woxdt aargegeven waardoor onze resultaten in bepalde opzichten verschillen van de literaturgegevens. Dok wordt getracht de verschillen in slaapsamenstelling van de le siapcyclus na 1 nacht TSD per anti-epilepticum te verklaxen uit de wijze waarop dit de hersenen beinvloedt.

In ex $3 \mathrm{e}$ en latste deel worden enkele van de belangrijkste voorwarden benoend waraan de TSD procedure moet voldoen om een zo hoog mogelijk didgnostisch rendement te verkrijgen alsook enkele aanbevelingen voor vexder onderzoek.

De addenda bevat een bespreking van de toegepaste automatische slaapelassificaties (Add. 1) en de gebruikte statistische methoden (Add. 2). Daxop volgt eer reak tabellen met a anvullende gegevens betreffende verschillen in gamenstelling van de le en $2 \mathrm{e}$ slaapcyclus tijdens de nachtelijke slaap en de slaap na 1 nacht TSD (Add. 3) en het laatste addendum bevat een lijst met alle geciteerde tabellen en Eiguren (Add. 4). 
Akerstedt, T., Palmblad, J., De La Torre, B., Marand, R., Gillberg, . Adrenocorticol and gonadal steroids during sleep aeprivation. sleep, 3: $23-30,1980$.

Albert, $I . B$.

REM sleep deprivation.

Biol. Psychiatry, 10: 341-351, 1975.

Angeleri, $\mathbf{F}$.

Il sionno notturno negli epilettici.

In: $\mathbb{E}$. Lugaresi and P. Pazzaglia (Eds.), l'ppliessia argomenti di fisiopatologia, clinica e terapia, A. Gaggi, Bologna, pp. 181-204, 1969.

Argumer, A.

Changes in the night sleep characteristlcs of epileptic patients:

a longitudinal study.

Electroenceph. clin. Neurophysiol., 43: 462, 1977.

Arne-tes, M.C., Calvet, U., Thiberge, M., Arbus, L.

Effects of sleep deprivation in an EEG study of eplleptics.

In: M.B. Steman, M.N. Shouse and P. Passouant (Eds.), Sleep and Epilepsy, Academic Press, New York, Pp. 441-452, 1982 .

Aserinsky, E*, Kleitman, N.

Regularly occurring periods of eye motility and concomitant phenomena duxing sleep.

Sclence, 118: 273-274, 1953.

Ballengex, J.C. "Post, R.M.

Carbamazepine in manic-depressive iliness. A new treatment.

Amer. J. Psychiat. (USA), 137: 782-790, 1980.

Bancaud, J., Talairach, J." Bonis, H., Schaub, C., Szllka, G., Morel, P., Bordas-Ferrer, $M$.

La stereoencephalographìe dans l'épilepsie. Informations neurophysiopathologiques apportees par l'investigation fonctionelle stéréotaxique, Masson et Cie, Paris, 321 p.. 1965.

Bechinger, D., Kornhuber, H.H.

The sleep deprivation EEG in childhood.

Electroenceph. clin. Neurophysio1., 41: 654, 1976.

Berger, H.

Übex das Elektroencephalogramm des Menschen.

Archiv fur Psychtatrie und Nervenkrankheiten, 87: 527-570, 1929.

Berger, R.J.

Tonus of extrinsic laryngeal muscles during sleep and dreaming.

Selence, 134: 840, 1961.

Bergex, R.J., Walker, J.M., Scott, T.D., Magnuson, L.J., Pollack, S.L. Dilurnal and nocturnal sleep stage pattern following leep deprivation.

Psychon. Sci., 23: 273-275, 1971.

Boyer, $\mathbb{P} \cdot \mathrm{A}$.

Anticonvulsant properties of benzodiazepines.

Dis. Nerv. Syst., 27: 35-42, 1966.

Bremer, $F \cdot C \cdot R$.

Cerveau "isolé" et physiologie du sommeil.

Comptes rendus heba. des seances et Mémolres de la socileté de Biologie, Paris, 118 : 1235-1241, 1935. 
Broughton, $R$.

sleep and clinical pathological states.

In: M.H. Chase (Ed.). The Sleeping Brain, Erain Research Institute, Pp. 363-446, 1972 .

Cadilihac, J., Passouant, P.

L'Influence des différentes phases du someil nocturne sur les decharges Eplieptiques chez l'homme.

In: M. Jouvet (Ed.). Aspects Aratome-Fonctionnels de la Physiologie du somel. Masson, Paxis, pp. 555-570, 1965.

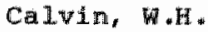

Synaptic potential summation and repetitive firing mechanisms: input-output theory for the recruitment of neurons into epileptic bursting firing patterns.

Brain Res., 39: 71, 1972.

MoCarley, R.H.

Advances in benzodiazepine research: receptors, kinetics and clinical hypnotic use.

sleep, 5: S1-52, 1982 .

Celesta, G.G. Jasper, H.H.

Acetylcholine released from cerebral cortex in relation to state of activation.

Neurology, 16: 1053-1064, 1966.

Chadwick, D., Trimble, M., Jenner, P., Driver, M.V., Reynolds, E.H.

Manipulation of cerebral monamines in the treatment of human epllepsy: a pilot study.

Epilepsia, 19: 3-10, 1978.

Chatrian, G.E., Bergamini, L., Dondey, M., Klass, D.W., Lennox-Buchthat, M., Petersen, I.

A glassary of terms most commonly used by olinical electroencephalographers.

Electroenceph. clin. Neurophysiol. , 37: 538-548, 1974.

Clemensi, B. "Mezey, I.

Diagmostic value of EEG in spontaneous sleep following sleep deprivation in epilepsy.

In: H. Lechner and A. Araniben (Eds.), Proceedings of the 2 nd European Congress of EEG and Clinical Neurophyslology, Salzburg, Excerpta Medica, Ansterdam, pp. 77-8.2, 1980.

Coenen, A.M.I.

De s.lap.

Van Goreum, Assen, 1979.

Cohen, H.B., Dement, W.

sleep changes in threshold to electroconvulsive shock in rats after deprivation of paradoxal phase.

Science, 150:1318-1319, 1965.

Dalby, M.A.

Epilepsy and 3 per second spike and wave rhythms, a clinical, electroencephalographic and prognostic analysis of 346 patients.

Acta Neurologica Scandinavica, 40:45, 1969.

Dealerck, A.C., Wauquier, A. , Sijben-Kiggen, R. , Pans-Raedts, M.

A central and central-temporal $3 \mathrm{c} / \mathrm{sec}$ rhythm occurring during REM and stage 2 of the N. REM sleep in humans.

In: W.P. Koella (Ed.), Sleep, Fifth European Congress of sleep Research, Amsterdam, s. Karger, Basel, Pp. 325-327, 1980. 
Declerck, A.C., Martens, W.L.J., Hoogslag, M.A., Kums, G.J.Th.M. The value of sleep spindle quantification for judging the effects of a new benzodiazepine derivative (RU 31.158).

Abstracts of the Sixth European Congress of Sleep Reseaxch, zürich, 1982.

Degen, $\mathbb{R}$., Degen, K.E.

Die diagnostische Bedeutung des Schlaf-EEG und Schlaf-EEG nach Schlafentzug bei Patienten mit psychosonatischen Anfallen unter anti-epileptischer Therapie.

Z.EEG-ENG, $10: 226-233,1979$.

Degen, $\mathbb{R}$.

A study of the diagnostic value of waking and sleep EEG after sleep deprivation in epileptic patients on anti-convulsant therapy.

Electroencepla. clin. Neurophysial., 49:577-584, 1980.

Degen, R. Degen, H.E.

The diagnostic significance of the sleep EEG and the sleep EEG after sleep deprivation in patients with psychomotor epilepsy receiving anticonvulsant therapy.

Electroenceph. clin. Neurophysiol., 50: 135P, 1980.

Degen, $\mathbb{R}$., Degen, H.E.

The diagnostic value of sleep and sleep deprivation in epileptogy. In: R. Degen and $\mathbb{E}$. Niedermeyer (Eds.), Epllepsy-sleep-sleep Deprivation, in press, 1982.

Deisenhammer, E., Klinger, D.

Das Schlafentzugs-EEG bei kranken mit gesicherter und fraglicher Epilepsie sowie bei Kranken ohne Epileptische Anfalle.

Z.EEG-EMG, 9: 38-42, 1978.

Delange, M. , Castan, Ph. "Cadilhac, J., Passouant, P.

Etudes du sommeil de nuit au cours d'epilepsies centrencéphaliques et temporales.

Rev. Neural., $106: 106-113,1962$.

Dement, W.

Dream recall and eye movements during sleep in schizophrenios and noxmalis.

J. Nerv. Ment. Dis., 122: 339-346, 1955.

Dement, $W$. , Kleitman, N.

Cyclic variations in EEG during sleep and their relation to eye movements, body motility and dreaming.

Electroenceph. clin. Neurophysiol., 9: 673-690, 1957.

Dement, $W . C$.

The effect of dream deprivation.

science, 131: 1705-1707, 1960.

Dement, $W_{m} C$.

sleep and dxeams.

In: A.M. Freedman and H.I. Kaplan (Ed.s.), Human Behaviour, Atheneum, New York, pp. 113-136, 1972.

Englander, R.N., Johnson, R.N., Brickley, J.J., Hama, R.

Effects of anti-epileptic drugs on thalamocortical excitability *

Neurology, 27: 1134-1139, 1977 .

Erba, G., Moschen, R.

sleep-related changes of bilateral synchxonous EEG aischarges in the Lennow-Gastaut synarome.

Electroenceph. clin. Neurophysiol., 49: 24P, 1980. 
Eaber, J.

Vigliance, sleep, petit mal and electroencephalogram as manifestations of programined brain regulation.

Acta Universitatib carolinae medica monographia, 87: 5-92, 1978.

Feerey, D.M., Gullotta, E.P*, Pittman, J.C.

Slow wave bleep and epllepsy: rostral thalamus and basal forebrain lestons suppress spindles and selzures.

Exp. Heuro1., 56: 212-2:26, 1977 .

Feinberg, I. Fein, G., Walker, J.M., Price, L.J., Floyd, T.C." March, I.D.

Flurazepam effect on sleep EEG.

Arch. Gen. Psychiatry, 36: 95-102, 1979.

Fere, C.

Les epulepsis et les epileptiques.

In: P. Passouant (Ed.), EEG and sleep. Handbook of Electroenceph. clin. Meurophysiol., 7A: 66, 1975 .

Findji, F., Bittner-Maricka, M., De Barros-Ferreira, M., Joseph, J.P. organisation temporelle des décharges paroxystiques chez l'enfant. II. Enxegistrements polygraphiques du someil.

Electroenceph. clin. Heurophysiol., 45: 740-753, 1978 .

Fischgold, H., Dxeyfus-Brisac, C., Monod, M., Samson-Dollfus, D., Kramarz, P., Blanc, C.L.

L"Electroencéphalogxame au cours de la maturation cérébrale.

Dehan, Montpelliex, 1: 66, 1959.

Foret, J., Webb, W.B.

Changes in temporal organization of sleep in men aged from 20 to 70 years.

Electroenceph. clin. Neurophys101., 52: 28P-29P, 1981.

Friedman, J., Globus, C., Kikex, G., Mullaney, D., Johnson, L., Moses, J.. Naitoh, P.

Gradual sleep restriction effects in EEG.

Sleep Res., 3: 150, 1974 .

Fukuda, H., Endo, S., Yamamoto, T., Kobayashi, T., Saito, Y. The effects of total sleep loss and selective sleep deprivation on sleep onset REM eplsodes.

Electroenceph. clin. Neurophysiol. 52: 532,1981 .

Fukuyama, Y., Ochiai, Y., Hayakawa, $\mathbb{T} *$, Miyagawa, F.

overnight sleep EEG and cerebrospinal fluid monoamines in seizures Induced by movement.

Neuropådiatrie, 10: 138-149, 1979.

Gabriel, M., Albani, M.

Rapld eye movement leep, apnea and cardiac slowing influenced by phenobarbital administration in the neonate.

Pediatries, 60: 426-430, 1977.

Gaillard, J.M., Schulz, R., Tissot, R.

Effects of three benzodlazepines (nitxazepam, flunitrazepam and bromazepam) on sleep of normal subjects, studied with an automatic sleep scoring system.

phamakopsychiatrie, 6: 207-217, 1973 .

Gaillard, J.M., Tissot, R.

Le sommeil du jeune adulte vu par analyse automatique des enregistrements.

Electroenceph. clin. Neurophysiol. , 41: 73-82, 1976. 
Gall1ara, J.M.

Brain catecholaminergic activity in relation to sleep.

In: R.G. Priest, A. Pletscher and I. flend (Eds.). Proceedings of the Northern European symposium on sleep Research, pp. 35-41, 1978 .

Gallager, D.W.

Benzodiazepines and gamma-aminobutyric acid.

sleep, 5: S3-511, 1982 .

Gastaut, H*, Batini, C*, Fressy, J., Broughton, R." Tassinari, C.A., vittini, F.

Etude êlectroencêphalografique des phénomènes êplsodiques êpileptiques au cours du sommeil.

In: Le Sommeil de Nuit Normal et Pathologique, Masson, Paris, pp. $239-254,1965$.

Gastaut, H.

Slow sleep (stages I and IV) (progressively fragments etc.).

Handbook of Electroenceph. clin. Neuxophysio1., 13A, 1975.

Gastaut, H., Tassinaxi, C.A.

Epiliepsies.

Handbook of Electroenceph. clin. Neurophysiol., 13A, 1975.

Geller, M.R., Gourdji, N., Christoff, N., Fox, E.

The effects of sleep deprivation on the EEG's of epileptic

chilidxen.

Develop. Med. Child Neurol., 11: $771-776$, 1969.

Gereby, G.

Experiments with sleep deprivation in cases of suspected epilepsy. Electroenceph. clin. Neurophysiol, 45: 9P, 1978.

Gibbs, F.A., Gibbs, E.L.

Atlas of electroencephalography.

Addison, Wesley, Cambridge, 1942.

Glaubman, H., Orbach, I., Aviram, O., Frieder, I., Frieman, M., Pelled, O., Glaubman, R".

REM deprivation and divergent thinking.

Psychophysiology, 15: 75-79, 1978.

Glenville, M., Broughton, R., Wing, A.M., Wilkinson, R.'T".

Effects of sleep deprivation on short duration performance measures compared to the Wilkinson Auditory Vigilance Task.

Sleep, 1 : 169-176, 1978 .

Gloor, $\mathbb{P}$.

Neurophysiological bases of generalized seizures, termed "centrencephalicite

In: Gastaut, H. Jasper, J. Baneaud and H. Waltregny (Eds.), The Physiopathogenesis of the Epliepsies, C. Ihomas, Springfield, I11. pp. 209-236, 1969 .

Gloor, P.

Generalized epilepsy with spike and wave discharge: a reinterpretation of its electrographic and clinical manifestations.

EpLlepsia, 20: 571-588 1979.

Gloor, p.

Electrophysiologie fondamentale et clinique de l'Epilepsie.

L'Union Medicale, $109: 7,1980$.

Gowers, $w$.

Epilepsy and other chronic convulsive diseases.

In: P. Passouant (Ed.), EEG and Sleep. Handbook of Electroenceph. clin. Weurophysiol. ,7A: 66, 1975 . 
Gozukimizi, E., Dervert, A., Altine1, A., zembilci, N.

All nigt aleep recordings in benlon chilahooa epilepsy.

Electroenceph. clin. Neurophysiol, $53: 28 R, 1982$.

Greenblatt, D.J., Schader, R.I.

Benzodiazepines in clinical practice.

sleep, 9: 183-196, 1973.

Guilleminault, C., Curmiskey, J., Dement, w.C.

sleep apnea syraxome, recent advances.

Adv. Int. Med*, 26: 3.47-372, 1980.

Ha lasz, P., Kundra, O., Rajna, $\mathbb{P} \ldots$, Pal, I., Vargha, M.

Micro-arousals during nocturnal sleep.

Acta Physiologlca Academiae scientianum Hungaxicae, 54: 1-12, 1979.

Halasz, P.

Generallzed epllepsy with spike wawe pattern (GEsw) and intermediate states of sleep.

In: M.B. Sterman, M.N. Shouse and P. Passouant (Eds.), sleep and Epllepsy, Academic Press, New York, pP. 219-237, 1982.

Hartley, $\mathbb{L}$, , Shirley, $E$.

sleeplosi, noise and decisions.

Ergonomics, 20: 481-489, 1977.

Hartman, E.L.

The sleep-dream cycle and brain.

Psychonom. Sc1., 8: 195, 1967.

Hartman, $\mathbb{E} \cdot \mathbb{L}$.

The functions of sleep.

London Yale Un. Press, 1973.

Hasan, J., Bjoerkquist, S.E. , Aronen, T* , Alihanka, J.

Treatment of sleep disturbance during alcohol withdrawal with carbamazepine (tegretol).

Paper at the XI. Annual Nordic Meeting on Biological Alcohol Resiearch, Helsinki, 1980.

Heinemarn, L.G.

Der mehrtägige schlafentzug in der experimentellen psychoseforschung: PSychopathologie und EEG.

Archiv für Psychiatrie und zeitschrift f.a. ges. Neurologie, 208: $177-197,1966$.

Hess, W.R.

The neural arganization of sleep: structural, biochemical and pha rmacologica 1 aspects.

In: W.P. Koella (Ed.), Int. Symposium Bad Kreuznacht, in press, 1962.

Van Heycop Ten Han, M.W.

Epilepgie.

Nederlandse Blbllotheek der geneeskunde, Stafleu's wetenschappelijke ultgeversmij B.V. Leiden, 1974.

Hokson, J.A., Mocarley, R.W., Wyzinski, P.W.

sleep oycle oscillation: reciprocal discharge by two brainstem neuronal groups.

Science, $189: 55,1975$.

Horlta, H., Kumagai, K., Endo, s., Miwa, N.

sleep pattern in mantally retarded children.

Electroenceph. clin. Neurophysiol., 52: 5109-5110, 1981. 
Inoue, H., Ishida, J., Ishida, T., Kanda, S. Yamatogi, Y, oka, E., Ishida, S.T.

Sleep in the west and the Lennox syndrome, a polygxaphic all-night: study *

Electroencept , clin. Neurophysiol., 43: 898, 1977.

Jacobs, B.L., MeGinty, D.J.

Effects of food deprivation on sleep and wakefulness in the rat.

Exp. Neurol., 30: 212, 1971.

Janz, D.

The grand mal epilepsies and the sleep-waking cycle.

Epilepsia, 3:60-109, 1962 .

Jasper, H.H.

The ten-twenty electrode system of the International Federation.

Electroenceph. clin. Neurophysiol., 10: 371-375, 1958.

Jeavons, P.M.

Nosological problems of myoclonic epilepsies in childhood and adolescence.

Develop. Med. Child Neurol., 19: 3-8, 1977.

Johnson, I. C.

Psychological and physiological changes following total sleep deprivation.

In: A. Kales (Ed.), Sleep: Physiology and Pathology, Lippincott, Philadelphia, pp. 206-220, 1969.

Johnson, L.C., McLeod, W.

sleep and awake behavior during gradual sleep reduction.

Perceptrul \& Motor Skills, 36: 87-97, 1973.

Johnson, I.C., Hanson, K., Bickford, R.G.

Effect of flurazepam on sleep spindles and $K$-complexes.

Electraenceph. clin. Neurophysiol., 40:67-77, 1976.

Johnson, I.C. , Spinweber, C.I.

Effects of a short-acting benzodiazepine on EEG during sleep.

Electroenceph. clin. Neurophysiol., 51: 36P, 1981.

Johnson, L.C.

Effects of anticonvulsant medication of sleep patterns.

In: M.B. Sterman, M.N. Shouse and P. Passouant (Eds.), Sleep and Epilepsy, Academic Press, New York, pp. 381-394, 1982.

Jouvet, M., Michel, F.

Correlations électromyographique du sommeil chez le rat decortique et mesencéphalique chronique.

Comp. Rend. Bi.o1. "153" 422-425, 2959.

Jouvet, M.

Recherches sux les structures nerveuses et les méchanisms responsables des différentes phases du sonmeil physiologique.

Arch. Itail. Biol., 100: 125-206, 1962.

Jouvet, $M$.

Paradoxal sleep, a study of its natuxe and mechanisms.

Prog. Brain Res., 28: 20-57, 1965.

Jovanovic, U.J.

Die dilagnostische Bedeutung des schlaf-Elektra-enzephalogramms.

Deutsches Medizinisches Journal, 17: 121-132, 1966.

Jovanovic, U.J." Liebaldt, G.P., Muhl, M., Nlppert, M., Stocker, G., Stumkat, E.

Längerer Schlafentzug und seine Begeleiterscheinungen.

Arch. Psychlat. Nerwenkr., 214: 183-202, 1971. 
Joranovic, U.J.

Categories of psychotropic drug effects on sleep EEG and EOG. Activ. Werv. Sup. (Frahal, 16: 209-210, 1974.

Kales, A., Kales, A.

Evaluation diagnosig and treatment of clinical conditions related to sleep.

Jama, $213: 2229-2235,1970$.

Karacan, I., Thornby, J.I., Booth, G.H.

Dose-respons effects of chefee on objective (EEG) and subjective measures of sieep.

In: P. Levin and A.P. Koella (Eds.), Second European Congress on sleep Research, Easel, g. Karger, Base1, Pp. 504-509, 1975.

Kazamatsuri, H.

Electroencephalographic study of petit mal epilepsy during nocturnal sleep. I. Studies on nocturnal sleep of epileptics.

Psychlatx. Meurol. Jap., 66: 650-679, 1964.

Kikuchi, s.

An electroencephalographic study of nocturnal sleep in temporal lobe epilepsy.

Fol1a Psych1atrica et Neurolagica Japonica, 23: 59-81, 1969.

Kinger, D., Deisenhamer, Ë. "Kropf, A.

Differenzierung von zwei paroxysmalen Reaktionstypen in EEG nach

Schlifentzug *

Z.EEG-EMG, 13: 138-142, 1982,

Knight, D.R., Le Portz, M.T.C., Harper, J.R.

Natural sleep as an ajid to electroencephalographic diagnosis in roung children.

Develop. Med. Child Neural., 19:503-508, 1977.

Koella, W.P.

Side effects of today's hyprotics and the hypnotic of the future.

In: W.P. Kovella (Ed.), Sleep, 5 th European congress on sleep Research, Amsterdam, S. Karger, Basel, pp. 158-164, 1981.

Kuglex, J.

Electroencephalografie in Klinik und Praxis.

G. Thieme Verlag, stuttgaxt, 1963.

Kuyer, A., Budt-Gutter, Th.

provoked sleep versus spontaneous sleep as a diagnostic tool in epilepsy.

In H.M. van Praag and H. Meinardi (Eds*), Braln and sleep, Erven

Bohn, Ansterdam, pp. $167-176,1974$.

Langdon-Down, M. " Brain, W.R.

Time of day in relation to convulsions in epilepsy *

Lancet, 2: 1029-1032, 1929.

Len a, C., Pa meggiani, P.L.

Hippocampa 1 theta rhy thm and activated sleep.

HeIv. Physioi. Acta, 22: 120, 1964 .

Lieb, J.P., Joseph, J.P., Engel, J. "walker, J., CrandaIl, P.H *

sleep state and selzure foci related to depth spike activity in patients with temporal lobe epilepsy.

Electroenceph. clin. Neurophysiol., $49: 538-557,1980$.

Lisper, H.O. Kjelliberg, A.

Effects of 24-houx sleep deprivation on rate of decrement in a 10-minute avaitory reaction time task.

J. Exp. Psychol., 96: 287-290, 1972 . 
Inirea, P., Di Reda, L., Puca, F.M., Genco, S. Specthilo, Lim, papagno, G*

Homovanilic acid and 5-hydroxyindoleacetic acid in lumbar cerebrospinal fluid aster total and RbM sleep deprivations in il umans:

Eur. Neurol., 16: 280-285, 1977.

Longo, V.G.

Effects of drugs on the EEG.

Hambook of Electroenceph. clin. Neurophysiol.,76, 1977.

Loomis, A. I. Harvey, E.N., Hobart, G.

Rotential Inythms of the cerebral cortex during sleep*

Science, 81: 597-598, 1935 .

Loomis, A.I., Harvey, E.N., Hobart, $\mathbb{E} \cdot \mathbb{A}$.

Cerebral states during sleep as studied by human brain potentials. J. Exp. Psycho1., 21: 127, 1937.

Ma cG 11 ivray, B.B.

Traditional methods of examination in clinical EEG.

Handbook of Electroenceph. clin. Neurophysiol., 3C, 1974.

Magnusi, 0 .

On the tecinique of location by electroencepha lography *

Electroenceph. clin. Neurophysiol. 19: 1-35, 1961.

Marosfi, $s$.

The distribution of convulsive activity in the night slep of epileptics.

Electroenceph. clin. Neurophysiol.,50: 1.15P, 1980.

Martens, W.I.J., Kums, G.J.Th.M., Declerck, A.C., Wavquier, A.

Considerations on a computerized analysis of long-term EEG

recordings.

Bx. J. Clin. Pxactice, Symposium supplement 18, pp. 71-74, 1982.

Mat thes, A *

Epilepsie.

Fibel. Georg Thieme Verlag, stuttgart, 1969.

Mattson, R.H., Pratt, K.I., Calverley, J.R.

Electroencephalograms of epileptics following sleep depaivation.

Arch. Neura1., 13: 310-315, 1965.

Me ier-Ewert, $\mathrm{K}$.

Schlaf und pilepsie.

Nervenarzt, $49: 324-331,1978$.

Metrakos, K., Metrakos, J.

Genetics of convulsive disorders II. Genetlo and electroncephalographic studies in centrencephaja epliepsy.

Neuro1ogy, 11: 474-483, 1961.

Monnier, M. "Schonenbergex, G.A.

Characterization, sequence, synthesis and sperify of a delta Eb sleep inducing peptide.

In: W.P. Koel1a and P. Levin (Eds."), SIeep, Karger, Base1, PP* $257-263,1977$

Monnier, M., Gaillard, J.M.

Biachemical regulation of sleep.

Experientia, 36: 21-24, 1980.

Montagu, J.D.

Effects of quinalbarbitone (secobarbital) and nitrazepam on the EEG in man: quantitative investigation

Eur. J. Pharmacol., 14:238-249, 1971. 


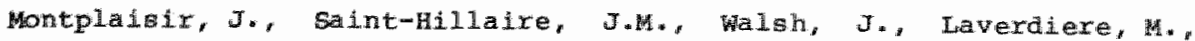
Rouvier, $G$.

Locallzation of primary eplleptic foci by all-night polygraphic recording.

31.me Congres International sur le Sommeil, Tokyo, Japan, sleep peseaxch, in presis, 1979.

Montplaidir, J., Laveralere, M., Walsh, J., Saint-hilaire, J.4., Bouvier, $G$.

Influence of nocturnal sleep on the epileptic spike activity recorded with multiple depth electrodes.

tectroenceph. clin. Neurophysiol.,49: 85P, 1980.

Montplaitix, J., SaInt-Hilaire, J.M., Laverdiere, M., Walsh, J., Bowviler, G.

Contribution of all-night polygraphic recording to the localization of primary eplleptic foci.

In: $R$. Canger, F. Angeleri and $x$. Kiffin-Penry, Advances in ep $1-$ leptology, XIth Epilepsy International Symposium, Raven Press, New York, Pp. 135-138, 1980 .

Moruzzi, G.; Magoun, M.W.

Brain stem reticulax formation and activation of the EEG.

Electroenceph. clin. Neurophysiol., 1: 455-473, 1949.

Murray, G.B.

Carbamazepine for central sleep apnea.

J. Amex. med. Ass: , 238, 18:212-213, 1977.

Naltoh, P., Pasnau, R.0., Kollar, E.I.

Psychophysiological changes affecting prolonged deprivation of sleep.

Biol. Psychiatry, 3: 309-320, 1971 .

Naitoh, $\mathbb{P}$.

Sleep deprivation in human subjects: a reappraisal.

Waking sleeping, 1: 53-60, 1976.

Naltoh, P., Antony-Baas, V., Muzet, A., Ehrhart, J.

Dynamic relation of sleep spindles and $K$-complexes to spontaneous phasic arousal in sleeping human subjects.

Sleep, 5: 58-72, 1982.

Niedermeyer, $\mathrm{E}$.

Common generalized epilepsy and generallzed-synchronous seizure discharges.

Epllepsy, Med. Probl. Phamacopsychiat., 4: 139-154, 1970 *

Niedemeyer,

Complexities of primary generalized epilepsy.

C11. El Ectroenceph., 12: 177-191, 1981.

Niedermeyer, E. Eaker, F., Freund, G., Takahashi, T.

EE, drowsiness and cerebrovasculax disorder.

Electroenceph. olin. Neurophysio1., 51: 42P, 1981.

oller-Daulrella, M.L.

La privation de sommell comme méthode d'activation de 1 "EEG chez 1 'epl leptique.

Rev. Neurol., 115: 530-535, 2966.

Oswald, I.

sleep mechanisms: recent advances.

Proc. R. Soc. Med., 55: 910-912, 1962 . 
Passouant, P. , Latour, H., Cadilhac, J.

I "Epilepsie morphejuue.

Ann. Med. Psychol. 109:526-540, 1951.

Passouant, P., Cadilhac, J., Dellange, M. , Castan, P.

Indications apportes par 1 etude des difers stades de sommell sur la physiopathologie du petit ma 1.

Arch. Franc. Pediat., 19: 1389-1397, 1962.

Passouant, P. Cadilhac, J.

Décharges épileptiques et sommeil.

Epliepsy, Mod. Prob1. Pharmacopsychiat. 4: 87-104, 1970.

Passouarti, $\mathrm{p}$.

Sleep deprivation in humans.

Handbook of Electroenceph. clin. Neurophysiol., 7A: 46-51, 1975.

Passoluant, $P$.

Neurological diseases in sleep.

Handbook of Electroenceph. clin. Neurophys101.,7A: 66-71, 1975.

Passowant, $P$.

Evoked responses and atomatic EEG analysis.

Handbook of Electroenceph. clin. Neurophysdo1., 7A: 16-17, 1975.

Patry, $E^{\prime \prime}$.

The relation of time of day, sleep and other factors to the 1ncidence of epileptic seizures.

Am. J. Psychiat., 87: 789-813, 1931.

Patry, G., Lyagoubi, S., Tassinari, C.

A subcinical electrical status epilepticus induced by sleep in allilaren.

Arch. Newrol $, 24: 242-252,1971$.

Ferria, I. , Rosadini, G., Rossi. G.F., Gentilono, A.

Neurosurgical aspects of epilepsy: physlological sleep as a mean for focalizing EEG eplieptic discharges.

Acta Neurochir., 14: 1-9, 1966.

Philipson, I., Risberg, A.M., Ingvar, D.H.

Nomal sleep pattern amalyzed statistically and studied by colow "Dormograms" "

sileep, 2: 437-451, 1980 .

Phillipson, E.A., Murphy, E., Kozat, L.T.

Regulation of respiration in sleeping dogs.

J. Appl. Physiol., 40:688, 1976.

Poller, D.A., Reia, K.H., Perot, P.

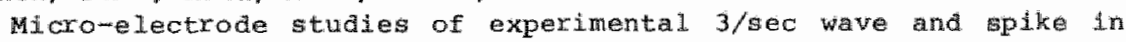

the cat.

Electromceph. c1in Neurophystod*,17:57-67, 1964.

Potvin, A.R., Selamy, J.G. "Crosier, W.G."Jones, K.W., Door., J.A. iffects of secobarbital on perfomance upon arousal from ${ }^{2}$ tage 4 sleep.

Appl. Neuraphystol., 38:240-250, 1975 .

Pratt, K.J., Mattson, R.H., Welkers, N.J., Willidas, R.

EEG activation of epliepticg following slep deprivation w a progressive study of 114 cases.

Electroenceph * c1n. Weurophysiol., 24:12-15, 1968 .

Rayna $1, D *$, Montplaisir, J゙* Dement, ".

K-alpha events in hypersomiacs and noxtula.

Sleep Fes., 3: 144, 1974. 
Rechtschafen, A., Kales, R.

A manual of standardized teminology, techniques and scoxing system for sleep stages of human subjects, 1968.

Public Health service, U.S. Government printing office, Mashington, D.C., 62 p., 1968.

Ritter, G., Becker, A Duensing, F.

Zum diagnostischen wert des $E E E^{*}$ s nach schlafentzug.

Mervenarzt, $48: 365-368,1977$.

Roder, U.U. "Wolif, $\mathrm{P}$.

Effects of treatment with dipropylacetat $(D P A$ and ethosuximide (ES) on sleep organisation in epileptic patients.

Acta Neurol. Scand., 62 (suppl. 79 ): 22, 1980.

Roder, U.u., Wolf, F.

Schlafänderungen bei Patienten mit primärer generalisierter Epilepsie unter Ethosuximid und Valproinsáure.

EEG-EMG, $12: 212,1981$.

Rolf, L.H., Matern, K.U., Brune, G.G.

Reduced uptake of serotonin $(5-\mathrm{H})$ by platelets in patients with grand mal seizures.

Electraenceph. clin. Meurophysiol., 53: 57P, 1982.

Rossi, G.F*., Gentilomo, A*, Colicchio, G.

Le probleme de la recherche de la topographie a"origine de l"épiLepsie.

Schweiz, Arch. Neurol. Psychiat., 115: 229-270, 1974 .

Rothova, N., Nevsimalova, S., Roth, B.

EEG activation using graded sleep deprivation in children and adolescents.

Electroenceph. clin. Neurophysiol., 50: 146P, 1980.

Rothova, M." Nevsimalova, S., Roth, B.

changes in EEG manifestations of N.REM sleep following graded sleep deprivation.

Electroenceph . clin. Neurophysiol., 50, 146P, 1980.

Rundel1, O.H., Lester, B.K., Griffiths, W.J.

Alcohol and sleep in young adults.

Psychophaxmacologica, 26: 201, 1972 .

sato, S., Dreifuss, F.E., Kiffin Penry, J.

The effect of sleep on splke-wave discharges in absence seizures.

Neurology, $23: 1335=1345,1973$.

Scaxpalezos, S., Maliara-Loulakaki, S., Mantouvalos, B., Davaki. P.

correlation of total sleep deprivation $(26-28 \mathrm{~h})$ and drug induced sleep as activating methods in the EEG of epileptics.

Acta Neurol. Scand., 62 (suppl. 79): 116, 1980 .

Schndat-Kessen, W* Kendel, K.

Einfluse der Raumtemperatur auf den Nachtschlaf.

Res. Exp. Med., 160: 220, 1973 .

Schwartz, B.A., Gullbaud, G., Fischgold, H.

single and multiple spikes in the night sleep of epileptics.

Electroenceph. clin. Neurophysiol., 16: 56-67, 1964.

Schwartz, I.R., Zangemeister, W.H.

The diagnostic walue of the short sleep EEG and other provocation methods following sleep deprivation.

J. Neurol., 218: 179-186, 1978. 
Scollo-Lavizarri, G., Pralle, W.

schlaf und Schlafentzug als Provokationsmethode in der Bpilepsiediagnostik.

Z.EEG-EMG, 4: $188-1.92,1973$.

Scollo-Lavizarri, G., Pralle, W., Radue, E.W.

Comparative study of efficacy of waking and sleep recordings following sleep deprivation as an activation method in the dlagnosis of epilepsy.

Eur. Neuro1., 15: 1.21-123, 1977.

Sengoku, A., Wolf, P.

Spindeln und Spike wave-Complexe im Schlif-EEG von Epilepsilekranken unter phenobarbital und Diphenylhydantoin.

Z.EEG-EMG, 12: 132-134, 1981.

Shapiro, C.M., Moore, A.T." Mitchell, D.

How well does man themoregulate during sleep?

Experientia, 30: 1279, 1974 .

Shibagraki, M "Kiyono, S., Watanabe, K.

Nocturnal sleep in severely mentally retarded children: abmomal

EEG patterns in sleep cycle.

Electroenceph. clin. Neurophysiol., 49: 337-344, 1980.

Shibagaki, M. , Kiyono, S., Matanabe, K., Hakamada, S.

Concurrent occurrence of rapid eye movements with splnale burst

during nocturnal sleep in mentally retarded children.

Electroenceph. clin. Neurophysiol., 53: 27-35, 1982 .

sillampaa, M.

Carbamazepine, pharmacology and cilinical uses.

Acta Neurol. Scand., 64: 88, 1981.

snljder, F., Hobson, J.A., Morrison, D.F., Gold-Frank, F.

Changes in respiration, heart rate and systolic blood pxessure in human sleep.

J. Appl. Physiol. "19: 417, 1964.

Spijkers, w.

Slaapdeprivatie en taakprestatie: een literatuuroverzicht.

Mederlands Tijdschrift voor de Psychologie, 35: 151-172, 1980.

Steriade, M.

Interneuronal epileptic discharges related to splke- and wave cortical seizures in behaving monkeys.

Electroenceph. clin. Neurophysiol., 37: 247-263, 1974.

Sterman, M.B., Berntsen, I. , Matsuno, D.

guantitative comparison of sleep EEG spectral profiles in nomal, insomiac and eplieptic subjects.

Electroenceph. clin. Neurophysiol., 47: 24P, 1979.

Sterman, M.B., Shouse, M.N.

Quantitative analysis of training, sleep EEG and clinicel rosponses ta EEG operant conditioning in epileptics.

Electroenceph. clin. Neurophysiol., 49: 558-576, 1980.

Stom van Leeuwen, W. "Bichford, R., Brazier, M., Cobb, W.A., Dondey, M., Gastaut, H., Gloor, P., Henry, C.E., Hess, R., Knott, J.R., Kugler, J., Lairy, G.C., Loeb, C., Magnus, O., ollex-Daurella, L., Petsche, H., Schwab, R., Walter, W.G. and Widen, L.

Proposal for an EEG terminology by the terminology committee of the International Federation for electroencephalography and clinical neurophysiology.

Electroenceph. alin. Neurophystol., 20:293-320, 1966. 
Tartai, A. "Moglia, A., Manni, R., Corbellini, C.

LEC IIndinge and leep deprivation.

Eux. Heuro1., $19: 330-334,1980$.

Vogel, G.W.

A revilew of REM sleep deprivation.

Arch. Gen. Psychiatry, 32: 749-761, 1975.

wachner, R.

Die Wrkung von Carbamatepin auf das Schlaf-EEG und die nächtliche Wachgtumshomon-, Prolaktin und Vasopressin-Freisetzung von gesunden Versuch spersonen.

Inaugural Dissertation Newrol. Klinik der Albert-Ludwigs-Universitat, $P P .3-4,1980$.

We uquier, A., verheyen, J.L." Vanderbroeck, W.A.E., Jansser, P.A.J.

Visual and computer-based analysis of $24 \mathrm{~h}$ sleep-waking patterns in dogs.

Electroenceph. clin. Heurophysiol, 46: 33-48, 1979.

Webt, W.B.

Sleep deprivation: total partial and selective.

In: M.H. Chase (Ed.). The sleeping Brain, Brain Research Institute, PP. 323-361, 1972 .

Webb, W.B., Agnew, H.W.

The effects of a chronic limitation of sleep length.

Poychophysiology, 11: 265-274, 1974 .

Webl, W.B., Bonnet, M.H.

The sleep of "Morning" and "Evening" types.

Biol. Psychol. , 7: 29-35, 1978 .

Webb, W.E." Cartwright, R.D.

sleep and dreams.

Ann. Rev., 29: 223-252, 1978.

De Weerd, J.P.C., Martens, W.I.J.

Theory and practice of a posteriori "Wiener"filtering of average evoked potentials.

Biol. Cybernetics, 30:81-94, 1978.

wieser, H.G*

Arousal patterns in epilepties.

Electroenceph. clin. Neurophysiol., 53, 53P, 1982.

Wilkinson, R.T.

sleep deprivation.

In: O.G. Edholm and A.L. Bachrach (Eds.). The Physiology of Human survital, Acadenic Press, pp. 399-430, 1965.

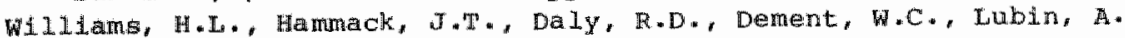

Re sponses to anditory stimulation, sleep loss and the EEG stages

of isep.

Ellectroenceph. clin. Neurophysiol., 16: 269-276, 1964.

wittenbecher, H*, Kubicki, st.

statistical evaluation of 719 short-time recoxaings following sleep deprivation.

Electroenceph. clin. Neurophysio1., 43: 128P, 1977.

Wittenbecher, H." Kubicki, St.

Eplleptische scharfe vertexentladungen im Kurzschlaf nach Schiafreduktiom.

Z.EEG-EMG, 13: 133-137, 1982 *

Zinuerma $n$, W.B.

sleep mentation and auditory awakening threshold.

Psychophysiology, 6:540-549, 1970 . 
August Declerck werd geboren op 20.11.1933 te westkerke (Belgiè) en volgde van 1946 - 1952 de midalbare schoolopleiding aan het $0 . t$. Wrouwen-college te oostende.

Hij studeerde geneesknde an de Universiteit te Leuven en behaalde zijn artsexamen in juli 1959.

Van december 1959 tot februari 1961 was hij in militaire diensten werkzam op de afdeling Interne Geneeskunde van het Militair Hospitaal te oostende.

Van april 1961 tot mei 1963 deed hij algemene huisartsengeneeskunde.

op 1 mei begon zijn oplejaing tot zenuwarts warvan l jaar psychiatrie te Kortrijk (hoofa Dr. J. van Iuaere) en 3 jaat neurologie op de afdeling neurologie van het Academisch ziekenhuis te Leuven (hoofd Prof. P. van Gehuchten, opgevolga door prof. R. wan den Bergh).

In het kader van zijn opleiding tot zenuwarts was hij in 1966-1967 gedurende 6 maanden werkzaam op de afdeling neurologie van het Withelmina Gasthuis te Amsterdam (hoofd Prof. Dr. D. Biemond).

In 1967 volgde zijn benoeming tot adjunct kiniekhoofd van de afdeling neurologie van het Academisch ziekenhuis te Leuven, cen funktie die hij heeft vervuld tot oktober 1970. In deze periode had hij specialle interesse voor de kinderneurologie.

Van oktober 1970 tot februari 1972 was hij als zenuwarts gevestigd te oostende.

Van februari 1972 tot april 1975 was hij full-time werkzaam op de afdeling electroencephalografie en klinische neurofysiologile van het St. Antoniusziekenhuis te utrecht (hoofd Dr. A.J.R. Simons). Tevens heeft hij veel aandacht besteed aan de bestudering van het centrale "mu-ritme" in het electroencephalogram.

sinds april 1975 is hij full-time werkzaam in het epilepsiecentrum "Kempenhaeghe" te Heeze als hoofd van de afdeling electroencephalografie en kinische neurofysiologie. Hilj heeft veel onderzoek verricht naar het belang van slaaponderzoek voor het diagnostiseren van epilepsie en voor het bepalen, van de invloed van antiepileptica, en nax de diagnostische waarde van de evoked potential methode bij epileptici. Samen met zijn medewerkers worden die onderzoekingen gekontinueexd max worden nu aangevuld met de betudering van de mogelijkheden voor langdurige (24-48 uurs) ambulante EeG registraties In kombinatie met automatische verwerking. 


\section{ERRATA}

$$
\begin{array}{cl}
\text { Page } 7 & : 1 / 12(1 / 2) \\
" & 25: \text { uninterrupted (interrupted) } \\
" & 27: \text { sleep (recording) } \\
" 120: & \text { transition (activation) } \\
" 122: & \text { state (stage) } \\
" 132: \text { question } 3: \text { and medication? }
\end{array}
$$

